\title{
Control Without Confirmation: The Politics of Vacancies in Presidential Appointments
}

\author{
by \\ Christina M. Kinane \\ A dissertation submitted in partial fulfillment \\ of the requirements for the degree of \\ Doctor of Philosophy \\ (Political Science) \\ in The University of Michigan \\ 2019
}

Doctoral Committee:

Professor Charles R. Shipan, Chair

Professor Richard L. Hall

Professor Arthur Lupia

Professor Rocío Titiunik 
Christina M. Kinane

ckinane@umich.edu

ORCID iD: 0000-0003-1913-5274

(c) Christina M. Kinane 2019 
For Eleanor and Ethan. 


\section{ACKNOWLEDGEMENTS}

While the long and arduous act of writing this dissertation was, fundamentally, a solo adventure, I did not go through the process alone. There are so many people to whom I will be forever grateful for their support, their guidance, and their encouragement throughout this incredible experience.

The members of my dissertation committee, together and each in their own way, were reliable sources of support and advice. Skip Lupia provided essential guidance on my formal model and his thoughtful feedback helped me find my direction. He challenged me to pursue a project that has real world implications and contributes to political science in a meaningful way. Rick Hall's candid feedback pushed me to continually refine and clarify my argument into one that could persuade even the strongest skeptic. From early methods coursework to advice about the job market, I have had the privilege to learn from Rocío Titiunik. As a mentor and committee member, Rocío has profoundly shaped my understanding of what rigorous research is and this dissertation is richer for it. I owe much of my perspective and sense of self as an academic to Rocío’s mentorship.

Finally, I came to Michigan to work with Chuck Shipan, and it was the best decision I have made in my academic career. Chuck's guidance imparted an unfailing sense of calm during the otherwise stressful and challenging enterprise of dissertation research. He encouraged me to develop my raw ideas while also pushing back with constructive criticism, and along the way, Chuck taught me how to pursue meaningful political science research. Chuck's thoughtful advice was instrumental at each stage and, ultimately, my dissertation is infinitely better because of his 
meticulous feedback. I could not have had a more supportive and exceptional chair and, for that, I am deeply grateful.

The University of Michigan Department of Political Science, the Institute for Social Research, and the Rackham School of Graduate Studies generously provided resources and funding that allowed me to undertake and complete this dissertation. I also would like to thank Jacob Wellner for his outstanding research assistance.

I feel incredibly fortunate to be able to thank an even larger set of academics who sustained my enthusiasm for this project and whose fingerprints can be found within the pages of this dissertation. As an undergraduate at UCLA, I was lucky enough to work with Mike Thies, who introduced me to academic research and is entirely responsible for me not taking the path of least resistance. Rob Mickey, my trusted mentor and coauthor, provided encouragement and support from day one. His mentorship and friendship have been invaluable. I am also grateful for helpful suggestions from many faculty members at Michigan and beyond: Kenny Lowande, John Jackson, Ken Kollman, Sean Gailmard, Dan Magleby, Dave Lewis, George Krause, Anne Joseph O’Connell, and Larry Rothenberg.

To my fantastic set of grad friends - to whom I could always look for encouragement, inspiration, and feedback on even the most ridiculous ideas - thank you for being my sources of happiness in and out of Haven. Elizabeth, your brilliant example, advice, and dear friendship gave me so much strength and confidence. Alba, our hearts are forever fused from those late nights and long laughs. Anita, Marc, Fabian, Issac, Julia, Hakeem, Geoff, Alton, Erin, Carly, Jess, Nicole, thank you for making it all so much fun and interesting. Zander and Jesse - my academic brothers - thank you for your steadfast support, for reading so much (or all) of this dissertation, and for pushing me to always be a better scholar. Kiela, I didn't know it at the time, but the day you moved into our office was one of the best days I could have had at Michigan. Thank you for literally everything - the laughs, the coffee, the crutches, the tears, the crocheted blankets, the nights out, the days at the atrium, the laptop recovery, the Christmas music, the talks, the hugs 
- I am so lucky.

Lastly, I am so grateful to have an amazing family who never missed a beat, even when I did. Our Ann Arbor family filled our lives with so much joy. Emily, Damen, Asher, Ryder, looking forward to your smiles and laughter on Sunday afternoons is exactly what I needed to get through many, many weeks. Missy, Bob, Beckett, you always let us bring the chaos to your home on a moment's notice, and gave me an escape so I could keep my sanity - thank you for the all dinners and all the love. Dad, Susan, Hersch, I am so grateful for your support, encouragement, and good humor, which were constant throughout this entire endeavor. Mom, you gave me the confidence and the courage to get here, and made finishing this dissertation even possible. So many of these pages were written because of your support and love, and all the miles you flew to be there with us. When I was running on empty, you came and gave me time to finish this huge undertaking. I cannot thank you enough. And finally, to Cory: this is yours as much as it is mine. From the late nights working out the theory to scraping data to writing at all hours, you were with me every step of the way, all while we built our family. You taught me, you inspired me, you challenged me, and you believed in me. You are the best partner, the most amazing dad, and you patiently keep me grounded in all the chaos. I can't imagine doing any of this without you - thank you for going on this journey with me. On to the next one! 


\section{TABLE OF CONTENTS}

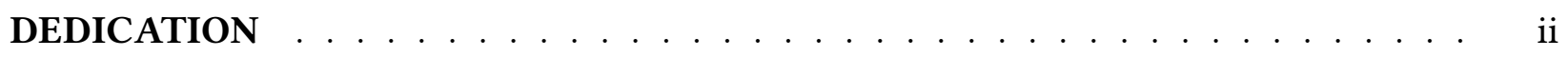

ACKNOWLEDGEMENTS . . . . . . . . . . . . . . . . . iii

LIST OF FIGURES . . . . . . . . . . . . . . . . . . . . . . . ix

LIST OF TABLES . . . . . . . . . . . . . . . . . . . . . . . . xiii

LIST OF APPENDICES . . . . . . . . . . . . . . . . . . . . . xvi

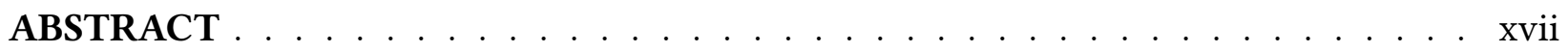

\section{CHAPTER}

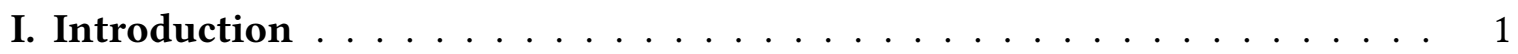

1.1 An Introduction to Vacancies: Empty Positions and Interim

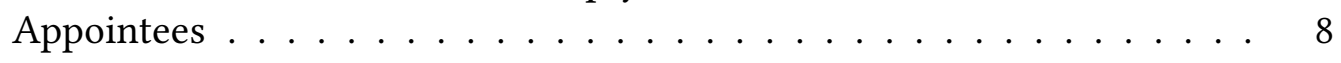

1.2 The Central Argument . . . . . . . . . . . . . . . . . . . 12

1.3 Plan of the Dissertation . . . . . . . . . . . . . . . 14

II. Background on Presidential Appointments and Vacancies . . . . . . . . . . 19

2.1 Current Perspectives of Presidential Appointments . . . . . . . . . . . . 21

2.1.1 Separations of Powers and Political Control of the Bureaucracy 22

2.1.2 Appointments: Nomination and Confirmation . . . . . . . . 25

2.1.3 Appointments: Vacancies . . . . . . . . . . . . . . . 28

2.1.4 The Administrative Presidency and Unilateral Action . . . . . 33

2.2 The Institutional Framework Governing Vacancies . . . . . . . . . . . . 36

2.2.1 Procedural regimes: The Vacancies Act and beyond . . . . . . 39

2.3 Exploring Vacancies Across Presidencies . . . . . . . . . . . . . . . . 43

2.4 Conclusion . . . . . . . . . . . . . . . . . . . . . . . . 49 


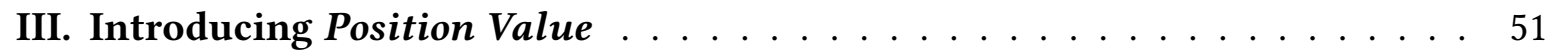

3.1 Introducing Policy Priorities . . . . . . . . . . . . . . . . . . 53

3.1.1 Expansion and Contraction Policy Priorities . . . . . . . . . . . 57

3.2 Introducing Position Capacity . . . . . . . . . . . . . . . . 61

3.3 Constructing Position Value . . . . . . . . . . . . . . . . . . . . . 64

IV. A Theory of Vacancies and Appointments . . . . . . . . . . . . . . . . 67

4.1 A New Theory of Vacancies and Appointments . . . . . . . . . . . . . . 68

4.2 A Generalized Appointments Model . . . . . . . . . . . . . . . . . . . 70

4.3 Equilibrium Results and Proofs . . . . . . . . . . . . . . . . . 81

4.3.1 Proofs of Equilibrium Solution . . . . . . . . . . . . . 89

4.4 Central Empirical Hypotheses . . . . . . . . . . . . . . . . 103

4.5 Discussion . . . . . . . . . . . . . . . . . . . . . . 109

V. Introducing the Data and Explaining the Likelihood of Vacancies and Ap-

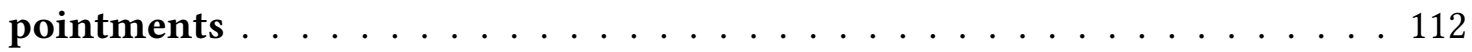

5.1 Introducing New Data on Vacancies and Appointments . . . . . . . . . . 114

5.1.1 Measuring Position Status . . . . . . . . . . . . . . . . . . 114

5.1.2 Measuring Position Value . . . . . . . . . . . . . . . . . 124

5.2 Explaining Position Status with Position Value . . . . . . . . . . . . . . . 139

5.2.1 Non-Parametric Analysis . . . . . . . . . . . . . . . . 139

5.3 Explaining the Likelihood of Position Status with Position Value . . . . . . 143

5.3.1 Estimation Strategy: Multinomial Probit Regression . . . . . . 143

5.3.2 Results: Three-Category Position Status . . . . . . . . . . . . . 147

5.3.3 Results: Five Category Position Status . . . . . . . . . . . . . . 159

5.4 Discussion . . . . . . . . . . . . . . . . 166

VI. Examining Vacancies in the Context of the Federal Vacancies Reform Act 171

6.1 Likelihood Models of Position Status, with Federal Vacancies Reform Act Fixed Effects . . . . . . . . . . . . . . . . . . . . . . . 172

6.2 Likelihood Models of Position Status, Before and After the Federal Vacancies Reform Act . . . . . . . . . . . . . . . . . . . . . 180

6.3 Discussion . . . . . . . . . . . . . . . . . . . . 189

VII. Examining the Incidence of Vacancies and Appointments . . . . . . . . . 191

7.1 Introducing Position Status Count Data . . . . . . . . . . . . . 192 
7.2 Explaining the Incidence of Position Status with Policy Priorities . . . . 196

7.2.1 Estimation Strategy: Negative Binomial Regression . . . . . . . 196

7.2.2 Results: Incidence of Empty Positions . . . . . . . . . . . . . . 198

7.2.3 Results: Incidence of Interim Appointees . . . . . . . . . . . . 201

7.3 Examining the Incidence of Permanent Appointees . . . . . . . . . . . 202

7.3.1 Estimation Strategy: Negative Binomial Regression . . . . . . . 202

7.3.2 Results: Incidence of Permanent Appointees . . . . . . . . . 205

7.4 Discussion . . . . . . . . . . . . . . . . 211

VIII. Conclusion . . . . . . . . . . . . . . . . . . . . . . . . 212

8.1 Summary . . . . . . . . . . . . . . . . . . 214

8.2 Contributions . . . . . . . . . . . . . . . . 218

8.3 Implications of Strategic Vacancies . . . . . . . . . . . . . . . 220

8.4 Future Research . . . . . . . . . . . . . . . . . . . . . 222

APPENDICES . . . . . . . . . . . . . . . . . . . . . . . . 225

BIBLIOGRAPHY . . . . . . . . . . . . . . . . . . . . . . . 244 


\section{LIST OF FIGURES}

\section{$\underline{\text { Figure }}$}

$1.1 \quad$ Percentage of PAS Positions: Empty, Interim, Vacant $(1977-2015) \ldots \ldots$

$1.2 \quad$ Full Appointment Process and Outcomes . . . . . . . . . . . . . . . 11

$2.1 \quad$ Federal Civilian Personnel System . . . . . . . . . . . . . . . . . 37

2.2 Distribution of Presidential Appointments requiring Senate Confirmation . . . . 38

2.3 Percentage of Reported Vacancies Left Empty or Filled with Interim, 1995-2016 . 47

2.4 Executive Department PAS Positions in the Trump Administration (as of June

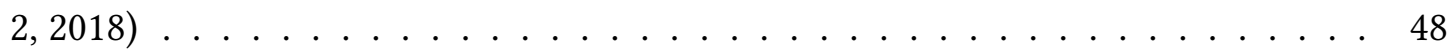

$4.1 \quad$ Appointments Model Outcomes . . . . . . . . . . . . . 71

$4.2 \quad$ Vacant Positions Model in Extensive Form . . . . . . . . . . . . . . . 81

5.1 Percentage of Executive Department PAS Positions: Vacancy, Empty, or Filled by Interim Appointees, $1977-2015$. . . . . . . . . . . . . . . . 117

5.2 Percentage of PAS positions empty or filled by interim appointees, by depart-

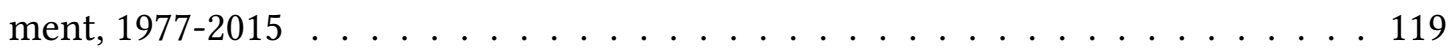

5.3 Box Plot of Percentage of PAS Positions Left Empty, 1977-2015 . . . . . . . . . 120

5.4 Box Plot of Percentage of PAS Positions Filled with Interim Appointees, 1977-2015 121

5.5 Percentage of Vacant Executive Department PAS Positions: Empty and Interim Appointees, With and Without Nominees, 1981-2015 . . . . . . . . . . . 124 
5.6 Presidential Policy Priorities, by department, 1977-2015 . . . . . . . . . . . 128

5.7 Congressional Policy Priorities, by department, 1977-2015 . . . . . . . . . . 129

5.8 President's Position Value, by department, 1977-2015 . . . . . . . . . . . . . . 137

5.9 Congress's Position Value, by department, 1977-2015 . . . . . . . . . . . 138

5.10 Adjusted Predictions of the Probability of Empty Positions and Interim Appointees, given President's Position Value . . . . . . . . . . . . . 150

5.11 Adjusted Predictions of the Probability of an Empty Position, given President and Congress Position Value . . . . . . . . . . . . . . . . 151

5.12 Adjusted Predictions of the Probability of an Interim Appointee, given President and Congress Position Value . . . . . . . . . . . . . . . . . . 155

5.13 Adjusted Predictions of the Probability of Empty Positions and Interim Appointees, With and Without Nominees, given President's Position Value . . . . 162

5.14 Adjusted Predictions of the Probability that a Vacancy is Empty Position or Filled with Interim Appointee, With and Without Nominees, given President's Position Value . . . . . . . . . . . . . . . . . . 166

6.1 Adjusted Predictions of the Probability of an Empty Position and Interim Appointee, given FVRA Institutional Regime . . . . . . . . . . . . . . 175

6.2 Adjusted Predictions of the Probability of a Permanent Appointee, given FVRA Institutional Regime . . . . . . . . . . . . . . . . . . 175

6.3 Adjusted Predictions of the Probability of an Empty Position, given President Position Value and FVRA Institutional Regime . . . . . . . . . . . . 178

6.4 Adjusted Predictions of the Probability of an Interim Appointee, given President Position Value and FVRA Institutional Regime . . . . . . . . . . . . . 178

6.5 Adjusted Predictions of the Probability of a Permanent Appointee, given President Position Value and FVRA Institutional Regime . . . . . . . . . . . . . . . 179

6.6 Adjusted Predictions of the Probability of an Empty Position and Interim Appointee, given President Position Value, pre-FVRA (1977-1997) . . . . . . . . . . 184 
6.7 Adjusted Predictions of the Probability of an Empty Positions and Interim Appointee, given President Position Value, post-FVRA (1998-2015) . . . . . . . . 186

6.8 Adjusted Predictions of the Probability of a Permanent Appointee, given President Position Value, Pre-FVRA (1977-1997) _. . . . . . . . . . . . . . 187

6.9 Adjusted Predictions of the Probability of a Permanent Appointee, given President Position Value, Post-FVRA (1998-2015) . . . . . . . . . . . . . . . 187

6.10 Adjusted Predictions of the Probability of a Permanent Appointee, given President Position Value and Congress Position Value, Pre-FVRA (1977-1997) . . . . 188

7.1 Distribution of Empty High Capacity PAS Positions, 1977-2015 _ . . . . . . . 195

7.2 Distribution of Interim Appointees in High Capacity PAS Positions, 1977-2015 . 195

7.3 Distribution of Permanent Appointees in High Capacity PAS Positions, 1977-2015 196

7.4 Predicted Number of Empty High Capacity PAS Positions, given President Policy Priority . . . . . . . . . . . . . . . . . . . 200

7.5 Predicted Number of Interim Appointees in High Capacity PAS Positions, given President Policy Priority . . . . . . . . . . . . . . . . . . . 202

7.6 Predicted Count of Permanent Appointees in High Capacity PAS Positions, given President Policy Priority . . . . . . . . . . . . . . . . . . . . . 209

7.7 Predicted Count of Permanent Appointees in High Capacity PAS Positions, given President Policy Priority (lagged) _ . . . . . . . . . . . . . . . . . . 209

7.8 Predicted Count of Permanent Appointees in High Capacity PAS Positions, given (lagged) President and Congress Policy Priority . . . . . . . . . . . . 210

B.1 Predicted Count of Interim Appointees in High Capacity PAS Positions, given

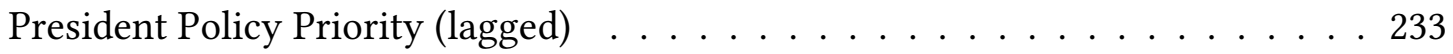

B.2 Predicted Count of Empty High Capacity PAS Positions, given President Policy Priority (lagged) . . . . . . . . . . . . . . . . . . . 233

B.3 Predicted Count of Permanent Appointees in High Capacity PAS Positions, given President and Congress Policy Priority . . . . . . . . . . . . . 234 
C.1 Predicted Count of Interim Appointees in High Capacity PAS Positions, given President Policy Priority (lagged) _ . . . . . . . . . . . . . 240

C.2 Predicted Count of Empty High Capacity PAS Positions, given President Policy Priority (lagged) . . . . . . . . . . . . . . . . . . . 240

C.3 Predicted Count of Permanent Appointees in High Capacity PAS Positions, given President and Congress Policy Priority . . . . . . . . . . . . . . 243 


\section{LIST OF TABLES}

\section{Table}

3.1 Position Value: Combining Position Capacity and Policy Priorities _ . . . . . . 65

$4.1 \quad$ Predicted Appointment Strategy Outcomes and Position Value . . . . . . . . . 108

5.1 Distribution of PAS Position-Year Observations by Position Status, 1977-2015 . 117

5.2 Political Characteristics Surrounding PAS Positions, by Position Status, 1977-2015 118

5.3 Political Characteristics Surrounding PAS Positions, by Position Status (With and Without Nominees), 1981-2015 . . . . . . . . . . . . . 123

5.4 Levels of Policy Control Capacity for PAS Positions in Executive Departments,

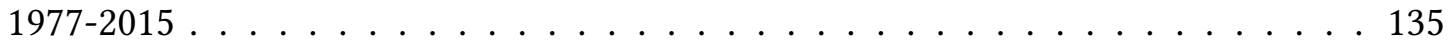

$5.5 \quad$ Position Value: Combining Position Capacity and Policy Priorities . . . . . . 136

5.6 Distribution of Permanent Appointees and Vacancies . . . . . . . . . . . . 140

5.7 Distributions of Permanent Appointees, Empty Positions, and Interim Appointees 141

5.8 Distributions of Permanent Appointees, Empty Positions, and Interim Appointees, excluding the Department of Defense . . . . . . . . . . . . . . . . 142

5.9 Distributions of Vacant PAS Positions: Empty Positions and Interim Appointees, With and Without Nominees (1981-2015) . . . . . . . . . . . . . . 142

5.10 Likelihood Models of Presidential Appointment Strategy in Executive Departments, 1977-2015 . . . . . . . . . . . . . . . . 148

5.11 Predicted Probabilities of Position Status Outcomes ． . . . . . . . . . . . 149 
5.12 Predicted Probabilities of Position Status Outcome: Permanent Appointee . . . . 157

5.13 Likelihood Models of Presidential Appointment Strategy in Executive Departments, 1981-2015 . . . . . . . . . . . . . . . . . 160

5.14 Predicted Probabilities of Position Status Outcomes . . . . . . . . . . . 161

5.15 Predicted Probabilities of Position Status Outcomes Among Vacancies . . . . . . 165

$6.1 \quad$ Predicted Probabilities of Position Status Outcomes ． . . . . . . . . . . 177

6.2 Likelihood Models of Presidential Appointment Strategy in Executive Departments, Pre-FVRA (1977-1997) and Post-FVRA (1998-2015) . . . . . . . . . . 182

6.3 Predicted Probabilities of Position Status Outcomes, Pre-FVRA (1977-1997) . . . 183

6.4 Predicted Probabilities of Position Status Outcomes, Post-FVRA (1998-2015) . 183

7.1 Means and Variances of Position Status Count Data: Numbers of Empty, Interim Appointees, and Permanent Appointees in High Capacity Positions, DepartmentYear $1977-2015 \ldots \ldots$. . . . . . . . . . . . . . . . . . 193

7.2 Count Models of Presidential Appointment Strategy in Executive Departments, $1977-2015 \ldots \ldots \ldots \ldots$. . . . . . . . . . . . . . . . . . . . . . . . . . . .

7.3 Predicted Number of Empty Positions and Interim Appointees in High Capacity Positions, 1977-2015 . . . . . . . . . . . . . . . . 200

7.4 Count Models of Presidential Appointment Strategy in Executive Departments, $1977-2015 \ldots \ldots \ldots \ldots \ldots \ldots$. . . . . . . . . . . . . . . . . . . . . . . . .

7.5 Predicted Number of Permanent Appointees in High Capacity Positions, 1977$2015 \ldots \ldots \ldots \ldots \ldots \ldots \ldots$. . . . . . . . . . . . . . . . . . . . . . . . . . . . . .

8.1 Distribution of Confirmed and Interim Department Heads, 1977-2019 _ . . . . . 214

A.1 Likelihood Models of Presidential Appointment Strategy in Executive Departments, 1981-2015 . . . . . . . . . . . . . . . . 227

B.1 Likelihood Models of Presidential Appointment Strategy in Executive Departments, 1977-2015 . . . . . . . . . . . . . . . . . . 229 
B.2 Predicted Probabilities of Position Status Outcomes . . . . . . . . . . . . 230

B.3 Predicted Probabilities of Position Status Outcomes, Pre-FVRA (1977-1997) . . 231

B.4 Predicted Probabilities of Position Status Outcomes, Post-FVRA (1998-2015) . 232

B.5 Means and Variances of Position Status Count Data: Numbers of Empty, Interim Appointees, and Permanent Appointees in Low Capacity Positions, DepartmentYear, $1977-2015 \ldots \ldots \ldots$. . . . . . . . . . . . . . . . . 234

B.6 Predicted Number of Empty Positions and Interim Appointees in High Capacity Positions, 1977-2015 . . . . . . . . . . . . . . . . . . . 235

B.7 Predicted Number of Permanent Appointees in High Capacity Positions, 1977$2015 \ldots \ldots \ldots \ldots \ldots$. . . . . . . . . . . . . . . . 236

B.8 Count Models of Presidential Appointment Strategy in Executive Departments,

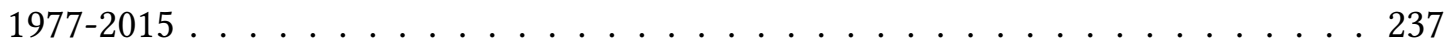

C.1 Means and Variances of Position Status Count Data: Numbers of Empty, Interim Appointees, and Permanent Appointees in Low Capacity Positions, DepartmentYear $1977-2015 \ldots \ldots \ldots$. . . . . . . . . . . . . . . 238

C.2 Predicted Number of Empty Positions and Interim Appointees in High Capacity Positions, 1977-2015 . . . . . . . . . . . . . . . . . . . . . . . . 239

C.3 Predicted Number of Permanent Appointees in High Capacity Positions, 19772015 . . . . . . . . . . . . . . . . . . . . . . . . 241

C.4 Count Models of Presidential Appointment Strategy in Executive Departments, $1977-2015 \ldots \ldots \ldots \ldots \ldots$. . . . . . . . . . . . . . 242 


\section{LIST OF APPENDICES}

\section{Appendix}

A. Chapter 5: Likelihood Models of Vacancies _ . . . . . . . . . . . 226

B. Chapter 6: Likelihood Models of Vacancies, Pre and Post-FVRA . . . . . . . . . . 228

C. Chapter 7: Count Models of Vacancies . . . . . . . . . . . . 238 


\begin{abstract}
All presidential administrations experience vacancies in agency leadership. Separation of powers models typically assume that executives are constrained by the need for legislative approval when placing these agents in unelected office. Yet, in practice, these vital policymaking positions are often filled with temporary officials - or left empty entirely - without Senate confirmation. These unexpected outcomes raise the important question of why presidents choose to leave certain positions vacant while seeking the Senate's advice and consent for others. Even though much has been written on the president's strategies for choosing appointees in light of their potential for Senate confirmation, the president's use of vacancies is almost completely absent from the literature on presidential appointments. This absence is striking since presidents have perpetuated vacancies in their appointments, without submitting nominations, for decades.

In this dissertation, I argue that vacancies in appointments that require Senate confirmation are calculated choices presidents make, within their larger nomination strategies, to advance their policy priorities. To do so, I develop and test a novel theory of appointments that corrects our conception of vacancies to differentiate between empty positions and interim appointees, while also incorporating the Senate's leverage to veto a nomination and the president's power to choose not to submit one in the first place. Two key findings predict that, first, when presidents prioritize policy contraction, persistently empty positions without nominees will occur even in unified government; and second, when presidents prioritize policy expansion, they are more likely to use interim appointees to fill positions with a high capacity to control policy outcomes. I assess these implications using an original dataset on vacancies and appointments, across all fifteen
\end{abstract}


executive departments from 1977 through 2015; and find considerable support for my theory.

The results here suggest that, indeed, presidents strategically use vacancies to expand their executive power and achieve their policy priorities. This dissertation makes three notable contributions to our understanding of presidential power by investigating how position characteristics and policy priorities influence the president's use of vacancies and appointments. First, it shows that to better understand institutions in separation-of-powers regimes, we must consider how deliberate sidestepping of formal powers impacts inter-branch bargaining and agenda setting strategies. Second, it presents a theory of appointments that provides a new and better understanding of presidential strategic behavior and the president's advantage in the nomination process. Moreover, it introduces the novel idea that these decisions are driven by the value of the positions themselves in terms of achieving policy priorities. Lastly, I have assembled the most comprehensive dataset to date on appointments to and vacancies in presidential appointments that require Senate confirmation. These data are new in political science research and will be helpful in exploring a new line of research on the politics of vacancies in presidential appointments. Executive politics scholars claim that the Senate's refusal to confirm appointments damages the president's ability to exercise his authority and execute the law. However, this dissertation discovers the conditions under which presidents, when they use empty posts and interim appointments, capitalize on their first-mover advantage to subvert the Senate's power to refuse confirmation. 


\section{CHAPTER I}

\section{Introduction}

66 Top posts at the Defense and Justice departments went vacant for months. Inspector general jobs in several agencies are still empty. The National Labor Relations Board came close to dysfunction because of empty chairs [...] Empty chairs make rotten policy.

The Washington Post Editorial Board

Presidents have the power to unilaterally set the direction of policy outcomes. Yet, to see this direction come to fruition, presidents must rely on the appointees who design and then implement said policies. Consider, for instance, President Obama's second term foreign policy priorities, which centered on developing new strategies to prevent the growth of terrorist groups and violent extremism. To do this, Obama relied on his Under Secretary for Civilian Security, Democracy, and Human Rights at the Department of State, Sarah Sewall, to craft and implement a new U.S. counterterrorism policy that emphasized governance and human rights: the Countering Violent Extremism (CVE) policy. ${ }^{1}$ The Obama administration’s 2015 CVE foreign ${ }^{2}$ policy sought

\footnotetext{
${ }^{1}$ The Under Secretary for Civilian Security, Democracy, and Human Rights has the largest budget in the Department of State ( $\$ 5$ billion) and coordinates U.S. foreign policy on combating terrorism, trafficking in persons, illicit drug activity, humanitarian efforts, human rights and labor issues, and the documentation of war crimes and atrocities.

${ }^{2}$ The Obama administration also developed a domestic CVE policy designed as a joint taskforce between the Department of Homeland Security and the Department of Justice to implement programs aimed at preventing domestic violent extremism.
} 
to "address the root causes of extremism through community engagement," ${ }^{3}$ was adopted by the United Nations in 2016, ${ }^{4}$ and has been widely accepted as the new counterterrorism paradigm for preventing the growth of terrorist groups. Alternatively, when President Trump officially outlined his priorities for counterterrorism policy in October $2018,{ }^{5}$ he all but eliminated previous humanitarian efforts for preventing violent extremism. We would have expected the Under Secretary for Civilian Security, Democracy, and Human Rights to be tasked with designing an alternative human rights policy option. This position, however, was empty.

In fact, after nearly 18 months in office, over 20 percent of presidential appointments whose authority requires Senate confirmation (known as PAS positions) were empty. ${ }^{6}$ Half of the leadership positions at the State Department were vacant, with no nominee, for the entirety of the Trump administration's first year. Positions like the Under Secretary for Arms Control and International Security Affairs and Assistant Secretary for Population, Refugees and Migration were empty. More than half of the PAS positions at the Department of Treasury were vacant, including the Assistant Secretaries for Economic Policy and for Financial Markets. Similarly, 11 of the 15 PAS positions at the Department of Education were vacant and fewer than half of them had nominees. Nearly a third of the PAS positions at the Department of Labor were also empty. Given these "empty chairs," The Washington Post excerpt above would likely surprise no one today except that it was published on March 14, 1994.

All presidential administrations experience vacancies in agency leadership. If presidents control the path of policy most effectively through their power to appoint personnel, as our typical understanding suggests, then we would expect few, if any, of these positions to remain vacant.

\footnotetext{
${ }^{3}$ https://obamawhitehouse.archives.gov/the-press-office/2015/02/18/fact-sheet-white-house-summitcountering-violent-extremism. Accessed 15 January 2019.

${ }^{4}$ In July 2016, the United Nations adopted that Preventing Violent Extremism (PVE) policy which was largely crafted from the Obama administration's CVP foreign policy. (https:/www.un.org/counterterrorism/ctitf/en/planaction-prevent-violent-extremism).

${ }^{5}$ https://www.whitehouse.gov/wp-content/uploads/2018/10/NSCT.pdf

${ }^{6}$ Original analysis of departmental websites and organizational charts to identify the status of all PAS positions in the Trump administration as of June 2, 2018.
} 
This, however, is not the case. Over the past five administrations, executive agency PAS positions were vacant, on average, 25 percent of the time (O’Connell, 2009). Presidents perpetuate vacancies, regularly forgo nominations, and often use lengthy interim appointments without Senate confirmation.

Nevertheless, scholars regularly gauge vacancies in PAS positions as sporadic events that warrant, at most, a footnote. They mistakenly cast vacancies as mechanical byproducts of presidential transitions, or miscalculations in identifying a nominee, or senatorial delays in confirmation. Consequently, the standard perspective fundamentally misinterprets the absence of a confirmed appointee as an arbitrary gaffe in the appointment process, when actually - as this dissertation makes clear - vacancies are a distinct feature of presidential appointment strategy. Most recently, Trump has kept positions vacant for months and refused to pursue nominations in many agencies where he has proposed slowdowns and dramatic cuts on regulation, workforce, and budget (e.g., Education and State). Yet, he has been quicker to nominate in priority areas like commerce and defense, and left entire agencies to be run by interim appointees when he has sought considerable expansions in implementation and enforcement activities (e.g., Immigration and Customs Enforcement). ${ }^{7}$ Yet, existing theories of appointment strategy do not allow vacancies to be anything other than aberrations and expect presidents to unfailingly pursue formal nominations, when presidents obviously have alternative approaches to staffing these critical positions.

These unexpected outcomes raise the important question of why presidents choose to leave certain positions vacant while seeking the Senate's advice and consent for others. This puzzle is important for two reasons. First, one of the president's most influential powers is to appoint the 1,200 cabinet secretaries, agency directors, general counsels, and other personnel whose day-today actions determine the actions of the government. These PAS positions are routinely respon-

\footnotetext{
${ }^{7}$ Acting Assistant Secretaries for Immigration and Customs Enforcement at the Department of Homeland Security (often referred to as the Director of ICE) were: Daniel Ragsdale (January 20-30, 2017), Thomas Homan (January 30, 2017-June 30, 2018), Ronald D. Vitiello (June 30, 2018-April 12, 2019), and Matthew Albence (April 13, 2019 until present, as of May 10, 2019).
} 
sible for major policy decisions that impact the lives of many, if not all, Americans. Consequently, whether these positions are filled or not, and why, matters for our understanding of presidential power and how that power shapes policy. Second, vacancies in agency leadership impact agency performance and interfere with the accountability, efficiency, and responsiveness of government to its citizens. Particularly in agencies like the Department of Veterans Affairs, vacancies can stall critical decisions and delay the provision of essential services, both of which could have severe consequences. ${ }^{8}$ Despite these important implications, we know very little about why presidents choose to maintain vacancies and not to nominate when the benefits of nominating seem obvious. Even though much has been written on the president's strategies for choosing appointees in light of their potential for Senate confirmation, the president's use of vacancies is almost completely absent from the literature on separation of powers and presidential appointments. ${ }^{9}$

This absence is striking given that presidents can and do maintain vacancies in their appointments. First, however, we need to be more precise in our discussion of "vacancies." That is, as I discuss below, we need to correct how we define vacancies in PAS positions. With existing research focused on nominees and confirmed appointees, our current conception of vacancies identifies the absence of Senate confirmed appointees. Yet, PAS positions without confirmed appointees could be empty or filled with interim appointees, temporary officials exercising the authority of the position without Senate confirmation. In fact, in June 2018, interim appointees filled nearly a third of vacant PAS positions. ${ }^{10}$ This is not a new phenomenon either: between 1996 and 2016, nearly 40 percent of vacant positions reported to the Government Accountability Office went without subsequent nominations; and 60 percent of those vacant positions were temporarily filled by interim appointees.

\footnotetext{
${ }^{8}$ For example, in 2014, with nearly 40 percent of PAS positions vacant, the Department of Veterans Affairs "was in crisis" with a "management vacuum" that could not address the excessive wait times for medical services that affected nearly 121,000 veterans, caused at least 40 deaths, and ultimately, led Secretary Eric Shinseki to resign (Kesling and Nelson, 2014; Buell, 2016).

${ }^{9}$ See Hollibaugh (2015) and Hollibaugh and Rothenberg (2017) for two notable exceptions.

${ }^{10}$ See Figure 2.4 in Chapter 2 for a more detailed picture of vacancies in the Trump Administration as of June 2 , 2018.
} 
In this dissertation, I explore the politics of this unconventional presidential appointment strategy. Clearly, a president's choice to not nominate or the Senate's choice to not confirm does not exclusively create "empty chairs;" instead, the reversion point includes empty positions and interim appointees. And yet, the president's systematic use of each type of vacancy remains largely unexamined. By overlooking this distinction, existing theories do not account for the walk-away value of interims and empty positions, ${ }^{11}$ and doing so ultimately reshapes how we represent the strategic considerations of the president and the Senate when they are faced with an appointment opportunity. Perhaps because we have not yet examined opportunities to consolidate political power by avoiding the formal, institutionalized ones, we lack an explanation of presidents' strategic use of vacancies. Thus, in recognizing that we have long confounded empty positions and interim appointees - when we have not been ignoring them altogether - this dissertation offers new perspectives and corrections to our understanding of presidential power.

The chapters that follow address three related questions: how do presidents use vacancies, why do presidents seek the Senate's advice and consent for certain positions and not others, and when do presidents choose to leave certain positions empty while filling others with interim or permanent appointees? Two central observations shape this inquiry. First, vacancies offer the president a remarkable opportunity to circumvent the Senate. Presidents unilaterally choose to leave positions empty or to fill them with interim appointees. The Senate enters the appointment calculus only after a president, again unilaterally, chooses to submit a nominee. Ultimately, this grants presidents considerable power to not appoint and not nominate. Second, the president's decision to keep a position empty requires an appointment strategy that centers on the characteristics of the position itself, rather than the characteristics of a potential appointee. This strategy, then, offers the president an additional degree of flexibility to consider whether an open

\footnotetext{
${ }^{11}$ Ultimately, existing theories do not frame the Senate's choice to not confirm (walk away from the nominee) with the position filled by an interim appointee in comparison. That is, by not differentiating between an empty position and an interim appointee, they do not accurately represent the status quo for the Senate's confirmation strategy. The theoretical framework presented in Chapter 4 formalizes this reversion point within the nomination-confirmation bargaining subgame.
} 
position requires an appointee before devoting resources to identify the short list of potentially Senate-confirmable appointees.

This dissertation makes three notable contributions to our understanding of presidential power by investigating how position characteristics and policy priorities influence the president's use of vacancies and appointments. First, this dissertation challenges the dominant paradigm in separation of powers models of presidential appointments. This paradigm proceeds from the assumption that executives are constrained by the need for legislative approval when placing principal officers in unelected office. ${ }^{12}$ This assumption itself presumes that presidents will always make appointments, through the nominations process, to head agencies. Presidents, in fact, do not. The perspective that the set of appointment choices include only formal powers like nominations or recess appointments does not leave room to consider the informal power of unilateral presidential inaction. Hence, this dissertation highlights that, for our theories of institutions and separation of powers to be complete, they need to consider how deliberate sidestepping of formal powers impacts inter-branch bargaining and agenda setting strategies.

Second, this dissertation begins with a new theory of appointments that offers its own set of contributions. Specifically, this framework provides a new and better understanding of presidential strategic behavior and the president's advantage in the nomination process. By explicitly differentiating between empty positions and those filled by interim appointees, my theory identifies the more accurate, and therefore complete, choice set available to presidents for maintaining political control of the bureaucracy. Moreover, it introduces the novel idea that these decisions are driven by the value of the positions themselves in terms of achieving policy priorities. Lastly, as discussed at length in Chapter 5, I have assembled the most comprehensive dataset on appointments to and vacancies in PAS positions. This data is new in political science research, and I harness it to empirically test the implications of my theoretical model. From a series of non-parametric and parametric analyses, I find evidence to support my theory that presidents

\footnotetext{
${ }^{12}$ An assumption driven entirely by the Appointments Clause of Article II in the United States Constitution.
} 
strategically use interim appointees to advance their expansion policy priorities and leave positions empty when they prioritize contraction.

This chapter proceeds as follows. First, given that vacancies are not well-known features of presidential appointment strategy, I provide an introduction to vacancies. Next, I introduce the central argument of the dissertation. Finally, I outline the plan of the dissertation, explaining the role that each chapter plays and the relationship between those chapters. 


\subsection{An Introduction to Vacancies: Empty Positions and Interim Appointees}

The fact that positions do not have Senate confirmed appointees - that they are vacant - does not necessarily mean that these agencies are headless or that those chairs are empty. Presidents can leave positions empty but they can also unilaterally fill these positions with people they want, outside of the formal nomination-confirmation process. The Obama administration's use of vacancies - that is, positions without a Senate confirmed appointee - offers a case in point: consider, for instance, the resignation of Harold Koh. In January 2013, Koh stepped down as the Senate-confirmed Legal Adviser at the State Department under President Obama. His departure created what would be a three-year vacancy in the critical position responsible for developing and defending the international legal basis for the use of force. For more than 16 months, Obama did not submit a nominee for Senate confirmation, even though the Democrats controlled the Senate. Instead, he relied on an interim appointee, Acting Legal Adviser Mary McLeod. Consequently, the person responsible for major policy decisions regarding the legal use of force, including military interventions in Syria, was not a confirmed appointee for more than half of Obama's second term. Interim appointees, like Mary McLeod, are options that presidents can and do use in the absence of a Senate confirmed appointee, but they have been entirely omitted from the literature on presidential appointments and unilateral action.

This omission is surprising, as empty positions and interim appointees have been in the president's toolbox for decades. Figure 1.1 presents a snapshot of the original data at the heart of this project, and highlights that interim appointees filled nearly half of vacancies across administrations from 1977-2015. Here, the grey line in Figure 1.1 shows the percentage of PAS positions without a Senate confirmed appointee, the conventional definition of vacancies, across this time period and the orange line indicates those filled by an interim appointee. As shown, interim appointees filled 10 percent of PAS positions on average. Yet this varies, by year, by administration, 
Figure 1.1: Percentage of PAS Positions: Empty, Interim, Vacant (1977-2015)

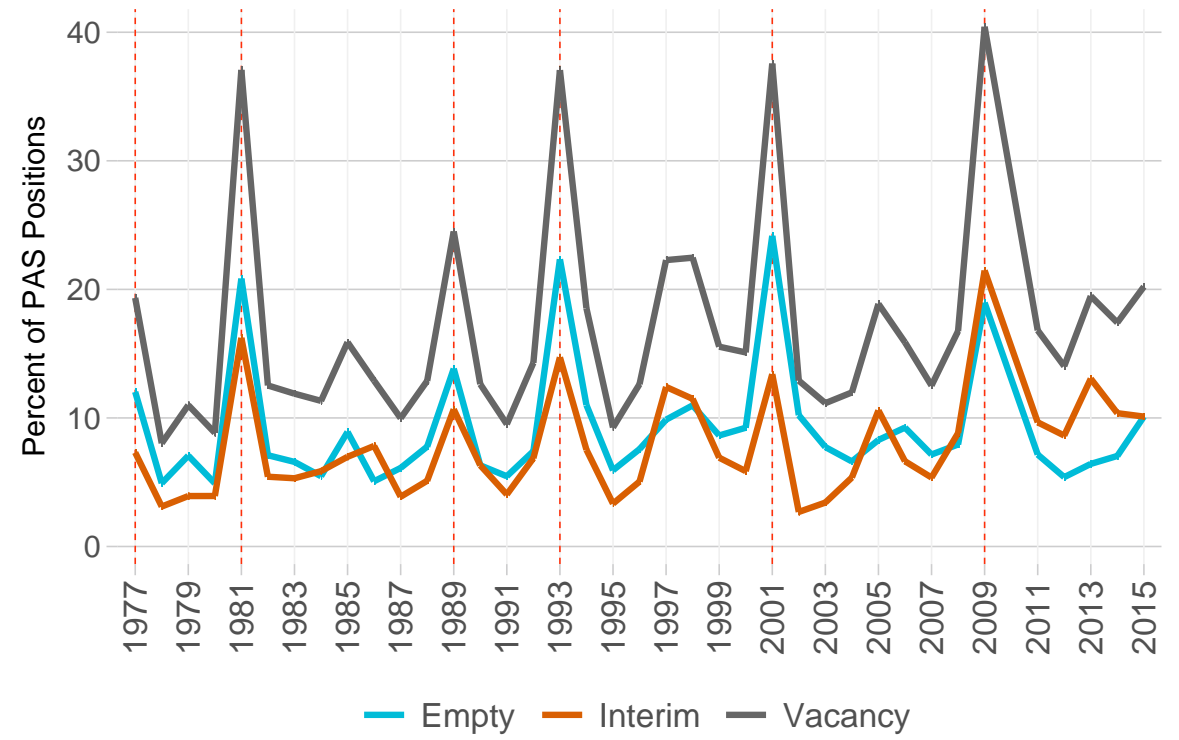

and, as the empirical analysis in Chapter 5 will show, even by department. Moreover, when we look specifically at the percentage of PAS positions left empty - the teal line - we can see that the relationship between the two different types of vacancies is not constant. Thus, only when we correct our conceptualization of vacancies to identify these two very different realities, can we then rethink how they factor into the strategic considerations of presidents and the Senate when they are faced with an appointment opportunity. Figure 1.1 provides a first look at the necessity of differentiating between interim appointees and empty positions, as well as the opportunity for presidents to use vacancies strategically. No current study considers interim appointees as strategic appointments by presidents who seek to expand their political control of the bureaucracy and achieve specific policy goals. This dissertation does exactly that.

While this distinction between vacancies that are empty positions and filled with interim appointees creates a more accurate set of appointment outcomes, it does not offer a clear picture of what produces those outcomes. To that end, let us consider the full appointment process ${ }^{13}$

\footnotetext{
${ }^{13}$ The full appointment process described here establishes the foundation for the formal model developed in Chap-
} 
(presented in Figure 1.2) that starts with someone leaving a position. The departure could result from retirement, transition to a new administration, reassignment, resignation, or death; either way, the position now has no one serving in it. And, consistent with previous literature and common parlance, I label this position as "vacant." Next, when faced with this vacant position, the president makes a calculated decision based on the political context he faces within his administration and within the inter-branch bargaining circumstances of Senate confirmation. He has to decide what to do about the vacancy. Suppose such appointment opportunities offer a president the occasion to pursue diverging policy goals, depending on his policy priorities for that agency and the role that position could play in achieving those priorities. Starting from this assumption, we can imagine that the president makes a sequence of decisions: first whether to immediately fill the position and then whether to pursue a permanent appointment by submitting a nominee for Senate confirmation.

As the first two branches in Figure 1.2 indicate, the president has two initial options: to fill the position immediately with an interim appointee or to not fill and leave empty. If the president chooses to fill the position immediately, the position will have an interim appointee when the president makes the second decision of whether to nominate someone for Senate confirmation or not. Consequently, if the president decides to not nominate, he circumvents the Senate and has a filled position, albeit with an interim appointee, without Senate confirmation. We could imagine circumstances when the president would like to see the position filled but does not want to engage in the often politically costly endeavor of selecting a nominee and submitting to the Senate for formal confirmation - perhaps when the Senate and the president are diametrically opposed in their policy agendas.

However, we might also imagine circumstances when the president would first want the position filled temporarily but then choose to nominate someone to be a permanent appointee. Given the constitutional constraint of advice and consent for permanent appointees, if a nomiter 4 . 
Figure 1.2: Full Appointment Process and Outcomes

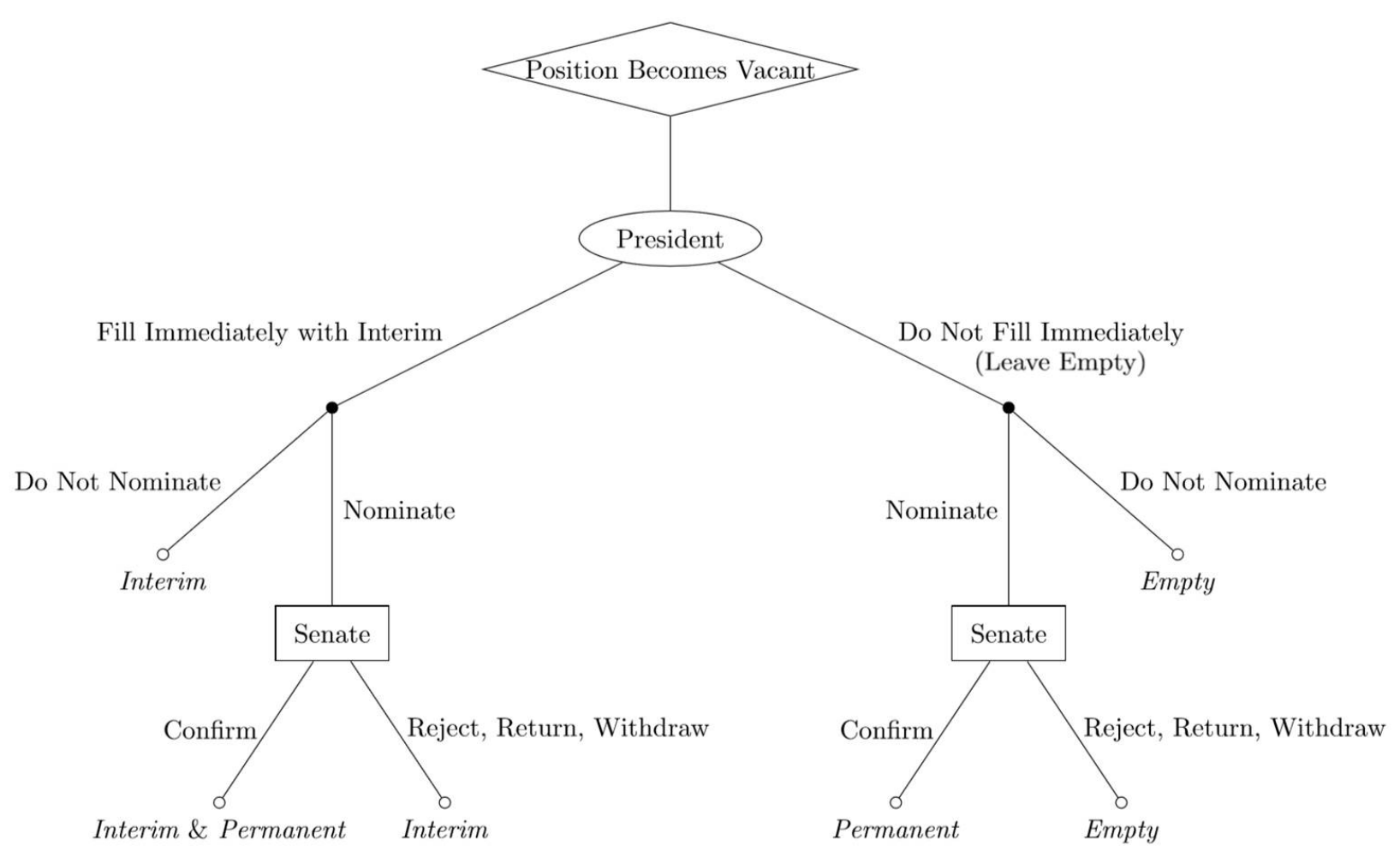

nee is submitted, the Senate responds with a confirmation decision. In making that decision, the Senate must weigh not only the political costs and benefits of confirming the president's nominee, but also the cost of the status quo - here a position filled by an interim appointee - and any gains from returning ${ }^{14}$ that nomination. If the Senate confirms the nomination, the interim appointee is then replaced by the permanent one. However, if the Senate rejects or returns the nomination, or if the president withdraws the nomination, then the position continues to be filled by the interim appointee.

Alternatively, as the right side of Figure 1.2 indicates, if the president chooses to not fill the

\footnotetext{
${ }^{14}$ Here, 'returning' a nomination occurs when the Senate does not confirm a nominee due to an official floor vote rejection, failure from adjournment sine die or recess in accordance with Senate Rule XXXI, or not reported from committee. While only nine cabinet-level nominees have ever been returned (the 1989 rejection of Bush's nominee for Secretary of Defense, John Tower, was the most recent), nomination records from Congress.gov show that approximately 10 percent of PAS nominees have been returned since 1987.
} 
position immediately, it will be empty when the president makes the second decision of whether to nominate or not. If the president decides to not nominate, again he sidesteps the Senate and unilaterally maintains an empty position. We could imagine circumstances when the president would like to see the position empty - perhaps to render the agency ineffective. However, if the president does nominate someone to fill the empty position, the Senate must then respond with a confirmation decision based on the status quo of an empty position. If the Senate confirms the nominee, the position is then filled by a permanent appointee; but, if not, or if the president withdraws the nomination, the position will remain empty. In other words, as a first-mover, the president sets the reversion point (i.e., an empty position or interim appointee) for the Senate's choice to confirm a nominee, if one is submitted.

In all, presidents from Carter through Obama have taken advantage of unilaterally leaving vacant positions empty and filling them with interim appointees. However, as Figure 1.1 highlighted and the empirical analysis in Chapter 5 will confirm, this varies by year, by administration, and by department.

\subsection{The Central Argument}

In this section, I preview my theory of vacancies and appointments, which Chapter 4 develops in detail. Specifically, I argue that presidents strategically use vacancies in their appointments that require Senate confirmation to expand their executive power and achieve their policy priorities. Considerable work has been done to understand the politics surrounding nominated and confirmed appointees, but much less has been done to evaluate the politics of their absence. To date, scholars have largely neglected how much influence vacancies, particularly those in leadership positions, can exert on political and policy objectives. ${ }^{15}$ While this dissertation continues the

\footnotetext{
${ }^{15}$ As discussed in Chapter 2, only a handful of scholars explicitly address vacancies: O'Connell (2009); Hollibaugh (2015); Hollibaugh and Rothenberg (2017). None of these explicitly differentiate between vacancies that are filled with interim appointees or left empty.
} 
existing emphasis that policy agendas drive presidential appointment strategies, I deviate from the current literature and offer a wider perspective that the position, not just the confirmed appointee who may or may not fill it, matters. I show that presidents can choose to not nominate and rely on an interim appointee, or to not appoint at all, in order to achieve their larger policy objectives.

I offer a new, generalized model of appointments - building on the observed phenomena that have gone largely unexplained: vital policymaking positions are often filled with temporary officials without Senate confirmation or left empty entirely. Ultimately, I argue that the capacity of positions themselves to control policy outputs and advance policy priorities, their Position Value, leads rational presidents to strategically forgo appointments and nominations. My theory considers a more complete choice set for appointment strategies that includes empty positions and interim appointees and generates a more accurate reversion point for confirmation bargaining when it does occur. Furthermore, the lack of attention to these features of the appointment process limits existing empirical expectations about the politics of vacancies and interim appointees. As a first step towards filling that gap, this theory tenders new, testable insights into presidential strategy and separation of powers.

First, this model predicts that a vacant position will stay empty only when the position has a high level of capacity to control policy outputs and the president prioritizes policy contraction, no matter the priorities of the Senate. This implies that, if the president prefers to shrink the policy reach of an agency, persistently empty high-capacity positions will occur even in unified government. Second, the president's choice to submit a nominee hinges on the cost of bargaining, conditioned by the Senate's value for oversight and time to confirmation. Although this result is not surprising, it lends credence to the more unexpected ones. Lastly, presidents appoint interims no matter the position capacity but do not fill vacancies immediately with interim appointees when prioritizing contraction. This implies that as presidential policy agendas slant towards expansion, the number of interim appointees in vacant positions will increase. Scholars have 
consistently indicated that the Senate's refusal to confirm appointments damages the president's ability to exercise his authority and execute the law (e.g., Binder and Maltzman, 2002; Bond et al., 2009). However, I have identified conditions under which presidents, when they use empty posts and temporary appointments, capitalize on their first-mover advantage to subvert the Senate's power to refuse confirmation.

\subsection{Plan of the Dissertation}

This dissertation proceeds as follows. In Chapter 2, I begin with a review of how existing research has engaged with the politics of appointments. To establish how this dissertation contributes to our current understanding of appointments and executive power, I review four main veins of research: separation of powers and political control of the bureaucracy, appointments within the formal nomination and confirmation process, vacancies in appointments, and the administrative presidency and unilateral action. Then, I outline the institutional structure governing vacancies in various types of PAS positions. Here, it becomes clear that interim appointments are a potentially powerful strategy for presidents to employ. Overall, Chapter 2 lays the groundwork

for the theory that I develop in Chapter 4 and concludes with a brief portrait of vacancies in PAS positions across six administrations, from Presidents Carter to Obama.

Next, in Chapter 3, I introduce the key concept driving my theory and empirical analysis: Position Value. As mentioned earlier, to examine a strategy set that includes leaving positions empty, we need to move beyond our traditional focus on the appointee and consider how positions, filled or empty, can distinctly increase utility. That is, we need to consider their Position Value, a concept that classifies positions by their capacity to control policy output and the policy priorities for their parent agency. Ultimately, Position Value functions as the central element of the model, creating the incentives that drive the Senate's choice to confirm a nominee and the president's strategic choice to submit one, given the Senate's confirmation strategy. 
In Chapter 4, I develop a novel theory of vacancies and appointments that incorporates the Senate's leverage to veto a nomination and the president's power to choose not to submit one in the first place. As discussed above, my central argument is that presidents strategically use vacancies in their appointments that require Senate confirmation to achieve their policy priorities. Advancing from the existing appointments paradigm and building on a set of clear and reasonable assumptions, I analyze a new model of vacancies in presidential appointments - taking into account both types of vacancies - as strategic choices driven by the capacity of those positions to achieve policy priorities. This theoretical framework identifies the conditions that lead presidents to leave certain positions empty while filling others with interim or permanent appointees. Yet, the core purpose of this model is to formalize a logic to explain the unexpected observed outcomes of interim and empty positions and to discipline my empirical analysis. Accordingly, I use the model's empirical predictions to generate several testable hypotheses, which I explore in the subsequent three chapters using the original dataset described in Chapter 5.

Specifically, I begin Chapter 5 by introducing this original dataset of empty positions, interim appointees, permanent appointees, and nominations from 1977 through 2015. The data includes the status of PAS positions in fifteen Executive departments, their levels of capacity to control policy outcomes, and the corresponding congressional and presidential policy priorities for each department. This data is the most comprehensive in political science to date and covers a total of 10,331 position-year observations. In the second half of Chapter 5, I present the first two of four analyses that evaluate the hypotheses offered by the theory presented in Chapter 4 . First, I explore several non-parametric cross-tabulations of distributions to establish the empirical consequences of a keystone of my research: the distinction between vacancies left as empty positions and those filled with interim appointees. The results show that under the conventional definition, vacancies appear to be similarly distributed across the categories of the president's Position Value which would suggest an absence of strategic behavior. Yet, when we differentiate between empty positions and interim appointees, the distributions change as predicted and offer initial 
evidence to support my theory. Critically, these findings begin to address the general underlying question of this dissertation: how do presidents use vacancies? The answer: presidents use them strategically.

The central parametric analysis in Chapter 5 takes up the two questions at the heart of this dissertation: why do presidents seek the Senate's advice and consent for certain positions and not others, and when do presidents choose to leave certain positions empty while filling others with interim or permanent appointees? I evaluate my hypotheses, formally derived in Chapter 4, simultaneously by modelling the likelihood of each position status as a function of Position Value. This analysis allows for formal statistical inference and provides strong support for the conjecture that presidents fill vacant positions with interim appointees when they prioritize policy expansion and some support for the conjecture that presidents leave vacant positions empty when they prioritize policy contraction. Yet this analysis does not offer a complete examination of the president's strategic use of vacancies, nor does it provide definitive evidence of each theoretical condition motivating that strategy.

In Chapter 6, I continue to leverage my original data in an extension of the multi-choice models presented in Chapter 5. Specifically, as detailed in Chapter 2, several institutional regimes govern who can serve as an interim appointee and for how long. The Federal Vacancies Reform Act (FVRA) of 1998, which currently governs interim appointments to Executive department PAS positions, stipulates the length of the prospective terms. Critically, the amount of time that interim appointees can serve increases considerably after the passage of the FVRA, which could explain the mixed findings presented in Chapter 5. I test this conjecture, and my hypotheses in this context, by extending the central likelihood analysis to account for the impact of the FVRA on the conditions under which presidents engage in specific appointment strategies. I find striking results that continue to provide support for my theory, suggesting that presidents leverage vacancies to set the direction of policy outcomes.

Chapter 7 tackles the question of when presidents choose to leave certain positions empty 
while filling others with interim or permanent appointees from an alternative perspective: the accumulation of vacancies and appointments. Specifically, I examine the incidence of empty positions, interim appointees, and permanent appointees across departments using aggregate counts of each position status. Consequently, I begin Chapter 7 with an introduction to these data. Next, I evaluate the three central hypotheses individually by modelling the counts of each position status among high capacity positions as a function of policy priorities. Here, I find evidence that is, again, consistent with my theory. Presidents leave more high capacity positions empty when they prioritize policy contraction, but fill more high capacity positions with interim appointees when they prioritize policy expansion. Finally, I assess whether we see a strategic accumulation of permanent appointees after we account for the incongruity of presidential policy priorities due to the length of the formal nomination-confirmation process; and find evidence that this is, in fact, the case.

In Chapter 8, I summarize the theory and findings from the previous chapters. I discuss the specific contributions this dissertation makes to scholarship on separation of powers and executive politics and reflect on further implications of the strategic use of vacancies. Additionally, I point to two broader policy implications of this research, each of which specifically highlight the new perspectives about empty positions and interim appointees that my approach brings and the corrections to elements of the appointment process we thought we already understood. First, the patterns of vacancies we find in the periods before and after the Federal Vacancies Reform Act speak to the ability of legislation to reform the nomination process and offers implications for any future reforms. Second, this dissertation provides a foundation for discussing the effect of empty positions and interim appointees on bureaucratic performance, a new way of understanding them, and a springboard for future research. Finally, I conclude by identifying several additional inquiries that would build on and extend the analysis presented here.

The chapters that follow explore how and when presidents use vacancies to achieve their policy goals, an unconventional appointment strategy that looks quite different from the formal 
nomination-confirmation process we generally expect presidents to use. Fundamentally, in this dissertation, I explore the possibility that policy priorities to expand or contract the reach of an agency lead rational presidents to strategically forgo formal appointments and nominations. As such, this inquiry contributes to existing scholarship by incorporating empty positions separate from interim appointees as well as the value of positions themselves into our understanding of the institutional conditions that shape the exercise of presidential appointment power. 


\section{CHAPTER II}

\section{Background on Presidential Appointments and Vacancies}

In the broadest sense, scholars have been concerned with questions of how political actors use the individuals to whom they delegate policymaking power to advance their own political and policy goals. Research on nominations, confirmations, and the administrative presidency demonstrate that appointees' preferences matter for policy and political control of the agencies they are

appointed to direct (e.g., Kaufman, 1981; McCarty and Razaghian, 1999; Lewis, 2008; Hollibaugh et al., 2014). Ultimately, this work reveals that members of Congress and presidents care about the appointments process because they also believe appointees shape policy and dictate agency performance, which matters both for their actual choice of agent and our understanding of the strategies leading to that choice. Moreover, understanding the importance of appointees for policy and agency performance, scholars have modeled the nomination and confirmation process. As they examine the balance of executive and congressional control of the bureaucracy, these theories of appointments maintain that presidents' choices over agency leadership are constrained by the extent to which Senate preferences deviate from those of the president. These separation of powers models assume that presidents will always make appointments, through the nominations process, to head agencies. Presidents, as we have seen, do not.

The inter-branch politics of presidential appointments, particularly those that require Senate 
confirmation (PAS positions ${ }^{1}$ ), sit at the heart of this dissertation. Specifically, I want to understand why, when the benefits of submitting a nominee for Senate confirmation seem obvious, presidents choose to not nominate or otherwise fill certain positions but seek confirmation for others. In the following chapters, I introduce a new approach to thinking about presidential appointment and Senate confirmation strategies, but we first need to establish how existing research has engaged with the politics of appointments. As this chapter presents, the established focus on nominees and confirmed appointees ${ }^{2}$ reveals why the distinction between vacant positions that are left empty and those filled by interim appointees has yet to be made.

The importance of recognizing this distinction largely derives from the institutional structure governing vacancies, which allows for the appointment of interim officials. As the second section in this chapter will explain in detail, there are five different procedural regimes that have governed vacancies in the executive branch since the $19^{\text {th }}$ century: the Vacancies Act and its reforms offer three regimes that cover interim appointments to executive agencies, various originating statutes for specific agencies that govern succession and identify "acting” officials provides a fourth regime and, by default, the fifth covers independent agencies and does not allow for interim appointees. These regimes create variation in the mechanism that matters most for my inquiry: whether a president can appoint an interim official to a vacant post and for how long the appointee can serve in that position. Under certain conditions, an interim can serve for almost two years or even indefinitely.

This chapter has three goals. First, I discuss the current perspectives of presidential appointments. To establish how this dissertation contributes to our current understanding of appointments and executive power, I review four main veins of research: separation of powers and political control of the bureaucracy, appointments within the formal nomination and confirmation process, vacancies in appointments, and the administrative presidency and unilateral action. Sec-

\footnotetext{
${ }^{1}$ Recall, presidential appointments requiring Senate confirmation are known as PAS positions.

${ }^{2}$ E.g., Lewis (2008); O’Connell (2009); Dull et al. (2012); Hollibaugh (2015); Chiou and Rothenberg (2014); Ostrander (2016); Hollibaugh and Rothenberg (2017).
} 
ond, I outline the institutional structure governing vacancies in various types of PAS positions. Here, it becomes clear that interim appointments are a potentially powerful strategy for presidents to employ. Lastly, this chapter concludes with a brief portrait of vacancies in PAS positions across six administrations, from Presidents Carter to Obama.

\subsection{Current Perspectives of Presidential Appointments}

Most of the current work on presidential appointments - including research on separation of powers, political control of the bureaucracy, and the administrative presidency - examines the power dynamics surrounding the initial selection and subsequent control of appointees to the bureaucracy. Traditionally, studies in separation of powers offer the most holistic examinations by considering how Congress, the president, the courts, and the bureaucracy balance their Constitutional powers and bargain toward their different policy objectives (Moe, 1985; McCubbins et al., 1987; Ferejohn and Shipan, 1990; McCarty and Poole, 1995; Epstein and O’Halloran, 1999; Moraski and Shipan, 1999; Cameron, 2000; Gailmard and Patty, 2007). When considering appointee selection, separation of powers models typically assume presidents are constrained by the need for Senate approval when placing agents in unelected office. These studies seek to identify the conditions under which the influence from one institution might dominate the other (McCarty and Poole, 1995; Moraski and Shipan, 1999; Chang, 2001; Carpenter, 2001; Chiou and Rothenberg, 2014; Hollibaugh and Rothenberg, 2017). In doing so, they often focus on how presidents, in strategic anticipation of Senate preferences for confirmation, and senators, in their potentially delayed response, seek to shape the ideological composition of the bureaucracy (e.g., Snyder and Weingast, 2000; Lewis, 2011).

Alternatively, when considering confirmed appointees, scholars turn to examinations of how congressional oversight influences the bureaucracy, how politicization of these appointments affects presidential control, and how political appointees impact agency performance and pol- 
icy outcomes. These studies investigate whether the level of discretion delegated to appointees through agency design and enacted laws molds their policy decisions and how responsive they are to congressional influence (e.g., Weingast and Moran, 1983; Bawn, 1995; Epstein and O’Halloran, 1999; Huber and Shipan, 2002; Volden, 2002; Miller, 2005; Lowande, 2018b). Moreover, this line of research examines how political appointees affect agency performance and whether they translate vague laws into policies that align with the preferences of the president or those of their congressional principals (Aberbach, 2001; McGrath, 2013). In what follows, this section reviews the existing research that my theory and empirical analyses draw from and contribute to, including studies on separation of powers and political control of the bureaucracy, the administrative presidency, the theoretical and empirical studies of the nomination and confirmation processes, and presidential unilateral action.

\subsubsection{Separations of Powers and Political Control of the Bureaucracy}

The separation of powers literature finds its roots in principal-agent theory. From Weingast (1984) to Miller (2005), principal-agent scholars highlight that when one or more principals delegate decision-making to agents, the choice of agent, or appointee, matters. The president cannot possibly "faithfully execute" every law on his own; he must delegate. Moreover, members of Congress cannot realistically accumulate the breadth of expertise required to write every aspect of policy; they must also delegate. While delegation increases the efficiency of policy-making and implementation through division of labor and comparative advantage, it leaves principals vulnerable to a potential loss of control over delegated issues. That is, they will likely encounter drift between their preferred outcome and the one pursued by agents through delegation.

If principals could appoint agents with perfectly aligned interests and be completely informed about every action they might take, there would be no problem. In these terms, the president and Congress will generally want appointees with similar, if not identical, preferences. ${ }^{3}$ Building on

\footnotetext{
${ }^{3}$ Formal models of bureaucracy refer to this as the "ally" principle: a principal is made best off by appointing as
} 
this and recognizing the political reality that appointees are increasingly more involved in setting policy agendas and implementing policy decisions, scholars have addressed questions of how this similarity in preferences matters for policy and political control of the agencies that appointees direct (e.g., Kaufman, 1981; McCarty and Razaghian, 1999; Lewis, 2008; Hollibaugh, Horton, and Lewis, 2014). Ultimately, this research demonstrates the importance of appointees, as agents for the president and Congress, for policy and agency performance.

Recognizing the importance of appointees, many have modeled how these appointments are made through the formal nomination and confirmation process. Specifically, they examine how Congress and the president balance their separate powers and bargain for appointees with policy preferences most similar to their own (e.g., Kaufman, 1981; Nixon, 2001; Lewis, 2008; Chiou and Rothenberg, 2014; Hollibaugh, Horton, and Lewis, 2014). Importantly, theories of presidential anticipation in nominee selection maintain that presidents' choices over agency leadership are constrained by the extent to which Senate preferences - those of key individual Senators or of Senatorial institutions like committees - deviate from those of the president (Calvert et al., 1989; Hammond and Hill, 1993; Snyder and Weingast, 2000; Bailey and Chang, 2001; Chang, 2001). Generally, these studies use ideology as indicators of anticipated policy preferences. Most often, they seek to predict the ideological composition of a set of appointees and identify the conditions under which presidents nominate individuals with certain ideological leanings. And empirical analyses of these theories, made possible by new measures of ideology for bureaucratic agents, offer evidence that presidents strategically condition their nominee selection in anticipation of Senate actions as well as the ideology of the agency itself (e.g., Nixon, 2004; Clinton et al., 2012; Bonica et al., 2015). For instance, Nixon (2004) demonstrates that the dynamics of separation of powers lead presidents to select nominees whose ideologies sit between their own ideology and the ideologies of key members in both the House and the Senate, many of who function as his or her agent the individual whose preferences over outcomes are most similar to those of the principal (Bendor and Meirowitz, 2004). 
veto-override pivots for legislation that might constrain agency policy-making. And Clinton et al. (2012) similarly find that the ideological position of the Senate median, vis-à-vis the ideological leanings of the nominee and the agency, also influence the president's selection.

Studies have also questioned whether appointees pursue their own policy goals or those of any one of their multiple principals - Congress, the president, the courts, or the broader public (e.g., Wood and Waterman, 1994; Carpenter, 2001; Whitford, 2005). That is, they question how effectively principal institutions can maintain political control over their agents. Critically, our conventional wisdom gathers that appointees are rarely perfect representatives of their principals and may be motivated to act in their own interest at their principals' expense. Consequently, scholars have made a substantial effort to understand the instruments of delegation and oversight that principals might use to minimize such drift and ensure that bureaucratic agents pursue the right policy goals (Aberbach, 2001; McCubbins et al., 1987, 1989; Epstein and O'halloran, 1994; Bawn, 1995; Gailmard, 2002; Huber and Shipan, 2002; Bendor and Meirowitz, 2004; Nixon, 2004). In other words, the drift enabled by delegation requires mechanisms for principals to retain political control of the bureaucracy.

The rich literature on political control of the bureaucracy follows the natural division in any principal's available options for managing an agent: ex ante versus ex post control. Scholars have examined conflicts over ex ante control including structural choice in the design of the agency (e.g., McCubbins et al., 1987, 1989; Moe, 1989), how these choices balance with goals like expertise (Bawn, 1995), and the procedures that govern bureaucratic decisions (McCubbins et al., 1989). Others have concentrated on questions of ex post control like what mechanisms of oversight principals use to monitor agencies (e.g., McCubbins and Schwartz, 1984; Lupia and McCubbins, 1994b), when legislatures delegate varying degrees of discretion to agencies (e.g., Epstein and O'Halloran, 2000; Huber and Shipan, 2002), whether principals actually influence the bureaucracy (e.g., Shipan, 2004), and the impact of agents' policy preferences on the extent of imposed control (Gailmard and Patty, 2007; Clinton et al., 2012). The contests for control over appointments of 
bureaucratic agents arguably includes aspects of both ex ante and ex post control.

Ultimately, this dissertation builds on two themes common across the separation of powers and political control literatures. First, following the separation of powers paradigm, the theoretical framework I propose in Chapter 4 is set in an inter-branch bargaining context. I assert that my consideration of presidential appointment strategies needs to be one that recognizes the potentially countervailing influence of Senate preferences for the president's choice to submit a nominee. And, second, presidents and the Senate ultimately aim to retain political control of the bureaucracy in order to advance their policy agendas. Existing research concentrates on the prospect that individual nominees and confirmed appointees will deliver policy objectives.That is, nomination and confirmation strategies are conditioned by the policy preferences of these principal actors. Drawing from this idea that presidents and the Senate use the appointment process to control the policy outputs and outcomes that result from agency decisions, my theory integrates the capacity for positions control agency decisions and deliver those preferred policy outputs.

\subsubsection{Appointments: Nomination and Confirmation}

Research on presidential appointments represents an influential subset of the separation of powers literature described above, and has three major streams: nominee selection, confirmation politics, and appointee-agency relations. Although the theory I propose in this dissertation does not focus exclusively on the qualities and characteristics of the individuals that presidents appoint when they do choose to fill these positions, the vast majority of existing research does. Critically, much of this research centers on either the selection of the president's nominee and Senate's role post-nomination, with very little attention paid to the president's decision to submit a nomination in the first place.

First, scholars who examine presidential influence through nominations have largely focused on the battles over judicial appointees, especially at the Supreme Court level (e.g., Segal, 1987; Cameron and Segal, 1998; Nixon, 2001; Binder and Maltzman, 2002; Shipan and Shannon, 2003; 
Shipan et al., 2014; Cottrell et al., 2019) and Cabinet-level agency appointees (e.g., Nathan, 1983; Moe, 1985; McCarty and Razaghian, 1999; Aberbach and Rockman, 2000; Lewis, 2008; Chiou and Rothenberg, 2014). These theories typically model the appointment process with presidents as agenda-setters in their nominee selection and the Senate as a veto player over confirmation. They often emphasize the role that individual characteristics like ideological preferences, and the congruence between them, of the president, Senators, and nominees play in the choice of appointee in equilibrium (e.g., Epstein and O’Halloran, 1999; Snyder and Weingast, 2000; McCarty, 2004; Bertelli and Feldmann, 2006; Hollibaugh and Rothenberg, 2017). Scholars also consider how other traits like competence, experience, and loyalty (e.g., Heclo, 1977; Edwards III, 2001; Jo and Rothenberg, 2012; Krause and O’Connell, 2016) influence presidential nominee selection. Fundamentally, these studies implicitly assume that presidents will always nominate someone for open positions by concentrating on the choice of nominee, without accounting for the choice to skip nomination and leave posts vacant; a shortcoming this project ultimately seeks to resolve.

Second, when scholars shift from the individual characteristics of would-be appointees, they do so to examine the institutional influence of confirmation politics - particularly those generating senatorial delay and obstruction - on the president's nominee selection (Bond et al., 2009; McCarty and Razaghian, 1999; Aberbach and Rockman, 2000; Binder and Maltzman, 2002; Chiou and Rothenberg, 2014; Ostrander, 2016). For instance, McCarty and Razaghian (1999) assume that the president, when choosing a nominee, weighs how his policy preferences align with those of the appointee against the likelihood of Senate delay. They find the probability of rejection and the length of Senate delay increases with party polarization and divided government. Despite the president's first-mover advantage, the Senate's veto power ultimately means that the refusal to confirm appointments damages the president's ability to exercise his authority and execute the law. Chiou and Rothenberg (2014) return to McCarty and Razaghian (1999) and build on their theory by explicitly incorporating the appointee's ideology, strategic behavior between the executive and pivotal members of the Senate, and the agency position's importance relative to the 
larger executive branch hierarchy. However, they find that the effect of ideology and divided government on the duration of delay are conditioned by the office's policy importance and the Senate's tolerance for delay costs relative to the nominee's influence.

Uniquely, Chiou and Rothenberg (2014) motivate their empirical analysis by modeling the appointment process as a game of delay assuming an inevitable confirmation, which pivots from the traditional perspective theorists have taken. Previous models had not considered the potential equilibrium in which the president endures a longer confirmation process - that is, a longer vacancy in that position - to secure an appointee more closely aligned with his preferences. Chiou and Rothenburg provide for this; and while vacancies are more theoretically integrated than before, they are still not captured as a deliberate outcome of the appointment process. Pivoting from the trade off between preference alignment and confirmation delay, Ostrander (2016) demonstrates that the Senate engages in strategic delay based on position characteristics, agency ideology, and expected differences in how confirmed appointees will engage in policy implementation. He suggests that senators seek to delay certain nominees - based on their position and agency - in order to maintain their preferred policy status quo, particularly when the policy output is more favorable during the stalemate.

In addition to considering the dynamics of appointee selection and confirmation, executive politics scholars emphasize the implications of altering the set of those appointees for political control and bureaucratic performance (e.g., Aberbach and Rockman, 2000; Lewis, 2008). In particular, Lewis (2008) examines the politicization of appointments and the nomination process as major instruments for presidential influence. He presents a theory to explain when presidents look to change the size of agencies, especially those agencies with countervailing policy views, in order to regain or maintain control of administrative policy. Since adding appointed positions typically decreases performance, Lewis finds that presidents are more likely to do so when an agency's views differ from their own and when the agency's performance is not particularly sensitive to the additional positions. 
At its core, my dissertation advances our general understanding of presidential appointments built by this rich literature. Critically, however, I deviate from existing work by focusing on more than the subgame of installing an individual appointee, from either the president's perspective of nominee selection or the Senate's perspective of confirmation. Instead, in a similar vein as Ostrander (2016), I concentrate on the role that the position's characteristics play in the appointment process, with a broader approach that the president need not select a nominee to achieve the goals of his appointment strategy. Specifically, I theoretically integrate vacancies as a part of the appointment strategy set and consider how policy outputs generated in the absence of a confirmed appointee determine nomination and confirmation decisions.

\subsubsection{Appointments: Vacancies}

All presidential administrations have vacancies. At inauguration, a president faces over 4000 vacancies throughout the executive branch, $1217^{4}$ of which are presidential appointments requiring Senate confirmation (PAS positions). Initial vacancies are expected as a natural byproduct of an appointment process that demands extensive vetting before nomination and debate before confirmation. Yet, time is of the essence: presidents have just 1461 days to accomplish their policy and political goals and an administrative presidency's success or failure often hinges on the president's control of agencies and their personnel (Nathan, 1983). Given the time constraints and impact of the top positions in the federal bureaucracy - ultimately shaping the substance of the administration's politics and policy - one might expect vacancies throughout a president's term to be sporadic at worst. This, however, is not the case. In fact, over the past five administrations, executive agency positions did not have a Senate-confirmed appointee, on average, 25 percent of the time (O’Connell, 2009).

Given that appointees matter, their absence - especially if extensive - is likely as conse-

\footnotetext{
${ }^{4}$ The United States Policy and Supporting Positions (the "Plum Book"), a quadrennial publication, lists all presidential appointments for each new administration. Here, the number of PAS positions is drawn from the 2012 Plum Book.
} 
quential. Yet, the inter-branch politics of vacancies remains understudied and untested. Instead, extant research cites vacancies as unfortunate consequences of turnover in a large administrative bureaucracy (e.g., Chang, Lewis, and McCarty, 2001), confirmation delays (e.g., Binder and Maltzman, 2002; Ostrander, 2016; Madonna and Ostrander, 2017) that are prolonged by nominee ideologies (e.g., Chiou and Rothenberg, 2014; Bonica, Chen, and Johnson, 2015), in periods with divided government (e.g., McCarty and Razaghian, 1999), or presidential delays in nomination due to the vetting process (O’Connell, 2009; Hollibaugh, 2015). While scholars have made important progress in illuminating key aspects of the appointment process, most overlook the decision to forgo nominations entirely.

As mentioned previously, a considerable line of research examines the likelihood and determinants of Senate confirmation delay and its contribution to protracted vacancies (e.g., Aberbach and Rockman, 2000; Binder and Maltzman, 2002; Chiou and Rothenberg, 2014; Madonna and Ostrander, 2017; McCarty and Razaghian, 1999; Nixon, 2001; O’Connell, 2015; Shipan and Shannon, 2003) but just a handful of scholars explicitly consider how the president's inclination to delay nomination contributes to the accumulation of vacancies (Nixon, 2001; O'Connell, 2009; Hollibaugh, 2015; Hollibaugh and Rothenberg, 2017). This includes a notable exception, Hollibaugh (2015), who theoretically integrates sustained vacancies as a deliberate strategy within a president's larger nomination strategy space. However, as explained below, more work still needs to be done as Hollibaugh's theoretical model considers only the timing of nominations and does not set them within a larger bargaining game over Senate confirmation. Alternatively, Nixon (2001) offers a rare empirical analysis of vacancies on the Federal Communications Commission (FCC), an independent commission not covered by the Vacancies Act, but his study is limited to just one agency. He finds that ideology and non-partisan restrictions of appointees increases confirmation delays thereby increasing the duration of the vacancy. Importantly, each of these studies defines vacancies as positions that are either empty or filled by an interim appointee, without differentiating between the two. 
O'Connell (2009) offers the first comprehensive descriptive look at the patterns of vacancies across departments and administrations. In doing so, O’Connell makes a considerable contribution to our understanding of presidential appointments by drawing much needed attention to several key features of vacancies. She demonstrates that delays in confirmation and nomination contribute to more open posts in executive agencies, and finds that PAS positions - across policy area, level of appointment, and partisanship - were vacant 15 to 25 percent of the time, averaging 219 days to an entire year (O’Connell, 2009). While O’Connell does not explore specific mechanisms to explain this variation, she does speculate about the potential impact from organizational factors like the capacity of the White House personnel office, institutional forces (i.e., divided government), policy preferences, or the legal framework that governs the appointment process. Moreover, her data focuses on major Cabinet-level agencies, which disregards all independent agencies and commissions that are not covered by the Vacancies Act and therefore cannot have temporary appointments to reach the required quorum to conduct official business. ${ }^{5}$ Furthermore, O’Connell (2009) does not differentiate between vacancies filled with interim appointees or those left empty. Nor does she consider interim appointees as strategic appointments by presidents who seek to expand their political control of the bureaucracy and achieve specific policy goals. Since previous theories focus on the subgame of choosing a nominee, we have yet to consider the full choice set available to presidents within a complete, extended model of appointments.

Whereas O’Connell (2009) details the empirical importance of vacancies, Hollibaugh (2015) and Hollibaugh and Rothenberg (2017) pursue the first theoretically-driven examinations of vacancies that integrate the presidents' choice to submit a nominee. First, Hollibaugh (2015) develops a novel theory of nominations from the perspective of personnel screening. Notably, Hol-

\footnotetext{
${ }^{5}$ Similarly, the analysis included here also does not include independent agencies. However, my full dataset of vacancies does include independent agencies and future extensions beyond the scope of the project at hand will address these positions.
} 
libaugh directly incorporates vacancies into the nomination process. ${ }^{6}$ Similarly, Hollibaugh and Rothenberg (2017) offer a theory of the political determinants of vacancy length (in terms of time to nomination and time to confirmation). Their article identifies sustained vacancies as a president's deliberate choice, but does not set it within the larger bargaining game over Senate confirmation. Furthermore, neither Hollibaugh (2015) nor Hollibaugh and Rothenberg (2017) differentiate between interim appointees and empty posts in their theory or analyses. Recent work from Moore (2018) takes up the question of presidents circumventing Senate advice and consent but does not examine PAS vacancies directly; instead, she argues that, when faced with Senate opposition, presidents turn to Schedule C appointments.

Given the veritable paucity of research on vacancies in the bureaucracy, this project wades into rather uncharted territory. Very few have explicitly considered the role that vacancies play in the appointment process and none explicitly differentiate between vacancies left empty and those with interim appointees. Consequently, we do not have a rich literature to draw from in terms of expectations of the impact of vacancies, compared to the literature on nominations and confirmations. However, based on the work that has been done, we can conjecture as to the likely impact of the two different types of vacancies.

Vacancies without interim appointees (empty posts) likely reduce the responsiveness of the administrative state, limit the generation of public policy, and erode morale among careerists if agency operations stall. The absence of key officials will generally make agencies less productive

\footnotetext{
${ }^{6}$ Hollibaugh (2015) develops a formal model of personnel screening that speaks directly to the fact that high search costs and relatively low competence among potential candidates lead to nomination lags and large numbers of vacancies. Hollibaugh offers the first theoretical framework that directly incorporates vacancies into the nomination process, making important progress in highlighting important structural aspects of vacancies; however, his model construction does not integrate the distinction between interim appointees and leaving a post unfilled. He builds on theories of agenda-setting (Romer and Rosenthal, 1978) and imperfect information between principals and agents (Bendor and Meirowitz, 2004) to construct a dynamic model that incorporates time, agency ideology, nominee competence, and information about the supply of potential nominees learned through time-dependent vetting procedures. Essentially, Hollibaugh finds that nomination lags, particularly at the end of a term, increase the president's agenda-setting power and may result in less-competent nominees. However, we observe increases in vacancies and decreases in submitted nominations near the end of presidents' terms (O'Connell, 2009), which is not particularly consistent with this finding. While I share Hollibaugh's perspective that timing and vacancies must be integrated into our models of the appointment process, I propose a different model construction.
} 
and less able to handle time-sensitive crises that require swift decision-making and leadership (O’Connell 2009). For instance, Bolton et al. (2015) find that a vacant Administrator position at the White House Office of Information and Regulatory Affairs (OIRA) generates longer regulatory review periods and less responsiveness to the president's policy agenda. In many ways, empty posts promote agency inaction, particularly for independent commissions (e.g., the Consumer Financial Protection Bureau) that require a quorum for official business or regulatory agencies that need leadership to determine which issues within their legal jurisdiction have priority for rule-making (e.g., the Food and Drug Administration or the National Highway Traffic Safety Administration). The absence of leadership can make careerists feel "rudderless," and "thwarted for months or even years from doing the government jobs they were hired to do" (Leonnig, 2008, 1). Such widespread frustration can often decrease morale and likely erode the trust that reinforces careerist compliance with the administration's larger agenda.

Yet, agency inaction that aligns with the presidents' larger policy agenda could lead to political benefits for the president and his supporters. For instance, President Reagan famously left vacancies at more liberal agencies like the Environmental Protection Agency, which generated generous support from his conservative base (Houck 1987). Moreover, widespread and incapacitating vacancies offer a seemingly quicker avenue to centralization from predecessors' politicized agencies. For instance, more than seven months into the Trump administration, the State Department had just two confirmed PAS appointees (Secretary of State Rex Tillerson and Deputy Secretary of State John Sullivan), two submitted nominees, and 28 vacant key policy-making PAS positions (as of July 20,2017). In other words, Trump had not submitted nominees for 88 percent of the top State Department positions; an approach to diplomacy, one could argue, that seems to prefer policy formulation centralized in the White House. Even so, successful implementation of these centralized policies requires the White House to "monitor, prod, and pressure [the bureaucracy] to carry out policy" (Durant and Resh, 2010b, 580). Thus, with so few people to rely on for implementation leadership, President Trump seems to be investing in inaction. 
Alternatively, vacancies with interim appointees potentially increase responsiveness to the president's preferences since they are not subject to Senate confirmation (O'Connell, 2009). If drawn from long-term employees with more agency work history, 'acting' officials may have more competence and expertise than their Senate-confirmed alternatives (O'Connell, 2009). The absence of a confirmed appointee may be motivated by inverse objectives: empty posts promoting inaction versus interim appointees offering more effective reactions. One could easily imagine that these objectives produce conflicting outcomes depending on the type of position and the alignment of the agency's policy preferences with those of the president.

\subsubsection{The Administrative Presidency and Unilateral Action}

Existing research on the administrative presidency emphasizes that political appointees strengthen political control due to their role in changing agency policies to be more in line with those of the president (e.g., Wood and Waterman, 1991, 1994). Scholars assume that appointees can success-

fully advance the president's policy agenda (Durant and Resh, 2010a), particularly since “appointee decisions about budget requests to Congress, rulemaking, personnel, and the allocation of resources [...] can significantly influence policy [and more generally,] appointees monitor bureaucratic activity and communicate the president's vision to the press, agency employees, clients, and stakeholders" (Lewis, 2009, 3). Consequently, our conventional wisdom suggests that the people presidents choose to appoint are especially important elements for determining the success of the administrative presidency (Nathan, 1983; Aberbach and Rockman, 2000). In particular, this success is largely determined by levels of bureaucratic performance and the ability for agencies to produce outputs aligned with presidential policy priorities, which often requires finding the right balance between appointees and careerists (Krause et al., 2006).

Moreover, the power to appoint creates the advantages of the modern administrative presidency that allow for unilateral policy-making through executive orders, administrative regulations, and the structural changes to the bureaucracy (Moe and Howell, 1999; Aberbach and 
Rockman, 2000; Howell, 2003). Research on how presidents use these kinds of unilateral powers to make policy highlight the growing set of constitutional ambiguities that presidents can exploit and the political reality that Congress and the courts are increasingly relegated to reactionary positions. Recent research on recess appointments emphasize the unilateral nature of one alternative to the confirmation process (e.g., Black et al., 2007), but does not capture when the president chooses to neither nominate nor appoint and instead maintain empty positions. By more accurately representing vacancies in the appointment process, this dissertation builds on recent research that identifies new forms of unilateral action. The power to not appoint and not nominate is the newest manifestation of presidential unilateral power. Presidents maintaining vacancies - either by leaving a position empty or appointing an interim appointee - without submitting nominations denies the Senate its advice and consent constitutional prerogative.

The limits of the president's power to make appointments, as established in Article II, are clear: congressionally-designated high-ranking officials require the Senate's advice and consent. Senate confirmation sanctions appointees' delegated authority and preserves separation of powers. Confirmation hearings offer ex ante oversight opportunities to establish expectations for the nominee, should she be confirmed as the permanent appointee (Dull et al., 2012). They also provide a forum for senators to examine the direction of the agency as well as the administration's policies towards the major groups within the agency's jurisdiction. When a president does not submit a nominee, the Senate loses these oversight opportunities. While the Appointments Clause expressly allows the president to nominate individuals to fill PAS positions, it does not compel him to do so:

$[\mathrm{H}] \mathrm{e}$ shall nominate, and by and with the Advice and Consent of the Senate, shall appoint Ambassadors, other public Ministers and Consuls, Judges of the supreme Court, and all other Officers of the United States, whose Appointments are not herein otherwise provided for, and which shall be established by Law.

U.S. Constitution. Article II, Section 2. 
When presidents perpetuate vacancies without submitting nominations, as they have for decades, they challenge the authority of the separation of powers principle. Yet existing research typically identifies threats to separation of powers in terms of usurpation of power through unilateral action (e.g., Moe and Howell, 1999; Chiou and Rothenberg, 2017), rather than consolidation of power through inaction. Scholars examine expansions of presidential policy-making power through executive orders (e.g., Howell, 2003), proclamations (Rottinghaus and Maier, 2007), signing statements (Sievert and Ostrander, 2017), and presidential memoranda (Lowande, 2014) as strategic tools that can unilaterally achieve policy goals without legislation (Ouyang and Waterman, 2015). Others address how presidents indirectly influence policy by unilaterally constructing more controllable agencies (Howell and Lewis, 2002) or adjusting the number of political appointees within agencies (Lewis, 2005).

Others still consider how gridlock-induced congressional inaction often cedes power to the executive branch (e.g., Volden and Wiseman, 2014; Brady and Volden, 2018). Yet few consider how presidential inaction shifts power, and how not exercising formal powers consolidates influence over outcomes, particularly when presidents choose not to submit nominees for Senate confirmation or choose not to appoint at all. Furthermore, studies of how presidents unilaterally appoint interim officials to vacant posts, often in lieu of a nominee, are missing from executive politics research. As the first mover in the appointment process, presidents have the opportunity to unilaterally appoint interim officials or leave positions empty. If the impact of the roughly 1,200 PAS positions on the direction and scope of policy outcomes were minimal, perhaps then vacancies would be inconsequential. This, however, is not the case (Nathan, 1983; Lewis, 2008; O'Connell, 2009). These appointments have long been viewed as a president's most important instrument of political influence that shape the political and policy success of administrative presidencies (Wood and Waterman, 1991). My project contributes to our understanding of unilateral action by demonstrating that the power to not nominate and not appoint is an effective tool for the president's unilateral toolbox. 


\subsection{The Institutional Framework Governing Vacancies}

Politicians see that appointees matter since they often shape policy and agency performance. Consequently, scholars and elected officials can agree on this key point: appointees matter. In these terms, presidents generally want appointees with similar, if not identical, interests who are then more likely to do his bidding than not. Thus, appointees' preferences matter for policy and political control of the agencies they are appointed to direct, as demonstrated by extant work on nominations, confirmations, and the administrative presidency (e.g., Kaufman, 1981; McCarty and Razaghian, 1999; Lewis, 2008; Hollibaugh et al., 2014).

However, presidential appointees - specifically those in PAS positions - represent a modest bloc atop a much larger pyramid of nearly 3 million civil servants spread across over 200 departments and agencies. Figure $2.1^{7}$ displays the position of these appointees within the hierarchy of the federal civilian personnel system; and Figure 2.2 documents the distribution of PAS positions across the entire executive branch. We can see from Figure 2.2 that two-thirds of the 1,242 PAS positions listed in the 2016 United States Policy and Supporting Positions are housed in Executive departments (e.g., Department of the Interior). Moreover, the State Department holds 268 and the Department of Justice holds 210 of those positions, the vast majority of which are United States ambassadors and United States attorneys, respectively. The remaining PAS positions are more evenly spread across the other Executive departments (except the Department of Defense, which houses 52 PAS positions across the Departments of the Army, the Navy, and the Air Force). Since the larger set of careerists are generally responsible for implementing agency policy, the degree to which PAS appointees can be effective in advancing the president's agenda largely depends on appointee-careerist relations (Durant and Resh, 2010b).

In some cases, the agencies these appointees seek to manage naturally produce policies consistent with the president's wishes with very little attention from the White House; others need

\footnotetext{
${ }^{7}$ See Lewis and Selin (2012).
} 
Figure 2.1: Federal Civilian Personnel System

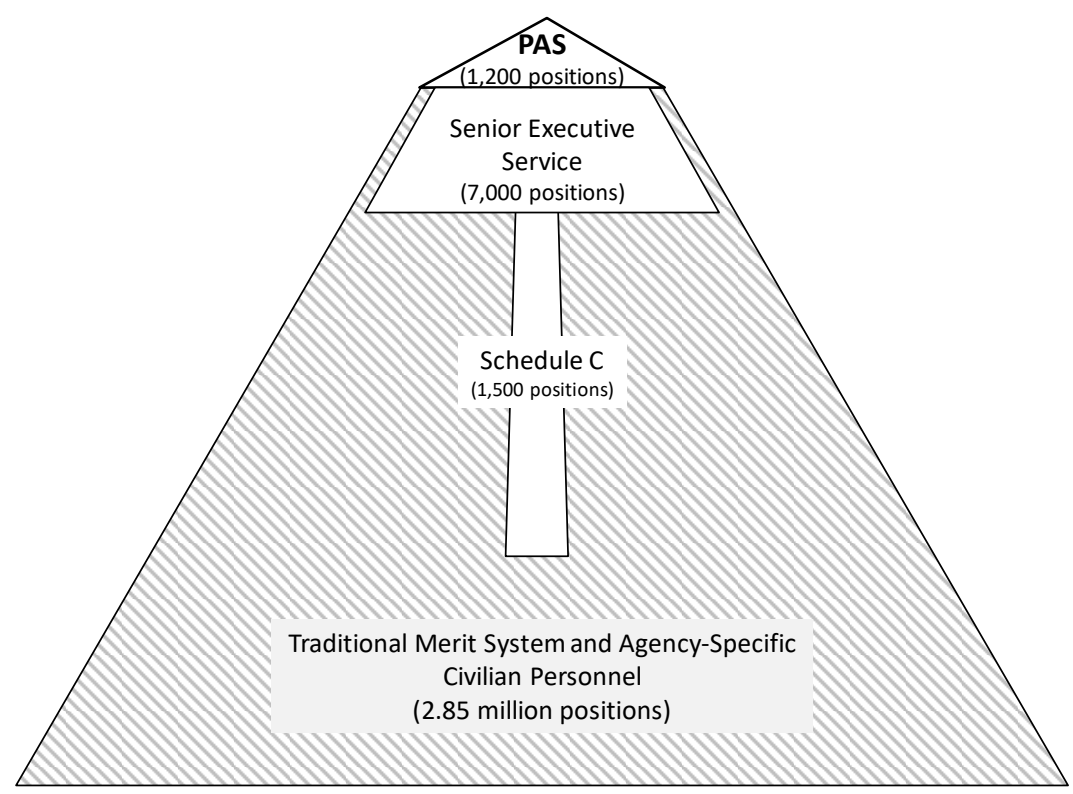

Adapted from Lewis and Selin 2012.

active management. Consequently, presidents may be better served by concentrating on appointing allies to more actively lead agencies whose missions and policy preferences are not aligned with their own (Gailmard and Patty, 2007; Lewis, 2011). For such agencies, new presidents are motivated to select appointees adept to change agency policy and ensure the agency performs to the president's expectations (Lewis, 2011). Moreover, certain positions structurally afford appointees more discretion with which to impact policy and agency performance. Variations in positions' levels of policy discretion - or their capacity to control policy outcomes - and the (in)congruence in policy preferences between the agency and the president offer distinct opportunities for appointees to (in)effectively change agency policy.

In other words, presidents can use appointments (filled and unfilled) to ensure that some agencies continue to implement and produce policies in a constant direction while pushing others to change course. For instance, hypothetically, if a president prioritizes expansion of policies governing alternatives to fossil fuels - which implies continued research into renewable energy - he 


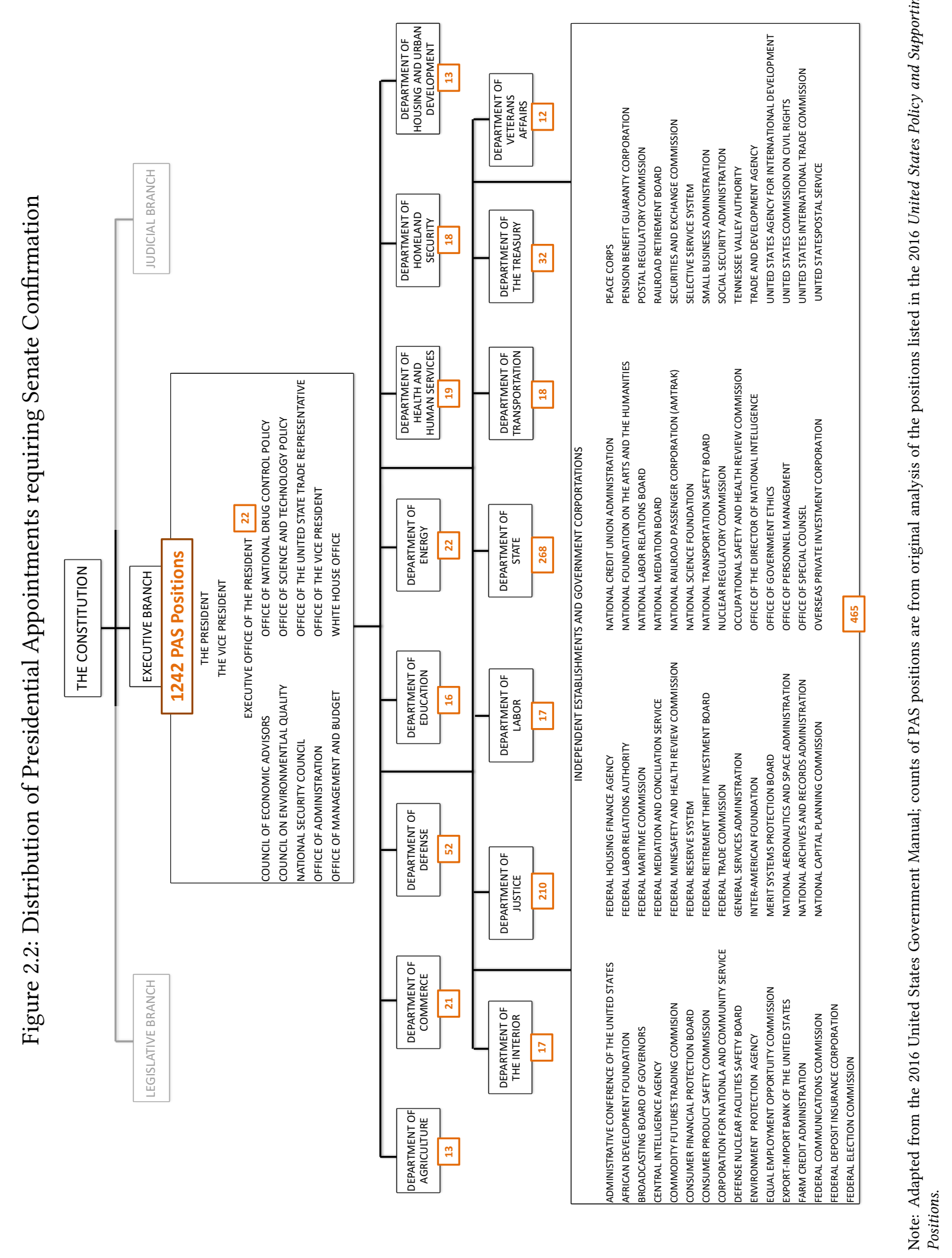


might want an effective appointee as the Assistant Secretary of Energy for Efficiency and Renewable Energy to maintain a steady course. Alternatively, if a president prioritizes contraction of policies relating to climate change, he might want an ineffective appointee, or none at all, as the Assistant Secretary of State for Oceans and International Environmental and Scientific Affairs to shift away from engagement with other countries on a global response to climate change. Critically, since presidents use interim appointments to place individuals they want in PAS positions without pursuing Senate confirmation or purposefully leave positions empty, we need to understand the conditions under which interim officials can serve. The next section breaks down the several procedural regimes that govern whether and for how long interim appointees can serve in vacant positions.

\subsubsection{Procedural regimes: The Vacancies Act and beyond}

As mentioned previously, five procedural regimes have governed vacancies in the executive branch. These include the Vacancies Act of 1868, the Presidential Transition Effectiveness Act of 1988, and the Federal Vacancies Reform Act of 1998, which govern the majority of appointments to executive agencies; a fourth regime composed of several originating statutes and executive orders for specific agencies that govern succession and identify interim officials; and, by default, the fifth covers most independent agency positions and does not allow for interim appointees. ${ }^{8}$ These regimes determine whether, and for how long, a president can appoint an interim official to a vacant post. ${ }^{9}$

The Vacancies Act of 1868 provides the basis for interim appointments and grants the president the power to temporarily fill vacancies to keep a functioning executive branch. It was

\footnotetext{
${ }^{8}$ See Hogue (2017) for a more detailed description of the procedural regimes.

${ }^{9}$ Here, interim appointees include holdovers. The FVRA "specifies that the expiration of a term of office constitutes an inability to perform the functions and duties of the office" and designates the position as "vacant" (U.S. Office of Personnel Management 2016: 11), but presidents often request the previous administration's PAS appointees to continue in an acting capacity. For independent agencies with fixed terms and quorum requirements, holdover provisions allow for confirmed members to serve beyond their term to ensure operational continuity (Madonna et al., 2016).
} 
originally intended to "prevent the President from delaying sending forth nominations for advice and consent positions" and to dictate the means "for temporarily filling vacancies in covered positions unless Congress explicitly provided a superseding mechanism” (Rosenberg, 1998). Until 1988, interim tenure was 30 days and was increased in 1988 to 120 days by the Presidential Transition Effectiveness Act.

A vacant position covered by the Federal Vacancies Reform Act can legally be filled temporarily in one of three ways under the act:

1. The first assistant to such a position may automatically assume the functions and duties of the office;

2. the President may direct an officer who is occupying a different advice and consent position to perform these tasks;

3. the President may select an officer or employee who is occupying a position, in the same agency, for which the rate of pay is equal to or greater than the minimum rate of pay at the GS-15 level, and who has been with the agency for at least 90 of the preceding 365 days (Hogue, 2017, 3).

The reforms to the Vacancies Act have adjusted the length of an interim appointee's tenure and provide three procedural regimes that, when combined with the fourth regime that governs those positions not covered by the Vacancies Act, ${ }^{10}$ provide a structural foundation for both my theoretical and empirical approaches.

The Federal Vacancies Reform Act (FVRA) in 1998 further lengthened the time restrictions.

\footnotetext{
${ }^{10}$ One alternative method, not proscribed by the Vacancies Act, for filling vacant posts within the bureaucracy that has drawn attention from political scientists, constitutional legal scholars, and the Supreme Court are recess appointments (e.g., Rappaport 2004; Corley 2006; Black et al. 2007, 2011). The Recess Appointments Clause in the Constitution expressly provides that " $[\mathrm{t}]$ he President shall have Power to fill up all Vacancies that may happen during the Recess of the Senate, by granting Commissions which shall expire at the End of their Next Session" (Article 2, $\S$ 2, cl. 3 of the Constitution). While the Vacancies Act does not cover independent agencies, the Recess Appointments Clause does and allows for inherently temporary appointments, since the appointee may only serve until the end of the next congressional session. Presidents have frequently used their recess appointment power to essentially circumnavigate the confirmation process (Corley, 2006). Recently, Noel Canning v. NLRB (2014) challenged the constitutionality of President Obama's recess appointments to the National Labor Relations Board during a pro forma session of Congress. The Supreme Court ruled that the pro forma session prevented a sufficiently long recess thereby invalidating the appointments and severely curtailing future presidents' use of this power (Krotoszynski Jr, 2014). Furthermore, Congress's more frequent use of pro forma sessions to preempt presidential recess appointments indicates an attempt to recapture bargaining power and their oversight prerogative in the confirmation process. However, the success of this strategy is limited to those positions not covered by the Vacancies Act.
} 
An initial interim appointment under the FVRA continues "no later than 210 days after the date the vacancy occurred or, if the vacancy occurred during a Senate recess, 210 days after the date the Senate reconvenes" (Hogue, 2017, 1). However, an interim appointee can potentially serve much longer than just 210 days. First, the restriction is suspended and the acting official can remain in office if a first nomination has been submitted to the Senate and is pending. Moreover, an interim can continue for an additional 210 days after the rejection, withdrawal, or return of that nomination. If the vacancy occurs during the 60 days following inauguration then the first 210-day period does not begin until the later of either 90 days after the president takes office or 90 days after the vacancy occurs. Second, the time restriction is suspended again and the acting official can remain in office if a second nomination has been submitted to the Senate and is pending. Then, if that nomination is rejected, withdrawn, or returned, an acting official can serve for another 210 days. Thus, the 210-day tenure can repeat twice; after each of two submitted nominations are rejected, withdrawn, or returned. Consequently, an interim appointee could fill the position for 300 days before any nomination is submitted, upwards of 720 days if the respective nominations are withdrawn, rejected, or returned, and nearly indefinitely if the Senate does not act on a submitted nomination.

Importantly, several positions have fixed terms longer than four years - thereby naturally overlapping across administrations - which could yield policy benefits beyond the end of an administration: the Consumer Product Safety Commission (7-year term), the Defense Nuclear Facilities Safety Board (5-year term), Director of the Mint in the Department of the Treasury (5-year term), or Administrator of the Federal Aviation Administration in the Department of Transportation (5-year term), to name a few. While these extensions to tenures were intended to ensure continuity in leadership and maintain agency productivity (Hogue, 2008), they created a larger set of vacant positions for which timing considerations encourage presidents to forgo nomination entirely.

Generally, once time restrictions stipulated in the FVRA are exhausted, the interim appointee 
loses her temporary authorization and only the head of the agency may perform any non-delegable function or duty of the office. While there are no immediate ramifications for an interim's overstay, outside of a violation letter from the GAO, legal action could be brought that challenges an interim appointees' standing to engage in official business when in violation of the time limit. For instance, in March 2017, National Labor Relations Board v. SW General challenged whether an interim appointee could legally serve in that capacity if she is also the administration's submitted nominee. In the majority decision, the Supreme Court rejected the conventional interpretation of the FVRA, and historical practice of the previous three administrations, that a nominee could serve in an interim capacity while awaiting Senate confirmation. Instead, the Court concluded that the text of the FVRA specifically precludes individuals officially nominated for Senate confirmation to concurrently serve as an interim appointee (Howe, 2017). The Court also held that the service of the Acting General Counsel of the National Labor Relations Board (NLRB) violated the Vacancies Act, but noted that this position was exempt "from the general rule that actions taken in violation of the [Vacancies Act] are void ab initio. The Court affirmed the D.C. Circuit's ruling vacating the Acting General Counsel's noncompliant actions, but did not explicitly reconsider the issue of remedy" (Brannon, 2017, 6).

PAS appointees on boards, commissions, or similar multi-headed entities are not covered by the Vacancy Act, or its reforms, and therefore any vacant posts must remain empty until filled by Senate-confirmed appointees, thereby creating the fourth procedural regime. However, for certain PAS independent and Cabinet-level agency positions, Congress explicitly stipulates the one of four general methods for temporary filling vacancies: "(1) a specified official is automatically designated as acting; (2) a specified official is automatically designated as acting unless the President provides otherwise; (3) the President designates an official to serve in an acting capacity; or (4) the head of the agency in which the vacancy exists designates an acting official" (Houge 2015). The Federal Aviation Administration (FAA), the Office of Management and Budget (OMB), and the Small Business Administration (SBA) are among those whose top posts are temporar- 
ily filled according to first method (Houge 2015). Alternatively, the second method provides for top positions in the Social Security Administration (SSA) and General Services Administration (GSA) and the third method covers positions like the General Counsel at the National Labor Relations Board and the Special Counsel for Immigration-Related Unfair Employment Practices at the Department of Justice (Houge 2015). Lastly, the fourth provision applies to certain positions in departments like the Department of Education or the Department of Justice and allows agency heads to assign acting officials in lower level positions (Houge 2015).

\subsection{Exploring Vacancies Across Presidencies}

The personnel delegated the power to craft and implement policies can significantly shape their impact (Nathan, 1983; Lewis, 2008). Accordingly, the expectation that presidents will maximize their influence with strategic nominations to all vacancies has driven a long line of research on presidential appointments. Vacancies in PAS positions are frequent and persistent, they shape the political and policy success of administrative presidencies, and have severe implications for separation of powers. But we have not yet systematically and quantitatively investigated whether and when vacancies in presidential appointments are left empty or filled with an interim appointee, even though they have had a near-ubiquitous presence in political journalism. Consider the following headlines:

- "The EPA; Acting Officials Filling More Roles" (The Washington Post 4/16/1985);

- "Lacking Top Appointees, U.S. Agencies Face Growing Backlogs" (The Washington Post 5/1/1989);

- "So Few Agencies, So Many Official Seats Unfilled" (The New York Times 7/27/2002);

- "Interim Heads Increasingly Run Federal Agencies" (The New York Times 10/15/2007);

- "Panel chides Obama for inspector-general vacancies" (The Washington Post 5/10/2012);

- "Top Posts Remain Vacant Throughout Obama Administration: Politics and Vetting Leave Key U.S. Posts Long Unfilled" (The New York Times 5/2/2013);

- "Vacancies at VA's Top Add to Agency's Problems: Unfilled Posts lead to a Management Vacuum" (The Wall Street fournal 6/11/2014); 
- "Obama's vanishing administration: Why are so many crucial jobs empty?" (POLITICO $1 / 5 / 2016)$;

- "85 percent of the top science jobs in Trump's government don't even have a nominee" (The Washington Post 6/6/2017).

Empty posts and interim appointees have seemingly been in the president's toolbox as ways to achieve political and policy goals for decades. For instance, President Carter famously sought to expand the reach of the Immigration and Naturalization Service (then within the Department of Justice) to deal with:

undocumented immigrants,

I am proposing to Congress today a set of actions to help markedly reduce the increasing flow of undocumented aliens in this country and to regulate the presence of the millions of undocumented aliens already here;" (Jimmy Carter: "Undocumented Aliens Message to the Congress., August 4, 1977 ${ }^{11}$ ),

Iranian students holding temporary visas in response to the Iran Hostage Crisis, ${ }^{12}$

President Carter asked Attorney General Civiletti...to identify all Iranian students in the United States who were not in compliance with their visas ...Civiletti issued regulation setting up the interviewing and registration procedures, ${ }^{13}$

and refugees:

Now we must take additional steps to end Cuba's inhumane actions and to bring safety and order to a process that continues to threaten lives. Therefore we will implement a five-point program to permit safe and orderly passage from Cuba for those people who sought freedom in the U.S. (Jimmy Carter: "Cuban Refugees Remarks to Reporters Announcing Administration Policy Toward the Refugees," May 14, 198014).

Importantly, the INS did not have a confirmed commissioner from October 1979 to January 1981, during which much of Carter's immigration policy expansion took effect, and he did not submit

\footnotetext{
${ }^{11}$ Online by Gerhard Peters and John T. Woolley, The American Presidency Project. Accessed 20 November 2016.

${ }^{12}$ Now an infamous directive linked to President Trump's attempts to institute a "Muslim ban:" "the Secretary of [State]...will invalidate all visas issued to Iranian citizens for future entry into the United States, effective today. We will not reissue visas, nor will we issue new visas, except for compelling and proven humanitarian reasons or where the national interest of our own country requires;" (Jimmy Carter: "Sanctions Against Iran Remarks Announcing U.S. Actions," April 7, 1980. Online by Gerhard Peters and John T. Woolley, The American Presidency Project. Accessed 20 November 2016.)

${ }^{13}$ Whitaker et al., 1979

${ }^{14}$ Online by Gerhard Peters and John T. Woolley, The American Presidency Project. Accessed 20 November 2016.
} 
a nominee until nearly nine months into that vacancy. Facing one of its most challenging times, the INS interviewed nearly 60,000 Iranian students in November and December 1979 alone and processed more than 112,000 Cuban refugees arriving in the U.S. between April and June 1980, all under the direction of Acting Commissioner David W. Crosland (Pear, 1980).

A few years later, President Reagan had a remarkably clear priority: shrink the reach of nearly all federal domestic policy implementation. The application of this priority to national labor policy included weakening the capacity for government intervention in labor disputes. ${ }^{15}$ Specifically, the National Labor Relations Board (NLRB), the neutral arbitrator and regulator of labor-management disputes, handed down only 800 decisions per year, ${ }^{16}$ which nearly tripled the backlog from 535 cases in 1981 to 1,434 in 1984. The House Subcommittee on Manpower and Housing cited that this increase was most visibly caused by the Reagan administration's failure to fill vacancies promptly (Earley, 1984; Silver and McAvoy, 1987). Comparably, for most of his first year, President H.W. Bush left three empty seats of the five on the Consumer Product Safety Commission. Without the necessary quorum, the Commission was "paralyzed" and unable "to compel emergency recalls or crack down on recalcitrant manufacturers of dangerous products" (Havemann, 1989, 2).

Perhaps the most infamous use of an interim appointee to fill an empty post is President Clinton's appointment of Bill Lann Lee as Acting Assistant Attorney General for Civil Rights. Clinton formally nominated Lee for the position in July 1997 but Lee's "expansive interpretations of civil rights laws were unacceptable to the Senate Judiciary Committee” (Will, 1998). After the committee failed to recommend confirmation, Clinton appointed Lee to the post on an interim basis, intending to resubmit the nomination in the following Congressional session. ${ }^{17}$ This series

\footnotetext{
${ }^{15}$ Reagan also famously changed the course of federal labor relations by breaking the Professional Air Traffic Controllers Organization by making good on his threat to fire nearly 13,000 air traffic controllers unless they returned to work from an illegal strike.

${ }^{16}$ In comparison, the NLRB under Carter averaged 1,700 per year (Greenhouse, 1984).

${ }^{17}$ William J. Clinton: "Remarks Announcing the Appointment of Bill Lann Lee as Acting Assistant Attorney General for Civil Rights and an Exchange With Reporters," December 15, 1997. Online by Gerhard Peters and John T. Woolley, The American Presidency Project.
} 
of events, seen by most as an overt circumvention of the Senate's advice and consent, ultimately led to the passage of the Federal Vacancies Reform Act (FVRA) of 1998.

While the FVRA was an effort to reaffirm the power of the Senate's prerogative by establishing clearer constraints on interim appointees, it has been less than successful in limiting presidential use of temporary officials. With nearly 15 months left as president, George W. Bush kept interim appointees to manage entire agencies within his executive branch without submitting nominees for Senate confirmation (Shenon, 2007). At the State Department, for example, the Under Secretary for Arms Control and International Security was left empty for much of 2007 before Acting Under Secretary John Rood was appointed in September and served for the remainder of the Bush administration without a submitted nominee.

Furthermore, the Centers for Medicare and Medicaid finally secured a Senate-confirmed administrator in 2013 after over nine years of interim appointees, spanning both the Bush and Obama administrations. Similarly, for much of 2015, more than half of President Obama's PAS appointees at the Environmental Protection Agency were interim, and the Treasury's Acting Undersecretary of Terrorism Financing served without a submitted nominee even as the administration expanded efforts to contain the rising threat of the Islamic State (Samuelsohn, 2016). This end-of-term trend of vacancies and interim appointments seemed to worsen for the Obama administration (O’Connell, 2014). The State Department was without a permanent legal adviser for three years, "a job crucial to shaping the country's stance on drones, NSA surveillance and other high-profile international matters" (Samuelsohn, 2016). A deputy temporarily replaced former Secretary Arne Duncan at the Department of Education, and the "Cabinet post [was] likely to be filled by an acting secretary for the remainder of President Barack Obama’s term" (Samuelsohn, 2016).

The landscape of American politics has changed considerably since January 20, 2017; particularly given a president who, by his first August recess, had not submitted nominees for an unprecedented 60 percent of key PAS positions. By comparison, Presidents Obama, W. Bush, and 
Figure 2.3: Percentage of Reported Vacancies Left Empty or Filled with Interim, 1995-2016

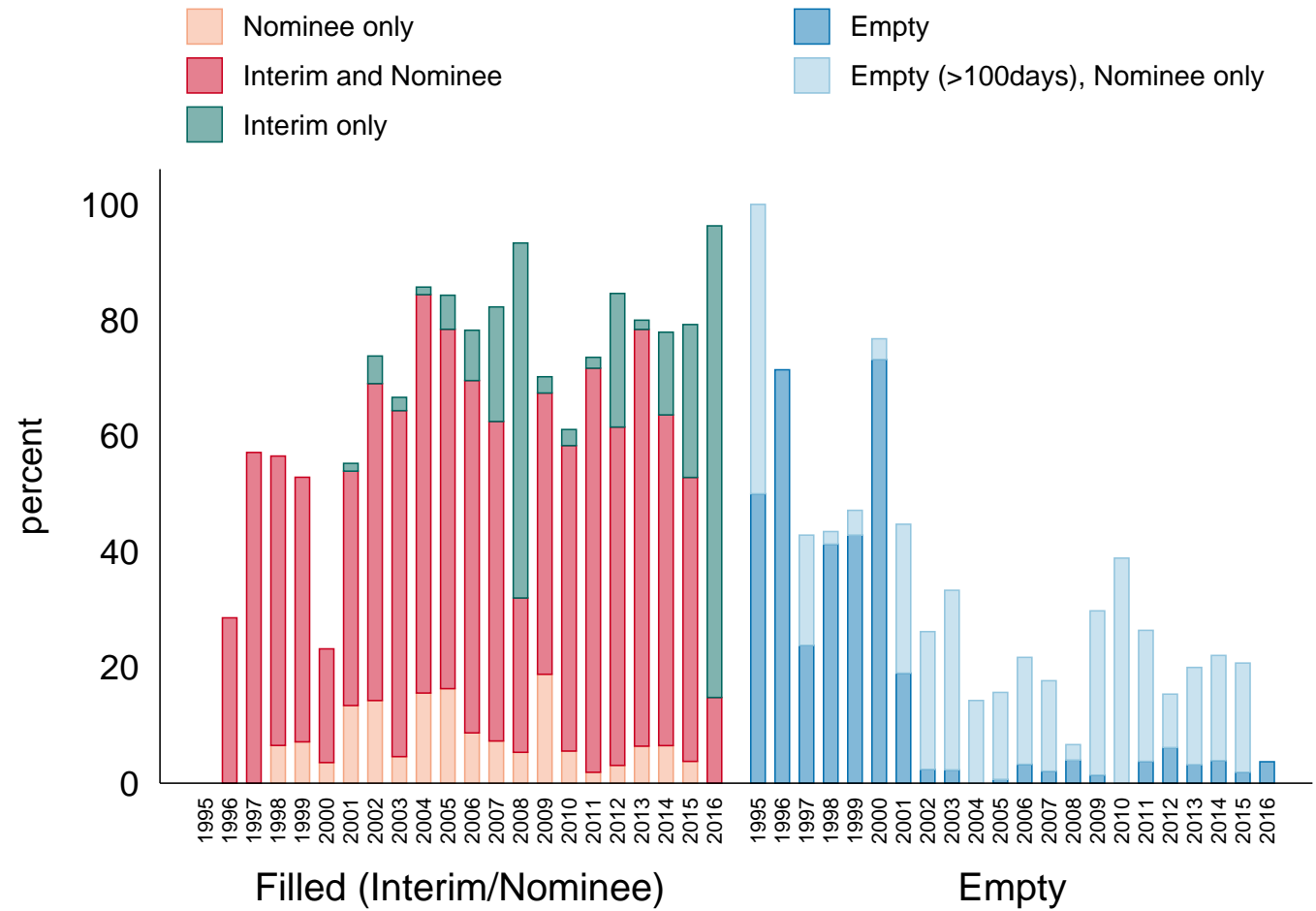

Original analysis of data from vacancies reported to the GAO.

Clinton had not submitted nominees for 26 percent, 29 percent, and 41 percent, respectively, of key PAS positions by their first August recess. ${ }^{18}$ Yet, data from the Government Accountability Office (GAO), shown in Figure 2.3, indicate that the past three administrations left anywhere from 10 to 70 percent of their vacancies, each year, empty or filled with only interim appointees. Moreover, the variation in how vacancies are addressed highlights the importance of distinguishing between positions that are empty and those filled by an interim appointee. Despite the temptation to view the Trump administration as an outlier among conventional presidencies, this suggests that Trump might not be completely out of step in his approach to vacancies. In fact, in June 2018, after more than 18 months with a Republican majority Senate, 30 percent of PAS positions in the

\footnotetext{
${ }^{18} \mathrm{https} / /$ www.washingtonpost.com/graphics/politics/trump-administration-appointee-tracker
} 
Figure 2.4: Executive Department PAS Positions in the Trump Administration (as of June 2, 2018)

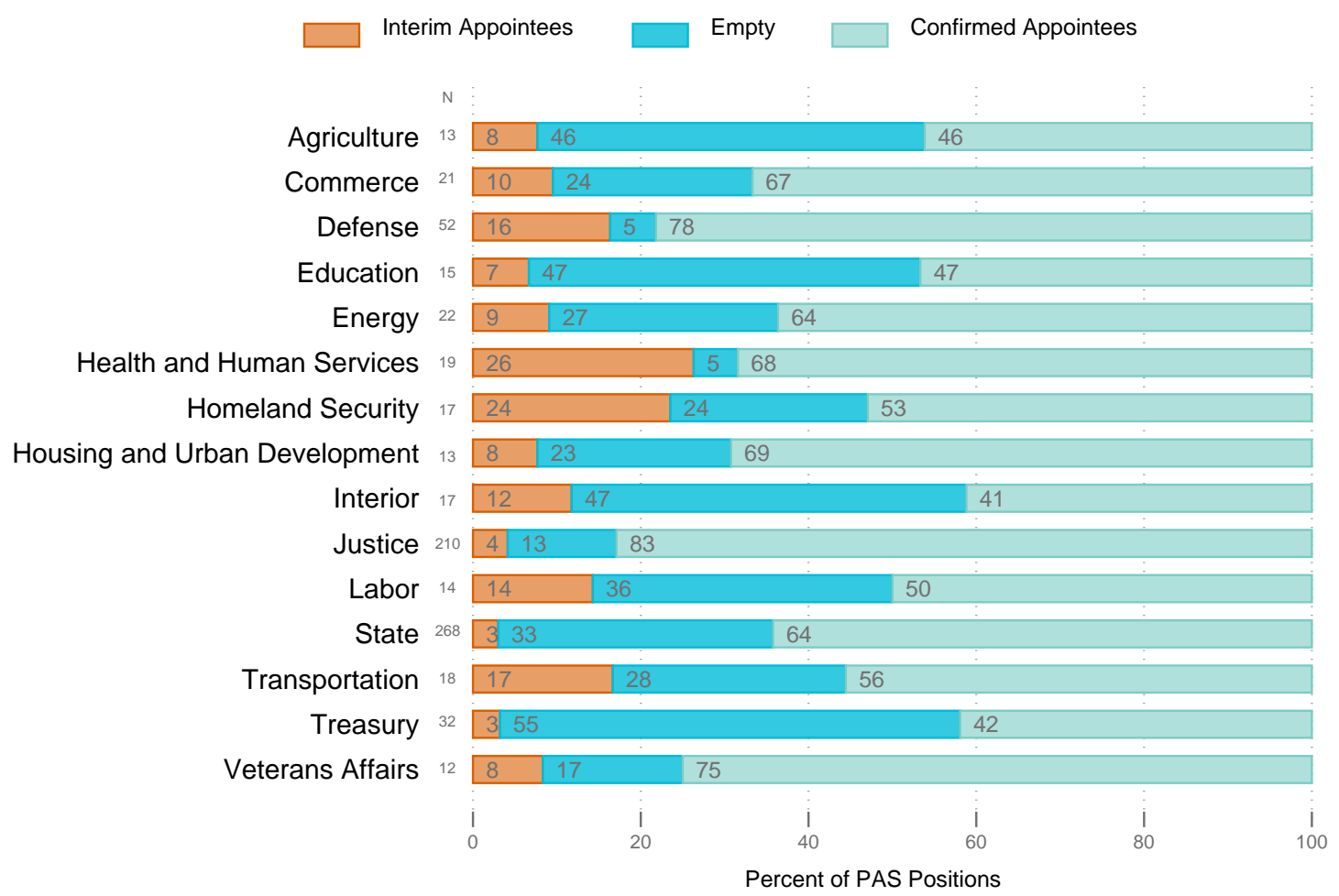

Appointments data collected from the various departmental websites, last accessed June 2, 2018.

Trump administration were vacant and more than half of those vacancies did not have a nominee awaiting confirmation. Instead, as Figure 2.4 shows, interim appointees filled nearly a third of those vacant PAS positions and accounted for one in every nine appointments. Perhaps the only difference is that President Trump blatantly stated that he deliberately did not fill vacancies ${ }^{19}$ and that he preferred having interim appointees: "I sort of like acting. It gives me more flexibility. Do you understand that?' Trump told reporters as he left the White House for Camp David. 'I like acting. We have a few that are acting but we have a great, great, Cabinet." (Samuels, 2019).

\footnotetext{
${ }^{19}$ www.foxnews.com/politics/2017/02/28/trump-no-plans-to-fill-unnecessary-appointed-positions.html
} 


\subsection{Conclusion}

Vacancies are not a new phenomenon. Yet, as reviewed in this chapter, scholars have largely considered vacancies in PAS positions as an asterisk or a footnote; vacancies have been cast as the mechanical byproduct of changes in administration, the inadvertent failure to find a nominee, or senatorial delays in confirmation. Furthermore, existing research on separation of powers assumes that executives are constrained by the need for legislative approval when placing these agents in unelected office. Building on this assumption, theories of appointments focus on the choice of nominee, often in terms of ideological alignment, loyalty, or competence. They offer reasons why, for instance, President Trump would select Michael Pompeo for Secretary of State or why President Reagan would select Donald Regan for Secretary of the Treasury. Alternative studies of presidential appointments focus on the Senate's role post-nomination. In doing so, those theories also implicitly assume that presidents will always seek Senate confirmation to fill open positions. Yet, as we have seen here, this is not the case. While personnel and policy are not the same thing, the power to determine personnel - including their absence - is one of the most effective ways to control the path of policy. Yet, scholars have completely overlooked the fact that filling openings with confirmed appointees is not a president's only option in staffing these critical positions. We have not yet examined why presidents choose to leave certain positions vacant and not others. Until now. This dissertation shows that the politics of vacancies matter for our understanding of executive politics, political control of the bureaucracy, and separation of powers.

Furthermore, while considerable and important work has been done to understand the politics of presidential appointments from a variety of perspectives, scholars have not yet examined an entire class of appointments: interim appointees. As discussed in this chapter, not only are there several institutional regimes that govern who can serve as an interim appointee and for how long, presidents have consistently filled nearly half of vacant PAS positions with these tem- 
porary appointees for at least four decades. The anecdotes from the previous section provide a historical context that suggests there is reason to believe that presidents have been using vacancies strategically to achieve their policy and political objectives. However, without a clear theoretical framework from which to draw out empirical implications and data on which to systematically test those expectations, the countless stories of presidents appearing to strategically leave positions empty or fill them with interim appointees would remain simply that: stories. In the chapters that follow, I add a new perspective to the current literature on presidential appointments; I develop a new theory and rigorously test it using original data; and I present clear evidence that presidents do use empty positions and interim appointees strategically to advance their policy priorities. 


\section{CHAPTER III}

\section{Introducing Position Value}

Now that we have established the institutional and historical context of vacancies in PAS positions, we can head out into the relatively uncharted territory of modeling an appointment process that begins with the president's decision of whether or not to fill the position at all. My theory, presented in the next chapter, formalizes the president's choice to fill a position in an inter-branch bargaining context: one that incorporates both the Senate's leverage to veto a nomination and the president's power to choose not to submit one in the first place. In Chapter 4, I model vacancies - explicitly taking into account both types of vacancies (i.e., empty positions and interim appointments) - as strategic choices that offer presidents the opportunity to pursue diverging policy goals. By incorporating these choices, I present a more accurate and complete representation of the appointment process and argue that we need to widen our lens to see more than the subgame of nomination and confirmation ${ }^{1}$ that our current theories of appointments focus on. When we entertain what the president and the Senate are looking to achieve more broadly from their policy agenda, we can generalize to consider how the position - whether left empty or filled with a specific confirmed or interim appointee - can be used to advance that

\footnotetext{
${ }^{1}$ This refers to the fact that previous models of presidential appointments, discussed in Chapter 2, evaluate the incentives and conditions that underpin the nomination-confirmation process. As Figure 1.2 in Chapter 1 indicated and the formal model in Chapter 4 will show, nominee selection and Senate confirmation are fundamentally decision nodes that follow the initial decision to fill the position or leave it empty, thereby making confirmation a subgame of the larger appointment process.
} 
agenda. To do that, we need to move beyond our traditional focus on the appointee and consider how positions can distinctly increase utility; that is, we need to consider the value of the position itself. This chapter deliberately proceeds to that end.

Accordingly, I will first briefly introduce the conceptual distinction of Position Value. I use this concept to characterize the opportunities that positions - either filled or empty - have to deliver policy benefits to the president or the Senate. Ultimately, Position Value functions as the central element of the model, creating the incentives that drive the Senate's choice to confirm a nominee and the president's strategic choice to submit one, given the Senate's confirmation strategy. In this chapter, I propose that certain high value positions have a distinct capacity to influence policy output and advance an actor's policy priorities. While this capacity is necessary, I argue that it is not sufficient to designate positions as high value. Crucially, an actor must also prioritize the policy outcomes, and the policy output that generates those outcomes, under the positions' jurisdiction. A position with high Position Value is one with a high capacity to advance clear policy priorities; otherwise the position has low value. In other words, both capacity and priorities are necessary. When a position has a low capacity to control agency actions and policy output, any appointee - interim or permanent - has minimal ability to create policy change and the value of that position is nil, no matter the policy priorities. Likewise, when the president or the Senate does not prioritize the policies under the agency's purview (i.e., they have neutral policy priorities), the value of the position for advancing the player's larger agenda is also nil, no matter the position's capacity level. Thus, Position Value is determined by two variables: Position Capacity and Policy Priorities.

As detailed below in this chapter's second section, Policy Priorities capture whether the player prefers to expand, contract, or neutrally maintain the agency's status quo policy generating activities. Here, Policy Priorities are inherently concerned with the level of agency action in a particular policy space. Specifically, priorities emphasizing an increase in agency actions toward a policy goal are expansion priorities, whereas a focus on decreasing agency actions toward a 
policy goal are contraction priorities. Neutral priorities center on maintaining the status quo level of agency policy-oriented actions. ${ }^{2}$ While policy priorities are not agnostic of ideology, the expansion-contraction dimension generalizes over time and shifting party platforms. ${ }^{3}$

Importantly, the concept of Position Value shifts our focus away from the individual traits of appointees toward those of the position so that we can consider how a position without an appointee would deliver desired outcomes to the president or the Senate. The extent to which any valuable position can advance each actor's Policy Priorities is institutionally constrained by the capacity of each position to actually change policy output. Accordingly, the third section outlines the construction of Position Capacity; that is, the capacity of each position to control policy output and agency actions. To preview, positions with low capacity are administrative or routine in nature and have little to no latitude to affect agency action. Alternatively, high capacity positions manage policy implementation activities directly and have more room to influence policy output. Policy Priorities and Position Capacity separately identify aspects of the nonlegislative policymaking process that are important for appointment strategies, but it is the combination of the two that create the more complete picture of what positions themselves can deliver: their Position Value.

\subsection{Introducing Policy Priorities}

When aspiring elected officials campaign for voter support, they generally offer their vision of what the new status quo should be, and could be, if they are elected. Candidates delineate agendas that, at a minimum, offer some sense of the direction they would like to see various

\footnotetext{
${ }^{2}$ Critically, as I will expand on later, the expansion-contraction dimension is not a surrogate for the standard liberal-conservative one. Here, priorities over the status quo are distinct from ideology in that liberal and conservative actors both might prefer to diminish and cultivate policy reach, albeit often on competing issues. For instance, self-styled conservative policy priorities might include expansion in border protection and reductions in anti-trust enforcement, whereas liberal priorities might include decreasing immigration enforcement and expanding federal lands protections.

${ }^{3}$ At the end of this chapter, I address the issue of ideology.
} 
public policies move toward; and in the clearest cases, candidates have distinct priorities for multiple policy areas. The most recognizable of these policy agendas come from presidential campaigns. When Barack Obama campaigned for the presidency in 2008, his platform prioritized domestic energy security with policies like investing in infrastructure and renewable sources of energy. For instance, during a campaign speech in Raleigh, North Carolina on October 29, 2008, then-candidate Barack Obama detailed his priorities:

We'll create two million new jobs by rebuilding our crumbling roads, and bridges, and schools, and by laying broadband lines to reach every corner of the country. And I will invest $\$ 15$ billion a year in renewable sources of energy to create five million new energy jobs over the next decade - jobs that pay well and can't be outsourced; jobs building solar panels and wind turbines and a new electricity grid; jobs building the fuel-efficient cars of tomorrow, not in Japan or South Korea but here in the United States of America; jobs that will help us eliminate the oil we import from the Middle East in ten years and help save the planet in the bargain. ${ }^{4}$

The Obama-Biden campaign website also offered several statement briefs and fact sheets about each issue on their agenda of policy priorities. For instance, the "Barack Obama and Joe Biden: New Energy for America Fact Sheet” described their energy policy priorities:

Prioritize the Construction of the Alaska Natural Gas Pipeline. Barack Obama and Joe Biden will work with stakeholders to facilitate construction of the pipeline. While this pipeline was proposed in 1976, and Congress authorized up to $\$ 18$ billion in loan guarantees for this project in 2004, there has been no progress in building this critical energy infrastructure under the Bush Administration. The planned pipeline would have a daily capacity of 4 billion cubic feet of natural gas, or almost 7 percent of current U.S. consumption. Not only is this pipeline critical to our energy security, it will create thousands of new jobs. ${ }^{5}$

Likewise, when Ronald Reagan campaigned in 1981, his platform also prioritized addressing energy security by increasing domestic energy production, albeit through deregulation (Shogan, 2004). These two presidential candidates, from different parties in different political contexts, had similar policy priorities centered on decreasing U.S. reliance on foreign energy sources. However, they championed completely different approaches to achieve those policy goals, highlighting that

\footnotetext{
${ }^{4}$ Barack Obama, Remarks in Raleigh, North Carolina. Online by Gerhard Peters and John T. Woolley, The American Presidency Project. https://www.presidency.ucsb.edu/node/284715. Accessed 15 January 2019.)

${ }^{5}$ Barack Obama and Joe Biden: New Energy for America Fact Sheet. Wayback Machine Internet Archivehttp://www.barackobama.com/pdf/factsheet nergy $_{\text {speech }}$ 80308.pdf.Accessed15 January 2019.
} 
policy priorities are not just priorities over outcomes but also over outputs. That is, policy priorities should include both the preferred new policy status quo and the action necessary to generate it.

When candidates successfully take office, their priorities over how to achieve their policy agendas are central to the success of their administration or legislative majority. Admittedly, policy agendas and priorities change frequently post-election. For instance, candidate George H. W. Bush campaigned to continue the Reagan legacy without any major policy changes: "he opposed flag burning and abortion, supported free trade and community volunteerism, and wanted to be remembered as the education President," with little emphasis on foreign policy. ${ }^{6}$ As president, however, George H. W. Bush devoted much of his time to foreign affairs and oversaw an expansive foreign policy agenda that included negotiating the end of the Cold War and signing the North American Free Trade Agreement (NAFTA), among many others. ${ }^{7}$

A substantial body of work seeks to understand just how presidents and parties use their political power to achieve their policy objectives. Kingdon set the stage by arguing "no other single actor in the political system has quite the capability of the president to set agendas in given policy areas" $(1984,23)$. A core part of this extant research examines the president's influence on the legislative policy-making process, specifically the production of significant legislation, through agenda-setting and "going public" (e.g., Peterson, 1990; Edwards III and Barrett, 2000; Canes-Wrone, 2001; Beckmann, 2010; Lee, 2009; Gelman et al., 2015). By construction, this line of research focuses only on legislative action. While presidents' and congressional majority parties' agendas and priorities play a large part in determining which policy issues are addressed and the success of their respective legislative proposals (Lee, 2009), they continue to influence the policy-making process long after the president signs legislation into law.

\footnotetext{
${ }^{6}$ Stephen Knott, https://millercenter.org/president/bush/campaigns-and-elections. Accessed 25 January 2019.

${ }^{7}$ The empirical tests of my theory examine presidents' and congressional policy priorities each year, which allows for this variance within and across administrations as well as across agencies.
} 
Hence, these priorities also steer the policies that result from nonlegislative ${ }^{8}$ means - from agency actions like implementation, (de)regulation, enforcement, adjudication, benefit distribution, and grantmaking - led by the bureaucratic actors at the center of this larger research project. Since the status quo has long been recognized as 'sticky' and not easily moved by new legislation, particularly in an era of polarization and routine obstruction (e.g., Jones and Baumgartner, 2005; McCarty et al., 2016), achieving policy goals through implementation and administrative law offers a viable alternative (Farber and O'Connell, 2014). And we know that one of the most effective means through which presidents can influence policy outcomes is the choice of personnel (Nathan, 1983). Appointees, especially those in positions that require Senate confirmation, play a significant role in the nonlegislative policy-making process and have a clear influence through their decisions about which actions their agencies will take to achieve specific objectives (Lewis, 2011).

Policy Priorities are inherently concerned with the level of agency action in a particular policy space. Political actors - and their constituents - experience the policy outcomes that result from the current levels of agency actions. Given their set of policy preferences, these actors identify the requisite change in agency outputs to move the policy status quo in their preferred direction. If the status quo aligns with their preferences, the political actors require no change in agency output. However, when circumstances require change, agency outputs can only be increased or decreased to generate that preferred policy. That is, when political actors do not prefer to maintain the status quo, they can, inevitably, only prioritize either the expansion or contraction of agency actions. Next, I will sketch out the specific features of this proposed expansion-contraction di-

\footnotetext{
${ }^{8}$ These nonlegislative activities also include, paradoxically, legislation development. Executive departments each have bureaus or divisions charged with developing proposals for new legislation to address any number of issues that affect either their clients or policy areas. These bureaus - termed anything from Office of Congressional Relations to Office of Legislative Affairs - manage the intergovernmental relations between the agency and Congress by supplying witness testimony, reports on program budgets and development, and responses to congressional oversight, while also crafting legislative proposals for the administration. The nonlegislative distinction here is that agencies are not engaged in creating and sustaining the coalitions necessary to pass legislation, but rather offer a on the ground perspective of what might be needed for its current and future activities and submit legislative proposals to be revised by various congressional entities or administration officials.
} 
mension as well as the types of agency actions that translate these priorities into their respective policy outputs.

\subsubsection{Expansion and Contraction Policy Priorities}

Again, I define Policy Priorities as the preferred agency actions that generate the new policy outcome. Specifically, I construct Policy Priorities to identify whether an actor prefers to expand, contract, or maintain an agency's current output in order to achieve a desired change in policy outcomes, relative to the status quo. Consequently, we need to unpack the logic that underpins the distinction between expansion and contraction policy priorities, and to do that, we will begin with a hypothetical.

Suppose there has been an increase in reported episodes of lead in drinking water, more reports of pollutants and toxic materials contaminating ground water, and rising sea levels leading saltwater to penetrate fresh water sources in coastal areas. In response, President $\mathrm{K}$ designates water quality as a top issue on her policy agenda. Specifically, she prioritizes federal activities to mitigate ground water pollution, improve the quality of drinking water for rural and low income areas, and maintain fresh water aquifers while protecting the biological diversity of coastal areas. These clear policy outcomes will change the clean water policy status quo and can be achieved through a variety of agency actions; but the overarching priority is increased agency output. Perhaps this could include more regulations on wastewater systems, investments in infrastructure that will repair or build new water supply systems, increased benefit distributions to households to offset costs of new plumbing systems, or increased enforcement of environmental regulations. With these preferred agency actions, President K has policy priorities that emphasize expanding the policy reach of agencies with jurisdictions over water policy (e.g., the Environmental Protection Agency, the Bureau of Reclamation in the Department of the Interior, the U.S. Fish and Wildlife Service, and the U.S. Geological Survey). The emphasis, here, is on the agency action that produces the desired policy output. Extrapolating from this hypothetical, we can see that 
Expansion Policy Priorities indicate when actors would direct their appointees to increase agency policy outputs in order to advance their agenda and reach a new policy outcome.

Importantly, however, Expansion Policy Priorities also apply to policy agendas that include deregulation. Consider an alternative hypothetical. An unprecedented shortage of fossil fuels has hastened the transition to an electric power system largely supplied by renewable energy like wind and solar technologies. The current regulations governing the integration of this energy into the grid are cumbersome and appear to be stunting the growth of this new energy sector. In response, President $\mathrm{K}$ designates deregulation of renewable energy technologies and grid interconnections as a top issue on her policy agenda for the Department of Energy. Importantly, as discussed in detail below, regulatory reform like deregulation follows the same procedures as new regulations. Consequently, deregulation requires the same agency actions and policy outputs as an expansionary regulatory agenda; even though the policy outcome will shrink the regulatory status quo. The emphasis is on the agency actions that produce the outcome. Again, we can see from this hypothetical that Expansion Policy Priorities identify when an actor prioritizes expanding the agency's current footprint in policy output, and deregulation efforts require an increase in agency output.

An alternative scenario for the above hypothetical would be that President K prioritizes a decrease, or contraction, in agency actions; for instance, an intentional decrease in the investigation and monitoring activities required to enforce current regulations on renewable energy suppliers. In this case, President $\mathrm{K}$ would be pursuing a new, albeit temporary, regulatory status quo by seeking to diminish the agency footprint through inaction. ${ }^{9}$ While the policy outcome is similar - a decreased regulatory burden for the renewable energy sector - the agency actions and corresponding policy outputs are considerably different. Here, we can extrapolate again from this example and see that Contraction Policy Priorities focus on shrinking the agency's policy reach

\footnotetext{
${ }^{9}$ Certainly, not enforcing regulations could have legal ramifications and the outcome could be litigated in the courts, however, the longer term legal consequences are beyond the scope of this hypothetical.
} 
and decreasing their outputs to achieve a new policy outcome.

Ultimately, the design of Policy Priorities implies that any one appointee filling a particular position is the arbiter of agency action rather than the focus the president's appointment strategy - that is, appointees are a means rather than the end. ${ }^{10}$ Accordingly, we also need to establish the kinds of agency action and policy outputs that foster particular Policy Priorities and would fall under the purview of a potentially high value PAS position. Broadly speaking, Executive branch departments, independent and regulatory agencies, and government corporations have an extensive menu of actions that can produce various desired policy outputs. These agency actions include rules promulgation, adjudication, investigations, enforcement, benefit distribution, goods and service provision, policy development and implementation, information dissemination, and intergovernmental relations. In many cases, the agency outputs that result from these actions are expected and straightforward. First, rulemaking encompasses both regulation and deregulation, ${ }^{11}$ the most recognizable policy outputs. All proposed regulations or deregulation are required to meet the same standards in terms of cost and consistency with current statutes, be published in the Federal Register, be open for public comment and require agency response, and, in many cases, be subject to review by the Office of Information and Regulatory Affairs (OIRA).

Second, adjudications center on dispute resolution over compliance with regulations and can occur informally by agency officials or formally by administrative law judges. Agencies engaged in investigations and enforcement also have outputs aimed at ensuring compliance with current statutes and regulations as well as information gathering. Third, agencies charged with benefit distribution, goods and service provision, and procurement have seemingly less obvious policy outputs than actions like rules promulgation, adjudication, and investigations. However, the distributive nature of these agency outputs creates opportunities for electorally or politically ad-

\footnotetext{
${ }^{10}$ The shift in focus from the appointee to the position is therefore also inherent in the larger notion of Position Value.

${ }^{11}$ Critically, deregulation here is in the analytical sense of regulatory reform rather than the ideological construct built on widespread relaxation or termination of economically constraining and business unfriendly rules.
} 
vantageous allocations. ${ }^{12}$ Lastly, agencies - or, more often, offices within Executive departments - tasked with policy development, information dissemination, and intergovernmental relations create the least measurable agency outputs, compared with rulemaking or benefit distribution; but these agency actions most recognizably contribute to the new policy status quo. For instance, foreign policy development in the State Department determines the footing for international negotiations and cross-border relationships; and information campaigns like the Dietary Guidelines, jointly published by the Department of Health and Human Services and the Department of Agriculture, frame national discourse on nutrition.

It is important to recognize that policy outputs like those described above and agency performance are separate and distinct ends of agency action, although obviously related. Research on the administrative presidency, including the politicization of agency appointments, recognizes the impact that appointees have on both policy outputs and agency performance (e.g., Lewis, 2008; Resh, 2015). However, performance offers a metric of judging how efficiently, effectively, or competently agencies are producing policy outputs. Most often the impact of appointees on agency performance is cased in studies of politicization. ${ }^{13}$ Some find that political appointees can increase the overall responsiveness of agencies to their principals when they strengthen the managerial relationship between appointees and career civil servants (e.g., Moe, 1985; Bok, 2003). Yet, others argue that politicization hurts agency performance because of lower competence, a lack of subject-specific expertise, and high turnover (e.g., Heclo, 1977; Huber and McCarty, 2004; Lewis, 2008). For the purposes at hand, agency performance matters only in the production of

\footnotetext{
${ }^{12}$ See Lewis (2011) for a review of work on appointees and distributive policies.

${ }^{13}$ To accommodate the inherent influence of higher quality appointees, my theory includes a parameter for the appointee effectiveness that functions as a multiplier for achieving the full value of the position. In other words, the effectiveness of appointees filling positions matters only if the position has an inherent value to either the president or the Senate. A competent, effective, high quality expert appointed to a low value position will have either very little capacity to affect policy output or occupy a position in a low priority policy area. Likewise, a incompetent, low quality appointee in a low value position has very few opportunities to translate that ineptitude into policy or performance blunders. Consequently, while the influence of appointees on performance clearly matters, when we moderate that influence by the position value - and specifically, on the capacity of the position to control agency outputs and policy outcomes, as detailed at the end of this chapter - the larger concern becomes how the position inherently creates value that the most effective appointee can fully attain.
} 
agency outputs, rather than a metric on its own. While a low performing agency will produce fewer outputs, if fewer outputs are the policy priority then lower performance may be the preferred mechanism to advance those priorities. Hence, it is the level of agency action generating desired levels of outputs that sits at the center of the expansion-contraction dimension described above.

Placing the preferred agency output alternatives on a linear dimension allows us to see that expansion- or contraction-branded policy priorities classify the actor's ideal policy output relative to the status quo, achieved through changes in the requisite agency action. Accordingly, Neutral Policy Priorities indicate maintaining the status quo level of agency actions, whereas Expansion Policy Priorities indicate when an actor prefers agencies to increase their policy output in order to move the policy outcome status quo and Contraction Policy Priorities indicate when an actor prefers agency actions that decrease output to shift the status quo. For instance, Contraction Policy Priorities might include decreasing agency supervision of liquefied natural gas pipelines by weakening the Federal Energy Regulatory Commission, while Expansion Policy Priorities might include expanding protections for intellectual property by strengthening the Patent and Trademark Office. Critically, however, the value of the position and the ability for appointees to deliver on these Policy Priorities is constrained by how much capacity the position has to influence agency actions and affect agency output. That is, our broader variable of interest, Position Value, is constructed as a combination of Policy Priorities and Position Capacity. Accordingly, the next section explains how I define Position Capacity.

\subsection{Introducing Position Capacity}

The key feature of Position Value, which motivates our larger theoretical endeavor, stems from shifting our focus from the appointee to the position. Ultimately, the formal model outlined in Chapter 4 seeks to examine the incentives that underpin the president's choice of whether to 
fill an empty position, then whether to nominate, and how that more accurate reversion point influences the Senate's choice to confirm if a nominee is submitted. In order to consider how the status of the position, rather than the characteristics of any potential appointee, create these incentives, we need to identify the feature that varies across positions and also varies in its contribution to the utility gained from any change in position status. Since we know that a large share of policy gains made in an era of legislative gridlock are achieved through the non-legislative policy-making process (Durant and Warber, 2001; Farber and O'Connell, 2014), the feature that institutionally constrains which positions play a significant role in this process offers a logical way forward. This leads us to consider how appointments have a variant degree of opportunities to contribute to policy change by directing changes in agency action. Accordingly, I propose that the value of a position to either the president or the Senate is conditioned on its Position Capacity to direct agency actions and policy output.

The concept of bureaucratic capacity is not new. Huber and McCarty (2006) define capacity as "the likelihood that bureaucrats can take actions that yield their intended outcomes" (51). While this definition frames bureaucratic capacity as delegated policy-making authority, like other research on capacity (e.g., Carpenter, 2001), which aligns with how I frame Position Capacity, it differs from the construct I propose here in two ways. First, bureaucratic capacity captures variation in agency-level divergence between intended and actual outcomes of implementation activities. While Huber and McCarty (2006) use this construct to examine how the strategies and actions of bureaucrats impact the feasible set of alternative policies that can actually be implemented, thereby influencing the adoption of new legislation, they do not explicitly consider how this capacity can vary within agencies. Similarly, Carpenter (2001) examines how variation in bureaucratic capacity at the agency level influences non-legislative policy innovation, but also does not explicitly account for the impact of within-agency variation in capacity. Critically, I have defined Position Capacity here to explicitly account for the variation in the capacity of positions within an agency. 
Second, the concept of bureaucratic capacity emphasizes that variation in delegated policymaking authority directly affects how accurately bureaucrats' actions generate the intended policy outcomes. By contrast, I define Position Capacity as the policy-making authority and jurisdiction to direct the agency actions necessary to achieve a desired policy outcome. While the distinction may appear slight, it significantly alters the focus of my analysis. Most importantly, I want to understand how variation in the capacity of a position to influence agency actions and policy output - not the ability of a specific appointee to deliver intended outcomes - affects the president's decision to fill the position. Here, the emphasis is on the potential for positions to engineer prioritized agency actions, treating the link between actions and policy outcomes as exogenous and constant. Thus, while capacity in terms of the authority to influence the nonlegislative policymaking process has an established origin, I offer a novel adaptation with this construction of Position Capacity.

As a matter of simplicity and tractability, I define Position Capacity in two categories: high and low. The positions that have clear responsibilities for policy development, implementation, or explicit coordination among policy implementers carry the lion's share of the success or failure in achieving policy goals. While all PAS positions have some impact on the agency's operations and will, even if only implicitly, influence how well other positions are able to advance on their priorities, it is those that clearly impact policy outcomes that have high capacity. More specifically, high capacity positions manage policy implementation activities - like rules promulgation, adjudication, and investigations - that require a broader perspective of policy actions, have more room to influence policy outcomes, and can advance a larger political agenda. Agency heads such as secretaries, administrators, and directors, general counsels, inspectors general, and deputy or assistant secretaries that have jurisdiction and responsibilities for policy direction and implementation have High Position Capacity.

Alternatively, positions with low capacity to control policy output are administrative or routine in nature, have little to no latitude in decision-making, and generally provide few opportu- 
nities to reach larger political goals. They are responsible for an agency's internal management or policies governing departmental operations, like assistant secretaries of administration. These roles do indeed have important functions with respect to internal management and operation, but they have low capacity given the position's low impact on the policy output direction of the agency. Similarly, positions with responsibilities for relating information or maintaining public relations (e.g., assistant secretaries for communication), and positions responsible only for research and data collection without grant making or policy recommendation responsibilities (e.g., director of the Bureau of Mines at the Department of the Interior) also have little opportunity to influence the promulgation, enforcement, or implementation of the substantive rules that guide policy outcomes. Consequently, these positions' Position Capacity level is low.

\subsection{Constructing Position Value}

The concept of Position Value, as a combination of Policy Priorities and Position Capacity, allows us to consider the larger picture that appointees are not the first-order option for presidents to achieve their policy goals. My objective here is to provide an intuition for the circumstances under which a president and the Senate might each prefer an empty PAS position to one filled by an interim or confirmed appointee. In the theoretical framework described in the next chapter, I build on this core assumption that leadership positions in the bureaucracy are valuable for their ability to deliver outcomes in line with player's policy priorities. Furthermore, to make the theory's implications as stark as possible, the value of a position is high only when a player prioritizes the agency's policy jurisdiction and the position has the capacity to achieve those priorities, which Table 3.1 highlights.

Traditionally, when we theorize about appointments, we begin with appointees and their ideology. ${ }^{14}$ Consequently, when considering the full construction of Position Value, one question that

\footnotetext{
${ }^{14}$ Many have examined how the characteristics of these actors, their relationships with each other, and their relationships with their principals - including the promises and pitfalls of delegating to these agents (e.g., McCubbins
} 
Table 3.1: Position Value: Combining Position Capacity and Policy Priorities

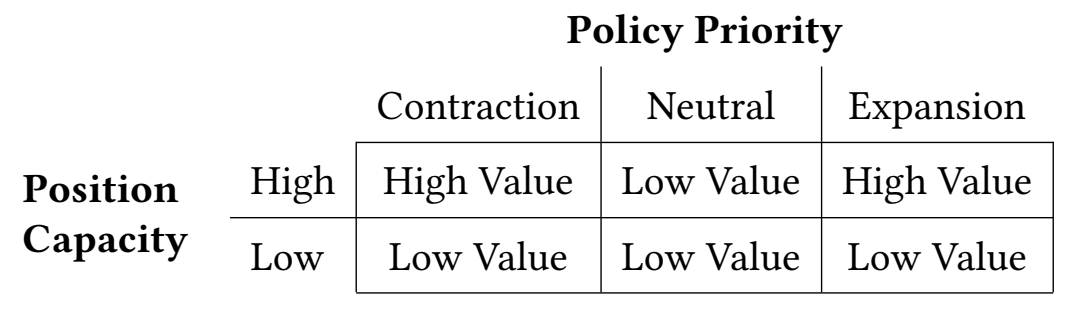

might arise is: what about ideology? As discussed in Chapter 2, most models of presidential appointments focus on the choice of nominee in terms of ideological alignment with the president and the Senate. Yet, ideology is just one element in the basket of what appointments can deliver. When we entertain what the president and the Senate are looking to achieve more broadly - their policy agenda - we can generalize to consider how a filled or unfilled appointment advances that agenda. Ideology provides a measure of policy preferences and an indication of one's policy agenda, but does not provide any indication of one's ability to achieve those policy goals. Ideological alignment between agents and principals matters less if agents are unable to accomplish goals in line with those preferences. In other words, ideology does not reveal an agent's effectiveness in delivering realized value to a principal. One could reason that if the objective is, in effect, ideological, then the agent's alignment with a principal could indicate effectiveness in delivering value.

However, I contend that policy preferences and priorities vis-a-vis the status quo ultimately transcend ideology. Our conventional understanding of ideology derives from a collection of policy preferences along a policy dimension (liberal versus conservative; left versus right), and our measures of ideology capture these preferences as ideal points (e.g., NOMINATE scores from et al., 1989; Lupia and McCubbins, 1994a; Bawn, 1995; Epstein and O’Halloran, 1999; Huber and Shipan, 2002; Volden, 2002; Gailmard and Patty, 2007) - impact the nonlegislative policy outcomes central to the modern administrative state. Others concentrate on the president's use of nonlegislative means and strategies to advance their policy agenda (e.g., Lewis, 2009; Lowande, 2014; Reeves and Rogowski, 2018; Lowande, 2018a), particularly how appointees can contribute to those advancements. Yet, these studies do not consider how the position frames and often constrains the ability of the appointee to deliver on those strategies, which ultimately means that previous studies overlook the value of an absent appointee. 
Congressional roll call votes (Lewis, Poole, and Rosenthal 2017) or citizen ideology estimates using item response theory models (Tausanovitch and Warshaw, 2013)). Thus, while an objective in selecting an agent might be congruent ideologies, those ideologies represent policy preferences, whereas effectiveness, separately, represents the agent's ability to achieve those policy goals. Moreover, an ideologically-aligned appointee in a low capacity position that is institutionally constrained has minimal ability to effectively shape policy change, mimicking an ineffective appointee regardless of their ideological alignment.

Most importantly, Position Value, as a combination of Position Capacity and Policy Priorities, bridges the notions that bureaucratic politics matter for policy outcomes and policy agendas matter for the politics of appointments. Previous research on appointments have not required a position-centric approach as their focus has been on the individuals filling the positions. Yet, we cannot attribute appointee characteristics, like ideology, to empty positions. Thus, to examine the decision to leave a position empty on the same footing as the decision to submit a nominee for that position, we need to consider how the characteristics of positions themselves lead to the outcomes of the appointment process. We need a concept that accounts for the policy priorities that ultimately drive political actors to prefer certain agency actions as well as the capacities of the positions to advance those priorities. As we have seen here, Position Value accomplishes both those objectives; and, as the theoretical framework developed in the next chapter reveals, Position Value offers a robust mechanism for examining the strategic choices to leave certain positions empty or to fill them with appointees. 


\section{CHAPTER IV}

\section{A Theory of Vacancies and Appointments}

In this chapter, I discuss a new theory of appointments that integrates the empty-interim and confirmed appointee distinction while incorporating the Senate's leverage to veto a nomination and the president's power to choose not to submit one in the first place. Importantly, when the president decides against nominating after appointing an interim, he circumvents the Senate's right to review, advise, and consent to the individuals serving in key policy-making positions in the Executive Branch. Alternatively, if the president maintains the empty post, he again sidesteps Senate participation in how the position will be filled. Crucially, the option to avoid advice and consent removes the constraint of the Senate's pivotal actor on presidential appointments and highlights opportunities for presidents to consolidate power and fulfill their policy goals. Building on the existing appointments paradigm, this theory considers how policy priorities to expand or contract the reach of an agency leads rational presidents to strategically forgo appointments and nominations. This chapter has four sections: the first offers a stylized version of the model and its intuition, the second presents the formal treatment of the model, the third proves the equilibrium solution, and the fourth derives a series of expectations about when positions are more likely to be left empty or filled with interim and confirmed (permanent) appointees. 


\subsection{A New Theory of Vacancies and Appointments}

Vacancies offer presidents an opportunity to pursue diverging policy goals. Starting from this assumption, I introduce a theory of appointments based on a model that formalizes the president's choice to fill a position or leave it empty in an inter-branch bargaining context. The model begins with a vacancy and has two stages and two Players, the president and the Senate. In the first stage, the president makes a sequence of decisions: first whether to immediately fill the empty post with an interim appointee and then whether to submit a nominee for Senate confirmation. In response, the Senate pursues confirmation when the cost of empty posts and interim agents outweighs any gains from returning a president's nominee, albeit only if one is submitted. Both players maximize utility from policy outcomes in terms of Position Value. Ultimately, Position Value and the anticipation of Senate confirmation or rejection shape the president's strategy to appoint an interim appointee, nominate a permanent appointee, or leave vacant position empty.

Recall from Chapter 3, Position Value is a function of two variables: Position Capacity and Policy Priorities. The integral piece of each player's utility function, Position Value creates the incentives that drive the Senate's choice to confirm a nominee, and the president's strategic choice to submit one, given the Senate's confirmation strategy. Formally, and to preview Section 2, the generalized utility functions for each player $i$ reflect the payoff for filling the position immediately ( $\left.\beta \tau V_{i y}\right)$, the payoff for filling the position for the long-term $\left(\beta \tau \gamma V_{i y}\right)$, and the bargaining cost $\left(c_{i}\right)$ of the confirmation process such that: $u_{y}=\beta \tau_{(f, \neg f)} V_{i y}+\beta \tau_{(f, \neg f)} \gamma V_{i y}-c_{i}$. Here, Position Value $\left(V_{i y}\right)$ is weighted by three multipliers. First, $\beta$ indicates the effectiveness of any appointee (interim or permanent), should one fill the position, in achieving the full value of the position. I assume that the president chooses appointees based on their level of effectiveness in delivering the full position value, where an ineffective appointee cannot deliver the high value of the position which imitates the low value of a low capacity position. Importantly, to focus on the choice to fill the position rather than whom to fill it with, I assume that interim appointees and nominees are 
identical in terms of effectiveness. ${ }^{1}$

Previous models of presidential appointments focus on the choice of nominee in terms of ideological alignment with the president and/or the Senate. As mentioned in Chapter 3, ideology does not reveal an agent's effectiveness in delivering realized value to a principal. As such, ideological alignment between appointees and the president or Senate matters less if the appointees are unable to accomplish goals in line with those preferences. Appointees in low capacity positions ones that are institutionally constrained with little to no opportunity to effectively direct changes in policy - ultimately resemble ineffective appointees regardless of their ideological alignment. Accordingly, this model deviates from previous theories by emphasizing the effectiveness of an appointee instead of ideological alignment.

Second, $\tau$ indicates whether a position is filled. I assume that filled positions and empty ones differ, at a minimum, in terms of accountability and responsiveness. Empty PAS positions, inherently, do not have a person to fulfill basic responsibilities like executing presidential directives. Lastly, $\gamma$ indicates the anticipated degree of congressional oversight that might restrict or amplify the appointee's ability to deliver the full realization of position value. I assume the Senate impacts the full realization of the position value through the anticipated degree of oversight of a permanent appointee. Specifically, confirmation establishes the nominee as a permanent appointee, which generates confidence in the perpetuity of the filled position. Moreover, the evaluation of agency actions through oversight either constrains policy changes (when the Senate and president do not align in their priorities) or strengthens their legitimacy to vested interest groups (when the Senate and president align). In other words, $\gamma$ amplifies the realized position value when Senate and presidents policy priorities align and decreases it when they do not. Lastly, I assume that the political capital and time required for confirmation negotiations are costly, albeit not necessarily equally, to both the president and the Senate. The sequence of game play is as

\footnotetext{
${ }^{1}$ To clarify, I am assuming equal effectiveness per unit of time. We might expect that the longer someone serves (more units of time in a position) the more effective they become, comparatively.
} 
follows:

1. The president is presented with an empty position, with value to the Senate $V_{i S}$ and to the president $V_{i P}$, given the position's capacity and the Senate's and the president's policy priorities for the agency, respectively. The president observes $V_{i S}$ and $V_{i P}$, chooses a strategy to fill with an interim appointee or leave empty, and then to nominate or not.

2. If the president does not nominate, the game ends with an interim appointee or empty position. Payoffs are then allocated to both players.

3. If the president does nominate, the Senate chooses a strategy to confirm or not. If the Senate chooses to confirm, the game ends with a permanent appointee. If the Senate chooses to not confirm, the game ends with the reversion point from the president's move in the first stage, either an interim appointee or empty position. Payoffs are then allocated to both players.

As the third section in this chapter documents, I employ subgame perfect Nash equilibrium and solve the game via backwards induction. The game follows a straightforward sequential structure, has a unique equilibrium, and produces clear predictions about the way in which each of these outcomes arise. In the fourth section, I describe these predictions and use them to generate several hypotheses, which I will test in the proceeding chapters using new and original data on the status of positions, their capacity, and the corresponding policy priorities. But first, the next section provides the formalized treatment of this model.

\subsection{A Generalized Appointments Model}

The model presented here is built on a stylized setting involving the president $P$ and the Senate $S$. In the first period, the president is presented with a vacant PAS position. ${ }^{2}$ While there are potential non-random aspects of the data generating process behind vacancies, particularly for term-limited positions in independent agencies, I will black-box the vacancy generation and assume, for simplicity, that they are exogenous. The first period mimics a decision-theoretic

\footnotetext{
${ }^{2}$ Either at the start of or randomly throughout his term.
} 
model as the president makes a sequence of decisions: first whether to immediately fill the empty post with an interim and then whether to submit a nominee for Senate confirmation. Essentially, when faced with an opening, the president has three choices: fill the position immediately with an interim or not, submit a nominee for confirmation or not, or leave the position empty.

Given the advantage of a first-mover, the president sets the reversion point (i.e., an empty or temporarily filled position) for the Senate's choice in the second period to confirm a nominee, if one is submitted. However, the president need not submit a nominee for the Senate's consideration. When the president decides against nominating a permanent appointee after appointing an interim, he circumvents the Senate's right to review, advise, and consent to the individuals serving in key policy-making positions in the Executive Branch. Alternatively, if the president does not appoint an interim or submit a nominee, he maintains the empty post and, again, sidesteps Senate participation in how the position will be filled. The combinations of strategies can lead to any one of four outcomes, as depicted in Figure 4.1: an empty position, a position filled by an

Figure 4.1: Appointments Model Outcomes

\begin{tabular}{|c|c|c|c|c|}
\hline & & & $\begin{array}{r}\text { Pe } \\
\text { Senate' }\end{array}$ & $\begin{array}{l}\text { 2: } \\
\text { ategies }\end{array}$ \\
\hline & & & Confirm & Not confirm \\
\hline & Fill & $\begin{array}{l}\text { Submit } \\
\text { Nominee }\end{array}$ & $\begin{array}{c}\text { Interim and } \\
\text { Permanent }\end{array}$ & Interim \\
\hline $\begin{array}{l}\text { Period 1: } \\
\text { President's }\end{array}$ & $\begin{array}{l}\text { Immediately } \\
\text { with Interim }\end{array}$ & $\begin{array}{l}\text { Not } \\
\text { Submit } \\
\text { Nominee }\end{array}$ & & \\
\hline Strategies & Not Fill & $\begin{array}{l}\text { Submit } \\
\text { Nominee }\end{array}$ & Permanent & Empty \\
\hline & Immediately & $\begin{array}{l}\text { Not } \\
\text { Submit } \\
\text { Nominee }\end{array}$ & & \\
\hline
\end{tabular}


interim appointee with no action toward a permanent appointee, a position filled by a permanent appointee, or a position filled by an interim and then a permanent appointee.

The political capital and time required for confirmation negotiations are assumed to be costly, albeit not necessarily equally, to both the president and the Senate. The cost of confirmation might also be in terms of future legislative success of administration policy proposals (Madonna et al., 2016). These time-invariant costs are indexed to each player and incurred only when a nominee is submitted for Senate confirmation. Specifically, I assume that these non-zero costs are common knowledge, exogenously determined, and assigned by Nature for each vacant position. Several features of the confirmation process can be engineered to decrease or increase bargaining costs: bargaining for the success of a nominee throughout the confirmation process requires resources in terms of staff attention, opportunity costs of diverting valuable time away from other legislative (or executive) business, and political concessions from both the administration and members of the Senate. In cases of unified government - when the president and Senate are most likely to have similar, or even identical, priorities - successfully confirmed nominees require fewer staff resources and political concessions. Alternatively, easing the procedural rules that govern the confirmation process by limiting committee hearings and floor debate or relaxing the cloture requirement (i.e., the 'nuclear' option) decreases the time spent on confirmation and its consequent opportunity costs. The degree to which these bargaining costs diminish any benefit of a permanent, confirmed appointee might be minimized by unified government or procedural easing, however, they remain non-zero. However, I assume that these adjustments occur outside the scope of the game.

Strategies and Position Value. At any point in a president's term, there exists a set of vacant PAS positions $Y$; naturally, $Y$ is a larger set at the start of a term. Nature chooses an empty position $y \in Y$ with position value $V_{y i}$ to each player $i$. The president $P$ then makes a strategy choice $p$ from four possible options, $p \in\{I \& \neg N, I \& N, \neg I \& N, \neg I \& \neg N\}$ : to fill immediately with an interim appointee without submitting a nominee for Senate confirmation $(p=I \& \neg N)$, 
fill immediately and nominate $(p=I \& N)$, not fill immediately but submit a nominee $(p=\neg I \&$ $N$ ), or not fill at all ( $p=\neg I \& \neg N)$. If the president chooses a strategy that includes a nomination, the Senate $S$ then makes a strategy choice $s \in\{\text { Confirm, } \neg \text { Confirm }\}^{2}$ to confirm the nominee or not. While this strategy set condenses the larger set of available Senate responses (i.e., holds and blue-slips, filibusters, returns, and confirmations), it covers the principal outcomes of the confirmation process.

Position value, $V_{y i} \in(-1,1)$, is exogenously determined and represents each position's potential role in advancing player $i$ 's larger policy agenda. Specifically, $V_{y i}$ is a function of the position's capacity to control policy and the player's priorities of expansion, contraction, or neutrally maintaining the status quo policy reach of the agency. Importantly, players' larger policy agendas are common knowledge, determined ex ante, and exogenous to the specific positions' policy jurisdictions. ${ }^{3}$ Nature maps these policy agendas to the set of executive department and independent agencies with PAS positions, generating policy priorities for each parent agency. These policy priorities range from contracting implementation and outcomes under agency $a$ 's jurisdiction, expanding those outcomes, or neutrally maintaining the status quo. In other words, these priorities represent the degree to which each player would like to undercut, strengthen, or ignore the agency's status quo implementation, regulation, or policy generating efforts. ${ }^{4}$ However, the extent to which a specific position can contribute to each player's policy priorities is institutionally constrained by the position's capacity to advance those priorities. Recall, low capacity positions are administrative or routine in nature, have little to no latitude, and generally

\footnotetext{
${ }^{3}$ In other words, I assume that players do not target specific positions for expansion or contraction per se but establish a policy agenda and see positions and agencies with pertinent policy jurisdictions as vehicles for achieving policy goals. For instance, a president's larger policy agenda might prioritize environmental deregulation and devolution of education policy to the states, without tying these priorities to the specific positions like the Assistant Secretary for the Office of Fossil Fuels in the Department of Energy or Under Secretary for the Department of Education.

${ }^{4}$ For instance, a president's priorities might include rapid deregulation of liquefied natural gas pipelines by weakening the Federal Energy Regulatory Commission; increasing protections for intellectual property by strengthening the Patent and Trademark Office; or simply maintaining the status quo in government oversight by generally ignoring the role of Inspectors General.
} 
provide few opportunities to reach larger political goals. Alternatively, high capacity positions require more expertise, have more room to influence policy outcomes, and advance a larger political agenda. When a position has a low policy capacity any appointee - temporary or permanent has minimal ability to affect policy change and the value of that position to a player is nil $\left(V_{y i}=0\right)$ no matter the policy priorities. Likewise, when a player does not prioritize the agency and has strict preferences for contracting or expanding policies under agency $a$ 's purview the value of the position for advancing the player's larger agenda is nil $\left(V_{y i}=0\right)$ no matter the position's capacity level. Alternatively, the positions with the highest absolute value $\left(\left|V_{y i}\right|=1\right)$ are high capacity and high priority. Thus, to make the theory's implications as stark as possible, the value of an empty position is non-zero only when a player prioritizes the agency's policy jurisdiction and the position has the capacity to achieve those priorities.

As my objective is to provide intuition for the circumstances under which a president and the Senate might each prefer an empty PAS position to one filled by an interim or confirmed appointee, I focus the model on the operational differences between a filled and empty position instead of ideological differences between players or between each player and an appointee. I build this model on the core assumption that leadership positions in the federal bureaucracy are valuable for their ability to deliver outcomes in line with player's policy priorities. Ideological (mis)alignment between principals and agents, while a clear indicator of (dis)agreement on the content of policy, does not sufficiently determine the effectiveness of an appointee (or the lack thereof) in achieving outcomes. Furthermore, $V_{y i}$ specifies differences in policy priorities between players which indicates, at least in part, differences in ideological preferences. While I acknowledge that ideology plays an important role in the decision of who will fill a position, I contend that effectiveness in delivering value for a position captures a core element of the decision to fill a position in the first place.

Effectiveness. The value of a position to each player indicates the opportunity to accomplish their prioritized policy goals; however the success of this depends largely on how effective the ap- 
pointee is in that position. An ineffective appointee mirrors a low capacity position; neither offers valuable advancement of the player's policy agenda. Thus, each player must consider not only the position's value but also the appointee's ability to realize that value. Specifically, effectiveness aligns with the established notion of agents' capacity to fulfill the duties of their position based on their qualifications (Carpenter, 2010), while also accounting for PAS appointees' relations with their subordinate career civil servants. ${ }^{5}$

The degree to which appointees can be effective in advancing the president's agenda largely depends on their interactions with set of careerists who are largely responsible for implementing agency policy (Durant and Resh, 2010a). As described in Chapter 2, presidential appointees - specifically those in PAS positions - represent a modest bloc atop a much larger pyramid of nearly 3 million civil servants spread across over 200 departments and agencies. ${ }^{6}$ In some cases, the agencies these appointees seek to manage naturally produce policies consistent with the president's wishes with very little attention from the White House; others need active management. ${ }^{7}$

Here, PAS appointees as internal principals must establish trust in their appointee-careerist relations through "sanctioned acceptance" of their agent's legitimacy to facilitate careerist compliance with their ideal policy implementation (Resh, 2015; Carpenter and Krause, 2014). Thus, an appointee's effectiveness in advancing a player's policy agenda requires the capacity to fulfill the position's ascribed duties and foster productive relations with careerists. ${ }^{8}$ Importantly, the

\footnotetext{
${ }^{5}$ This, of course, requires that the appointee have careerists to manage, which is not the case for appointees to independent commissions.

${ }^{6}$ For a closer look at the structure of the federal civilian personnel system, see Lewis and Selin (2012).

${ }^{7}$ Consequently, presidents may be better served by concentrating on appointing allies to more actively lead agencies whose missions and policy preferences are not aligned with their own (Gailmard and Patty, 2007). For such agencies, "incoming presidents have incentives to select appointees who can effectively change agency policy" (Lewis, $2011,54)$ and ensure the agency performs to the president's expectations.

${ }^{8}$ Previous research on the administrative presidency traditionally focused on how presidents achieve policy goals and minimize agency loss through centralization of policymaking or politicization of the bureaucracy (Moe, 1993; Lewis, 2008), assuming a foundational distrust of career personnel that must be controlled or circumvented (Edwards III, 2001). However, more recent work on leadership traits among appointees (Krause and O'Connell, 2016), the role of transactional authority in bureaucratic politics (Carpenter and Krause, 2014), and bureaucratic competence (Resh, 2015) indicates that a partnership between appointees (as principals) and career personnel rooted in trust and managerial competence offers a third mechanism for optimizing careerist compliance in policy implementation.
} 
president chooses an appointee with a specific level of effectiveness. Given perfect information, both players perfectly anticipate the effectiveness of any appointee or nominee; however, by selecting the interim appointee or nominee, the president sets the appointee's level of effectiveness, $\beta \in(0,1]$.

For simplicity, interim appointees and nominees for position $y$ are assumed to be equally effective and therefore have the same $\beta .{ }^{9}$ If there exists an ideally effective nominee for the position and the president chooses to fill immediately with an interim appointee, it is reasonable to assume that the president would set the reversion point as close to the ideal nominee as possible, in the event that the Senate does not confirm. Identical interim appointees and nominees create a reversion point for Senate confirmation that is the president's ideal appointee. Moreover, this assumption simplifies the expected utility functions by reducing the variables that the president and the Senate must consider in their choices of strategies.

Filled Position. Filled positions and empty ones differ, at a minimum, in terms of accountability and responsiveness. Empty PAS positions, fundamentally, do not have a person to fulfill basic responsibilities like reporting to congressional oversight hearings, negotiating new or reauthorizing legislation with Congress, or executing presidential directives. ${ }^{10}$ Under more dire

\footnotetext{
${ }^{9}$ Not only does this assumption allow for model tractability, it represents the reality that presidents have often nominated the same person that they appointed on an interim basis, thereby ensuring identical effectiveness. While NLRB v. SW General (2017) removes this specific strategy as an option for future administrations, it does not restrict presidents from nominating and temporarily appointing equally effective individuals. (Howe, 2017, 2) describes a very recent example of this type of maneuvering: "Shortly after his inauguration, President Donald Trump named Washington lawyer Noel Francisco as the principal deputy solicitor general... Because Trump had not yet nominated (nor had the Senate confirmed) a solicitor general, Francisco soon began to serve as the acting solicitor general. [Two months later], Trump announced that he was nominating Francisco to serve as the solicitor general on a permanent basis. Francisco then moved to another job in the Department of Justice; Jeffrey Wall - the new principal deputy solicitor general - now serves as the acting solicitor general." Thus, I retain this assumption for its historic accuracy and future relevance.

${ }^{10}$ While an empty post necessarily means that no individual with that specific title can report to Congress, it does not necessarily mean that no one will appear. In some instances, the most senior appointee will testify on behalf of the position. For example, in March 2009, as the Obama administration experienced scores of empty deputy and undersecretary positions at the Treasury Department, (Naylor, 2009, 2) reports that "Treasury Secretary Timothy Geithner shuttle[d] between appearances before congressional panels to testify about the budget, [oversaw] the rollout of homeowner and bank bailout programs, and join[ed] talks to rescue the auto industry, he [was] pretty much the only Obama appointee with a desk at the Treasury. However, in most circumstances, interactions with Congress or other agencies stall when key posts are left empty. For instance, the Clean Air Act required re-authorization in
} 
circumstances, empty PAS positions do not have a person to prepare for and initiate response protocols in a crisis. Moreover, independent boards and commissions that require a quorum cannot engage in official business when the required number of seats are not filled. ${ }^{11}$ Players must differentiate between the time a position is filled and the time it is empty, as each scenario produces disparate prospects for achieving policy priorities. ${ }^{12}$ The filled position multiplier $\tau_{(f, \neg f)} \in\left\{\mathbb{Z}^{-}, \mathbb{Z}^{+}\right\}$captures this distinction, such that

$$
\tau_{(f, \neg f)}= \begin{cases}\tau_{k} \leq-1, & \text { if } k=\neg f ; \\ \tau_{k} \geq 1, & \text { if } k=f\end{cases}
$$

Permanence and Oversight. The president sets the reversion point by either choosing to leave a position empty or filling it immediately and choosing the effectiveness of the interim and nominee. In response, the Senate determines the magnitude of the permanence and oversight multiplier, $|\gamma| \geq 1$, with confirmation. ${ }^{13}$ Permanent, confirmed appointees magnify the position's

1989 and President George H. W. Bush did not "name an assistant administrator at the Environmental Protection Agency to handle the negotiations. A congressional aide said it 'definitely slow[ed] things down'" (Havemann, 1989, 4). Nevertheless, a post left unmanned will have at least some portion of its duties undone.

${ }^{11}$ For example, in 2007, the Consumer Product Safety Commission was without a chairman and therefore, as a three-person commission, lacked a quorum. President George W. Bush had not submitted a nominee even though "public safety may be at stake, too, because the lack of a quorum means the agency can't pursue its regulatory agenda to lower the level of led in children's jewelry, redesign portable generators and address safety risks of allterrain vehicles" (Skrzycki, 2007, 3).

${ }^{12}$ While this model does not explicitly incorporate the time horizon of a president's term, player's common knowledge of the remaining time for a position to be either filled or empty implicitly incorporates this limit. In other words, players know at the start of the game how much time remains in the president's term $\mathcal{T}$ such that

$$
\mathcal{T}=\sum_{\neg f}^{f}\left|\tau_{k}\right|
$$

This generalized form of the model does not specify a unit of time, however, iterations (including expanding to repeated play) incorporate a specific unit of time.

${ }^{13}$ Confirmation hearings offer ex ante oversight opportunities to establish expectations for the nominee should she be confirmed as the permanent appointee. The Senate has endowed committees with extensive authority to investigate and interrogate prospective nominees (e.g., Pfiffner, 2001). Confirmation hearings also provide a forum for senators to examine the direction of the agency or department as well as the administration's policies towards the major groups within the department's or agency's jurisdiction. When a president does not submit a nominee, the Senate loses these oversight opportunities. 
value in two circumstances. First, interim appointees are subject to tenure limitations required for compliance with the Federal Vacancies Reform Act, which creates expectations for future attention to the position. Confirmed appointees are not subject to these limits and do not have any anticipated cutoff to their tenure before the end of the president's term. While Senate confirmation does not guarantee that the appointee will serve the entire term, and the well-documented turnover of PAS appointees indicates a sustainable uncertainty about the actual permanence of the appointee (see Chang, Lewis, and McCarty, 2001), this theory concentrates on the decisions to appoint and confirm rather than the decision to keep one's position. In this context, appointees are expected to serve the length of their allotted tenure which makes permanent, confirmed appointees unlikely to require future attention. Thus, confirmation generates confidence in the perpetuity of an appointee and magnifies the realized value of the position. Second, while federal courts have generally treated interim appointees the same as confirmed appointees, some scholars argue that interim appointees have less influence over careerists than confirmed appointees and often fill multiple roles at once, which depletes their attention to any one position (O'Connell, 2009). While this difference in clout does not stem directly from specific statutes, the implication is that confirmed appointees have potentially larger capacity to achieve the players' policy and political goals.

The magnitude of $\gamma$ indicates the length of tenure for a permanent appointee as determined by the length of the Senate's confirmation process. Accordingly, the Senate establishes this magnitude by limiting the time to confirmation. Greater values of $|\gamma|$ indicate longer tenures that permanent appointees serve, given the time remaining in the president's term. ${ }^{14}$ Delays in confirmation reduce the maximum tenure of permanent appointees, thereby lowering $|\gamma|$. The Senate sets $|\gamma|$ at its minimum 1 by not confirming and returning the nomination to the president.

Senate confirmation establishes the permanence of an appointee, and a clear oversight re-

\footnotetext{
${ }^{14}$ For simplicity, this theory assumes that both players experience the same horizon of the current president's term.
} 
sponsibility. However, the effect of oversight activities depends on the players' preferences. If the president's policy priorities align with the Senate's, then oversight activities further increase the prospect of achieving those priorities: a positive multiplier. Alternatively, when the president's policy priorities conflict with the Senate's, oversight will naturally restrict the appointee's advancement of the president's agenda and circuitously impede the Senate's priorities: a negative multiplier. In other words, when priorities align $\gamma$ positively amplifies the value of the position $(\gamma>1)$, but when they diverge $\gamma$ decreases the value $(\gamma<-1)$. Thus, the alignment of players' policy priorities determines the sign of the permanence and oversight multiplier while the Senate sets the value of $|\gamma| \geq 1$ such that:

$$
|\gamma|= \begin{cases}\gamma, & \text { if } V_{y S}=V_{y P} \\ -\gamma, & \text { if } V_{y S} \neq V_{y P}\end{cases}
$$

Utility Functions. The president $P$ and the Senate $S$ derive utility from securing the value of a PAS position and achieving their priorities to expand or contract policy implementation. The generalized utility function player $i$ reflects the payoff for filling the position immediately $\left(\beta \tau V_{y i}\right)$, the payoff for filling to position for the long-term $\left(\beta \tau \gamma V_{y i}\right)$, and the bargaining cost $\left(c_{i}\right)$ of the confirmation process such that:

$$
u_{i}=\beta \tau_{(f, \neg f)} V_{y i}+\beta \tau_{(f, \neg f)} \gamma V_{y i}-c_{i}
$$

Given the president's strategy set $p \in\{I \& \neg N, I \& N, \neg I \& N, \neg I \& \neg N\}$, the Senate's payoff is 


$$
U_{S}(s ; p)= \begin{cases}\beta \tau_{f_{1}} V_{y S}+\gamma \beta \tau_{f_{2}} V_{y S}-c_{S}, & \text { if } s=\text { Confirm \& } p=I \& N ; \\ \tau_{\neg f_{1}} V_{y S}+\gamma \beta \tau_{f_{2}} V_{y S}-c_{S}, & \text { if } s=\text { Confirm \& } p=\neg I \& N ; \\ \beta \tau_{f} V_{y S}-c_{S}, & \text { if } s=\neg \text { Confirm \& } p=I \& N ; \\ \tau_{\neg f} V_{y S}-c_{S}, & \text { if } s=\neg \text { Confirm \& } p=\neg I \& N ; \\ \beta \tau_{f} V_{y S}, & \text { if } p=I \& \neg N ; \\ \tau_{\neg f} V_{y S}, & \text { if } p=\neg I \& \neg N,\end{cases}
$$

while, given the Senate's strategy set $s \in\{$ Confirm, $\neg$ Confirm $\}$ the president's payoff is

$$
U_{P}(p ; s)= \begin{cases}\beta \tau_{f_{1}} V_{y P}+\gamma \beta \tau_{f_{2}} V_{y P}-c_{P}, & \text { if } s=\text { Confirm \& } p=I \& N ; \\ \tau_{\neg f_{1}} V_{y P}+\gamma \beta \tau_{f_{2}} V_{y P}-c_{P}, & \text { if } s=\text { Confirm \& } p=\neg I \& N ; \\ \beta \tau_{\neg f} V_{y P}-c_{P}, & \text { if } s=\neg \text { Confirm \& } p=I \& N ; \\ \tau_{\neg f} V_{y P}-c_{P}, & \text { if } s=\neg \text { Confirm \& } p=\neg I \& N ; \\ \beta \tau_{f} V_{y P}, & \text { if } p=I \& \neg N ; \\ \tau_{\neg f} V_{y P}, & \text { if } p=\neg I \& \neg N,\end{cases}
$$

where $\tau_{(f, \neg f)}$ differentiates between a filled and unfilled position (in the first and second period if necessary), $\beta \in(0,1)$ represents the effectiveness of the (interim or confirmed) appointee, $|\gamma| \geq 1$ is the confirmed appointee's permanence, and $c_{i}>0$ accounts for the transaction costs to both players from bargaining over confirmation.

The Game. These features of my formal model are carried out through the following sequence of game play:

1. Nature selects empty position $y_{a} \in Y$ in agency $a$ with value to player $i, V_{y i} \in(-1,1)$, given the policy capacity level of position $y, s_{y} \sim U[0,1]$, and agency $a$ 's position on player $i$ 's policy agenda

2. The president $P$ observes $V_{y i}$ and chooses strategy $p \in\{I \& \neg N, I \& N, \neg I \& N, \neg I \& \neg N\}$.

3. If $p=I \& \neg N$ or $p=\neg I \& \neg N$, the game ends with an interim appointee or empty position. 
4. If $p=I \& N$ or $p=\neg I \& N$, the Senate $S$ chooses strategy $s \in\{$ Confirm, $\neg$ Confirm $\}$.

The figure below illustrates this sequence and the payoffs associated with each strategy pairing.

Figure 4.2: Vacant Positions Model in Extensive Form

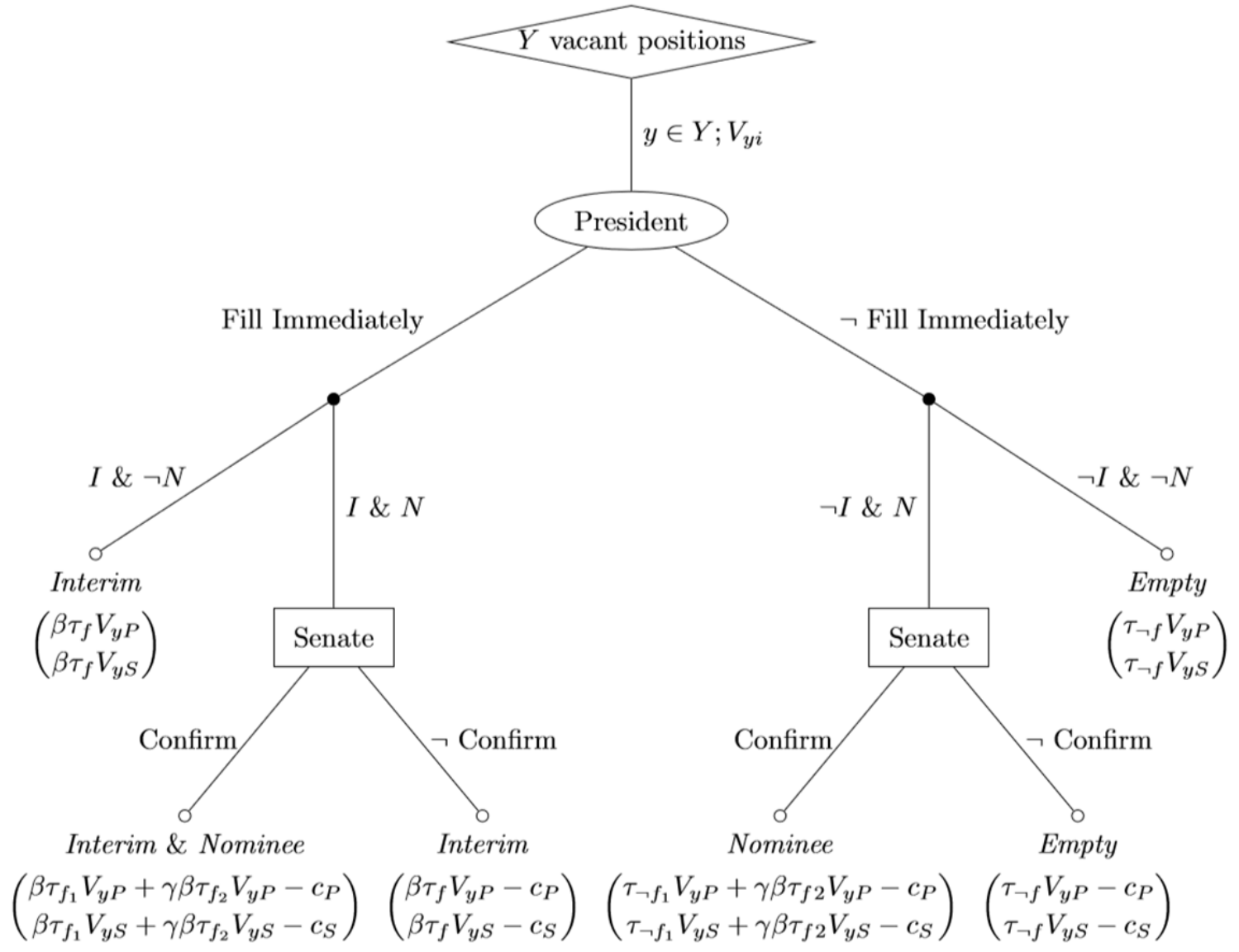

\subsection{Equilibrium Results and Proofs}

In this section, Lemmas 1-3 describe the pure strategy Subgame Perfect Nash Equilibrium (SPNE) results that generate the testable hypotheses presented in Proposition 1 and Corollaries 1 and 2. I assume that the president $P$ resolves indifference in strategy choices with a weak preference for filling the position immediately and subsequently submitting a nominee for con- 
firmation, while the Senate $S$ resolves indifference in favor of confirming the president's nominee.

Lemma 1 The Senate $S$ confirms the president P's nominee if

1. $\left\{V_{y S}=V_{y P}=1\right\}$

2. $\left\{V_{y S}=-1, V_{y P}=1\right\}$ and $p=I \& N$;

3. $\left\{V_{y S}=-1, V_{y P}=1\right\}, p=\neg I \& N$, and $\gamma<-\frac{1}{\beta}$;

4. $\left\{V_{y S}=1, V_{y P}=-1\right\}, p=\neg I \& N$, and $\gamma>-\frac{1}{\beta}$; or

5. $V_{y S}=0$.

Lemma 1 describes the Senate $S$ 's confirmation set when the president nominates a candidate. This result indicates that the position value - namely the combination of the position's policy control capacity (the ability of a minimally effective appointee to authorize and achieve desired policy implementation strategies) and players' policy priorities (expand or contract policy under the agency's jurisdiction) - governs the Senate's acceptance of the president's nominee. When given the choice, $S$ confirms the nominee under five sets of circumstances, the first four of which require that position $y$ is a position with high policy control capacity. First, $S$ confirms when the president and Senate both prioritize policy expansion $\left(V_{y i}=1\right)$, irrespective of the reversion point. $S$ also confirms a nominee when the president and Senate do not agree on policy priorities, albeit under specific conditions. In particular, when the president prioritizes policy expansion $\left(V_{y P}=1\right)$ and the Senate prioritizes policy contraction $\left(V_{y S}=-1\right)$, the Senate confirms if an interim has been appointed $(p=I \& N)$. If an interim has not been appointed ( $p=\neg I \& N)$, then the Senate confirms only when $\gamma<-\frac{1}{\beta}$ which indicates the trade-off between an effective nominee $(\beta)$ and the Senate's capacity for permanence and oversight $(\gamma)$. Fourth, $S$ confirms when the president prioritizes policy contraction $\left(V_{y P}=-1\right)$ and the Senate prioritizes policy 
expansion $\left(V_{y S}=-1\right)$ only if the reversion point is an empty position $(p=\neg I \& N)$ and $\gamma>-\frac{1}{\beta}$. Lastly, the Senate also confirms the president's nominee when the position delivers no value $\left(V_{y S}=0\right),{ }^{15}$ because indifference is resolved in favor of confirmation.

More specifically, when the president and Senate both support a policy area (for example, understanding the likelihood of large scale natural disasters due to climate change) and the vacant position is high capacity (i.e., the Director of the U.S. Geological Survey), the Senate will confirm the president's nominee. This result supports an expected scenario: when both players prioritize strengthening policy under the jurisdiction of a high capacity position that affords an appointee the discretion to meet those goals, the Senate will always confirm the president's nominee.

Alternatively, if the Senate opposes a policy that the president supports (for instance, government interventions in corporate mergers and acquisitions) and the position has high policy control capacity (i.e., the Assistant Attorney General for the Antitrust Division at the Department of Justice), the Senate will confirm the president's nominee if an interim has been appointed. In this case, the Senate and the president are at odds in their priorities for a position that has the capacity to effect policy change. With an interim appointee from a president who prioritizes policy expansion, the Senate faces an unfavorable reversion point without the benefit of oversight from confirmation. The Senate, under these circumstances, would be better served to acquiesce with the advantage of oversight than to contend with the identical appointee in an interim capacity without the institutional constraints of confirmation. If no interim has been appointed, the Senate will confirm only if the permanence and oversight multiplier $(\gamma)$ is sufficiently small given a relatively effective nominee or, conversely, if the nominee is relatively ineffective $(\beta \rightarrow 0)$ and $|\gamma|$ is sufficiently large. Without an interim appointee, the Senate faces an empty post as the reversion point. Given the high capacity position, the Senate intuitively prefers leaving the post empty than confirming an effective nominee $(\beta \rightarrow 1)$ from a president who seeks to expand policy. However, the Senate has an oversight incentive to confirm if the nominee is ineffective

\footnotetext{
${ }^{15} V_{y S}=0$ either because it is low capacity or the Senate is policy neutral.
} 
and appointee's tenure $(|\gamma|)$ is sufficiently long to allow for oversight activities. On the other hand, the Senate will confirm a relatively effective nominee only if the tenure of that permanent appointee is sufficiently small $(\gamma \rightarrow-1)$.

These two scenarios might appear at odds, particularly for the same confirmation strategy. However, once we consider the role of permanence and oversight the inconsistency dissipates. When the Senate shares the president's priorities to expand policy $\left(V_{y S}=V_{y P}=1\right)$, the permanence of a confirmed appointee magnifies that position value (by $\gamma>1$ ) and produces a dominant strategy of Senate confirmation. When the Senate prioritizes policy contraction and the president seeks expansion $\left(V_{y S}=-1\right.$ and $\left.V_{y P}=1\right)$, oversight of a formally confirmed appointee, compared to the reversion point of an interim appointee, offers an avenue to limit the president's influence and achieve more of the Senate's agenda thereby amplifying the value of that position. If the Senate prioritizes policy contraction and the president seeks expansion, but the reversion point is an empty position ( $p=\neg I \& N$ ), the Senate will prefer confirmation only if the president submits a sufficiently ineffective nominee, since $\beta \rightarrow 0$ mirrors the ineffectiveness of a low policy control capacity position. Higher levels of incapacity further limit the influence of the president, which complements the oversight of a formal confirmation. Otherwise, if the president offers a more effective nominee $\left(\beta>\frac{1}{|\gamma|}\right)$ the Senate would prefer to return the nominee and revert to an empty position.

Lastly, if the Senate supports policy expansion while the president prioritizes policy contraction and the position is high capacity, the Senate will confirm the president's nominee if an interim is not appointed and the magnitude of the permanence and oversight multiplier $(|\gamma|)$ is sufficiently small $(\gamma \rightarrow-1)$ given a relatively effective nominee $(\beta \rightarrow 1)$.

Lemma 2 presents the complement to the results in Lemma 1 and characterizes the Senate $S$ 's rejection set when the president submits a nominee: 
Lemma 2 The Senate $S$ does not confirm the president $P$ 's nominee if

1. $\left\{V_{y S}=V_{y P}=-1\right\}$;

2. $\left\{V_{y S}=1, V_{y P}=-1\right\}$ and $p=I \& N$;

3. $\left\{V_{y S}=1, V_{y P}=-1\right\}, p=\neg I \& N$, and $\gamma<-\frac{1}{\beta}$; or

4. $\left\{V_{y S}=-1, V_{y P}=1\right\}, p=\neg I \& N$, and $\gamma>-\frac{1}{\beta}$.

Specifically, Lemma 2 states that the Senate prefers to not confirm the nominee when the position is high capacity and its priorities to contract policy align with the president's $\left\{V_{y S}=\right.$ $\left.V_{y P}=-1\right\}$. The Senate also has a dominant strategy to not confirm for a high capacity position if policy priorities conflict such that the president prioritizes policy contraction while the Senate seeks expansion and there is an interim appointee. As described above, the Senate will also return the nominee when the president seeks expansion counter to the Senate's priority for contraction $\left(\left\{V_{y S}=-1, V_{y P}=1\right\}\right)$, the reversion point is an empty post, and the president offers a relatively effective nominee $\left(\beta>\frac{1}{|\gamma|}\right)$.

The first of these results, that is when $V_{y S}=V_{y P}=-1$, appears the most surprising, particularly as one might imagine that aligned priorities for contracting policy encourage a confirmed nominee that actively seeks to derail agency activity and performance. However, implicit in the construction of this model is an assumption that an appointee, however (in)effective, will minimally perform the responsibilities ascribed to that position. Ultimately, the ability of an appointee to impact the agency's performance is constrained by the cost (oversight, budgetary, or electoral/political) of appointees actively and/or visibly damaging agency performance. Government watchdog groups, vested interests, client advocacy groups, and potential electoral opponents have multiple methods of drawing attention to explicit bureaucratic drift. An appointee's actions are at least marginally undesirable compared to an empty position for players who prioritize contracting policy. Thus, the Senate's optimal strategy to narrow an agency's policy reach 
is to return a nominee if one is submitted.

Alternatively, the strategy choice to return a nominee if the president prioritizes policy contraction while the Senate seeks expansion results, in large part, from the oversight cost associated with disparate policy priorities $(\gamma<-1)$. Conceptually, oversight that obstructs or delays agency actions - as occurs when the Senate prefers policy contraction over expansion - requires less political capital and intervention than oversight that demands action. The capacity to achieve the Senate's expansion priorities diminish with larger values of $|\gamma|$ where $\gamma<-1$, which decreases the expected utility received with confirmation and makes returning the nomination the preferred choice.

Lemma 3 The president $P$ plays the following strategy choice after observing $V_{y i}$ for $i \in\{S, P\}$ :

$$
p= \begin{cases}I \& N, & \text { if } V_{y S}=V_{y P}=1 \text { and } c_{P} \leq(\gamma-1) \beta \tau_{f_{2}} V_{y P} ; \\ I \& \neg N, & \text { if } V_{y S}=V_{y P}=1 \text { and } c_{P}>(\gamma-1) \beta \tau_{f_{2}} V_{y P}, \\ & \text { or } V_{y S}=-1 \text { and } V_{y P}=1, \\ & \text { or } V_{y P}=0 ; \\ \neg I \& \neg N, & \text { if } V_{y S}=V_{y P}=-1, \\ & \text { or } V_{y S}=1 \text { and } V_{y P}=-1,\end{cases}
$$

Lemma 3 presents an important result: $p=\neg I \& N$, while contained in the president $P$ 's strategy space, is not contained within the set of optimal strategies. If the president chooses to not fill a position immediately, he will not then submit a nominee for Senate confirmation. This result is driven primarily by the strategic anticipation that the Senate will not confirm a nominee if one was submitted (under the scenario that the president has set an empty position as the reversion point). In other words, anticipating the Senate's pure strategy to return a nominee and end the game with an empty position, the president prefers to avoid the bargaining cost of appointment negotiations, forgo submitting a nominee entirely, and arrive at the same result of 
an empty position.

Given the SPNE results from Lemmas 1-3, the following propositions describe the testable predictions that obtain in equilibrium.

Proposition 1 Vacant position $y$ will stay empty in equilibrium if and only if the position is highcapacity and the president $P$ prioritizes policy contraction $\left(V_{y P}=-1\right)$.

Proposition 1 asserts that a vacant position $y$ with position value to the president of $V_{y P}=-1$ will not be filled by either an interim or confirmed appointee when the game ends. A few aspects of Proposition 1 are worth noting. First, as expected, the president's first-mover advantage manifests as dictatorial control over empty posts. Anticipating that, when the president prioritizes contracting policy, the Senate will confirm a nominee for high capacity positions only if the Senate is policy neutral $\left(V_{y S}=0\right)$ and will return nominees if $V_{y S} \neq 0$, the president prefers to avoid the bargaining cost by forgoing a nomination.

Second, and relatedly, the proposition implies that when an empty position is sustained, a nominee was not submitted for confirmation no matter the policy priority alignment with the Senate. While policy priorities are not explicit indicators of ideology, one can easily posit that a unified government would have considerable overlap in policy priorities. Consequently, Proposition 1 implies that sustained empty positions would occur even in unified government if the president prefers policy contraction.

Finally, the third implication of the proposition is that when a president chooses to keep a position empty, the vacant position is high-capacity. These positions have the most potential for advancing policy priorities but also have real-world consequences for agency performance and policy outcomes when left empty. This proposition implies that widespread empty posts are not expected among low-level, heavily administrative PAS positions, but rather among exactly those positions that need to be filled for a functioning agency. The following corollaries describe the 
conditions of confirmed and interim appointments in equilibrium.

Corollary 1 An interim appointment to position $y$ will occur in equilibrium if and only if the following occurs:

1. The position is high capacity, the Senate $S$ and the president $P$ both prioritize policy expansion $V_{y S}=V_{y P}=1$ or the president prioritizes policy expansion $\left(V_{y P}=1\right)$ while the Senate is policy neutral $\left(V_{y}=y S=0\right)$, and the president's bargaining cost is $c_{P} \leq c_{P}^{*}$ (such that $\left.\left.c_{P}^{*}=(\gamma-1) \beta \tau_{f_{2}} V_{y P}\right)\right)$, or

2. The position is high capacity, the Senate prioritizes policy contraction $\left(V_{y S}=-1\right)$, and the president prioritizes policy expansion $\left(V_{y P}=1\right)$, or

3. The position is low capacity or the president is policy neutral such that $V_{y P}=0$.

Corollary 2 A confirmed appointment to position $y$ will occur in equilibrium if and only if the following occurs:

1. The position is high-capacity,

2. The Senate $S$ and the president $P$ both prioritize policy expansion $\left(V_{y S}=V_{y P}=1\right)$ or the president prioritizes policy expansion $\left(V_{y P}=1\right)$ while the Senate is policy neutral $\left(V_{y S}=0\right)$, and

3. The president's bargaining cost, $c_{P}$, is less than or equal to the president's cutpoint $c_{P}^{*}\left(c_{P} \leq\right.$ $\left.c_{P}^{*}\right)$ such that $c_{P}^{*}=(\gamma-1) \beta \tau_{f_{2}} V_{y P}$.

The implications of Corollaries 1 and 2 complement those of Proposition 1 in the following two ways. First, Corollary 1 implies that interim appointees fill high and low-capacity positions, but that the president does not use interim appointees in high capacity positions when prioritizing policy contraction. This implication suggests that as policy agendas are increasingly dominated by expansion priorities, the frequency of vacant positions filled with interim appointees will also increase. Second, Corollary 2 implies that the president seeks to submit a nominee for only highcapacity positions when prioritizing policy expansion, and the Senate, when given the choice to 
confirm, will do so only when prioritizing expansion or policy neutrality. Importantly, the president's choice to submit a nominee hinges on the cost to bargain with the Senate over confirmation and the cut-point in equilibrium $\left(c_{P}^{*}\right)$ is largely driven by the Senate's value for permanence and oversight $\gamma$. Thus, by setting a high value of $\gamma$ (e.g., speedy confirmation hearings), the Senate increases the likelihood that the president's bargaining costs will fall below the cut-point, thereby ensuring a nominee to confirm.

\subsubsection{Proofs of Equilibrium Solution}

Proof for Lemma 1. First, suppose Nature chooses a position $y \in Y$ that is high skilled, such that $s_{y}=1$ and from an agency with jurisdiction that aligns with both players policy expansion priorities such that position value $V_{y P}=V_{y S}=1$. If the president chooses to fill the position immediately with an interim appointee and submit a nominee for Senate confirmation, ${ }^{16}$ the Senate prefers to confirm the nominee only if the expected utility from confirmation outweighs the expected utility from not confirming:

$$
\begin{aligned}
E U_{S}(C \mid I \& N) & >E U_{S}(\neg C \mid I \& N) \\
\beta \tau_{f_{1}} V_{y S}+\gamma \beta \tau_{f_{2}} V_{y S}-c_{S} & >\beta \tau_{f} V_{y S}-c_{S} \\
\beta\left(\tau_{f_{1}}+\gamma \tau_{f_{2}}\right) V_{y S} & >\beta\left(\tau_{f_{1}}+\tau_{f_{2}}\right) V_{y S} \\
\tau_{f_{1}}+\gamma \tau_{f_{2}} & >\tau_{f_{1}}+\tau_{f_{2}} \\
\gamma \tau_{f_{2}} & >\tau_{f_{2}} \\
\gamma & >1
\end{aligned}
$$

${ }^{16}$ Players know at the start of the game how much time remains in the president's term $\mathcal{T}$ such that

$$
\mathcal{T}=\sum_{\neg f}^{f}\left|\tau_{k}\right|
$$

The filled position multiplier $\tau_{(f, \neg f)} \in\left\{\mathbb{Z}^{-}, \mathbb{Z}^{+}\right\}$, such that $\tau_{(f, \neg f)}= \begin{cases}\tau_{k} \leq-1, & \text { if } k=\neg f \text {; } \\ \tau_{k} \geq 1, & \text { if } k=f\end{cases}$ 
By definition, if $V_{y P}=V_{y S}$ then $\gamma>1$; therefore $E U_{S}(C \mid I \& N)>E U_{S}(\neg C \mid I \& N)$. If, instead, the president chooses to not fill the position immediately but still submits a nominee for Senate confirmation, the Senate prefers to confirm the nominee only if the expected utility from confirmation outweighs the expected utility from not confirming:

$$
\begin{aligned}
E U_{S}(C \mid \neg I \& N) & >E U_{S}(\neg C \mid \neg I \& N) \\
\tau_{\neg f_{1}} V_{y S}+\gamma \beta \tau_{f_{2}} V_{y S}-c_{S} & >\tau_{\neg f} V_{y S}-c_{S} \\
\left(\tau_{\neg f_{1}}+\gamma \beta \tau_{f_{2}}\right) V_{y S} & >\left(\tau_{\neg f_{1}}-\tau_{f_{2}}\right) V_{y S} \\
\tau_{\neg f_{1}}+\gamma \beta \tau_{f_{2}} & >\tau_{\neg f_{1}}-\tau_{f_{2}} \\
\gamma \beta \tau_{f_{2}} & >-\tau_{f_{2}} \\
\gamma \beta & >-1
\end{aligned}
$$

By definition, $\beta \in(0,1]$ and if $V_{y P}=V_{y S}$ then $\gamma>1$; therefore $\gamma \beta>-1$ and $E U_{S}(C \mid \neg I \& N)>$ $E U_{S}(\neg C \mid \neg I \& N)$. This proves that if $V_{y P}=V_{y S}=1$, the Senate has a dominant strategy to confirm whenever the president submits a nominee.

Now consider the Senate's possible strategies when Nature chooses a position $y \in Y$ that is high skilled such that $s_{y}=1$ and from an agency with jurisdiction that aligns with the president's policy expansion priorities but the Senate prioritizes policy contraction such that position value $V_{y S}=-1$ and $V_{y P}=1$. If the president chooses to fill the position immediately and submit a nominee for Senate confirmation, the Senate prefers to confirm the nominee only if the expected utility from confirmation outweighs the expected utility from not confirming: 


$$
\begin{aligned}
E U_{S}(C \mid I \& N) & >E U_{S}(\neg C \mid I \& N) \\
\beta \tau_{f_{1}} V_{y S}+\gamma \beta \tau_{f_{2}} V_{y S}-c_{S} & >\beta \tau_{f} V_{y S}-c_{S} \\
\beta\left(\tau_{f_{1}}+\gamma \tau_{f_{2}}\right) V_{y S} & >\beta\left(\tau_{f_{1}}+\tau_{f_{2}}\right) V_{y S} \\
\tau_{f_{1}}+\gamma \tau_{f_{2}} & <\tau_{f_{1}}+\tau_{f_{2}} \\
\gamma \tau_{f_{2}} & <\tau_{f_{2}} \\
\gamma & <1
\end{aligned}
$$

By definition, $\gamma<-1$ if $V_{y P} \neq V_{y S}$; therefore $\gamma<1$ and $E U_{S}(C \mid I \& N)>E U_{S}(\neg C \mid I \& N)$. If the president chooses to not fill the position immediately but still submit a nominee for Senate confirmation, the Senate prefers to confirm the nominee only if the expected utility from confirmation outweighs the expected utility from not confirming. Given that $V_{y S}=-1$, the expected utility of confirmation is greater than that of rejection only when $\gamma<-\frac{1}{\beta}$ :

$$
\begin{aligned}
E U_{S}(C \mid \neg I \& N) & >E U_{S}(\neg C \mid \neg I \& N) \\
\tau_{\neg f_{1}} V_{y S}+\gamma \beta \tau_{f_{2}} V_{y S}-c_{S} & >\tau_{\neg f} V_{y S}-c_{S} \\
\left(\tau_{\neg f_{1}}+\gamma \beta \tau_{f_{2}}\right) V_{y S} & >\left(\tau_{\neg f_{1}}-\tau_{f_{2}}\right) V_{y S} \\
\tau_{\neg f_{1}}+\gamma \beta \tau_{f_{2}} & <\tau_{\neg f_{1}}-\tau_{f_{2}} \\
\gamma \beta \tau_{f_{2}} & <-\tau_{f_{2}} \\
\gamma & <-\frac{1}{\beta}
\end{aligned}
$$

Thus, if $V_{y S}=-1$ and $V_{y P}=1$, the Senate will confirm the president's nominee whenever an interim is also appointed $(p=I \& N)$ and, if an interim is not appointed $(p=\neg I \& N)$, only when $\gamma<-\frac{1}{\beta}$

Third, suppose that Nature chooses a position $y \in Y$ that is high skilled, such that $s_{y}=1$ and from an agency with jurisdiction that aligns with the Senate's policy expansion priorities but the president prioritizes policy contraction, such that position value $V_{y S}=1$ and $V_{y P}=-1$. If 
the president chooses to not fill the position immediately but still submit a nominee for Senate confirmation, the Senate prefers to confirm the nominee only if the expected utility from confirmation outweighs the expected utility from not confirming. Given that $V_{y S}=1$, the expected utility of confirmation is greater than that of rejection only when $\gamma>-\frac{1}{\beta}$ :

$$
\begin{aligned}
E U_{S}(C \mid \neg I \& N) & >E U_{S}(\neg C \mid \neg I \& N) \\
\tau_{\neg f_{1}} V_{y S}+\gamma \beta \tau_{f_{2}} V_{y S}-c_{S} & >\tau_{\neg f} V_{y S}-c_{S} \\
\left(\tau_{\neg f_{1}}+\gamma \beta \tau_{f_{2}}\right) V_{y S} & >\left(\tau_{\neg f_{1}}-\tau_{f_{2}}\right) V_{y S} \\
\tau_{\neg f_{1}}+\gamma \beta \tau_{f_{2}} & >\tau_{\neg f_{1}}-\tau_{f_{2}} \\
\gamma \beta \tau_{f_{2}} & >-\tau_{f_{2}} \\
\gamma & >-\frac{1}{\beta}
\end{aligned}
$$

Thus, if $V_{y S}=1$ and $V_{y P}=-1$, the Senate will confirm if an interim is not appointed $(p=$ $\neg I \& N)$ only when $\gamma>-\frac{1}{\beta}$.

Lastly, consider the Senate's confirmation strategy if Nature chooses a position $y \in Y$ that is low skilled where $s_{y}=0$ or for whose parent agency the Senate has no preference for either expanding or contracting policy (is policy neutral) $w_{a} i=0$ such that $V_{y S}=0$. Assuming that indifference is resolved in favor of confirmation, when $V_{y s}=0$, the Senate will always confirm the president's nominee.

Proof for Lemma 2. First, suppose Nature chooses a position $y \in Y$ that is high skilled such that $s_{y}=1$ and from an agency with jurisdiction that aligns with both players' policy contraction priorities such that position value $V_{y P}=V_{y S}=-1$. If the president chooses to fill the position immediately with an interim appointee and submit a nominee for Senate confirmation, the Senate will not confirm the nominee only if the expected utility from rejecting the nominee outweighs the expected utility from confirmation: 


$$
\begin{aligned}
E U_{S}(C \mid I \& N) & <E U_{S}(\neg C \mid I \& N) \\
\beta \tau_{f_{1}} V_{y S}+\gamma \beta \tau_{f_{2}} V_{y S}-c_{S} & <\beta \tau_{f} V_{y S}-c_{S} \\
\beta\left(\tau_{f_{1}}+\gamma \tau_{f_{2}}\right) V_{y S} & <\beta\left(\tau_{f_{1}}+\tau_{f_{2}}\right) V_{y S} \\
\tau_{f_{1}}+\gamma \tau_{f_{2}} & >\tau_{f_{1}}+\tau_{f_{2}} \\
\gamma \tau_{f_{2}} & >\tau_{f_{2}} \\
\gamma & >1
\end{aligned}
$$

By definition, if $V_{y P}=V_{y S}$ then $\gamma>1$, therefore $E U_{S}(C \mid I \& N)<E U_{S}(\neg C \mid I \& N)$. If, instead, the president chooses to not fill the position immediately but still submits a nominee for Senate confirmation, the Senate prefers to not confirm the nominee only if the expected utility from rejecting the nominee outweighs the expected utility from confirmation:

$$
\begin{aligned}
E U_{S}(C \mid \neg I \& N) & <E U_{S}(\neg C \mid \neg I \& N) \\
\tau_{\neg f_{1}} V_{y S}+\gamma \beta \tau_{f_{2}} V_{y S}-c_{S} & <\tau_{\neg f} V_{y S}-c_{S} \\
\left(\tau_{\neg f_{1}}+\gamma \beta \tau_{f_{2}}\right) V_{y S} & <\left(\tau_{\neg f_{1}}-\tau_{f_{2}}\right) V_{y S} \\
\tau_{\neg f_{1}}+\gamma \beta \tau_{f_{2}} & >\tau_{\neg f_{1}}-\tau_{f_{2}} \\
\gamma \beta \tau_{f_{2}} & >-\tau_{f_{2}} \\
\gamma \beta & >-1
\end{aligned}
$$

By definition, $\beta \in(0,1]$ and if $V_{y P}=V_{y S}$ then $\gamma>1$; therefore $\gamma \beta>-1$ and $E U_{S}(C \mid \neg I \& N)<$ $E U_{S}(\neg C \mid \neg I \& N)$. This proves that given $V_{y P}=V_{y S}=-1$, the Senate has a dominant strategy to not confirm whenever the president submits a nominee.

Suppose now that Nature chooses a position $y \in Y$ that is high skilled, such that $s_{y}=1$ and from an agency with jurisdiction that aligns with the Senate's policy expansion priorities but the president prioritizes policy contraction such that position value $V_{y S}=1$ and $V_{y P}=-1$. If the president chooses to fill the position immediately and submit a nominee for Senate confir- 
mation, the Senate prefers to reject the nominee only if the expected utility from not confirming outweighs the expected utility from confirmation:

$$
\begin{aligned}
E U_{S}(C \mid I \& N) & <E U_{S}(\neg C \mid I \& N) \\
\beta \tau_{f_{1}} V_{y S}+\gamma \beta \tau_{f_{2}} V_{y S}-c_{S} & <\beta \tau_{f} V_{y S}-c_{S} \\
\beta\left(\tau_{f_{1}}+\gamma \tau_{f_{2}}\right) V_{y S} & <\beta\left(\tau_{f_{1}}+\tau_{f_{2}}\right) V_{y S} \\
\tau_{f_{1}}+\gamma \tau_{f_{2}} & <\tau_{f_{1}}+\tau_{f_{2}} \\
\gamma \tau_{f_{2}} & <\tau_{f_{2}} \\
\gamma & <1
\end{aligned}
$$

By definition, $\gamma<-1$ if $V_{y P} \neq V_{y S}$; therefore $\gamma<1$ and $E U_{S}(C \mid I \& N)<E U_{S}(\neg C \mid I \& N)$. If the president chooses to not fill the position immediately but still submits a nominee for Senate confirmation, the Senate prefers to reject the nominee only if the expected utility from rejection outweighs the expected utility from confirmation. Given that $V_{y S}=1$, the expected utility of returning the nominee is greater than that of confirmation only when $\gamma<-\frac{1}{\beta}$ :

$$
\begin{aligned}
E U_{S}(C \mid \neg I \& N) & <E U_{S}(\neg C \mid \neg I \& N) \\
\tau_{\neg f_{1}} V_{y S}+\gamma \beta \tau_{f_{2}} V_{y S}-c_{S} & >\tau_{\neg f} V_{y S}-c_{S} \\
\left(\tau_{\neg f_{1}}+\gamma \beta \tau_{f_{2}}\right) V_{y S} & >\left(\tau_{\neg f_{1}}-\tau_{f_{2}}\right) V_{y S} \\
\tau_{\neg f_{1}}+\gamma \beta \tau_{f_{2}} & <\tau_{\neg f_{1}}-\tau_{f_{2}} \\
\gamma \beta \tau_{f_{2}} & <-\tau_{f_{2}} \\
\gamma & <-\frac{1}{\beta}
\end{aligned}
$$

Thus, if $V_{y S}=1$ and $V_{y P}=-1$, the Senate will reject the president's nominee whenever an interim is also appointed $(p=I \& N)$ and, if an interim is not appointed $(p=\neg I \& N)$, only when $\gamma<-\frac{1}{\beta}$

Lastly, suppose that Nature chooses a position $y \in Y$ that is high skilled, such that $s_{y}=1$ 
and from an agency with jurisdiction that aligns with the president's policy expansion priorities but the Senate prioritizes policy contraction such that position value $V_{y S}=-1$ and $V_{y P}=1$. If the president chooses to not fill the position immediately but still submit a nominee for Senate confirmation, the Senate prefers to not confirm the nominee only if the expected utility from rejection outweighs the expected utility from confirmation. Given that $V_{y S}=-1$, the expected utility of confirmation is greater than that of rejection only when $\gamma>-\frac{1}{\beta}$ :

$$
\begin{aligned}
E U_{S}(C \mid \neg I \& N) & <E U_{S}(\neg C \mid \neg I \& N) \\
\tau_{\neg f_{1}} V_{y S}+\gamma \beta \tau_{f_{2}} V_{y S}-c_{S} & <\tau_{\neg f} V_{y S}-c_{S} \\
\left(\tau_{\neg f_{1}}+\gamma \beta \tau_{f_{2}}\right) V_{y S} & <\left(\tau_{\neg f_{1}}-\tau_{f_{2}}\right) V_{y S} \\
\tau_{\neg f_{1}}+\gamma \beta \tau_{f_{2}} & >\tau_{\neg f_{1}}-\tau_{f_{2}} \\
\gamma \beta \tau_{f_{2}} & >-\tau_{f_{2}} \\
\gamma & >-\frac{1}{\beta}
\end{aligned}
$$

Thus, if $V_{y S}=-1$ and $V_{y P}=1$, the Senate will reject a nominee (prefer an empty post) if an interim is not appointed $(p=\neg I \& N)$ only when $\gamma>-\frac{1}{\beta}$.

Proof for Lemma 3. Since I have structured this model as a sequential game, I employ a Subgame Perfect Nash Equilibrium concept. Let us examine the president's pure strategy choice given $V_{y i}$ and the Senate's strategies for confirming and rejecting a nominee.

First, suppose Nature chooses a position $y \in Y$ that is high skilled, such that $s_{y}=1$ and from an agency with jurisdiction that aligns with both players policy expansion priorities such that position value $V_{y P}=V_{y S}=1$. Anticipating that the Senate plays a dominant strategy of confirming whenever a nomination is tendered, the president chooses to submit a nominee after filling the position immediately with an interim appointee only if the expected utility from the nominee's confirmation outweighs the expected utility from not having submitted a nominee 
(with the outcome being an interim appointee). Given that $V_{y P}=V_{y S}=1$ and $\gamma>1$, the expected utility of nominating what will be a confirmed appointee is greater than not nominating only when $c_{P}<(\gamma-1) \beta \tau_{f_{2}} V_{y P}$ :

$$
\begin{aligned}
E U_{P}(I \& N \mid C) & >E U_{P}(I \& \neg N \mid C) \\
\beta \tau_{f_{1}} V_{y P}+\gamma \beta \tau_{f_{2}} V_{y P}-c_{P} & >\beta \tau_{f} V_{y P} \\
\beta \tau_{f_{1}} V_{y P}+\gamma \beta \tau_{f_{2}} V_{y P}-c_{P} & \left.>\beta \tau_{f_{1}} V_{y P}+\beta \tau_{f_{2}}\right) V_{y P} \\
\gamma \beta \tau_{f_{2}} V_{y P}-c_{P} & \left.>\beta \tau_{f_{2}}\right) V_{y P} \\
\left.\gamma \beta \tau_{f_{2}} V_{y P}-\beta \tau_{f_{2}}\right) V_{y P} & >c_{P} \\
(\gamma-1) \beta \tau_{f_{2}} V_{y P} & >c_{P}
\end{aligned}
$$

Thus, if $V_{y P}=V_{y S}=1$ and given the Senate's dominant strategy to confirm, if the president appoints an interim official immediately he will also submit a nominee for Senate confirmation only when $c_{P}<(\gamma-1) \beta \tau_{f_{2}} V_{y P}$.

Alternatively, the president chooses to submit a nominee after not filling the position immediately only if the expected utility from the nominee's confirmation outweighs the expected utility of not submitting a nominee and maintaining the empty post. Given that $V_{y P}=V_{y S}=1$ and $\gamma>1$, the expected utility of nominating what will be a confirmed appointee is greater than not nominating only when $c_{P}<(\gamma \beta+1) \tau_{f_{2}} V_{y P}$ :

$$
\begin{aligned}
& E U_{P}(\neg I \& N \mid C)>E U_{P}(\neg I \& \neg N \mid C) \\
& \tau_{\neg f_{1}} V_{y P}+\gamma \beta \tau_{f_{2}} V_{y P}-c_{P}>\tau_{\neg f} V_{y P} \\
& \tau_{\neg f_{1}} V_{y P}+\gamma \beta \tau_{f_{2}} V_{y P}-c_{P}>\left(\tau_{\neg f_{1}}-\tau_{f_{2}}\right) V_{y P} \\
& \tau_{\neg f_{1}} V_{y P}+\gamma \beta \tau_{f_{2}} V_{y P}-c_{P}>\tau_{\neg f_{1}} V_{y P}-\tau_{f_{2}} V_{y P} \\
& \gamma \beta \tau_{f_{2}} V_{y P}+\tau_{f_{2}} V_{y P}>c_{P} \\
&(\gamma \beta+1) \tau_{f_{2}} V_{y P}>c_{P}
\end{aligned}
$$


Thus, if $V_{y P}=V_{y S}=1$ and given the Senate's dominant strategy to confirm, if the president does not appoint an interim official immediately he will submit a nominee for Senate confirmation only when $c_{P}<(\gamma \beta+1) \tau_{f_{2}} V_{y P}$.

Since $(\gamma-1) \beta \tau_{f_{2}} V_{y P}<(\gamma \beta+1) \tau_{f_{2}} V_{y P}$, to consider the choice between filling a position immediately or not, with the anticipation of submitting a nominee, assume $c_{P}<(\gamma-1) \beta \tau_{f_{2}} V_{y P}$ as the maximal condition. Given $c_{P}<(\gamma-1) \beta \tau_{f_{2}} V_{y P}$ and that a nominee will be submitted and confirmed, the president chooses to fill the position immediately with an interim only if the expected utility from the confirmed nominee with an interim appointee outweighs the expected utility from the confirmed nominee without an interim appointee:

$$
\begin{aligned}
E U_{P}(I \& N \mid C) & >E U_{P}(\neg I \& N \mid C) \\
\beta \tau_{f_{1}} V_{y P}+\gamma \beta \tau_{f_{2}} V_{y P}-c_{P} & >\tau_{\neg f_{1}} V_{y P}+\gamma \beta \tau_{f_{2}} V_{y P}-c_{P} \\
\left(\beta \tau_{f_{1}}+\gamma \beta \tau_{f_{2}}\right) V_{y P} & >\left(\tau_{\neg f_{1}}+\gamma \beta \tau_{f_{2}}\right) V_{y P} \\
\beta \tau_{f_{1}}+\gamma \beta \tau_{f_{2}} & >\tau_{\neg f_{1}}+\gamma \beta \tau_{f_{2}} \\
\beta \tau_{f_{1}} & >-\tau_{f_{1}} \\
\beta & >-1
\end{aligned}
$$

By definition, $\beta \in(0,1]$, therefore $\beta>-1$ and $E U_{P}(I \& N \mid C)>E U_{P}(\neg I \& N \mid C)$. This proves that, given $V_{y P}=V_{y S}=1, c_{P}<(\gamma-1) \beta \tau_{f_{2}} V_{y P}$ and anticipating the Senate's dominant strategy to confirm, the president will prefer to fill the position immediately with an interim appointee and also submit a nominee for Senate confirmation $(p=I \& N)$.

Alternatively, if $c_{P}>(\gamma-1) \beta \tau_{f_{2}} V_{y P}$ the president will prefer to not submit a nominee for Senate confirmation. Given $V_{y P}=V_{y S}=1$ and that a nominee will not be submitted, the president chooses to fill the position immediately with an interim only if the expected utility from the interim appoint outweighs the expect utility from maintaining an empty position (not filling the position immediately): 


$$
\begin{aligned}
E U_{P}(I \& \neg N \mid C) & >E U_{P}(\neg I \& \neg N \mid C) \\
\beta \tau_{f} V_{y P} & >\tau_{\neg f} V_{y P} \\
\beta \tau_{f} & >-\tau_{f} \\
\beta & >-1
\end{aligned}
$$

By definition, $\beta \in(0,1]$, therefore $\beta>-1$ and $E U_{P}(I \& \neg N \mid C)>E U_{P}(\neg I \& \neg N \mid C)$. This proves that, given $V_{y P}=V_{y S}=1, c_{P}>(\gamma-1) \beta \tau_{f_{2}} V_{y P}$, and the anticipation of Senate confirmation, the president will prefer to fill the position immediately with an interim appointee but not submit a nominee for Senate confirmation $(p=I \& \neg N)$.

Now suppose Nature chooses a position $y \in Y$ that is high skilled, such that $s_{y}=1$ and from an agency with jurisdiction that aligns with the president's policy expansion priorities but the Senate prioritizes policy contraction such that position value $V_{y S}=-1$ and $V_{y P}=1$. Anticipating that the Senate confirms a nominee if an interim is appointed, the president chooses to not submit a nominee after filling the position immediately only if its expected utility outweighs that from a nominee's confirmation. Given that $V_{y P} \neq V_{y S}$ and $\gamma<-1$, the expected utility of not nominating what will be a confirmed appointee after appointing an interim appointee is greater than nominating:

$$
\begin{aligned}
E U_{P}(I \& N \mid C) & <E U_{P}(I \& \neg N \mid C) \\
\beta \tau_{f_{1}} V_{y P}+\gamma \beta \tau_{f_{2}} V_{y P}-c_{P} & <\beta \tau_{f} V_{y P} \\
\beta \tau_{f_{1}} V_{y P}+\gamma \beta \tau_{f_{2}} V_{y P}-c_{P} & \left.<\beta \tau_{f_{1}} V_{y P}+\beta \tau_{f_{2}}\right) V_{y P} \\
\gamma \beta \tau_{f_{2}} V_{y P}-c_{P} & \left.<\beta \tau_{f_{2}}\right) V_{y P} \\
\left.\gamma \beta \tau_{f_{2}} V_{y P}-\beta \tau_{f_{2}}\right) V_{y P} & <c_{P} \\
(\gamma-1) \beta \tau_{f_{2}} V_{y P} & <c_{P}
\end{aligned}
$$

By definition, $\gamma<-1$ and $\beta \in(0,1]$ which establishes that $(\gamma-1) \beta \tau_{f_{2}} V_{y P}<0$ and $c_{P}>0$; 
therefore $E U_{P}(I \& N \mid C)<E U_{P}(I \& \neg N \mid C)$. Alternatively, anticipating that the Senate confirms a nominee if an interim is not appointed only when $\gamma<-\frac{1}{\beta}$, the president chooses to not submit a nominee after not filling the position immediately (maintaining the empty post) only if its expected utility outweighs that from a nominee's confirmation. Given that $V_{y P} \neq V_{y S}$ and $\gamma<-1$, the expected utility of not nominating what will be a confirmed appointee after not appointing an interim appointee is greater than nominating:

$$
\begin{aligned}
E U_{P}(\neg I \& N \mid C) & <E U_{P}(\neg I \& \neg N \mid C) \\
\tau_{\neg f_{1}} V_{y P}+\gamma \beta \tau_{f_{2}} V_{y P}-c_{P} & <\tau_{\neg f} V_{y P} \\
\tau_{\neg f_{1}} V_{y P}+\gamma \beta \tau_{f_{2}} V_{y P}-c_{P} & <\tau_{\neg f_{1}} V_{y P}-\tau_{f_{2}} V_{y P} \\
\gamma \beta \tau_{f_{2}} V_{y P}-c_{P} & <-\tau_{f_{2}} V_{y P} \\
\gamma \beta & <-1 \\
\gamma & <-\frac{1}{\beta}
\end{aligned}
$$

By definition, $\gamma<-\frac{1}{\beta}$; therefore $E U_{P}(\neg I \& N \mid C)<E U_{P}(\neg I \& \neg N \mid C)$. Thus, given $V_{y S}=-1$ and $V_{y P}=1$ and the Senate's confirmation strategies, the president prefers to not submit a nominee whether he fills the position immediately or not. Given that the president will not submit a nominee, he prefers to fill the position immediately only if the expected utility of having the interim appointee outweighs the expected utility of maintaining the empty position:

$$
\begin{aligned}
E U_{P}(I \& \neg N \mid C) & >E U_{P}(\neg I \& \neg N \mid C) \\
\beta \tau_{f} V_{y P} & >\tau_{\neg f} V_{y P} \\
\beta \tau_{f} & >-\tau_{f} \\
\beta & >-1
\end{aligned}
$$

By definition, $\beta \in(0,1]$, therefore $\beta>-1$ and $E U_{P}(I \& \neg N \mid C)>E U_{P}(\neg I \& \neg N \mid C)$. This proves that, given $V_{y S}=-1$ and $V_{y P}=1$ and the anticipation of Senate confirmation, the 
president will prefer to fill the position immediately with an interim appointee but not submit a nominee for Senate confirmation $(p=I \& \neg N)$.

Furthermore, suppose Nature chooses a position $y \in Y$ that is high skilled, such that $s_{y}=1$ and from an agency with jurisdiction that aligns with both players policy contraction priorities such that position value $V_{y P}=V_{y S}=-1$. Anticipating that the Senate plays a dominant strategy of not confirming whenever a nomination is tendered, the president chooses to not submit a nominee after filling the position immediately with an interim appointee only if its expected utility outweighs that of the nominee's rejection. Given that $V_{y P}=V_{y S}=-1$ and $\gamma>1$, the expected utility of not submitting a nominee is greater than for submitting what will be a returned nominee:

$$
\begin{aligned}
E U_{P}(I \& \neg N \mid \neg C) & >E U_{P}(I \& N \mid \neg C) \\
\beta \tau_{f} V_{y P} & >\beta \tau_{f} V_{y P}-c_{P} \\
c_{P} & >0
\end{aligned}
$$

By definition, $c_{P}>0$ therefore $E U_{P}(I \& \neg N \mid \neg C)>E U_{P}(I \& N \mid \neg C)$. Again, anticipating the Senate's dominant strategy of not confirming whenever a nomination is tendered, the president chooses to not submit a nominee after not filling the position immediately only if its expected utility outweighs that from the nominee's rejection outweighs. Given that $V_{y P}=V_{y S}=-1$ and $\gamma>1$, the expected utility of not submitting a nominee is greater than that for nominating what will be a returned nominee:

$$
\begin{aligned}
E U_{P}(\neg I \& \neg N \mid \neg C) & >E U_{P}(\neg I \& N \mid \neg C) \\
\tau_{\neg f} V_{y P} & >\tau_{\neg f} V_{y P}-c_{P} \\
c_{P} & >0
\end{aligned}
$$

By definition, $c_{P}>0$, therefore $E U_{P}(\neg I \& \neg N \mid \neg C)>E U_{P}(\neg I \& N \mid \neg C)$. Lastly, consider the 
choice the president must make to fill the position immediately or not, given that he prefers to not submit a nominee in both scenarios. In this case, the president prefers to not fill the position immediately if the expected utility from the empty position outweighs that from the position filled by an interim, given that $V_{y P}=-1$ :

$$
\begin{aligned}
E U_{P}(\neg I \& \neg N \mid \neg C) & >E U_{P}(I \& \neg N \mid \neg C) \\
\tau_{\neg f} V_{y P} & >\beta \tau_{f} V_{y P} \\
-\tau_{f} V_{y P} & >\beta \tau_{f} V_{y P} \\
\beta & >-1
\end{aligned}
$$

By definition, $\beta \in(0,1]$ therefore $\beta>-1$ and $E U_{P}(\neg I \& \neg N \mid \neg C)>E U_{P}(I \& \neg N \mid \neg C)$. This proves that, given $V_{y S}=V_{y P}=-1$ and the anticipation of Senate rejection, the president will prefer to maintain an empty post by filling not the position immediately with an interim appointee and not submit a nominee for Senate confirmation $(p=\neg I \& \neg N)$.

Lastly, suppose Nature chooses a position $y \in Y$ that is high skilled, such that $s_{y}=1$ and from an agency with jurisdiction that aligns with the Senate's policy expansion priorities but the president prioritizes policy contraction such that position value $V_{y S}=1$ and $V_{y P}=-1$. Anticipating that the Senate only confirms a nominee if an interim is not appointed and $\gamma>-\frac{1}{\beta}$, the president chooses to not submit a nominee after not filling the position immediately only if its expected utility outweighs that from a nominee's confirmation. Given that $V_{y P} \neq V_{y S}$ and $\gamma<-1$, the expected utility of not nominating what will be a confirmed appointee after not appointing an interim appointee is greater than nominating: 


$$
\begin{aligned}
E U_{P}(\neg I \& \neg N \mid C) & >E U_{P}(I \& \neg N \mid C) \\
\tau_{\neg f} V_{y P} & >\tau_{\neg f} V_{y P}+\gamma \beta \tau_{f_{2}} V_{y P}-c_{P} \\
\tau_{\neg f_{1}} V_{y P}-\tau_{f_{2}} V_{y P} & >\tau_{\neg f} V_{y P}+\gamma \beta \tau_{f_{2}} V_{y P}-c_{P} \\
-\tau_{f_{2}} V_{y P} & >\gamma \beta \tau_{f_{2}} V_{y P}-c_{P} \\
c_{P} & >\gamma \beta \tau_{f_{2}} V_{y P}+\tau_{f_{2}} V_{y P} \\
c_{P} & >\tau_{f_{2}} V_{y P}(\gamma \beta+1)
\end{aligned}
$$

Given that $\gamma>-\frac{1}{\beta}$ then $\gamma \beta>-1$ and $V_{y P}=-1, \tau_{f_{2}} V_{y P}(\gamma \beta+1)<0$. By definition, $c_{P}>0$ so $c_{P}>\tau_{f_{2}} V_{y P}(\gamma \beta+1)$ and therefore $E U_{P}(\neg I \& \neg N \mid C)>E U_{P}(I \& \neg N \mid C)$.

Alternatively, anticipating that the Senate will not confirm a nominee if an interim has been appointed, the president chooses to not submit a nominee after appointing an interim only if the expected utility of not submitting a nominee outweighs the expected utility of a Senate rejection:

$$
\begin{aligned}
E U_{P}(I \& \neg N \mid \neg C) & >E U_{P}(I \& N \mid \neg C) \\
\beta \tau_{f} V_{y P} & >\beta \tau_{f} V_{y P}-c_{P} \\
c_{P} & >0
\end{aligned}
$$

By definition $c_{P}>0$, therefore $E U_{P}(I \& \neg N \mid \neg C)>E U_{P}(I \& N \mid \neg C)$. Given $V_{y P}=-1$, the president prefers to not fill the position immediately and not submit a nominee (maintain the empty post) if its expected utility outweighs the expected utility of filling the position immediately and not submitting a nominee:

$$
\begin{aligned}
E U_{P}(\neg I \& \neg N \mid \neg C) & >E U_{P}(I \& \neg N \mid \neg C) \\
\tau_{\neg f} V_{y P} & >\beta \tau_{f} V_{y P} \\
-\tau_{f} & <\beta \tau_{f} \\
\beta & >-1
\end{aligned}
$$


By definition, $\beta \in(0,1]$ therefore $\beta>-1$ and $E U_{P}(\neg I \& \neg N \mid \neg C)>E U_{P}(I \& \neg N \mid \neg C)$. This proves that, given $V_{y S}=1$ and $V_{y P}=-1$ and the Senate's confirmation strategy, the president will prefer to maintain an empty post by filling not the position immediately and not submitting a nominee for Senate confirmation $(p=\neg I \& \neg N)$.

Proof for Proposition 1. Suppose Nature chooses a position $y \in Y$ that is high skilled, such that $s_{y}=1$ and from an agency with jurisdiction that aligns with the president's policy contraction priorities such that position value $V_{y P}=-1$. From Lemma 1 and Lemma 2: If $V_{y S}=1$

and $\gamma>-\frac{1}{\beta}$, the Senate will confirm when the president submits a nominee without immediately filling the position with an interim appointee; If $V_{y S}=1$ and $\gamma<-\frac{1}{\beta}$, the Senate will not confirm when the president submits a nominee without immediately filling the position with an interim appointee; If $V_{y S}=-1$, the Senate has a dominant strategy to not confirm when the president submits a nominee regardless of whether the position has an interim appointee.

Given the Senate's confirmation strategy, from Lemma 3 the president chooses not to fill the position immediately and not to submit a nominee $(p=\neg I \& \neg N)$ regardless of $V_{y S}$, leading to the outcome of an empty post. Moreover, from Lemma 2, an empty post arises when, given $V_{y S}=-1, V_{y P}=1$, and $\gamma>-\frac{1}{\beta}$, the Senate does not confirm the president's nominee when the president does not appoint an interim appointee $(p=\neg I \& N)$. However, Lemma 3 proves that $p=\neg I \& N$ is not contained within the set of optimal strategies. Thus, the vacant position $y$ will stay empty in equilibrium if and only if the position is high-skilled $\left(s_{y}=1\right)$ and the president $P$ prioritizes policy contraction $\left(V_{y P}=-1\right)$.

\subsection{Central Empirical Hypotheses}

The model's equilibrium solution generates four sets of empirical predictions related to $\mathrm{Po}$ sition Value, Position Capacity, and Policy Priorities. First, empty positions occur either when 
the president chooses not to appoint an interim and also not nominate, or when the president chooses to nominate without appointing an interim but the Senate does not confirm the nominee. Through backward induction, we can mathematically derive the conditions - captured by the equations leading to Proposition 1 - under which the president chooses these strategies: a high value position with contraction presidential policy priorities will not be filled by either an interim or confirmed appointee - it will be empty - when the game ends. In other words, when a president prioritizes policy contraction, positions with high levels of capacity will stay empty, as the president will not appoint an interim or nominate a permanent appointee. ${ }^{17}$

As expected, the president's first-mover advantage manifests as dictatorial control over empty positions. It is important to note that when a president chooses to keep a position empty, the position is high capacity. These positions have the most potential for advancing policy priorities but also have real-world consequences for agency performance and policy outcomes when left empty. This implies that widespread empty posts are not among low-level, heavily administrative PAS positions, but rather among exactly those positions that need to be filled for a functioning agency. These conditions yield the theory's first testable hypothesis:

H1. Empty Position Hypothesis: A president is more likely to leave high value positions empty when prioritizing policy contraction.

Second, consider the outcome of an interim appointee. Interim appointees can occur when the president chooses to appoint one either without submitting a nominee or with a nominee that the Senate does not confirm. Again, through backward induction, I find that the president chooses to appoint interims, in equilibrium, to all low-value positions - which amounts to low-capacity positions across all policy priorities and high-capacity positions when the president has neutral policy priorities - and to high-value positions when prioritizing policy expansion. Importantly,

\footnotetext{
${ }^{17}$ When the president prioritizes contracting policy, the Senate will not confirm nominees for high-value positions. In other words, anticipating the Senate's pure strategy to return a nominee and end the game with an empty position, the president prefers to avoid the bargaining cost of appointment negotiations, forgo submitting a nominee entirely and arrive at the same result of an empty position. Low-capacity positions, on the other hand, will be filled with interim appointees when the president prioritizes contraction, but no nominee will be submitted.
} 
these conditions continue to highlight the president's first-mover advantage over vacancies in agency appointments and the endogenous reversion point that is created. The president's choice to fill a position immediately with an interim appointee (or not) does not explicitly depend on the Senate's policy priorities or on the Senate's confirmation strategy. Instead, when a president seeks to expand the reach of an agency, he fills all vacant PAS positions with interim appointees. This suggests that as policy agendas are increasingly dominated by expansion priorities, the use of interim appointees will also increase. These conditions generate the theory's second testable hypothesis:

H2. Interim Appointee Hypothesis: A president will always immediately fill low-value positions with interim appointees, and is more likely to immediately fill high-value positions with interims when prioritizing policy expansion.

Lastly, the remaining outcome of the model - and of the president's expanded choice set - is a permanent, confirmed appointee. Importantly, permanent appointees structurally occur if and only if the president chooses to submit a nominee for confirmation. However, the president's rational nomination strategy must anticipate the Senate's strategy for confirmation. When the Senate is presented with a nominee, given the reversion point of an interim or empty positions, confirmation occurs under four sets of circumstances.

First, the Senate confirms high-capacity positions when the president and Senate both prioritize policy expansion, no matter the reversion point. In other words, when the president and Senate both support a policy area (for example, understanding the likelihood of large scale natural disasters due to climate change) and the vacant position is high capacity (i.e., the Director of the U.S. Geological Survey), the Senate will confirm the president's nominee. This result supports an expected scenario: when both players prioritize strengthening policy under the jurisdiction of a high-capacity position that affords an appointee the discretion to meet those goals, the Senate will always confirm the president's nominee. ${ }^{18}$

\footnotetext{
${ }^{18}$ Additionally, the Senate might also engage in speedy confirmation proceedings to ensure the sufficiently low
} 
Second, when the Senate prioritizes policy contraction but the president prioritizes policy expansion, the Senate confirms high-capacity positions if an interim has been appointed; if the position is empty, the Senate will confirm only if the nominee is relatively ineffective and the Senate's anticipated degree of oversight is sufficiently large. In this case, the Senate and the president are at odds in their priorities for a position that has the capacity to effect policy change. With an interim appointee from a president who prioritizes policy expansion, the Senate faces an unfavorable reversion point without the benefit of oversight from confirmation. ${ }^{19}$ The Senate, under these circumstances, would be better served to acquiesce with the advantage of oversight than to contend with an interim appointee without the institutional constraints of confirmation. Alternatively, without an interim appointee, the Senate faces an empty post as the reversion point. Given the high capacity position, the Senate intuitively prefers leaving the post empty than confirming an effective nominee from a president who seeks to expand policy. ${ }^{20}$

Third, when the reversion point is an empty position and the president prioritizes policy contraction but the Senate prioritizes policy expansion, the Senate will confirm a nominee to high capacity position only if the anticipated tenure, and corresponding oversight, of the permanent appointee is sufficiently small. Conceptually, oversight that obstructs or delays agency actions - as occurs when the Senate prefers policy contraction over expansion - requires less political capital and intervention than oversight that demands action. The capacity to achieve the Senate's expansion priorities diminishes when higher levels of costly oversight are necessary. Lastly, the Senate confirms the president's nominee to all low value positions, whether due to low capacity

bargaining cost necessary to incentivize the nominations from the president; however the duration of confirmation is outside the scope of this paper.

${ }^{19} \mathrm{~A}$ recent, fitting example of this comes from the Obama administration. Senator Lamar Alexander (R-Tenn.) urged and largely facilitated the confirmation of Obama's then-Acting Secretary of Education John B. King, Jr. in 2016 to ensure that the Senate would have proper oversight over implementation of the Every Student Succeeds Act. Senate Republicans were particularly worried that the Obama administration would attempt to overreach executive authority and would have less accountability to Congress with an interim appointee (Brown, 2016).

${ }^{20}$ However, the Senate has an oversight incentive to confirm if the nominee is ineffective and appointee's tenure is sufficiently long to allow for oversight activities. On the other hand, the Senate will confirm a relatively effective nominee only if the tenure of that permanent appointee is sufficiently small. 
or neutral Senate policy priorities.

Anticipating these choices, the president nominates only for high policy capacity positions when prioritizing policy expansion and after filling the vacancy immediately with an interim appointee. Given the conditions of confirmation listed above, the Senate will confirm only when also prioritizing expansion or when policy neutral (the position is low value). With the position filled by an interim appointee, the president chooses to nominate only when the bargaining cost of confirmation is sufficiently low. This cost is largely driven by the magnitude of Senate's parameter for the anticipated degree of oversight. High values of this parameter set by circumstances like speedy confirmation hearings create opportunities for the president's bargaining costs to fall below his cut-point and incentivize a nomination for the Senate to confirm. This is formally stated as Corollary 2 and presented here as Hypothesis 3:

H3. Permanent Appointee Hypothesis: Confirmed appointees are more likely in high value PAS positions when the president prioritizes expansion, the Senate does not prioritize contraction, and the bargaining cost is sufficiently small (below the president's cutpoint).

The final hypothesis derives from an ancillary results obtained in the equilibrium solution. Namely, although the choice to not fill a position immediately with an interim appointee and then submit a nominee exists in the president's strategy space, it drops out of the optimal set. Thus, we would expect that presidents do not submit a nominee without also appointing an interim, as stated in Hypothesis 4:

H4. No Nominee Hypothesis: Presidents will not submit a nominee for confirmation without also appointing an interim appointee.

Most interestingly, when presidents prioritize policy contraction for agencies, they will not submit a nominee for confirmation. In these cases, presidents immediately fill low-capacity positions with interim appointees but high-capacity positions stay empty, even when the Senate agrees with contraction. The notable implication is that if a president prefers to shrink the policy reach of an agency, persistently empty high capacity positions, without nominees awaiting 
confirmation, will occur even in unified government. Thus, we would expect that, all else equal, the combination of high capacity and contraction priorities (high value, contraction positions) significantly increases the likelihood it remains empty. Additionally, this theory recognizes that a vacant position can be filled by a confirmed appointee, an interim appointee, or both. ${ }^{21}$ This model predicts that when the Senate and the president have conflicting priorities, contraction and expansion respectively, presidents will only appoint an interim and not submit a nominee.

Table 4.1: Predicted Appointment Strategy Outcomes and Position Value

President's Position Value

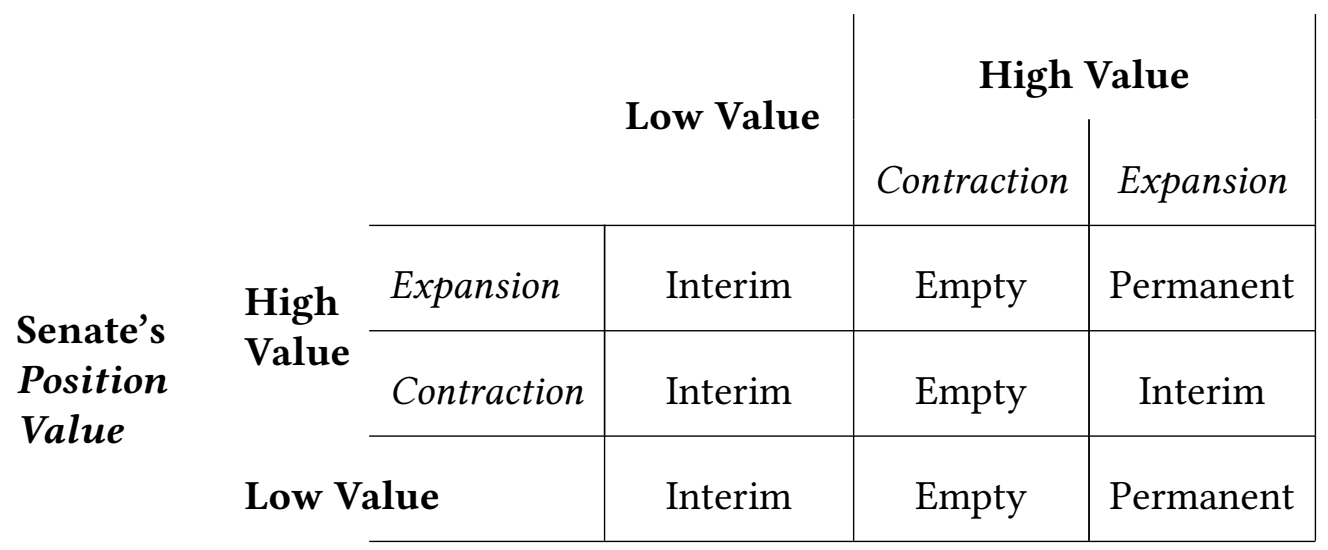

Taken together, these four hypotheses predict that presidents are more likely to leave positions empty that are "High Value (contraction)," are more likely to appoint interims to positions that are "High Value (expansion)," and are more likely to appoint (nominate) permanent appointees to positions that are "High Value (expansion)" when the Senate does not prioritize contraction. Table 4.1 highlights how the interaction between Position Value to the president and to the Senate produces these three various outcomes, which form the theoretical basis for my empirical strategy. In the chapters that follow, I test these hypotheses by estimating several likelihood and count models using original data - which I introduce in detail at the start of the next

\footnotetext{
${ }^{21}$ Importantly, a vacant position filled by both an interim appointee and a permanent appointee would be filled first by the interim (before confirmation of a submitted nominee) and then by the permanent appointee (after confirmation).
} 
chapter - on vacancies, position capacity, and policy priorities.

\subsection{Discussion}

This chapter offers one of the first attempts to theoretically integrate interim appointees and empty posts into a framework of executive-legislative bargaining over political control of the bureaucracy. This theory of appointments incorporates the Senate's prerogative to reject a nomination and the president's power to choose not to submit one in the first place, while accounting for the value of positions and the varying effectiveness of appointees in attaining that value. As a result, this model offers novel, important implications for bargaining between Congress and the president, as well as for how presidents manage the administrative state.

Most interestingly, when presidents prioritize policy contraction for agencies, they will not submit a nominee for confirmation. In these cases, presidents immediately fill low-capacity positions with interim appointees but high-capacity positions stay empty, even when the Senate agrees with retrenchment. The notable implication is that if a president prefers to shrink the policy reach of an agency, persistently empty high-capacity positions, without nominees awaiting confirmation, will occur even in unified government. Thus, we would expect that, all else equal, the interaction of high policy control capacity and contraction priorities significantly decreases a position's likelihood of a nominee while increasing the likelihood it remains empty.

A second, and related, implication is that greater policy complexity requiring higher levels of expertise, and consequently more high-capacity positions, will lead to more empty positions in a larger administrative retrenchment presidency. In other words, as agency jurisdictions subsume complex policy areas (e.g., commerce and the Internet) or as policy areas themselves grow more complex (e.g., healthcare), we would expect increases in the set of high-capacity positions as well as higher proportions of empty positions under presidents with contraction priorities. Thus, as Congress responds to a more complex reality by increasing the capacity of the administrative 
state, it ironically creates more incentive for retrenchment presidents to invest in incapacity. Importantly, conventional wisdom from scores of delegation models suggests that, when policy complexity and uncertainty require higher levels of expertise, legislators must manage the tension between discretion and drift. This assumes the delegate position will be filled by an appointee whose ideology or ambitions must be controlled to minimize drift. Strikingly, the model offered here highlights conditions under which there still may be drift, but no appointee to control.

Third, this theory, at the outset, recognizes that a vacant position can be filled by a confirmed appointee, an interim appointee, or both. The last category alludes to overlapping conditions under which presidents fill immediately with an interim and submit a nominee; and the equilibrium results indicate these conditions hinge on the bargaining cost of the confirmation process. In other words, when the cost of confirmation is below the president's cutpoint, a president who prioritizes expansion will submit a nominee; otherwise the president will rely on an interim only. Since existing literature does not explicitly identify interim appointees, we have few current expectations. However, we could imagine that divided government - when conflicting policy priorities across branches make confirmation difficult - or increased polarization - when conflicting policy priorities within the Senate make collective action towards confirmation difficult - likely make an interim appointee a more attractive option. Indeed, this model predicts that when the Senate and the president have conflicting priorities, contraction and expansion respectively, presidents will only appoint an interim and not submit a nominee. In other words, the likelihood of an interim-only outcome increases if the president's priorities conflict with those of the Senate.

However, when the Senate and the president are aligned on priorities, nomination still requires a sufficiently low bargaining cost, largely driven by the value the Senate sets for the permanence and oversight parameter. The notable implication here is that easing the procedural burden of confirmation or oversight of a confirmed appointee lead to higher values of the permanence and oversight parameter and lower bargaining costs, all else equal. Thus, we would expect that institutional changes like going nuclear with filibusters on all PAS positions or changing con- 
gressional capacity for oversight will increase the frequency of nominees submitted by presidents who prioritize policy expansion and have appointed interims to high-capacity positions. 


\section{CHAPTER V}

\section{Introducing the Data and Explaining the Likelihood of Vacancies and Appointments}

The theory presented in Chapter 4 stands as the first to incorporate interim appointees and empty positions into a framework of executive-legislative bargaining over presidential appointments. It has its own set of contributions; namely, broadening our theoretical approach to appointments beyond the limited focus on the individuals selected for formal nominations. However, I developed the framework in service of disciplining a new set of empirical analyses. Since we had not previously theoretically differentiated between vacancies left empty and those filled by interim appointees, we had little motivation for any empirical assessments of their frequency, patterns of occurrence across administrations and departments, or strategic underpinnings.

Given that we now have a set of theoretical expectations, we can advance on the analyses designed to discover whether presidents' policy priorities influence how they manage vacancies in appointments. In doing so, this project also stands as the first empirical work on interim appointments and empty positions. For that reason, I collected an entirely new dataset to construct the requisite outcome and explanatory variables, which include my theory's three key measures: the status of a PAS position (whether it is empty, filled with an interim appointee or filled with a permanent appointee, and whether there is a nominee awaiting Senate confirmation), the level 
of each position's capacity to control policy outcomes, and the policy priorities (i.e., expansion, contraction, or neutrally maintaining the status quo) of the president and the Senate. The combination of the latter two produces the measure of Position Value.

This new dataset is the most comprehensive one to date on appointments to and vacancies in PAS positions and requires a thorough description of my collection and measurement approaches as well as a summary of the raw data itself. Consequently, this chapter proceeds as follows. First, before presenting the core of my analysis, I begin with an introduction of this new data on vacancies. Section 1 details my data collection effort and summarizes each of the key variables in my analysis. Importantly, I construct two distinct versions of the dependent variable, Position Status. The first indicates whether a position is empty, filled by an interim appointee, or filled by a confirmed appointee, as reported in the Government Manual from 1977-2015. The second dissects the two vacancy categories to identify if a nomination was under Senate consideration when the position's status was published in the Government Manual. This creates five categories (i.e., empty position with nominee, empty position without nominee, interim appointee with nominee, interim appointee without nominee, and permanent appointee) and offers a more precise alignment with the full set of outcomes described in my theoretical model. However, the data on nominations available from Congress.gov - included in the second analysis - span only 1981-2015, which removes the Carter administration from the analysis. ${ }^{1}$ Consequently, I use both variable constructions in two separate analyses.

With this extensive and carefully constructed data, I can examine whether the patterns highlighted in my theoretical predictions bear out empirically. Notably, the hypotheses outlined in Chapter 4 (Section 4) lend themselves to three complementary tests using this data: nonparametric cross-tabulations of distributions, likelihood models of each position status, and count models of the incidence of each position status across departments. Analyzing the patterns dis-

\footnotetext{
${ }^{1}$ As shown in Section 2.2, the estimated likelihood models with the two constructions of Position Status yield similar and consistent results.
} 
played in the cross-tabulations in the context of the two parametric models allows for formal statistical inference about the role Position Value plays in a president's calculus to fill or not fill vacant positions. In Section 2 of this chapter, I present the results of the non-parametric tests, an outline of my first estimation strategy for the multinomial probit regression analysis, and the results of these likelihood models estimated on each of the two versions of Position Status. I reserve the outline of my second estimation strategy and the results of the count models for Chapter 7. Lastly, Section 3 offers a discussion of the findings and their limitations.

\subsection{Introducing New Data on Vacancies and Appointments}

\subsubsection{Measuring Position Status}

To systematically and quantitatively understand how and when vacancies in presidential appointments occur, I collected data on the status of PAS positions from Carter to Obama. The dataset covers PAS positions ${ }^{2}$ in all fifteen Executive departments (Agriculture, Commerce, Defense, Education, Energy, Health and Human Services, Housing and Urban Development, Homeland Security, Interior, Justice, Labor, State, Transportation, Treasury, and Veterans Affairs) from $1977-2015 .^{3}$

To identify whether a position is filled or empty, and specifically to differentiate between interim and permanent appointees, I rely on government published directories of PAS positions. With the help of a research assistant, using optical character recognition (OCR) software, I digitized data from archived editions of the quadrennial publication United States Government Policy

\footnotetext{
${ }^{2}$ The analysis here excludes United States Marshals, United States Attorneys, or United States Ambassadors, as they are appointments distinct from other Executive department PAS positions and they can be filled through varied processes. For instance, individuals can be selected to temporarily fill empty U.S. Attorney positions by their respective district courts, as well as selected by the president. Consequently, they require a separate examination beyond the scope of this project.

${ }^{3}$ The full dataset collected includes PAS positions to independent agencies and government corporations and covers a total of 20,110 position-year observations, 83 percent of which were filled by a permanent appointee, 8 percent were filled by an interim appointee, and 9 percent were empty. However, the focus of this dissertation and, consequently, the scope of this analysis is on the fifteen Executive departments only.
} 
and Supporting Positions (the Plum Book) and archived annual editions of the United States Government Manual. Each of the government reports lists who is occupying the position and whether they are an interim appointee, or if the position is empty, at the time of publication. Using these data, I constructed the three-category Position Status to identify whether the PAS position is empty, ${ }^{4}$ filled with an interim appointee, or filled with a confirmed appointee.

This measure offers a discrete snapshot of which positions are filled - and by whom - at a particular time of year: the Government Manual is published in June or July each year. Ultimately, this means that an empty position could be filled with a confirmed appointee the week following the published version or could have been filled up until the previous week, and in both cases the position would be (correctly) identified as empty. However, there is little reason to believe that the Senate, presidents, or appointees schedule their choices to confirm, appoint, or vacate positions to correspond with the publication date of a standard publication from the Government Printing Office.

Furthermore, another reasonable concern is that the discrete nature of the outcome variable - the single, yearly time-step of each record for each PAS position - does not offer a complete picture of all vacancies throughout each year of each administration. Vacancies that occur and are resolved outside each time step are not captured in this data. In other words, if observations of empty positions or interim or permanent appointees not included due to this data structure are systematic or widespread, then that could potentially lead to biased findings. However, there is good reason to believe this is not the case. To address this concern, I engaged in a comprehensive analysis of the Department of Labor (DOL), where I matched each position in my original data with data generously shared by Anne Joseph O'Connell, ${ }^{5}$ to create continous records for each

\footnotetext{
${ }^{4}$ The Plum Book and the Government Manual both state that a position is "vacant" when there is no individual appointed to fill the position, either in an interim or permanent capacity; whereas I use the term "empty." While it is indicating an empty position, these report's use of vacant is anomalous given the conventional use of vacancy or vacant in political science research, journalism, and other government reports from sources like the Government Accountability Office and the Congressional Research Service to indicate the absence of a Senate confirmed appointee.

${ }^{5}$ The O'Connell dataset contains employment records from 1977 to 2003 attained through a FOIA request to the
} 
position in the DOL from 1977 to 2003. From this continuous data, I find that 129 of the 138 unique permanent appointees (93\%) in the OPM data appear in my data. That is, when comparing the 1977-2003 subset, just 7\% of confirmed appointees had terms between the publication dates and, therefore, were not recorded in the Government Manual. Alternatively, the larger set that includes permanent appointees and interim and empty positions - with 206 unique appointees or empty positions for 1977-2003 - identifies the absence of a confirmed appointee with near perfect accuracy: just one observation in my data was reported as a vacancy when a permanent appointee was listed in the OPM data. This considerable overlap suggests that systematic missingness in the dependent variable is rather unlikely.

As Table 5.1 reports, of the 10,331 position-year observations, 8,308 (80.4 percent) were filled by permanent appointees, 1,069 (10.3 percent) were filled by interim appointees, and 954 (9.2 percent) were left empty. Importantly, this data quantifies the error in past work on appointments, which, on average, misses the reversion point for nearly 20 percent of positions. What is more, this trend is not constant. As shown in Figure 5.1, the percentage of Executive department PAS positions without a confirmed appointee - the conventional definition of a vacancy - fluctuated between 10 and 50 percent between 1977 and 2015, which aligns with previous findings from O'Connell (2009). Here, we can see that, on average, approximately half of these vacancies were filled by interim appointees while half were left empty; yet this varies by year and by administration. Additionally, Figure 5.1 highlights that the relationship between the two different types of vacancies also varies. Some years saw more empty positions than temporarily filled (e.g., 19871995) whereas others had more interims filling vacancies than empty chairs (e.g., 2007-2015). By correcting our conceptualization of vacancies to identify these two very distinct realities, we are able to see that presidents potentially use empty positions and interim appointees differently, and perhaps strategically, when they are faced with an appointment opportunity.

Moreover, we can easily see from Figure 5.1 that these patterns vary by administration and Office of Personnel Management (OPM) and used in the analysis for (O'Connell, 2009). 
Table 5.1: Distribution of PAS Position-Year Observations by Position Status, 1977-2015

\begin{tabular}{|c|c|c|c|}
\hline Total & Filled with & Filled with & Empty \\
\hline Observations & Permanent Appointee & Interim Appointee & Position \\
\hline 10,331 & $\begin{array}{c}8,308 \\
(80.4 \%)\end{array}$ & $\begin{array}{c}1,069 \\
(10.3 \%)\end{array}$ & $\begin{array}{c}954 \\
(9.2 \%)\end{array}$ \\
\hline
\end{tabular}

Figure 5.1: Percentage of Executive Department PAS Positions: Vacancy, Empty, or Filled by Interim Appointees, 1977-2015

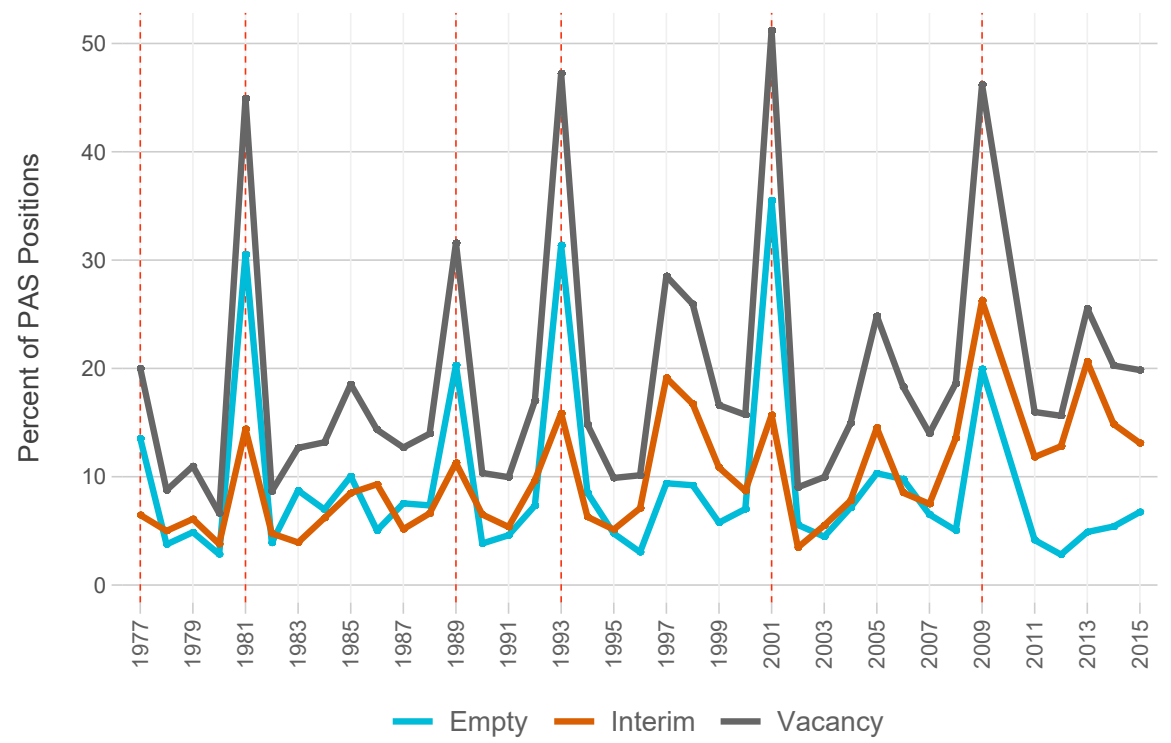

distinctive political contexts. As Table 5.2 reports, of the 8,308 positions filled with a permanent appointee and 954 positions left empty, over half of each were during Republican administrations; whereas, just 44 percent of the 1,069 positions filled with an interim appointee had Republican presidents. Our conventional wisdom might lead us to expect a smaller share of empty positions with co-partisan presidents and Senate majorities, since confirmation (and therefore nomination) would, presumably, be less costly. However, Table 5.2 shows that nearly a third of empty positions occurred during united government (House of Representatives, Senate, and president) and 59 percent saw party-aligned presidents and Senate majorities. In sum, Table 5.2 shows that Position Status varies by partisanship and institutional control, which suggests that there are other 
considerations beyond these traditional explanations - perhaps, as I posit, differences in the value of the position to the president and the Senate - that influence the decision to fill a position.

\begin{tabular}{|c|c|c|c|c|}
\hline $\begin{array}{l}\text { Position Status } \\
(\mathrm{N}=10,331)\end{array}$ & $\begin{array}{l}\text { Obs } \\
(\mathrm{N})\end{array}$ & $\begin{array}{c}\text { Republican } \\
\text { President }\end{array}$ & $\begin{array}{c}\text { Divided } \\
\text { Government }\end{array}$ & $\begin{array}{c}\text { Co-partisan Senate \& } \\
\text { President }\end{array}$ \\
\hline Filled with & 8,308 & 4,494 & 6,114 & 4,895 \\
\hline Permanent Appointee & $(80.4 \%)$ & $(54.1 \%)$ & $(73.6 \%)$ & $(58.9 \%)$ \\
\hline Filled with & 1,069 & 471 & 774 & 658 \\
\hline Interim Appointee & $(10.3 \%)$ & $(44.1 \%)$ & $(72.4 \%)$ & $(61.6 \%)$ \\
\hline Empty & $\begin{array}{c}954 \\
(9.2 \%)\end{array}$ & $\begin{array}{c}549 \\
(51.7 \%)\end{array}$ & $\begin{array}{c}636 \\
(66.7 \%)\end{array}$ & $\begin{array}{c}564 \\
(59.1 \%)\end{array}$ \\
\hline
\end{tabular}

Furthermore, when we examine empty positions and ones filled by interims within each department across this time period, as shown in Figure 5.2, we can see that they are not concentrated in any one department or by any one administration. Some departments experience considerable variation in how vacancies are dealt with. For instance, the Departments of Transportation and Housing and Urban Development (HUD) each oscillate between having 0 and 30 percent (on average) of their PAS positions left empty. Alternatively, the Departments of Energy, Justice, and Veterans Affairs regularly have higher percentages of their PAS positions filled by interim appointees than left empty. As expected given transitions between administrations, the percentage of empty PAS positions increases during the first year of an administration for most departments. These initial vacancies are expected as a natural byproduct of an appointment process that demands extensive vetting before nomination and debate before confirmation. However, the Departments of Energy, Labor, Justice, and State have higher proportions of interim officials even in those first years. Furthermore, HUD and Interior saw the percentage of interim appointees increase considerably from nearly zero in the first term of the Obama administration. This seems to suggest that interim appointees are not an instrument that presidents use universally across 


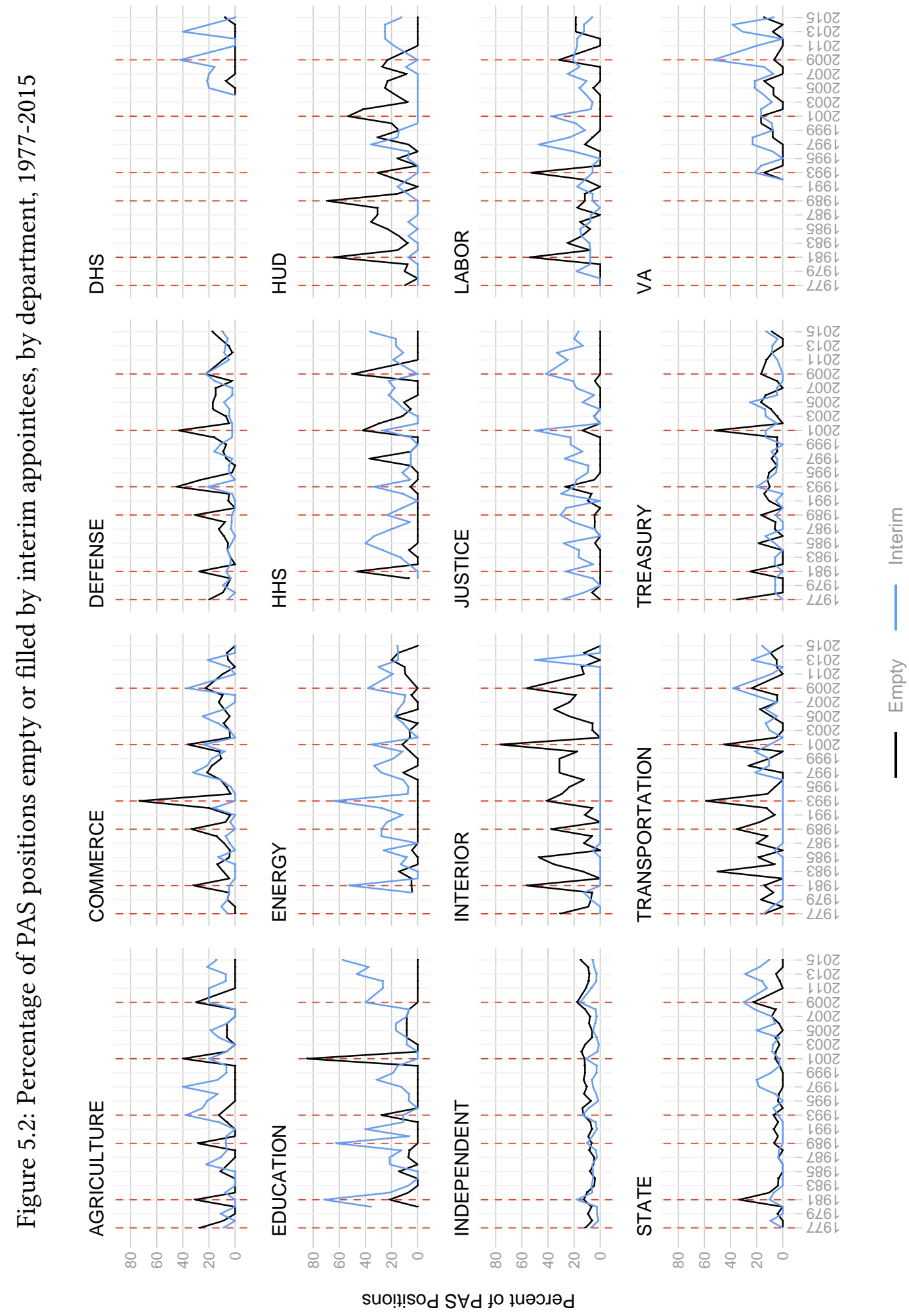


departments. Instead, the variation in empty posts and interim appointees, as proportions of the available PAS positions to fill, implies that administration policy priorities play a role.

To offer a wider perspective of these data, Figures 5.3 and 5.4 summarize the sets of PAS positions left empty and filled with an interim appointee, respectively, by displaying the minimum, first quartile, median, third quartile, and outlying years. In these figures, I also overlay the Trump administration (as of June 2018) onto each figure to show how the more recent distribution of interim appointees and empty positions fares against the previous six administrations. For example, in the Department of Commerce, the median percentage of PAS positions left empty is 8.33 percent, which occurred during Reagan's second term in 1987 and Bush's second term in 2006, and the first and third quantiles are 4.17 percent under Bush in 2003 and 13.64 percent under Reagan in 1984, respectively. Alternatively, in the Department of Education, the median percentage of PAS positions with interim appointees is 15.38 percent, with first and third quantiles of 6.67 percent and 31.25 percent, each under Clinton in 2000, 1996, and 1998, respectively.

Figure 5.3: Box Plot of Percentage of PAS Positions Left Empty, 1977-2015

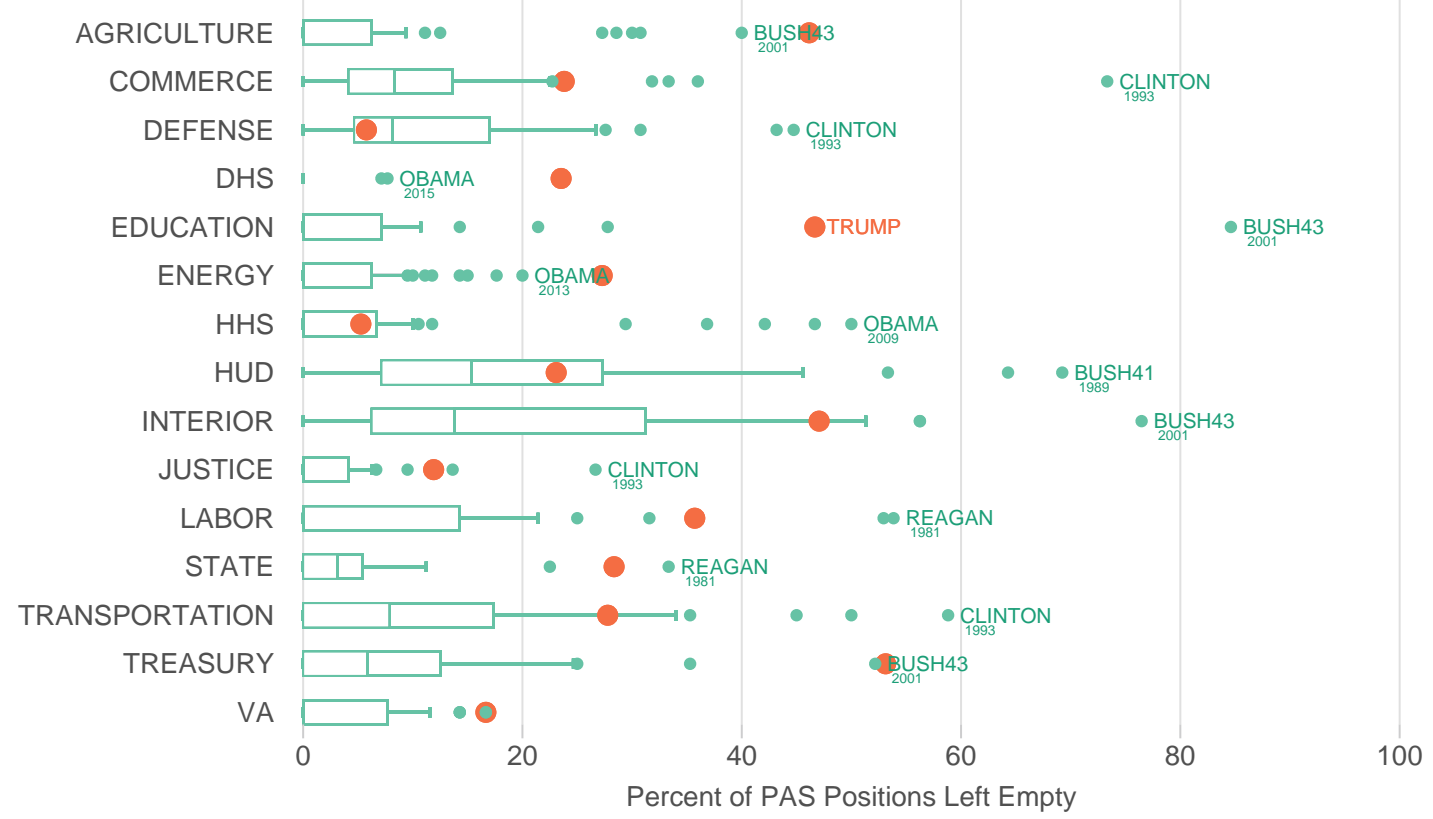

Note: Trump administration empty positions (the solid, large orange markers) as of June 2, 2018 transposed onto a box plot of previous administration's yearly percentages from 1977-2015; the maximium for each department are labelled with administration and year. 
Figure 5.4: Box Plot of Percentage of PAS Positions Filled with Interim Appointees, 1977-2015

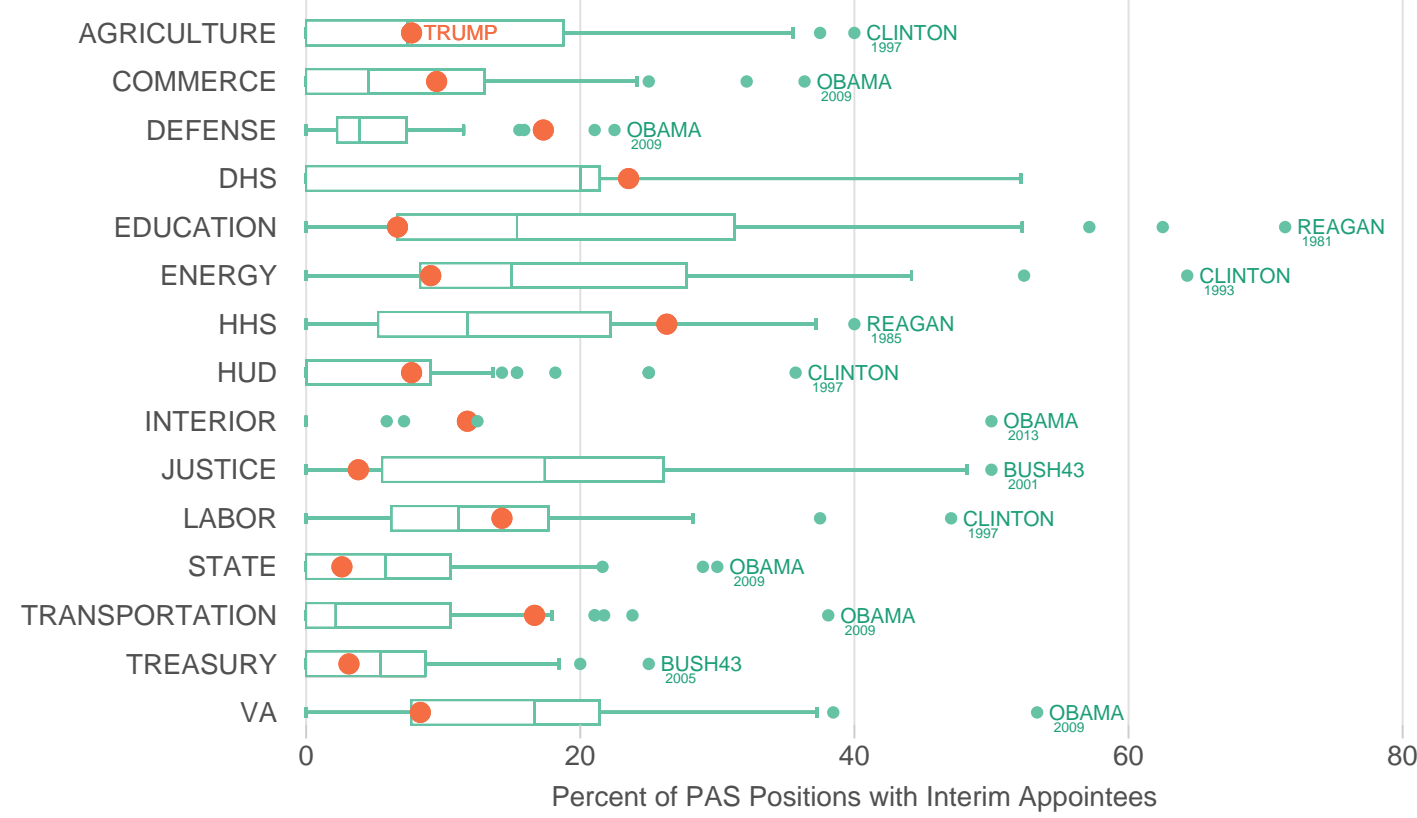

Note: Trump administration interim appointees (the solid, large orange markers) as of June 2, 2018 compared with previous administration's yearly percentages from 1977-2015; the maximum for each department are labelled with administration and year.

As Figure 5.3 illustrates, HUD and Interior have the highest concentrations of empty positions, while Justice and Homeland Security have the lowest. However, while each of the departments have outliers, the current administration is not consistently outpacing previous administrations. This trend also appears among the distributions of interim appointees, as shown in Figure 5.4. Thus, despite the temptation to view Trump as an outlier among conventional presidencies, this seems to suggest that the administration's approach to vacancies and interim appointees might not be an aberration.

As mentioned previously, to expand to five categories, I supplement this data with presidential nominations records, scraped from Congress.gov. I use these records to identify whether there were nominations in the Senate for positions that did not have confirmed appointees at the time of publication of the Government Manual. Each nomination submitted to the Senate by the president is assigned a unique "PN" (Presidential Nomination) number for that session of Congress, which identifies the nominee and the position for that specific nomination. Each record also iden- 
tifies the date the nomination was received by the president, the date of the latest action, and a description of the actions taken during the confirmation process (e.g., assignment to committee, committee hearings, reporting from committee, assignment to the Executive Calendar, voting results from the Senate floor, and if the nomination was returned or withdrawn).

Using these data, I identified which set of nominations remained in the Senate - as in, which nominations had not been confirmed, returned, rejected, or withdrawn from consideration - at the time of each year's Government Manual publication, and matched those nominations to their respective positions. From this matching, I constructed the five-category Position Status to identify whether the PAS position is empty with no nominee, empty with a nominee, filled with an interim appointee with no nominee, filled with an interim appointee with a nominee, or filled with a confirmed appointee. Of the 9,626 position-year observations between 1981-2015, 79.8 percent were filled by confirmed, permanent appointees, which is not statistically distinguishable from the percentage of permanent appointees filling positions in the full data set (1977-2015). Of the remaining 1,943 position-year observations that were vacant, 746 (38.39 percent) were empty with no nominee, 165 (8.49 percent) were empty with a nominee, 811 (41.74 percent) were filled by an interim appointee with no nominee, and 221 (11.37 percent) were filled by an interim with a nominee. Interestingly, and as Table 5.3 shows, half of PAS positions filled with interim appointees with nominees occurred in Republican administrations, whereas more than half of those filled with interim appointees without nominees occurred under Democratic administrations. Alternatively, vacancies (empty positions and those filled by interim appointees) with no nominees account for approximately 16 percent of PAS positions from 1981-2015; and the vast majority of those occurred in Republican administrations.

Vacancies with nominees account for just 20 percent of the PAS positions without permanent appointees. ${ }^{6}$ However, as we might expect given the patterns of the three-category Position Value,

\footnotetext{
${ }^{6}$ This is an artifact of including only the nominees under consideration at the time of publication (editions of the Government Manual are published annually on either June 1 or July 1) and potentially problematic for the proceeding analyses; particularly if the positions had nominees that are not observed, which would happen if nominations are
} 
Table 5.3: Political Characteristics Surrounding PAS Positions, by Position Status (With and Without Nominees), 1981-2015

\begin{tabular}{lcccc}
\hline $\begin{array}{l}\text { Position Status } \\
(\mathrm{N}=9,626)\end{array}$ & $\begin{array}{c}\text { Obs } \\
(\mathrm{N})\end{array}$ & $\begin{array}{c}\text { Republican } \\
\text { President }\end{array}$ & $\begin{array}{c}\text { Divided } \\
\text { Government }\end{array}$ & $\begin{array}{c}\text { Co-partisan Senate \& } \\
\text { President }\end{array}$ \\
\hline Filled with & 7,683 & 4,494 & 6,114 & 3,413 \\
Permanent Appointee & $(79.82 \%)$ & $(58.49 \%)$ & $(79.58 \%)$ & $(44.42 \%)$ \\
Filled with Interim, & 221 & 110 & 162 & 98 \\
With Nominee & $(2.3 \%)$ & $(49.77 \%)$ & $(73.3 \%)$ & $(44.34 \%)$ \\
Filled with Interim, & 811 & 361 & 612 & 313 \\
No Nominee & $(8.43 \%)$ & $(44.51 \%)$ & $(75.46 \%)$ & $(38.59 \%)$ \\
& & & & \\
Empty, & 165 & 112 & 114 & 85 \\
With Nominee & $(1.71 \%)$ & $(67.88 \%)$ & $(69.09 \%)$ & $(51.52 \%)$ \\
& & & & \\
Empty, & 746 & 437 & 522 & 305 \\
No Nominee & $(7.75 \%)$ & $(58.58 \%)$ & $(69.97 \%)$ & $(40.88 \%)$ \\
\hline
\end{tabular}

these trends are not constant over time. As Figure 5.5 illustrates, the percentage of vacant PAS positions (those without a confirmed appointee) left empty with no nominee maintains a higher average than those left empty with a nominee, but both trends fluctuate considerably. Similarly, the percentage of vacant PAS positions filled with an interim with no nominee also fluctuated, albeit with a sizable increase since 2001. These patterns offer initial support for my claim that nominations are not simply a default option that presidents choose after deciding to temporarily fill an empty position or not. Presidents can and do opt to not submit a nominee for Senate confirmation. To examine whether Position Value is the key factor in this calculus, as my theory predicts, I also need to construct this original measure. Accordingly, the next section builds on the submitted but returned or withdrawn - thus maintaining the vacancy - before the time of publication. Nearly two thirds (68 percent) of nominations submitted in the first six months of each year were either returned, withdrawn, or confirmed before the annual publication of the Government Manual. Critically, 95 percent of those nominations were confirmed, which means that the confirmed appointees would then be listed in the Government Manual, leaving just 5 percent that were nominated and then returned or withdrawn. Consequently, the set of vacancies that could have a nominee submitted and returned/withdrawn outside the observed time-step is, in fact, quite small, which considerably limits the potential for bias. 
Figure 5.5: Percentage of Vacant Executive Department PAS Positions: Empty and Interim Appointees, With and Without Nominees, 1981-2015

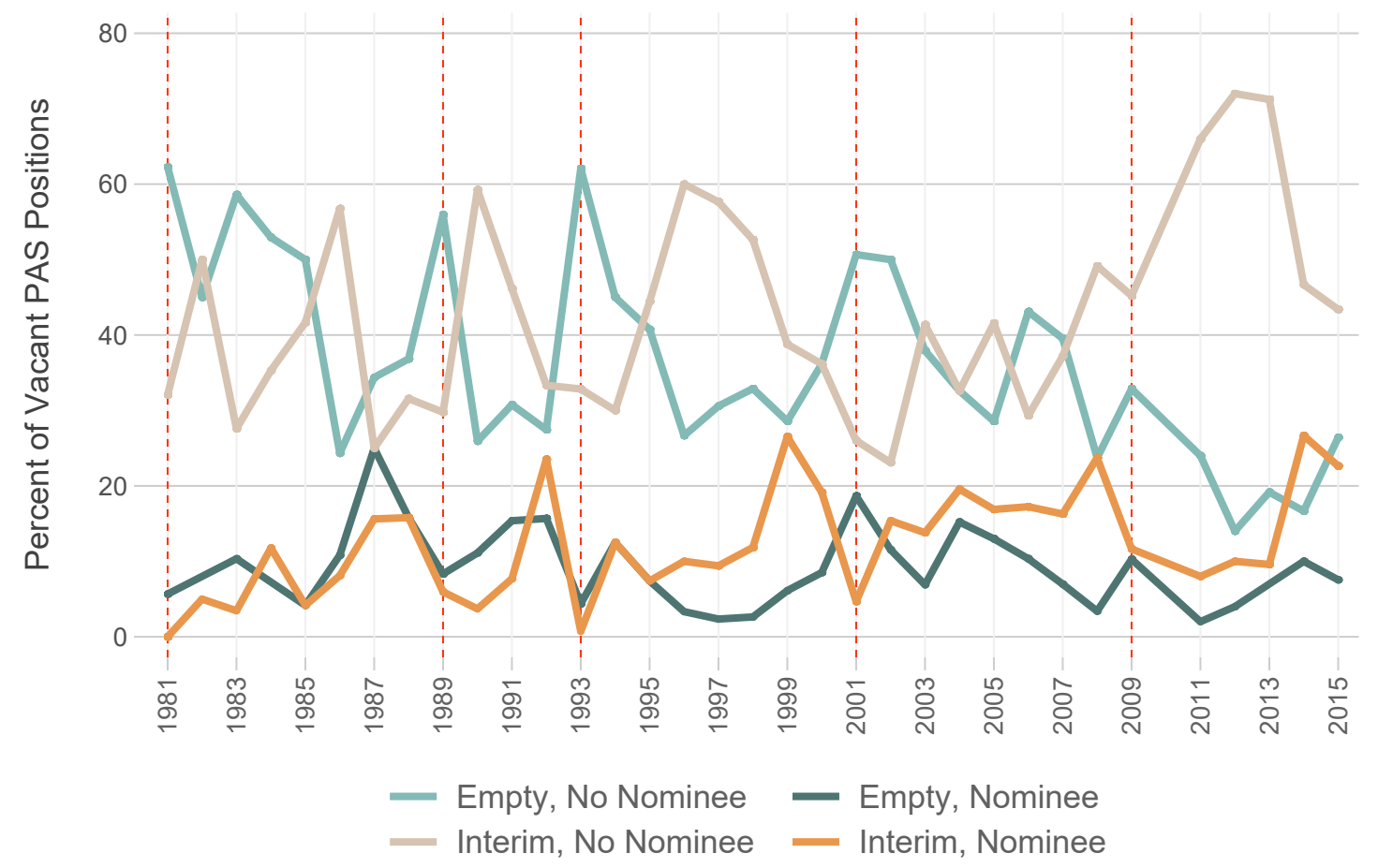

description of Position Value offered in Chapter 3 by delineating the data collected to construct my main theoretical and empirical variable of interest, as a composite of Policy Priorities and Position Capacity.

\subsubsection{Measuring Position Value}

I have proposed that presidents fill PAS positions - with interim or permanent appointees - or leave them empty based largely on Position Value, which indicates the capacity of certain positions to control policy outputs and agency actions in line with policy priorities. Accordingly, each of the empirical expectations outlined in Chapter 4 are characterized in terms of Position Value as a composite measure of Policy Priorities (contraction, neutral, expansion) and the level of Position Capacity (high or low). 


\subsubsection{Policy Priorities}

To operationalize the concept of Policy Priorities, I need to identify if the president and Senate prefer to expand or contract the reach of an agency in the year of the observed position status. There are various opportunities for each actor to reveal their preferences. Presidents convey their agenda through campaign platforms, State of the Union Addresses, signing statements, administration position statements, and official press engagements. Scholars often control for the salience of policy priorities in terms of mentions in the State of the Union (e.g., Krause and O'Connell, 2016) or frame these priorities in terms of a legislative agenda (e.g., Beckmann, 2010), but this theory requires a measure of the direction of policy priorities vis-à-vis the status quo. Fortunately, the annual budget process requires administrations and Congresses to take stock of each agency's current position relative to their ideal agency activities, determine areas for change, and create quantitative measures of desired shifts in budgetary authority. ${ }^{7}$

The executive budget process itself - that is, the preparation of the president's budget, the execution of the enacted budget, and subsequent management oversight activities - offers a centralized and significant tool for presidents to control agencies and their policy outputs (Pasachoff, 2016). Moreover, all government actions and outputs are structurally tied to government expenditures. Distributed benefits and grants are transfer payments from the government to constituent groups. Procurement contracts are government investments into fixed assets. Essential services provision, rule-making, enforcement actions, and general policymaking - each produced by public sector labor - ultimately originate from spending on personnel. In other words, the federal budget and policy are inseparable as the specific details of the budget reflect policy decisions,

\footnotetext{
${ }^{7}$ Importantly, the congressional policy priorities constructed here are not those of just the Senate. Budget authorizations must pass the Senate, and, therefore, Senate priorities are reflected in any budget authority. However, the realization of the Senate's priorities are likely constrained - in either direction - by the preferences of the House of Representatives. This constraint would be particularly prominent if the party leadership is divided between the House and the Senate, and would have largest implications when the Senate majority is not the president's party. To control for these potential biases in my analyses, I include an indicator for the the co-partisanship of the Senate and president.
} 
program initiatives, and performance goals (Martin, 2008). Inevitably, then, shifts in budget authority, either requested or approved, indicate desired shifts in agency actions and policy output. ${ }^{8}$ Thus, I am able to identify expansion and contraction policy priorities using administration budget requests and final appropriation levels. To compile these data, I scraped the annual presidential budget requests and previous years' budget authority, for each agency from 1977 to 2015, from the historical tables located in the appendices of every fiscal year edition of The Budget of the United States Government, archived by FRASER. ${ }^{9}$

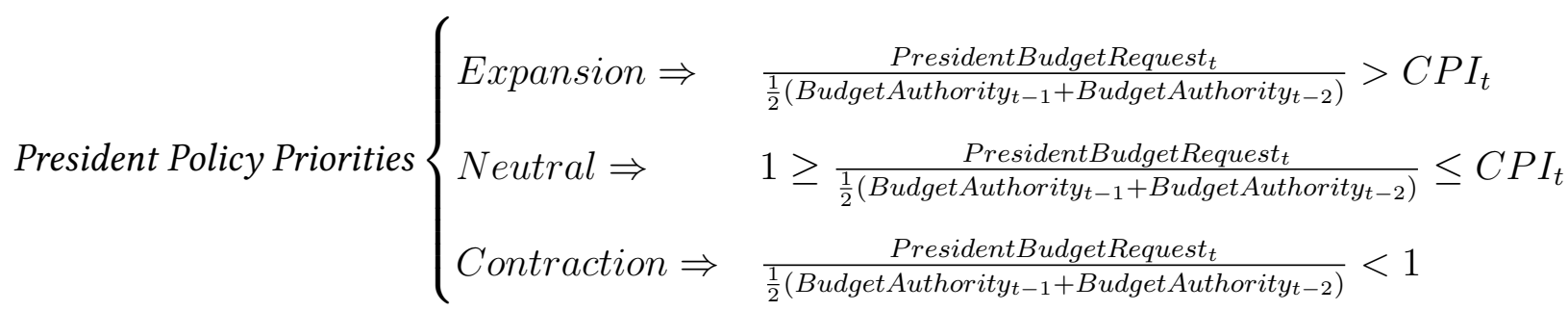

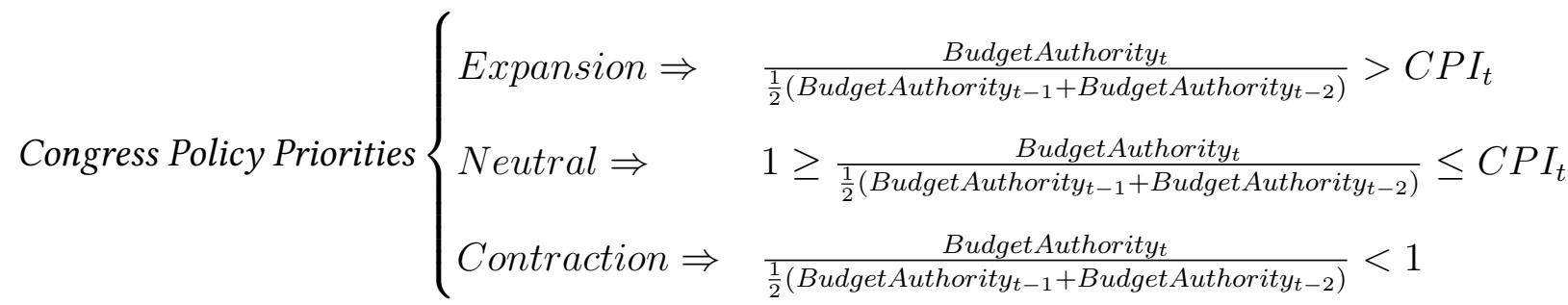

\footnotetext{
${ }^{8}$ As described by Paul O’Neill, former Deputy Director of the Office of Management and Budget (OMB): "One of the secrets only the initiated know is that those who labor here [at the OMB] for so long do so because the numbers are the keys to the doors of everything. Spending for the arts, the sciences, foreign policy and defense, health and welfare, education, agriculture, the environment, everything - and revenues from every source - all are reflected, recorded, and battled over - in numbers. And the sums of the numbers produce fiscal and monetary policy. If it matters - there are numbers that define it. And if you are responsible for advising the president about numbers, you are - de facto - in the stream of every policy decision made by the federal government" (Martin, 2008, 72).

${ }^{9}$ United States. Bureau of the Budget and United States. Office of Management and Budget. Budget of the United States Government. 1921-2018. https://fraser.stlouisfed.org/title/54.
} 
As indicated above, I measure presidential expansion policy priorities as budget requests to increase an agency's budget authority from the average of the previous two fiscal years, by an amount more than what would be required to maintain current levels given the annual rate of inflation. The average of the previous two appropriations smooths fluctuations in budget authority due to irregular spending from stimulus packages or new program roll-outs, or reductions from agency reorganizations or program terminations. Conversely, I measure presidential contraction policy priorities as budget requests to decrease an agency's budget authority from the average of the previous two fiscal years. Similarly, I measure congressional expansion policy priorities as increases, larger than inflation, in the congressionally approved budget authority from the average of the previous two fiscal years; and congressional contraction policy priorities as decreases to an agency's budget authority from the average of the previous two fiscal years. The remaining category of neutral policy priorities indicates requests or approved budget authority that maintain the same level of agency funding within the range of inflation.

To assess the face validity of this measure, Figures 5.6 and 5.7 display administration and congressional policy priorities, both of which align with general expectations. For instance, the Department of Education (ED), whose mission is to "foster educational excellence and ensure equal access," creates and implements policies that reach every past, present, and future schoolaged child, and has an enormous client base of which most voters are apart. Consequently, ED has drawn the ire of or been championed by nearly every modern president. From Reagan's campaign promises to abolish the department to Bush's No Child Left Behind to Obama's Race to the Top, ED has seen its share of expansion and contraction policy priorities. In particular, the "ClintonGore Administration Record of Progress," a report issued on the White House website in January 2001, listed "expanding education opportunity" as one of the chief policy accomplishments of the Clinton administration. ${ }^{10}$ These patterns materialize in the measure of policy priorities for the Department of Education; contraction priorities dominate the 1980s and 2000s under Reagan and

\footnotetext{
${ }^{10}$ See https://clintonwhitehouse5.archives.gov/WH/Accomplishments/eightyears-index.html.
} 


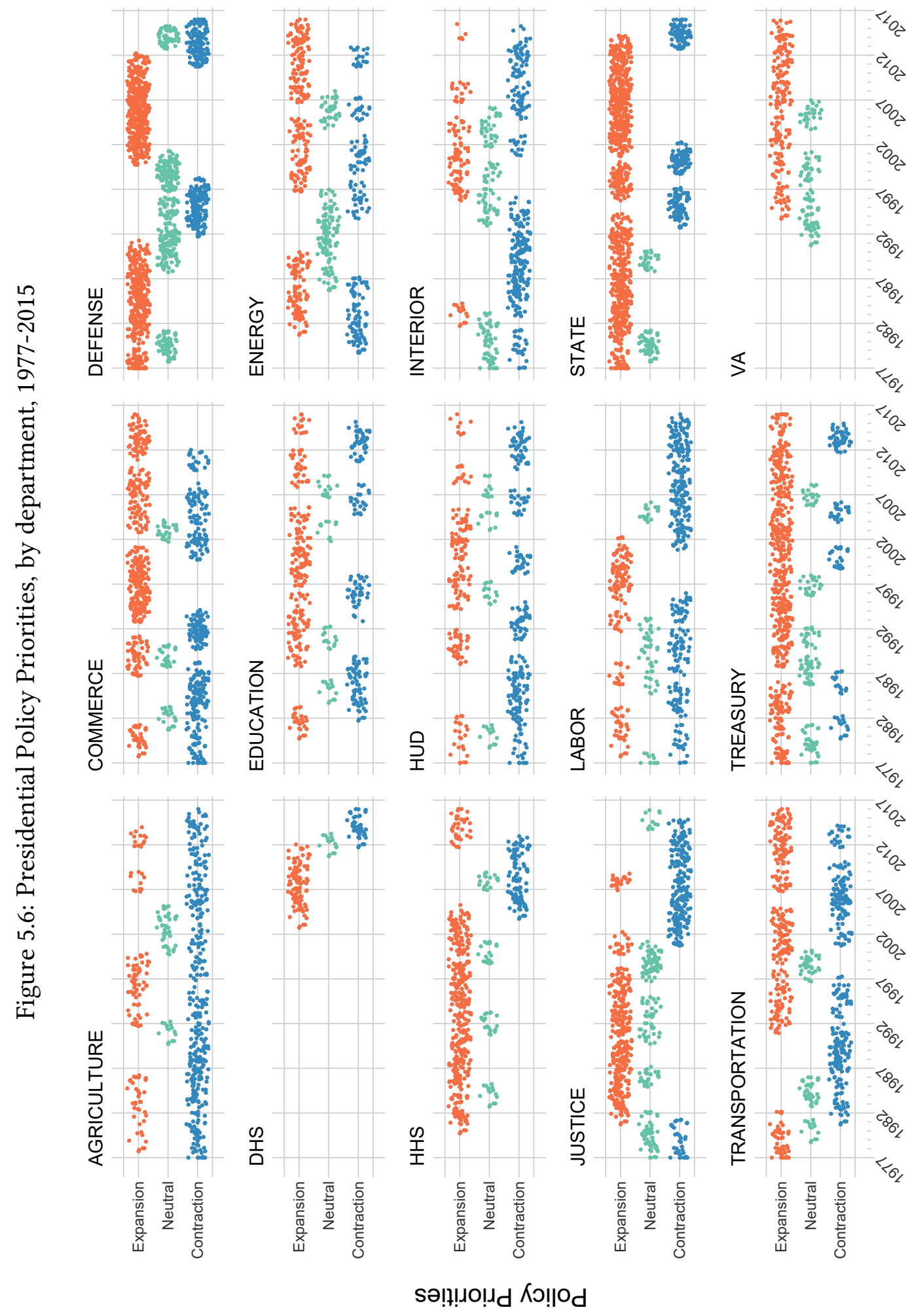




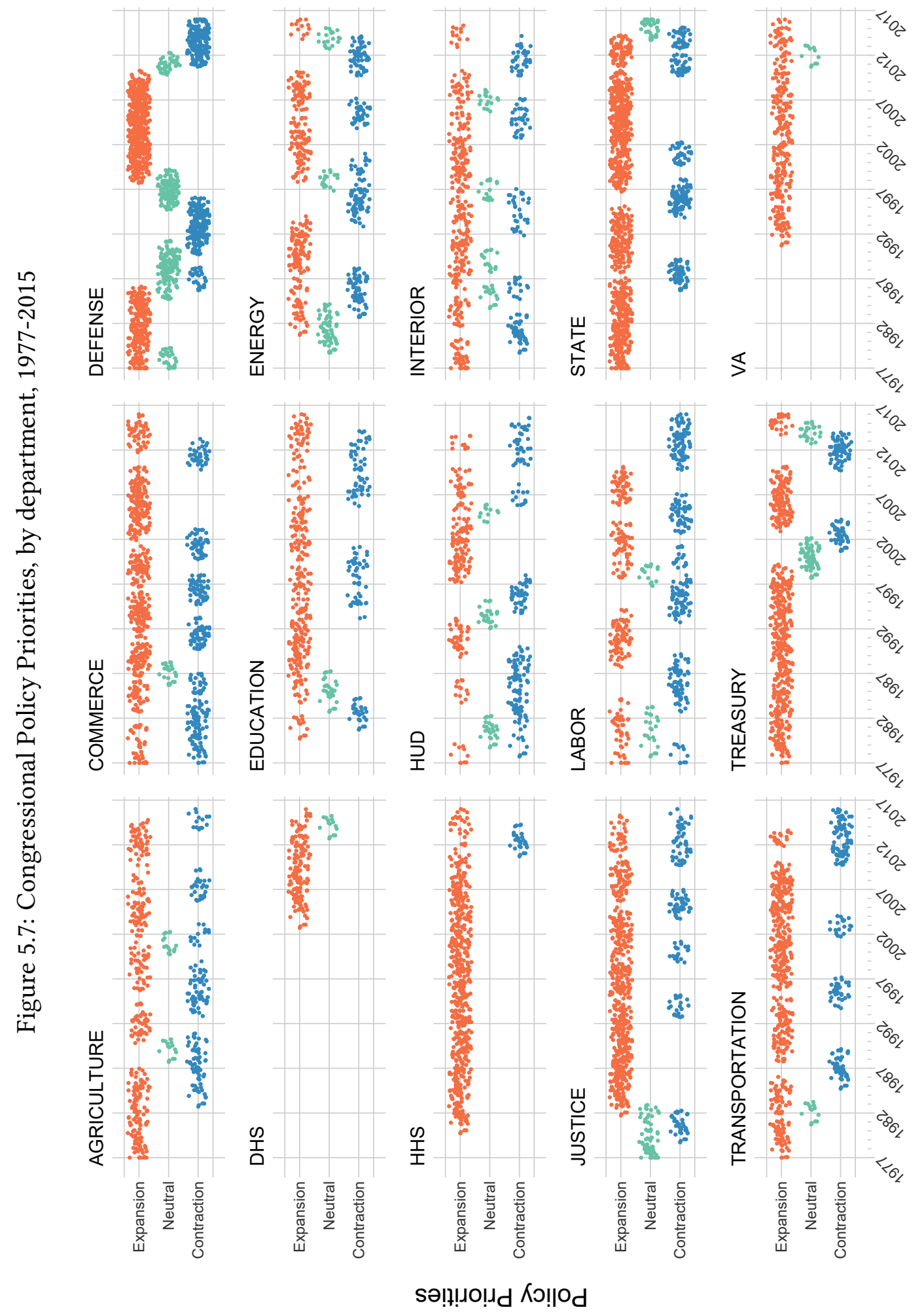


Bush, while expansion priorities dominate 1990s and 2010s under Clinton and Obama.

Importantly, presidential budget requests are not directly tied to congressional appropriations. While the budget process creates the opportunity for presidents to submit their annual budget request, Congress is not required to entertain any debate or hearings or to fund at the requested level. In fact, there are many instances when Congress has blatantly ignored the administration's request and funded at the levels it deemed appropriate; the most recent example comes from Trump's request to considerably decrease funding for the Department of Education, which was flatly rejected and, instead, the most recent funding package increased Education's budget authority. However, Congress has clear incentives to use the president's budget request as an oversight opportunity and as an information-sharing exercise. Ultimately, I structure Policy Priorities as a categorical variable identifying expansion, contraction, or neutral (maintaining the status quo funding level given inflation) presidential and congressional policy priorities.

\subsubsection{Position Capacity}

In my theory, I conjectured that positions themselves have the opportunity to deliver political or policy benefits to the president (or Senate); that is, they have the capacity to control policy output and the agency actions that shift policy outcomes. Consequently, I am most concerned with identifying which positions have a high level of policy control capacity. Each edition of the Government Manual offers brief descriptions of the position responsibilities, the general mission or scope of activities for agency or sub-agency that the position leads, and organizational charts that identify where the position or sub-agency fit in the larger agency structure. Using these position and agency descriptions, I identified whether the responsibilities of each PAS position

in each agency were for agency operations, policy development, policy implementation, inter- or intra-agency coordination, legislation development, agency management and communications or public relations to construct a measure of Position Capacity to control policy output. In what follows, I outline the overall position characteristics that frame each category of Position Capacity 
before illustrating the coding scheme with several specific examples.

The positions that have clear responsibilities for agency actions like policy development, implementation, or explicit coordination among policy implementers carry the lion's share of the success or failure in achieving policy goals. While all PAS positions have some impact on the agency's operations and will, even if only implicitly, influence how well other positions are able to advance on their priorities, it is those that clearly impact policy output and agency actions that have high capacity. These positions include: agency heads (e.g., secretaries, administrators, directors), general counsels, inspectors general, and deputy or assistant secretaries that have jurisdiction and responsibilities for policy direction and implementation. Consequently, each of these positions' Position Capacity level is high.

Alternatively, positions with low policy control capacity are responsible for an agency's internal management or policies governing agency operations, like assistant secretaries of administration. These roles do indeed have important functions with respect to internal management and operation, but they are coded here as low policy control capacity given the position's low impact on the policy direction of the agency. Similarly, positions with responsibilities for relating information or maintaining public relations (e.g., assistant secretaries for communication), and positions responsible only for research and data collection without grant making or policy recommendation responsibilities (e.g., director of the Bureau of Mines at the Department of the Interior) also have little opportunity to influence the promulgation, enforcement, or implementation of the substantive rules that guide policy outcomes. Consequently, these positions' Position Capacity level is low.

To illustrate the specific coding procedure, let us consider the Department of Labor (DOL). From 1977 to 2015, DOL had 28 unique PAS positions; however, once we account for slight changes in position title - for instance, the assistant secretary for congressional affairs was renamed assistant secretary for congressional and intergovernmental affairs in 1992 - the number 
shrinks to 24 unique PAS positions. ${ }^{11}$ Certain positions - secretary, inspector general, and solicitor - have standard and clear authority over agency actions, across all six administrations, which makes their Position Capacity consistently high. Moreover, certain other positions - chief financial officer and assistant secretary for administration and management - have standard responsibilities that are focused exclusively on agency operations and internal management, rather than policy output, which make their Position Capacity consistently low.

For the less clear positions, I relied on the position and agency descriptions in each annual edition of the Government Manual to individually code whether the position's responsibilities and jurisdiction fall into the low or high categories. ${ }^{12}$ For example, the position description for the administrator of the Wage and Hour Division (also called the Wage and Hour administrator) found in the 1977 edition of the Government Manual states:

The Wage and Hour Administrator is responsible for planning, directing, and administering programs dealing with a variety of Federal labor legislation. These programs are designed to increase and protect low-wage incomes; eliminate discriminatory employment based on sex and age; prevent curtailing of employment and earnings for students, trainees, and handicapped workers; minimize losses of income and job rights caused by indebtedness; safeguard the health and welfare of workers by discouraging excessively long hours of work; and direct a program of farm labor contractor registration designed to protect the health, safety, and welfare of migrant labor.

Here, the position description outlines explicit responsibilities for agency actions and jurisdiction over policy output, and as such, the Position Capacity for the administrator is coded as high. However, in many instances, the Government Manual offers a description of the bureau or agency that the position directs, rather than a description of the position itself. Consider, for instance,

\footnotetext{
${ }^{11}$ The DOL positions accumulate to 599 position-year observations as not all 24 positions existed continuously from 1977 to 2015. In fact, only 8 PAS positions have consistently been on the DOL roster: secretary, solicitor, director of the Women's Bureau, commissioner of the Bureau of Labor Statistics, assistant secretary for policy (which was titled "assistant secretary for policy evaluation and research" until 1983), assistant secretary of the Occupational Safety and Health Administration, assistant secretary of the Employment and Training Administration, and administrator of the Wage and Hour Division.

${ }^{12}$ Initially I sought to automate this process, however, the changes in position titles, in formatting of descriptions, and in the general typesetting of the archived editions of the Government Manual required that this manual coding procedure be used.
} 
the description from the 2013 Government Manual for the Wage and Hour Division:

The Wage and Hour Division (WHD) enforces Federal minimum wage, overtime pay, recordkeeping, and child labor law requirements of the Fair Labor Standards Act. WHD also enforces the Migrant and Seasonal Agricultural Worker Protection Act, the Employee Polygraph Protection Act, the Family and Medical Leave Act, wage garnishment provisions of the Consumer Credit Protection Act, and a number of employment standards and worker protection as provided in several immigration-related statutes. Additionally, the WHD administers and enforces the prevailing wage requirements of the Davis Bacon Act and the Service Contract Act and other statutes applicable to Federal contracts for construction and for the provision of goods and services.

Here, the description of the Wage and Hour Division clearly outlines the jurisdiction of the agency for policy output and the impact that agency actions have on policy outcomes. As the head of the agency, the administrator is responsible for managing these actions and objectives and, therefore, continues to be responsible for policy output with a high Position Capacity. Comparatively, the commissioner of the Bureau of Labor Statistics (BLS) directs research and information gathering activities and does not manage policy outputs, as evidenced by the description of the BLS in the 1977 Government Manual: ${ }^{13}$

The Bureau of Labor Statistics (BLS) has responsibility for the Department's economic and statistical research activities. The Bureau is the Government's principal factfinding agency in the field of labor economics, particularly with respect to the collection and analysis of data on manpower and labor requirements, labor force, employment, unemployment, hours of work, wages and employee compensation, prices, living conditions, labor-management relations, productivity and technological developments, occupational safety and health, structure and growth of the economy, urban conditions and related socio-economic issues, and international aspects of certain of these subjects. It has no enforcement or administrative functions. ${ }^{14}$

While the BLS clearly provides valuable information and resources for other PAS positions in the DOL (e.g., the assistant secretary for labor management relations) to use, it does not offer policy recommendations or direct agency actions. Instead, the commissioner of the BLS leads an agency explicitly tasked solely with information gathering and no jurisdiction over policy outputs; consequently, the Position Capacity for the commissioner is coded as low. Following

\footnotetext{
${ }^{13}$ This description of the Bureau of Labor Statistics is representative of all the BLS descriptions in the 1977-2015 editions of the Government Manual.

${ }^{14}$ Emphasis added.
} 
this coding procedure, I classified each of the positions across all fifteen Executive departments, and subsequently all position-year observations in this dataset, as having high or low Position Capacity.

While just over 13 percent of PAS positions are low capacity, as Table 5.4 displays, this varies by department. Nearly 18 percent of PAS positions at the Department of Interior are low capacity while less than 4 percent are low capacity at the Department of Justice. Alternatively, albeit unsurprisingly, just over 90 percent of PAS positions in the Departments of Defense, Energy, and Homeland Security and over 96 percent of PAS positions at the Department of Justice are high capacity positions. ${ }^{15}$ However, the number of high capacity and low capacity positions has remained relatively unchanged across this time period; except for instances of department-wide changes like the creation of the Department of Homeland Security in 2002 or the transition to the Cabinet-level Department of Veterans Affairs from the independent agency Veterans Administration in 1989.

\footnotetext{
${ }^{15}$ The Department of Justice (DOJ) uniquely does not have PAS positions explicitly tasked with department management. The positions in charge of operations, public relations/communications, or management do not require Senate confirmation. Each of the assistant Attorneys General leads a division (e.g., Criminal Division or Tax Division) and each division has a director of operations that is most often a non-career executive assignment position, not one that requires Senate confirmation. Moreover, nearly all the PAS positions in the DOJ that are not assistant Attorneys General lead an investigation or enforcement division or bureau (e.g., the director of the Federal Bureau of Investigation or the administrator of the Drug Enforcement Administration) and have high Position Capacity. Consequently, the commissioner of the Bureau of Justice Statistics is the only PAS position without explicit responsibilities over DOJ actions or jurisdiction for DOJ policy output, which classifies it as low capacity.
} 
Table 5.4: Levels of Policy Control Capacity for PAS Positions in Executive Departments, 1977-

\begin{tabular}{|c|c|c|c|}
\hline Department & Low Capacity & High Capacity & Total \\
\hline Agriculture & $\begin{array}{c}90 \\
(16.42 \%)\end{array}$ & $\begin{array}{c}458 \\
(83.58 \%)\end{array}$ & 548 \\
\hline Commerce & $\begin{array}{c}199 \\
(22.01 \%)\end{array}$ & $\begin{array}{c}705 \\
(77.99 \%)\end{array}$ & 904 \\
\hline Defense & $\begin{array}{c}152 \\
(9.92 \%)\end{array}$ & $\begin{array}{c}1,380 \\
(90.08 \%)\end{array}$ & 1,532 \\
\hline Education & $\begin{array}{c}74 \\
(15.20 \%)\end{array}$ & $\begin{array}{c}413 \\
(84.8 \%)\end{array}$ & 487 \\
\hline Energy & $\begin{array}{c}56 \\
(8.54 \%)\end{array}$ & $\begin{array}{c}600 \\
(91.46 \%)\end{array}$ & 656 \\
\hline Health and Human Services & $\begin{array}{c}87 \\
(15.24 \%)\end{array}$ & $\begin{array}{c}484 \\
(84.76 \%)\end{array}$ & 571 \\
\hline Homeland Security & $\begin{array}{c}14 \\
(8.81 \%)\end{array}$ & $\begin{array}{c}145 \\
(91.19 \%)\end{array}$ & 159 \\
\hline Housing and Urban Development & $\begin{array}{c}70 \\
(14.58 \%)\end{array}$ & $\begin{array}{c}410 \\
(85.42 \%)\end{array}$ & 480 \\
\hline Interior & $\begin{array}{c}103 \\
(17.7 \%)\end{array}$ & $\begin{array}{c}479 \\
(82.3 \%)\end{array}$ & 582 \\
\hline Justice & $\begin{array}{c}32 \\
(3.93 \%)\end{array}$ & $\begin{array}{c}783 \\
(96.07 \%)\end{array}$ & 815 \\
\hline Labor & $\begin{array}{c}90 \\
(15.03 \%)\end{array}$ & $\begin{array}{c}509 \\
(84.97 \%)\end{array}$ & 599 \\
\hline State & $\begin{array}{c}195 \\
(15.8 \%)\end{array}$ & $\begin{array}{c}1,039 \\
(84.2 \%)\end{array}$ & 1,234 \\
\hline Transportation & $\begin{array}{c}58 \\
(8.43 \%)\end{array}$ & $\begin{array}{c}630 \\
(91.57 \%)\end{array}$ & \\
\hline Treasury & $\begin{array}{c}99 \\
(12.77 \%)\end{array}$ & $\begin{array}{c}676 \\
(87.23 \%)\end{array}$ & 775 \\
\hline Veterans Affairs & $\begin{array}{c}75 \\
(24.92 \%)\end{array}$ & $\begin{array}{c}226 \\
(75.08 \%)\end{array}$ & \\
\hline Total & $\begin{array}{c}1,394 \\
(13.49 \%)\end{array}$ & $\begin{array}{c}8,937 \\
(86.51 \%)\end{array}$ & 10,331 \\
\hline
\end{tabular}




\subsubsection{Position Value}

Lastly, I construct the categorical variable, Position Value, as a function of Position Capacity and Policy Priorities. Recall, as outlined in Chapter 4 and displayed in Table 5.5, a position is "Low Value" when its Position Capacity level is low or Policy Priorities are neutral. A position is "High Value (contraction)" or "High Value (expansion)" when its Position Capacity is high and Policy Priorities are contraction or expansion, respectively.

Table 5.5: Position Value: Combining Position Capacity and Policy Priorities

\begin{tabular}{ll|l|l|l|} 
& \multicolumn{4}{c}{ Policy Priority } \\
& & Contraction & Neutral & Expansion \\
\cline { 2 - 5 } Position & High & High Value & Low Value & High Value \\
\cline { 2 - 5 } Capacity & Low & Low Value & Low Value & Low Value \\
\cline { 3 - 5 } & &
\end{tabular}

Below, Figures 5.8 and 5.9 illustrate the distributions of presidential and congressional Position Value categories across the fifteen departments included in this analysis. Here, each marker identifies an individual position within the agency in that year. The regular presence of "Low Value" markers indicates that there are low capacity positions in each agency; and an increase in the mass of those markers shows when policy priorities are neutral. The interaction of policy priorities and position capacity varies considerably across departments and administrations, with several recognizable patterns. For instance, given Clinton's second term priority of strengthening environmental conservation and expanding federal lands protections (Maraniss, 1996), we would expect larger masses of markers in the "High Value (expansion)" category for the Department of the Interior during the late 1990s. Figure 5.8 shows that we find exactly that.

Similarly, George H. W. Bush "devoted much of his time to foreign affairs" and oversaw a considerable foreign policy agenda that included negotiating the end of the Cold War and signing the North American Free Trade Agreement (NAFTA), among many others (Knott, 2018). Con- 


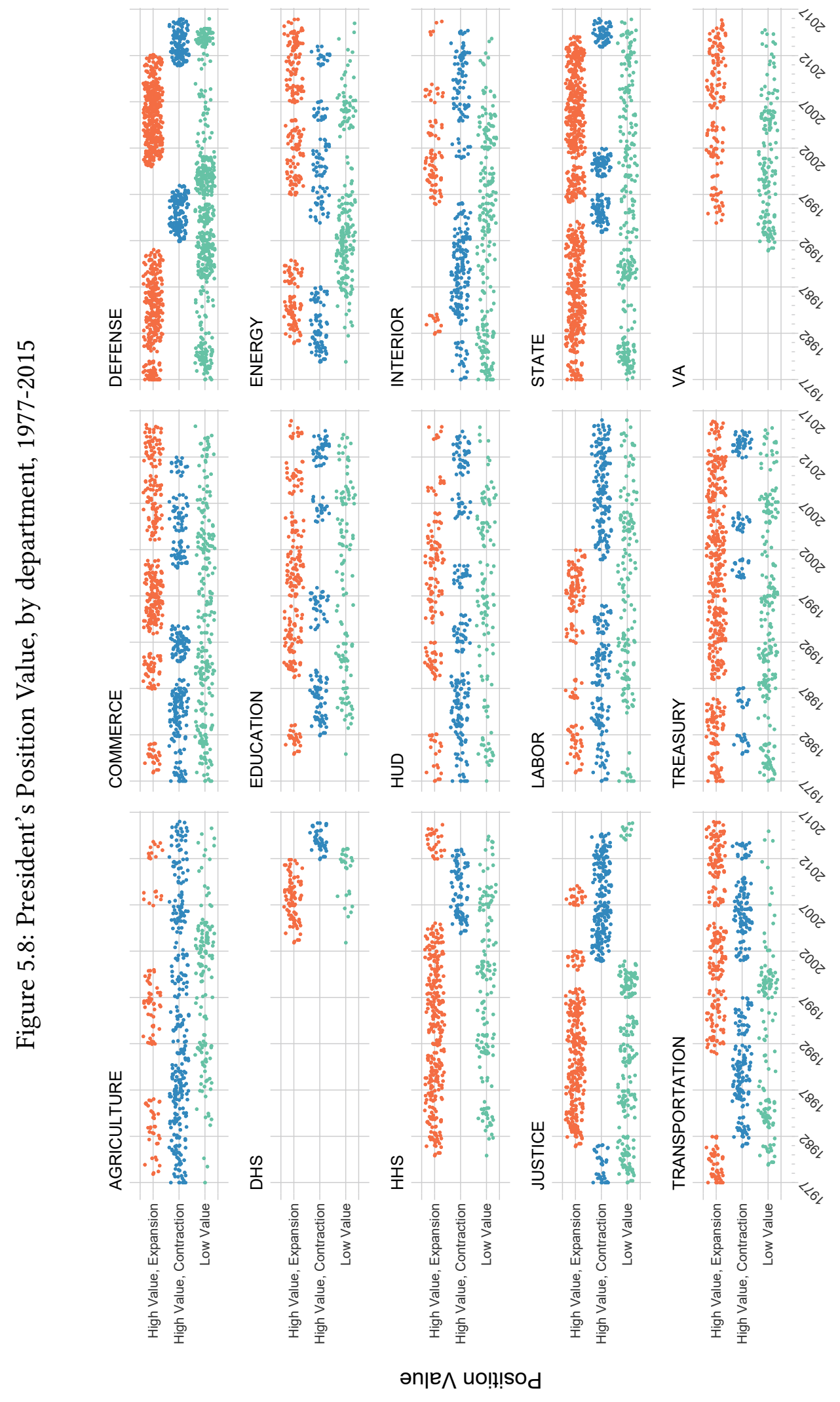




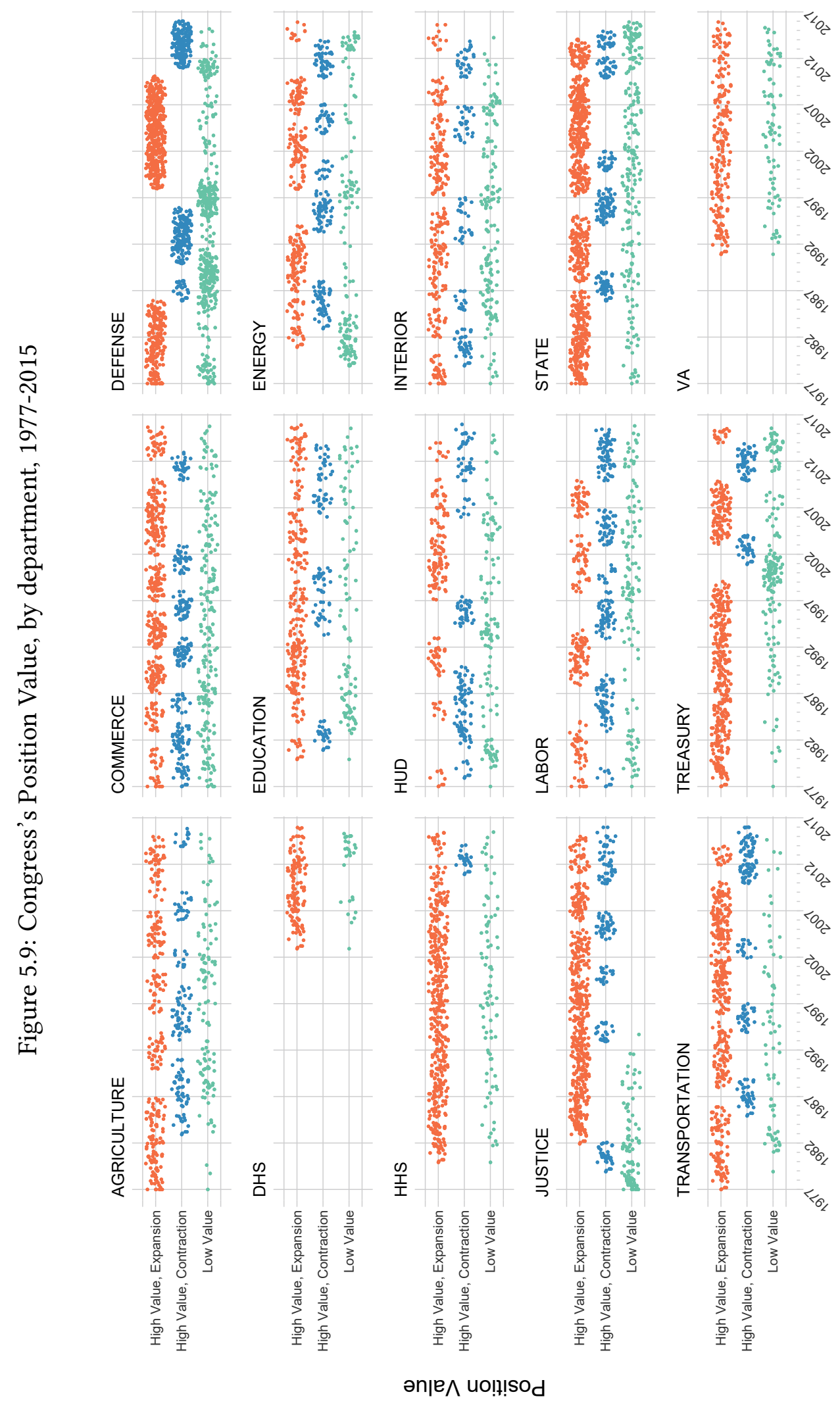


sequently, we would expect larger masses of position markers in the "High Value (expansion)" category for the State Department during the Bush administration (1989-1993), which results from expansion presidential policy priorities among the many high capacity positions. However, when Clinton took office, "he initiated a retrenchment of U.S. civilian presence abroad" that was met with similar congressional priorities for contraction at the State Department led by Republican Senator Jesse Helms (Konyndyk, 2017). ${ }^{16}$ Thus, we would expect larger masses of markers in the "High Value (contraction)" category for the State Department for both president Position Value (Figure 5.8) and Congress Position Value (Figure 5.9) during the Clinton administration. We see, in Figures 5.8 and 5.9, that all of these expectations for the State Department materialize in the data.

\subsection{Explaining Position Status with Position Value}

\subsubsection{Non-Parametric Analysis}

It is important to establish the empirical consequences of the keystone of my research: differentiating between vacancies left as empty positions and those filled with an interim appointee. The non-parametric cross-tabulations of the distributions reported in Tables 5.6 and 5.7 clearly demonstrate the significance of this distinction. Table 5.6 shows that, under the conventional definition, vacancies appear to be similarly distributed, accounting for approximately 19 percent of PAS positions in each category of president Position Value. Moreover, the distributions of permanent appointees and vacancies are not statistically significantly different at a 5 percent level. However, when we define vacancies more precisely, as shown in Table 5.7, substantively and significantly different distributions emerge.

\footnotetext{
${ }^{16}$ As Konyndyk (2017) writes, "Clinton also signed off on debilitating cuts-championed by Senator Jesse Helms-to U.S. civilian presence and staffing levels overseas activities [...] Helms pushed Clinton to eliminate several foreign affairs agencies and consolidate their functions into the State Department."
} 
Table 5.6: Distribution of Permanent Appointees and Vacancies

\begin{tabular}{|c|c|c|c|}
\hline & & $\begin{array}{l}\text { Percent } \\
\text { PAS Pos }\end{array}$ & $\begin{array}{l}\text { e of } \\
\text { ons }\end{array}$ \\
\hline & & $\begin{array}{l}\text { Permanent } \\
\text { Appointees }\end{array}$ & Vacancies \\
\hline President & High Value (expansion) & $79.7 \%$ & $20.3 \%$ \\
\hline Position & High Value (contraction) & $80.9 \%$ & $19.1 \%$ \\
\hline Value & Low Value & $81.1 \%$ & $18.9 \%$ \\
\hline
\end{tabular}

Specifically, Table 5.7 reports that empty positions and interim appointees vary considerably across the categories of president Position Value. In particular, 11.2 percent of "High Value (expansion)" positions are filled with interim appointees, compared to 9.2 percent left empty; and 9.8 percent of "High Value (contraction)" positions were left empty compared to 9.3 percent with interims. In other words, 55 percent of vacancies in "High Value (expansion)" positions and 54 percent of "Low Value" positions were filled with interim appointees, while 51 percent of "High Value (contraction)" positions were left empty; and we can statistically differentiate between these percentages at a less than ten percent level. Recall, my model predicts that presidents are more likely to leave positions empty that are "High Value (contraction)" and are more likely to appoint interims to positions that are "Low Value" and "High Value (expansion)." Thus, without controlling for any other factors, the distributions presented in Table 5.7 align with my theoretical expectations.

Critically, the Department of Defense houses a considerable proportion of Executive department PAS positions (nearly 15 percent), and, uniquely, decisions about defense policy outputs are fundamentally decisions about defense personnel. This starkly differs with the policy outputs from all the other departments as policies are not centered on departmental personnel. When we examine the distribution of permanent appointees, empty positions, and interim appointees 
Table 5.7: Distributions of Permanent Appointees, Empty Positions, and Interim Appointees

\begin{tabular}{lcccc|cc} 
& \multicolumn{2}{c}{ Percentage of PAS Positions } & \multicolumn{2}{c}{ Vacant PAS Positions } \\
\cline { 2 - 6 } & \multicolumn{2}{c}{$\begin{array}{c}\text { Permanent } \\
\text { Appointees }\end{array}$} & $\begin{array}{c}\text { Empty } \\
\text { Positions }\end{array}$ & $\begin{array}{c}\text { Interim } \\
\text { Appointees }\end{array}$ & $\begin{array}{c}\text { Empty } \\
\text { Positions }\end{array}$ & $\begin{array}{c}\text { Interim } \\
\text { Appointees }\end{array}$ \\
\cline { 2 - 6 } $\begin{array}{l}\text { Position } \\
\text { Value }\end{array}$ & $\begin{array}{c}\text { High Value } \\
\text { (expansion) }\end{array}$ & $79.7 \%$ & $9.2 \%$ & $11.2 \%$ & $45.1 \%$ & $54.9 \%$ \\
& $\begin{array}{c}\text { High Value } \\
\text { (contraction) }\end{array}$ & $80.9 \%$ & $9.8 \%$ & $9.3 \%$ & $51.4 \%$ & $48.6 \%$ \\
& Low Value & $81.1 \%$ & $8.7 \%$ & $10.2 \%$ & $46.2 \%$ & $53.8 \%$ \\
\hline
\end{tabular}

Note: For the percentage of overall PAS positions $(\mathrm{N}=10,331): \chi^{2}=8.5791, p=0.073$

For the percentage of vacant PAS positions $(\mathrm{N}=2,023): \chi^{2}=5.8564 p=0.053$

across the PAS positions in non-Defense Executive departments, we find a starker pattern.

As Table 5.8 displays, 12.3 percent of "High Value (expansion)" non-Defense positions are filled with interim appointees, compared to 8.5 percent left empty; and 9.4 percent of "High Value (contraction)" non-Defense positions were left empty compared to 9.5 percent with interims. In other words, by excluding Department of Defense positions, we see that 59 percent of vacancies in "High Value (expansion)" positions and 57 percent of "Low Value" positions were filled with interim appointees, while 50 percent of "High Value (contraction)" positions were left empty. Moreover, we can statistically differentiate between these percentages at a less than five percent level. Recall, I posit that presidents are more likely to appoint interims to positions that are "Low Value" and "High Value (expansion)." The distributions presented in Tables 5.7 and 5.8, without controlling for any other factors, align with my theoretical expectations.

Importantly, the three-category Position Status from these cross-tabulations does not indicate whether vacant positions had nominees submitted for Senate confirmation. However, when we examine the five-category construction of Position Status - which does account for nominations - we see that similar patterns clearly emerge. First, as Table 5.9 reports, vacant PAS positions that are "High Value (contraction)," 43.2 percent were left empty with no nominee, compared 
Table 5.8: Distributions of Permanent Appointees, Empty Positions, and Interim Appointees, excluding the Department of Defense

\begin{tabular}{|c|c|c|c|c|c|c|}
\hline & & \multicolumn{3}{|c|}{ Percentage of PAS Positions } & \multicolumn{2}{|c|}{$\begin{array}{c}\text { Percentage of } \\
\text { Vacant PAS Positions }\end{array}$} \\
\hline \multirow{4}{*}{$\begin{array}{l}\text { President } \\
\text { Position } \\
\text { Value }\end{array}$} & & $\begin{array}{l}\text { Permanent } \\
\text { Appointees }\end{array}$ & $\begin{array}{l}\text { Empty } \\
\text { Positions }\end{array}$ & $\begin{array}{l}\text { Interim } \\
\text { Appointees }\end{array}$ & $\begin{array}{c}\text { Empty } \\
\text { Positions }\end{array}$ & $\begin{array}{c}\text { Interim } \\
\text { Appointees }\end{array}$ \\
\hline & $\begin{array}{l}\text { High Value } \\
\text { (expansion) }\end{array}$ & $79.25 \%$ & $8.5 \%$ & $12.3 \%$ & $40.8 \%$ & $59.2 \%$ \\
\hline & $\begin{array}{l}\text { High Value } \\
\text { (contraction) }\end{array}$ & $81.15 \%$ & $9.4 \%$ & $9.5 \%$ & $49.6 \%$ & $50.4 \%$ \\
\hline & Low Value & $80.3 \%$ & $8.5 \%$ & $11.2 \%$ & $43.3 \%$ & $56.7 \%$ \\
\hline
\end{tabular}

Note: For the percentage of overall PAS positions $(\mathrm{N}=8,799): \chi^{2}=13.1630, p=0.011$

For the percentage of vacant PAS positions $(\mathrm{N}=1,751): \chi^{2}=9.7474 p=0.008$

Table 5.9: Distributions of Vacant PAS Positions: Empty Positions and Interim Appointees, With and Without Nominees (1981-2015)

Percentage of Vacant PAS Positions

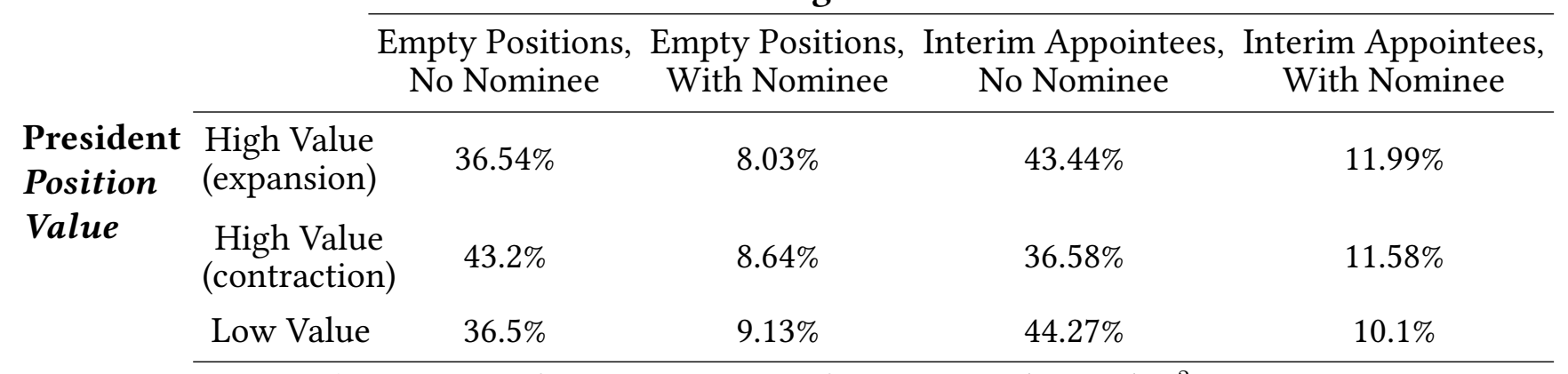

Note: For the percentage of vacant PAS positions from 1981-2015 ( $\mathrm{N}=1,943): \chi^{2}=10.9899, p=0.089$.

For the percentage of vacant PAS positions without nominees $(\mathrm{N}=1,557): \chi^{2}=9.3970, p=0.009$.

For the percentage of vacant PAS positions with nominees $(\mathrm{N}=386): \chi^{2}=1.4018, p=0.496$

to the 36.58 percent that were filled with interim appointees and no nominee. Since my theory predicts that presidents are more likely to leave "High Value (contraction)" positions empty, without submitting a nominee, this patterns aligns with our expectations. Similarly, we can also see in Table 5.9, that 43.44 percent of vacant "High Value (expansion)" and 44.27 percent of vacant "Low Value" positions are filled with interim appointees and have no nominee awaiting confirma- 
tion, compared to 36 percent of these positions left empty. We can also statistically differentiate these percentages of vacant positions without nominees across the categories of president $\mathrm{Po}^{-}$ sition Value at a less than one percent level. This, too, aligns with my theoretical expectations. Alternatively, while the expected patterns for vacant positions with nominees emerge as well higher percentages of interim appointees with nominees than empty positions with nominees in the "High Value (expansion)" and "Low Value" categories- they are not statistically distinguishable.

Each of these sets of comparisons demonstrate that when we coarsely group empty positions and interim appointees together, as the conventional definition of vacancies does in Table 5.6, we unfortunately and inaccurately perceive little effect of strategic behavior on the misleadingly similar distributions. My research remedies that oversight. In the next section, I analyze the patterns that emerged from this non-parametric analysis in the context of a parametric likelihood model, which allows for formal statistical inference about the role Position Value plays in a president's calculus to fill or not fill vacant positions.

\subsection{Explaining the Likelihood of Position Status with Position Value}

\subsubsection{Estimation Strategy: Multinomial Probit Regression}

Ultimately, this dissertation aims to examine what underpins and predicts the president's choice to leave certain positions empty and fill others with interim or permanent appointees. To do this, we need to employ an estimation strategy that accommodates a categorical outcome variable, such as multinominal probit or logistic regressions. Importantly, estimating the likelihood of empty positions and interim appointees (with and without the nomination distinction) also requires a statistical model that allows for comparisons between pairs of position status alternatives, while not imposing the independence of irrelevant alternatives (IIA) assumption. Notably, 
the strategic nature of the decision to fill with either an interim or confirmed nominee or not to fill a position at all violates the IIA assumption, which requires that evaluations between two alternatives do not change if a third alternative is added or dropped (Greene and Hensher, 2010). Obviously, adding the alternative to fill with an interim appointee will change the likelihood evaluation between leaving the position empty and filling it with a confirmed appointee. Consequently, a multinomial probit (MNP) model, ${ }^{17}$ which can facilitate comparisons between the position status alternatives and does not require the IIA assumption, ${ }^{18}$ is most appropriate for this analysis.

Accordingly, I estimate two MNP models of Position Status - modelling the three category variable without the nominee distinction separate from the five category variable with the nominee distinction - with cluster-robust standard errors to account for clustering within administrations. I estimate the likelihood of each Position Status as a function of the key predictor variables: Position Value for the president and for Congress and the interaction between them. ${ }^{19}$ Critically, I separately estimate two distinct likelihood models using the three-category and five-category measures of Position Status. In each of these models, I control for whether the administration is new and in transition or if it is an established administration; that is, Established Administration indicates that the administration is no longer in its first year. ${ }^{20}$ Although the months between election and inauguration are traditionally focused on assembling the top leadership in a new administration, the shear volume of vacant PAS positions due to structural turnover likely explains

\footnotetext{
${ }^{17}$ Multinomial probit models assume an underlying utility associated with each alternative $m$ that is partly determined by a random, normally distributed error term, thereby generating a random utility model. Specifically, the alternative $k$ is chosen when the utility from that alternative is larger than the utility from any other alternative.(Greene and Hensher, 2010)

${ }^{18}$ Given that the errors are distributed by a multivariate normal distribution (Greene and Hensher, 2010)

${ }^{19}$ Position Value $\left(V_{i y_{j t}}\right)$ is, fundamentally, the combination of Policy Priorities and Position Capacity. Kam and Franzese (2009) show that the individual terms of an interaction do not have to be included when there is clear theoretical evidence that points toward not including them. My theory offers a clear theoretical expectation that the predictors of the outcome variable are the various combinations of Policy Priorities and Position Capacity captured in Position Value, not the individual terms themselves. Consequently, I do not include them in this model specification; however, the results from this estimation are robust to their inclusion.

${ }^{20}$ The results presented below are robust to specifications that include only established administration years (i.e., observations from non-first years).
} 
at least some of the variation in empty positions and interim posts, outside of presidential strategic behavior. Additionally, I control for the department average time that nominations spent in the Senate each year, which operationalizes the Senate's Permanence and Oversight parameter from my theoretical model. Lastly, I control for whether the Senate majority is the same party as the president (Co-Partisan Control), which likely impacts the ease of confirmation that makes permanent appointees more valuable. Lastly, I include a control for the Department of Defense and administration fixed effects to control for time-invariant characteristics of administrations.

Specifically, as per Greene and Hensher (2010), the structural equation for the multinomial probit model is the following:

$$
\begin{aligned}
U_{y_{j t}}= & \alpha_{y_{j t}}+\beta_{V_{P}} V_{P y_{j t}}^{\prime}+\beta_{V_{C}} V_{C y_{j t}}^{\prime}+\beta_{V_{P x C}} V_{P y_{j t}}^{\prime} V_{C y_{j t}}^{\prime}+ \\
& \gamma_{1} E A_{t}^{\prime}+\gamma_{2} T_{j}^{\prime}+\gamma_{3} C P_{t}^{\prime}+\gamma_{4} D_{j}^{\prime}+\gamma_{5} A_{t}^{\prime}+\varepsilon
\end{aligned}
$$

such that

$$
\operatorname{Pr}\left(y_{j t}=S_{m}\right)=\operatorname{Pr}\left(u_{S_{m}}>u_{S_{k}} \forall m \neq k\right)
$$

for

$$
S_{1 m} \begin{cases}0 & \Rightarrow \text { Empty } \\ 1 \Rightarrow & \text { Interim Appointee } \\ 2 & \Rightarrow \text { Permanent Appointee }\end{cases}
$$

or

$$
S_{2 m} \begin{cases}1 & \Rightarrow \text { Empty, No Nominee } \\ 2 & \Rightarrow \text { Empty, Nominee } \\ 3 & \Rightarrow \text { Interim Appointee, No Nominee } \\ 4 & \Rightarrow \text { Interim Appointee, Nominee } \\ 5 & \Rightarrow \text { Permanent Appointee }\end{cases}
$$

where

$S_{1}$ is the status of a position $y_{j t}$ in department $j$ for year $t$, which indicates whether it is 
empty, filled with an interim appointee, or filled with a permanent appointee;

$S_{2}$ is the status of a position $y_{j t}$ in department $j$ for year $t$, which indicates whether it is empty without a nominee, empty with a nominee, filled with an interim appointee without a nominee, filled with an interim with a nominee, or filled with a permanent appointee;

$V_{P y_{j t}}$ is Position Value for the president;

$V_{C y_{j t}}$ is Position Value for Congress;

$V_{P y_{j t}} V_{C y_{j t}}$ is the interaction between the Position Value for the president and Congress, as driven by my theoretical expectations;

$E A_{t}$ and $\gamma_{1}$ is Established Administration and its effects;

$T_{j t}$ and $\gamma_{2}$ is average time nominations for department $j$ spent in the Senate in year $t$ and its effects; ${ }^{21}$

$C P_{t}$ and $\gamma_{3}$ is Co-Partisan Control of the Senate and its effects;

$D_{j}$ indicates the Department of Defense; $A_{t}$ is administration fixed effects; and $\varepsilon$ are the multivariate normally distributed errors.

These multi-choice models simultaneously test the four main hypotheses offered in Chapter 4, so for convenience, I list them again here and will address them each in turn.

H1. Empty Position Hypothesis: A president is more likely to leave high value positions empty when prioritizing policy contraction.

H2. Interim Appointee Hypothesis: A president will always immediately fill low value positions with interim appointees, and is more likely to immediately fill high value positions with interims when prioritizing policy expansion.

H3. Permanent Appointee Hypothesis: Confirmed appointees are more likely in high value $P A S$ positions when the president prioritizes expansion, the Senate does not prioritize contraction, and the bargaining cost is sufficiently small (below the president's cutpoint).

\footnotetext{
${ }^{21}$ The variable indicating the average time that nominations spent in the Senate for each department in each year is the corollary to the formalized Permanence and Oversight parameter.
} 
H4. No Nominee Hypothesis: Presidents will not submit a nominee for confirmation without also appointing an interim appointee.

The Empty Position Hypothesis predicts that presidents are more likely to leave "High Value (contraction)" positions empty. Alternatively, the Interim Appointee Hypothesis predicts that presidents will fill "Low Value" and "High Value (expansion)" positions with interim appointees. In other words, we would expect if two positions faced the same political context and were both high value, the one under expansion presidential policy priorities would face a higher probability of being filled with an interim appointee and the one under contraction policy priorities would face a higher probability of being left empty. Furthermore, the Permanent Appointee Hypothesis predicts that, all else equal, presidents will submit nominees for "High Value (expansion)" positions as long as they are also Senate "Low Value" and "High Value (expansion)" and will be confirmed. Thus, we would expect that high-value positions under presidential expansion priorities will face a lower probability of being filled with a permanent appointee under Senate contraction priorities than otherwise. However, given the sequential nature of filling positions - namely, that president must first choose to fill them immediately and then submit a nominee for confirmation - the No Nominee Hypothesis predicts that, when a nominee submitted, "High Value (expansion)" positions are more likely to be filled with an interim instead of left empty. The following two sections will test these hypotheses by estimating the above-specified multinomial probit model, first, on the three-category Position Status, which addresses H1-H3, and second, on the five-category Position Status, which addresses $\mathrm{H} 1-\mathrm{H} 4$.

\subsubsection{Results: Three-Category Position Status}

Table 5.10 reports the estimated coefficients and cluster-robust standard errors with the threecategory construction of Position Value. ${ }^{22}$ The coefficients for the baseline choice, "Permanent

\footnotetext{
${ }^{22}$ The structure of the three-category Position Status dependent variable does not indicate nominations, and does not require the inclusion of the variable measuring average time a nomination spent in the Senate. Tests for the
} 
Table 5.10: Likelihood Models of Presidential Appointment Strategy in Executive Departments, 1977-2015

Multinominal Probit

DV: 3 Category Position Status

\begin{tabular}{|c|c|c|c|}
\hline & & $\begin{array}{l}\text { (1) } \\
\text { Empty } \\
\text { Position }\end{array}$ & $\begin{array}{c}(2) \\
\text { Interim } \\
\text { Appointee }\end{array}$ \\
\hline $\begin{array}{l}\text { President } \\
\text { Position Value }\end{array}$ & $\begin{array}{l}\text { High Value (expansion) } \\
\text { High Value (contraction) }\end{array}$ & $\begin{array}{l}0.147 \\
(0.11) \\
-0.205 \\
(0.35)\end{array}$ & $\begin{array}{c}-0.285^{* *} \\
(0.11) \\
-0.191 \\
(0.38)\end{array}$ \\
\hline $\begin{array}{l}\text { Congress } \\
\text { Position Value }\end{array}$ & $\begin{array}{l}\text { High Value (expansion) } \\
\text { High Value (contraction) }\end{array}$ & $\begin{array}{c}-0.193^{* *} \\
(0.05) \\
-0.233 \\
(0.17)\end{array}$ & $\begin{array}{c}-0.138^{*} \\
(0.07) \\
-0.203^{* *} \\
(0.06)\end{array}$ \\
\hline $\begin{array}{l}\text { President X Congress } \\
\text { Position Value }\end{array}$ & $\begin{array}{l}\text { High Value High Value } \\
\text { (contraction) X (contraction) } \\
\text { High Value High Value } \\
\text { (contraction) X (expansion) } \\
\text { High Value High Value } \\
\text { (expansion) X (contraction) } \\
\text { High Value High Value } \\
\text { (expansion) X (expansion) }\end{array}$ & $\begin{array}{l}0.365 \\
(0.49) \\
0.488 \\
(0.38) \\
-0.201 \\
(0.30) \\
-0.068 \\
(0.10)\end{array}$ & $\begin{array}{c}0.160 \\
(0.33) \\
0.856 \\
(0.29) \\
0.138 \\
(0.09) \\
0.418^{* *} \\
(0.14)\end{array}$ \\
\hline \multicolumn{2}{|c|}{ Established Administration } & $\begin{array}{c}-1.078^{* *} \\
(0.06)\end{array}$ & $\begin{array}{c}-0.689^{* *} \\
(0.06)\end{array}$ \\
\hline \multicolumn{2}{|l|}{ Co-Partisan Control } & $\begin{array}{l}0.027 \\
(0.27)\end{array}$ & $\begin{array}{l}0.041 \\
(0.06)\end{array}$ \\
\hline \multicolumn{2}{|c|}{ Department of Defense } & $\begin{array}{l}0.227^{*} \\
(0.11)\end{array}$ & $\begin{array}{c}-0.452^{* *} \\
(0.09)\end{array}$ \\
\hline \multicolumn{2}{|c|}{ Administration Fixed Effects } & $\checkmark$ & $\checkmark$ \\
\hline \multicolumn{2}{|l|}{ Intercept } & $\begin{array}{c}-1.141^{* *} \\
(0.29)\end{array}$ & $\begin{array}{c}-1.354^{* *} \\
(0.15)\end{array}$ \\
\hline
\end{tabular}

Note: $\mathrm{N}=10290$ in all models. Table entries are multinomial probit estimates of Position Status.

The omitted (baseline) category is "Permanent Appointee," its coefficients have been normalized to zero in order to identify the model and allow for comparisons across equations. Reference category for Position Value is "Low Value." Cluster-robust standard errors appear in parentheses. ${ }^{*} \mathrm{p}<0.05,{ }^{* *} \mathrm{p}<0.01$ 
Table 5.11: Predicted Probabilities of Position Status Outcomes

\begin{tabular}{|c|c|c|c|c|}
\hline & & $\begin{array}{l}\text { Permanent } \\
\text { Appointee }\end{array}$ & $\begin{array}{c}\text { Interim } \\
\text { Appointee }\end{array}$ & $\begin{array}{l}\text { Empty } \\
\text { Position }\end{array}$ \\
\hline \multirow{6}{*}{$\begin{array}{l}\text { President } \\
\text { Position } \\
\text { Value }\end{array}$} & \multirow[t]{2}{*}{ High Value (expansion) } & 0.853 & 0.083 & 0.063 \\
\hline & & $(0.01)$ & $(0.01)$ & $(0.01)$ \\
\hline & \multirow[t]{2}{*}{ High Value (contraction) } & 0.854 & 0.073 & 0.073 \\
\hline & & $(0.02)$ & $(0.01)$ & $(0.02)$ \\
\hline & \multirow[t]{2}{*}{ Low Value } & 0.856 & 0.087 & 0.057 \\
\hline & & $(0.01)$ & $(0.01)$ & $(0.01)$ \\
\hline \multirow{6}{*}{$\begin{array}{l}\text { Congress } \\
\text { Position } \\
\text { Value }\end{array}$} & \multirow[t]{2}{*}{ High Value (expansion) } & 0.848 & 0.087 & 0.065 \\
\hline & & $(0.01)$ & $(0.01)$ & $(0.01)$ \\
\hline & \multirow[t]{2}{*}{ High Value (contraction) } & 0.874 & 0.071 & 0.055 \\
\hline & & $(0.015)$ & $(0.01)$ & $(0.01)$ \\
\hline & \multirow[t]{2}{*}{ Low Value } & 0.848 & 0.078 & 0.074 \\
\hline & & $(0.01)$ & $(0.01)$ & $(0.01)$ \\
\hline \multirow{4}{*}{$\begin{array}{l}\text { Established } \\
\text { Administration }\end{array}$} & \multirow[t]{2}{*}{ New Administration } & 0.646 & 0.146 & 0.208 \\
\hline & & $(0.02)$ & $(0.01)$ & $(0.02)$ \\
\hline & \multirow[t]{2}{*}{ Established Administration } & 0.854 & 0.081 & 0.064 \\
\hline & & $(0.01)$ & $(0.003)$ & $(0.01)$ \\
\hline \multirow{4}{*}{$\begin{array}{l}\text { Co-Partisan } \\
\text { Control }\end{array}$} & \multirow[t]{2}{*}{ Divided Control } & 0.86 & 0.077 & 0.062 \\
\hline & & $(0.02)$ & $(0.005)$ & $(0.02)$ \\
\hline & \multirow[t]{2}{*}{ Co-Partisan Control } & 0.854 & 0.081 & 0.064 \\
\hline & & $(0.01)$ & $(0.003)$ & $(0.01)$ \\
\hline \multirow{4}{*}{ Department } & \multirow[t]{2}{*}{ Defense } & 0.866 & 0.044 & 0.091 \\
\hline & & $(0.02)$ & $(0.004)$ & $(0.02)$ \\
\hline & \multirow[t]{2}{*}{ Non-Defense } & 0.85 & 0.09 & 0.06 \\
\hline & & $(0.01)$ & $(0.004)$ & $(0.01)$ \\
\hline
\end{tabular}

Note: Table entries are the predicted probabilities of each position status given specified row variables. Standard errors are in parentheses. Bold and colored entries denote alignment with theoretical expectations. Explanatory variables were held constant at their mean values. 
Appointee," have been normalized to zero in order to identify the model and allow for comparisons across equations. We can see that president Position Value significantly contributes to the likelihood of both an empty position and interim appointee. However, since parameter estimates from MNP models display the multinomial log-odds, relative to the base category, and coefficients for categorical variables are relative to the omitted category, their interpretation can be a bit onerous. Instead, as reported in Table 5.11, the predicted probabilities of each position status for each category of the explanatory variables, with all other variables at their means, reveals the precise nature and magnitude of these effects. Additionally, for visual ease, Figure 5.10 presents the predicted probabilities of empty positions and interim appointees for each category of president's Position Value, the variable at the core of each hypothesis.

Figure 5.10: Adjusted Predictions of the Probability of Empty Positions and Interim Appointees, given President's Position Value

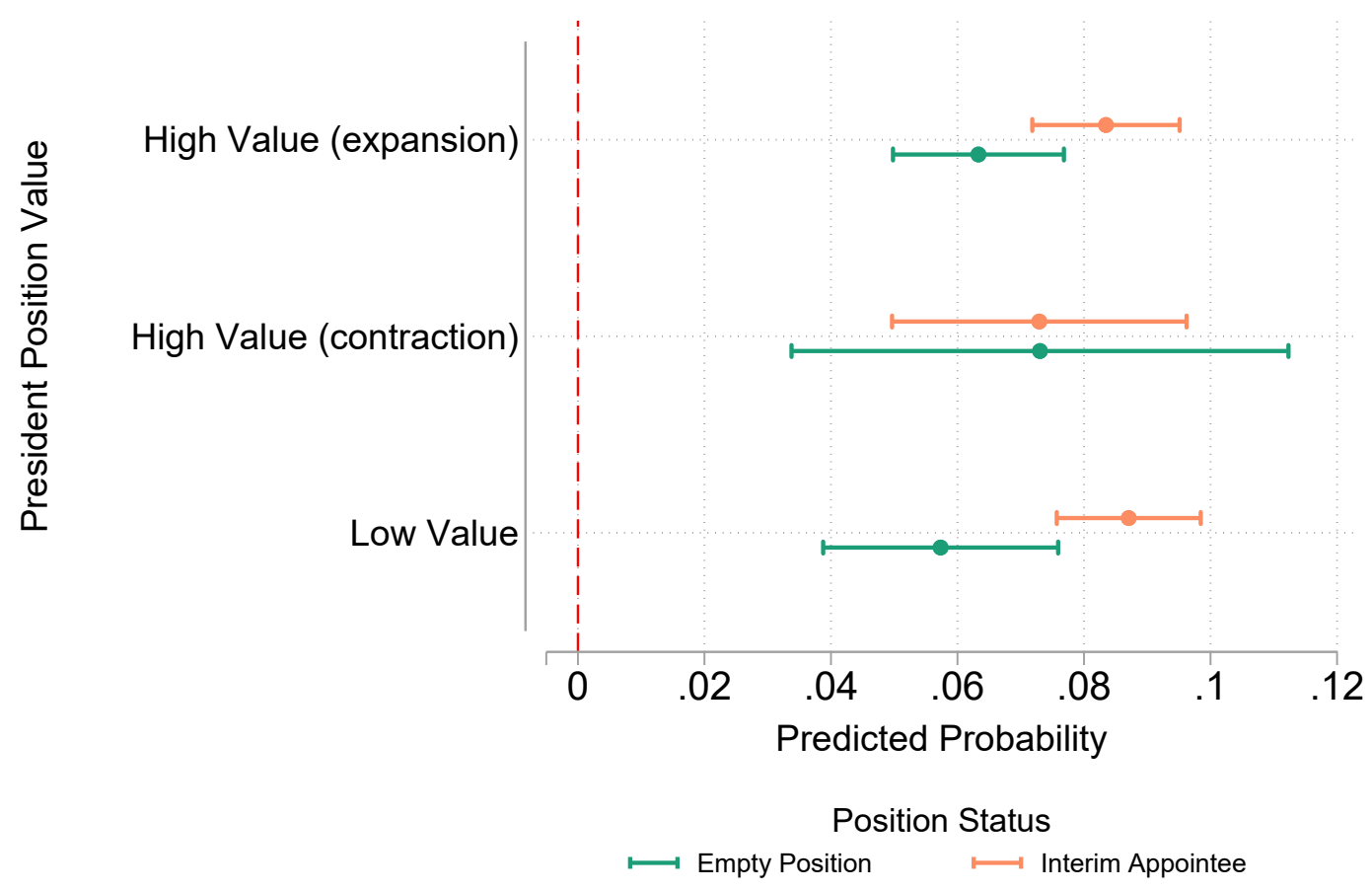

model's sensitivity to the variable's inclusion supports excluding it as the results do not change significantly or substantially. However, the estimation on the five-category Position Status does require the inclusion of the variable to avoid omitted variable bias. 


\section{H1. Empty Position Hypothesis}

The Empty Position Hypothesis states that presidents are more likely to leave high value positions empty when they have contraction policy priorities. Consequently, if the hypothesis is accurate, then we would expect to find a higher predicted probability of empty positions when president Position Value is "High Value (contraction)" than otherwise. The last column in Table 5.11 reports the results relating to the Empty Position Hypothesis. We can see that, as expected, "High Value (contraction)" positions have a higher predicted probability (7.3\%) of being empty than "High Value (expansion)" positions with a predicted probability of $6.3 \%$, and even higher than "Low Value" positions with a predicted probability of 5.7\%. However, neither of these differences are statistically significant at even the 10 percent level ( $p=0.541$ and $p=0.206$, respectively), which is more evident from their overlapping confidence intervals displayed in Figure 5.10. When we examine the predicted probabilities of an empty position, within each category of president Position Value, by Congress Position Value, as shown in Figure 5.11, an interesting result emerges.

Figure 5.11: Adjusted Predictions of the Probability of an Empty Position, given President and Congress Position Value

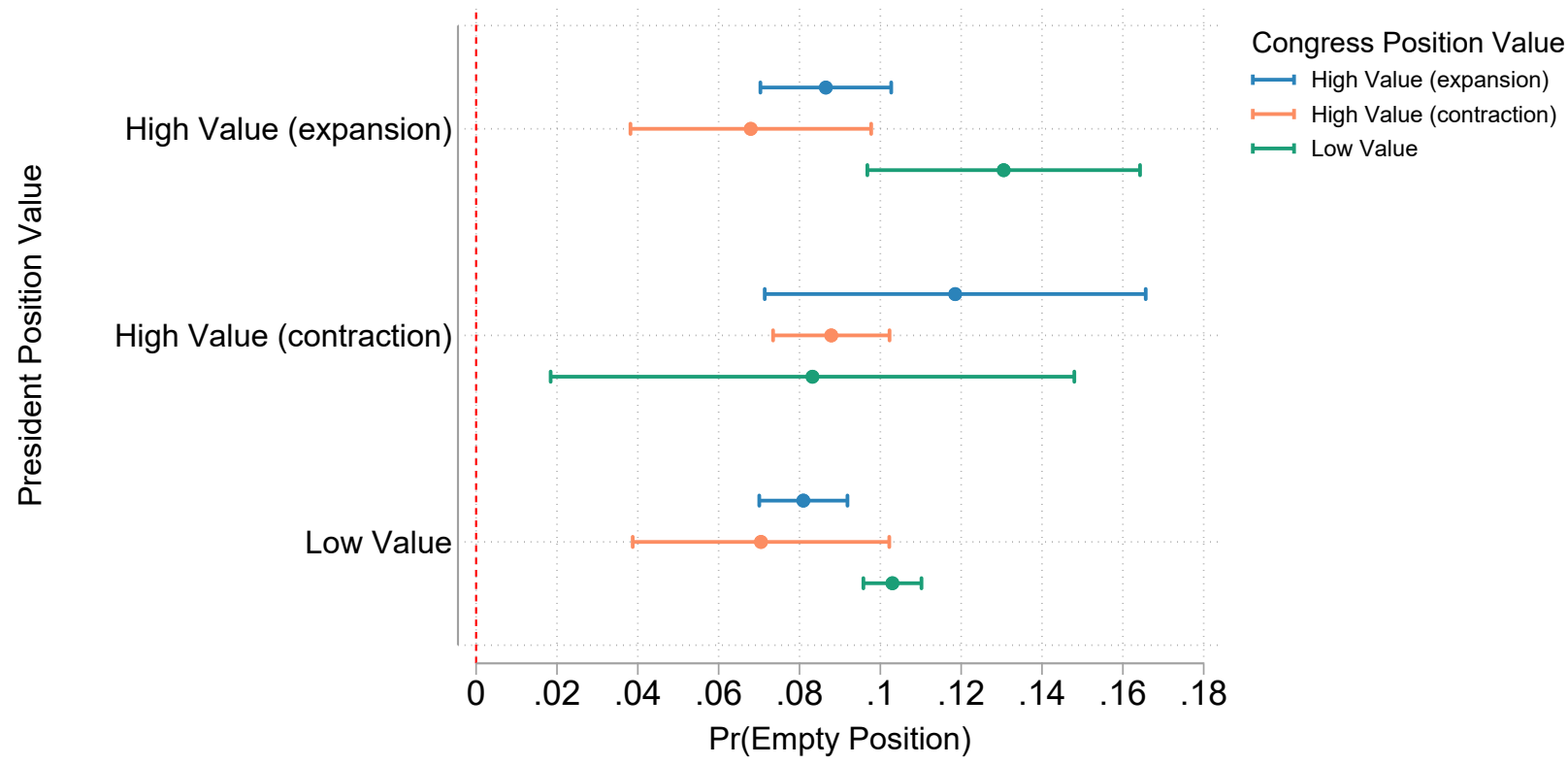


When a position is "High Value (contraction)" to the president, the likelihood of it being left empty is higher when Congress prioritizes expansion than otherwise. Specifically, the predicted probability of an empty position when president Position Value is "High Value (contraction)" is $11.9 \%$ when Congress Position Value is "High Value (expansion)" compared to $8.32 \%$ at "Low Value" and $8.79 \%$ at "High Value (contraction)." Moreover, the difference between the predicted probabilities under Congress "High Value (expansion)" and Congress "High Value (contraction)" are statistically distinguishable at a less than 10 percent level $(p=0.081)$. This aligns with the president's equilibrium strategy presented in Lemma $3{ }^{23}$ that the president will not appoint an interim and not nominate, thereby generating an empty position, when the position is "High Value (contraction)" to the president but is "High Value (expansion)" to the Senate. This result aligns with my theoretical expectations. The core of the Empty Position Hypothesis is that, when president Position Value is "High Value (contraction)," empty positions are more likely than the position filled by interim or permanent appointee. However, as Table 5.11 and Figure 5.10 show, when president Position Value is "High Value (contraction)," the predicted probabilities of an empty position and an interim appointee are equally as likely and not statistically distinguishable from each other.

Thus, the first likelihood model offers little support for the Empty Position Hypothesis and there are two potential reasons. First, the mixed result could be driven by a limitation of the data. Empty positions could be de facto filled temporarily by individuals who are performing all the powers and duties of the positions without having the official title of "Acting" appointee. ${ }^{24}$ A more nuanced distinction between these two kinds of empty positions - ones that are actually empty and those empty only in name - could yield more supportive results. Second, this result could be driven by the concentration of empty positions within departments. This likelihood model, with

\footnotetext{
${ }^{23}$ See Chapter 4, Section 3.

${ }^{24}$ Importantly, someone who signs official documents as "performing the duties of X position," who is essentially an interim appointee without the official "Acting" designation, is not the same as subdelegating duties of the position to other filled positions.
} 
the position status outcome at the position level, measures the probability that any one position is empty. It does not address the incidence of empty positions within a department. The generality of the theoretical hypotheses outlined above allow for considerations of both likelihood and incidence of empty positions and interim appointees within departments. Since congressional and presidential policy priorities correspond to each department, we would expect a larger number of empty positions when presidents prioritize contraction and a larger number would be filled with an interim when the president prioritizes expansion. In fact, the analysis of the aggregated counts of position status, as outlined in Chapter 7, shows that contraction policy priorities do increase the number of empty high capacity positions.

\section{H2. Interim Appointee Hypothesis}

The Interim Appointee Hypothesis states that presidents are more likely to fill positions with interim appointees when they are low value and, if they are high value, when presidents have expansion policy priorities. If the hypothesis is accurate, we would expect to find higher predicted probabilities of interim appointees when president Position Value is "Low Value" and "High Value (expansion)," than otherwise. And this is indeed what we find. The second column in Table 5.11 reports the results relating to the Interim Appointee Hypothesis. Specifically, exactly as predicted, interim appointees are more likely in "High Value (expansion)" positions, with a predicted probability of $8.3 \%$, than in "High Value (contraction)" positions with a predicted probability of $7.3 \%$. This difference in predicted probabilities is statistically significant at the 10 percent level $(p=0.080)$. While "Low Value" positions also have higher predicted probability of interim appointees (8.7\%) than "High Value (contraction)," the difference is not statistically significant $(p=0.819)$.

Figure 5.10 also clearly illustrates that interim appointees are more likely than empty positions under the "High Value (expansion)" category of president Position Value. In fact, when presidents prioritize expansion, interim appointees in high capacity positions are over 30 percent 
more likely (predicted probability of $8.3 \%$ ), as empty high capacity positions (predicted probability of 6.3\%); and this difference is statistically significant $(p=0.033)$. Additionally, Table 5.11 and Figure 5.10 show that, as expected, "Low Value" positions are 45 percent more likely to be filled with an interim appointee, with a predicted probability of $8.7 \%$, than left empty, with a predicted probability of 5.7\%; and this difference is also statistically significant $(p=0.005){ }^{25}$

Recall we derive the Interim Appointee Hypothesis from Lemma 3 in Chapter 4, which states that, in equilibrium, presidents appoint interim appointees to "Low Value" and "High Value (expansion)" positions, no matter the Senate's Position Value. ${ }^{26}$ Empirically, we would expect no statistically significant difference in the predicted probabilities of an interim appointee under president Position Value of "High Value (expansion)" across the categories of Congress Position Value. In Figure 5.12, which displays the predicted probabilities of an interim appointee for each category of president Position Value evaluated at each category of Congress Position Value, we find evidence to support this expectation. Specifically, the predicted probabilities for interim appointees under the president Position Value category of "High Value (expansion)" are: 6.14\% for Congress "Low Value," 7.15\% for Congress "High Value (contraction)," and 9.91\% for Congress "High Value (expansion)." Moreover, the predicted probability of an interim when the position is "High Value (expansion)" to the president and Congress "Low Value" is significantly less- at a 5 percent level $(p=0.018)$ - than when it is Congress "High Value (expansion)." Yet, the other pairwise differences across these predicted probabilities are not statistically significant at even a 10 percent level.

Additionally, as expected, within the president Position Value category of "Low Value," we do not find a difference in the predicted probabilities of an interim appointee across the categories of Congress Position Value. When a position is "Low Value" to the president, we cannot statistically differentiate between the predicted probability under Congress "High Value (contraction)"

\footnotetext{
${ }^{25}$ Interims also appear to be equally as likely as empty positions under "High Value (contraction)", with predicted probabilities of $7.3 \%(p=0.997)$.

${ }^{26}$ Again, here Congress Position Value is an empirical proxy for Senate Position Value.
} 
Figure 5.12: Adjusted Predictions of the Probability of an Interim Appointee, given President and Congress Position Value

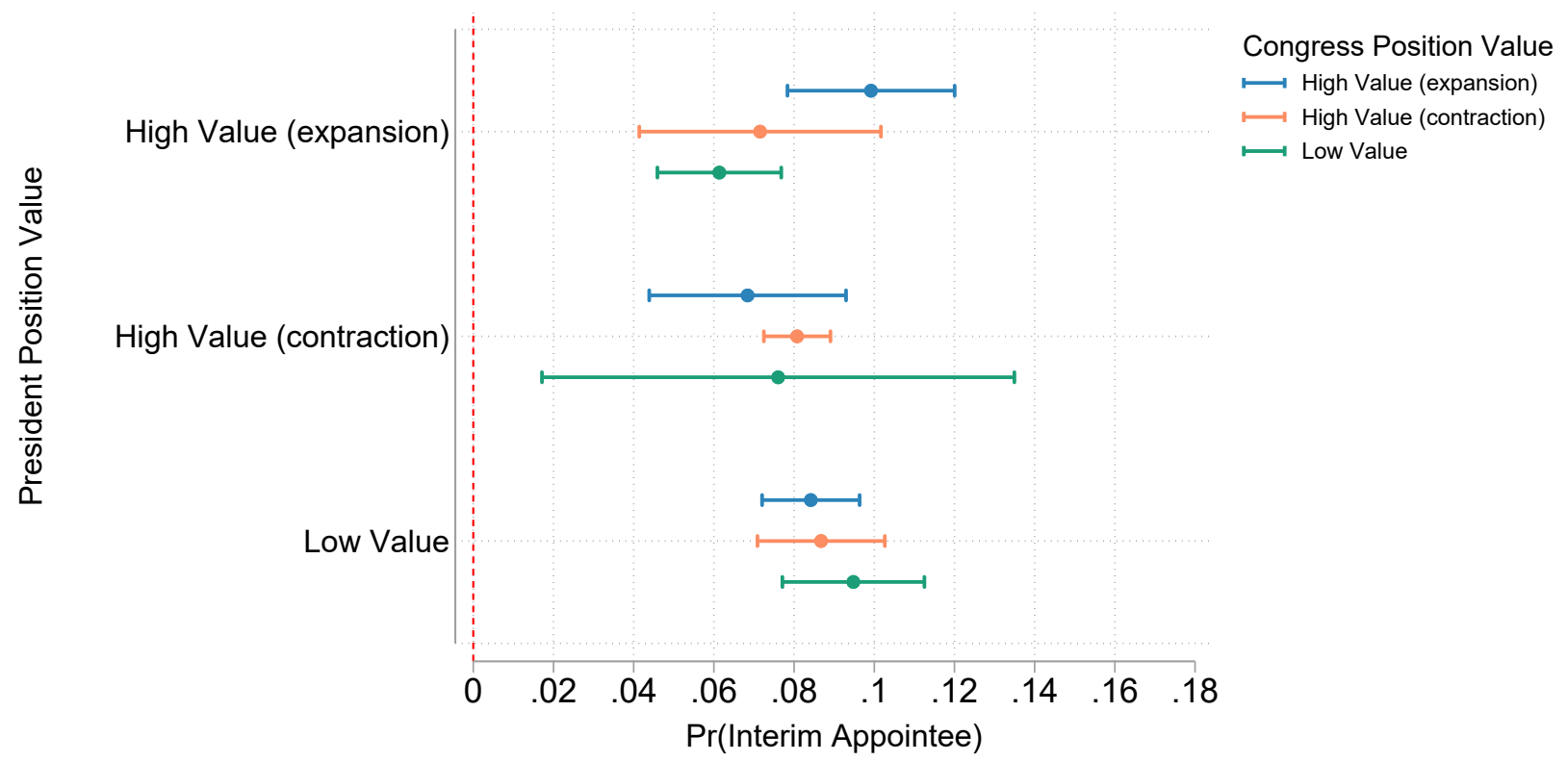

$(8.67 \%)$ and the predicted probabilities under Congress "Low Value" $(9.48 \% ; p=0.305)$ and under Congress "High Value (expansion)" (8.42\%; $p=0.205)$. Altogether, these results strongly support the Interim Appointee Hypothesis and offer considerable evidence that presidents use interim appointees to advance their policy goals.

\section{H3. Permanent Appointee Hypothesis}

The Permanent Appointee Hypothesis states that permanent, confirmed appointees are more likely in high value positions when the president has expansion policy priorities and the Senate does not have contraction policy priorities. If the hypothesis is accurate, then we would expect a high predicted probability of permanent appointees when president Position Value is "High Value (expansion)" and Congress Position Value is either "Low Value” or "High Value (expansion)." However, we do not find support for this hypothesis. The first column in Table 5.11 shows that 
all variables have their highest predicted probabilities for permanent appointee. This is expected given the distribution of Position Status, where permanent appointees fill 80 percent of positions. We can alse see in Table 5.11 that "Low Value" positions have the highest predicted probability, albeit only very slightly, of a permanent appointee (85.6\%). However, the predicted probability for "Low Value" positions is not statistically significantly different from the predicted probability of $85.4 \%$ for "High Value (contraction)" positions $(p=0.942)$, or the predicted probability of 85.3\% for "High Value (expansion)" positions $(p=0.793)$. The difference between the predicted probabilities for "High Value (expansion)" and "High Value (contraction)" are also not statistically significant $(p=0.964)$.

From these first results, the likelihood model appears to offer no support for the Permanent Appointee Hypothesis. However, the critical aspect of the Permanent Appointee Hypothesis is the requisite interaction between president Position Value and Congress Position Value. Whereas the president's first-mover advantage manifests as dictatorial control over the appointment of an interim or leaving an empty position, a position filled by a permanent appointee necessarily requires Senate confirmation. The Permanent Appointee Hypothesis predicts that confirmed appointees will fill PAS positions that are "High Value (expansion)" for the president when the Senate does not prioritize contraction. The implication of this condition is that we need to consider the interaction between president Position Value and Congress Position Value. Consequently, we need to examine the predicted probabilities of that interaction.

However, as Table 5.12 presents, the predicted probabilities of a permanent appointee, given the Position Value for both the president and Congress, continue to offer no statistically distinguishable pattern that would indicate strategic behavior. An explanation for this result might emerge from two different circumstances. First, perhaps this finding points to an enduring norm among presidents that the default appointment strategy is to fill positions with permanent appointees through Senate confirmation. Specifically, such an enduring norm would likely encourage presidents to not act rationally by appointing permanent appointees when they would be 
Table 5.12: Predicted Probabilities of Position Status Outcome: Permanent Appointee

\begin{tabular}{|c|c|c|c|c|}
\hline & & $\mathrm{Co}$ & ess Position $\mathrm{Va}$ & \\
\hline & & $\begin{array}{l}\text { High Value } \\
\text { (expansion) }\end{array}$ & $\begin{array}{l}\text { High Value } \\
\text { (contraction) }\end{array}$ & $\begin{array}{l}\text { Low } \\
\text { Value }\end{array}$ \\
\hline $\begin{array}{l}\text { President } \\
\text { Position }\end{array}$ & High Value (expansion) & $\begin{array}{l}0.839 \\
(0.01)\end{array}$ & $\begin{array}{l}0.885 \\
(0.02)\end{array}$ & $\begin{array}{c}0.843 \\
(0.017)\end{array}$ \\
\hline Value & High Value (contraction) & $\begin{array}{c}0.846 \\
(0.024)\end{array}$ & $\begin{array}{c}0.86 \\
(0.018)\end{array}$ & $\begin{array}{c}0.866 \\
(0.049)\end{array}$ \\
\hline & Low Value & $\begin{array}{c}0.859 \\
(0.013)\end{array}$ & $\begin{array}{l}0.868 \\
(0.01)\end{array}$ & $\begin{array}{c}0.83 \\
(0.016)\end{array}$ \\
\hline
\end{tabular}

Note: Table entries are the predicted probabilities of a Permanent Appointee given the specified category of president Position Value. Standard errors are in parentheses. Bold and colored entries denote alignment with theoretical expectations.

potentially better off with a vacancy. ${ }^{27}$

Alternatively, perhaps this finding highlights the permanence of a confirmed appointee while also calling into question the assumption that presidents dictate their own policy priorities. More specifically, policy priorities are subject to change within administrations - perhaps due to changing economic conditions, fluctuations in public opinion, or new policy actions necessary for responding to acute crises. And this shift might occur after a nominee is confirmed. ${ }^{28}$ Perhaps once presidents invest resources - political and otherwise - into nominees' confirmations, they are incentivized to see if the permanent appointees can advance the modified policy priorities before dismissing them to create a vacant position. Or, perhaps instead, once permanent appointees assume their offices, they instigate a shift in their president's policy priorities. ${ }^{29}$ In either case, strategic appointment behavior would be undetectable if the observed policy priorities for a per-

\footnotetext{
${ }^{27}$ Consider, for instance, if it were the case that presidents traditionally followed a norm in their appointment strategy that deferred to permanent appointees, even if their policy priorities are better served by a vacancy. Consider, now, that a president who forsakes that norm would maintain vacancies when they served his interests, yet he would also appear to be an anomaly for not seeking Senate confirmation. When, instead, he is atypically rational in his appointment strategy.

${ }^{28}$ If the change in policy priorities occurred after the nomination was submitted but before Senate confirmation, we might expect the president to withdraw the nomination.

${ }^{29}$ Both of these propositions would make for interesting inquiries but fall outside the scope of this dissertation.
} 
manent appointee are not aligned with the policy priorities from when that appointee was nominated.

\section{Additional Findings}

The controls included in this analysis also offer two interesting findings. First, permanent appointees are not significantly more likely during periods of co-partisan control versus periods of divided control $(p=0.775)$. This result is surprising since we would expect from previous work on appointees, ideology, and confirmation delay (e.g., McCarty and Razaghian, 1999) that permanent appointees would be significantly less likely under divided control. Instead, when we account for vacancies and include the capacity of the position to achieve policy priorities, permanent, confirmed appointees are not any more likely when the Senate majority party is the same as the president's party than when its not. Second, interim appointees are statistically significantly more likely in new administrations in their first year, with a predicted probability of $14.6 \%$, than in established ones, with a predicted probability of $8.1 \%(p=0.000)$. But established administrations are statistically significantly more likely to have interim appointees than empty positions with a predicted probability of $6.4 \%(p=0.002)$. We know from the distribution of vacancies over time (highlighted at the outset of this chapter in Figure 5.1) that presidents inherently experience fewer vacancies outside of their first, transition year. These results suggest that experienced presidents are more likely to fill those fewer vacant positions with interim appointees than to leave them empty. These higher likelihoods might also suggest that as the end of an administration's term draws closer, and within the interim tenure limit, interim appointees become a more attractive strategy for presidents to achieve their policy priorities. 


\subsubsection{Results: Five Category Position Status}

Table 5.13 lists the estimated coefficients and cluster-robust standard errors for the MNP model estimated on the five-category construction of Position Status. Recall that the five categories here capture a more complete set of the outcomes in my formalized model: permanent appointee, empty with no nominee, empty with a nominee, interim appointee with no nominee, and interim appointee with a nominee ${ }^{30}$ Critically, by integrating the nomination data, this analysis employs a smaller ${ }^{31}$ the sample covering 1981 to 2015 which, consequently, excludes the Carter administration. However, in doing so, we can identify whether the vacancy (empty position or interim appointee) had a nominee awaiting confirmation which is an improvement from the omission of this distinction and clearly contributes to our larger understanding of appointments and separation of powers.

Additionally, differentiating between vacancies with and without nominees facilitates a more nuanced examination of the three hypotheses tested in the previous analysis as well as new tests of the fourth No Nominee hypotheses. As with the previous estimation, the coefficients for the baseline choice, "Permanent Appointee," have been normalized to zero in order to identify the model and allow for comparisons across equations. This estimation also includes a measure of the department-level average time a nomination spent in the Senate, as specified previously. These results show, again, that president Position Value significantly contributes to the likelihood of an empty position and interim appointee, and more specifically, to those outcomes with and without a nominee awaiting confirmation. Additionally, Table 5.14 presents the predicted probabilities of each position status for each category of the explanatory variables, with all other variables at

\footnotetext{
${ }^{30}$ While the outcome "interim appointee with a nominee" captures the potential for that interim appointee to be followed by a permanent one, it does not capture the realized confirmation of the nominee. Similarly, the outcome "permanent appointee" does not capture if the position was filled with an interim appointee or left empty before that permanent appointee was confirmed.

${ }^{31}$ Importantly, the likelihood model estimation on the three category construction of Position Status (as described in the previous section) is robust to using the restricted sample covering 1981-2015. As Table AA.1 in the Appendix reports, the results are strikingly similar with slight differences in magnitude and very little difference, if any, in statistical significance between the estimated coefficients.
} 
Table 5.13: Likelihood Models of Presidential Appointment Strategy in Executive Departments, 1981-2015

Multinominal Probit

DV: 5 Category Position Status

\begin{tabular}{|c|c|c|c|c|c|}
\hline & & $\begin{array}{c}(1) \\
\text { Empty, } \\
\text { No Nominee }\end{array}$ & $\begin{array}{l}(2) \\
\text { Empty, } \\
\text { Nominee }\end{array}$ & $\begin{array}{c}(3) \\
\text { Interim, } \\
\text { No Nominee }\end{array}$ & $\begin{array}{l}(4) \\
\text { Interim, } \\
\text { Nominee }\end{array}$ \\
\hline $\begin{array}{l}\text { President } \\
\text { Position Value }\end{array}$ & $\begin{array}{l}\text { High Value (expansion) } \\
\text { High Value (contraction) }\end{array}$ & $\begin{array}{c}0.069 \\
(0.156) \\
-0.17 \\
(0.396)\end{array}$ & $\begin{array}{c}0.397 \\
(0.216) \\
-0.483^{* *} \\
(0.156)\end{array}$ & $\begin{array}{c}-0.499^{* *} \\
(0.13) \\
-0.422 \\
(0.44)\end{array}$ & $\begin{array}{c}0.349^{* *} \\
(0.122) \\
0.146 \\
(0.373)\end{array}$ \\
\hline $\begin{array}{l}\text { Congress } \\
\text { Position Value }\end{array}$ & High Value (expansion) & $\begin{array}{c}-0.264^{* *} \\
(0.099) \\
-0.342 \\
(0.178)\end{array}$ & $\begin{array}{c}0.157^{* *} \\
(0.059) \\
0.209 \\
(0.199)\end{array}$ & $\begin{array}{c}-0.189 \\
(0.099) \\
-0.484^{* *} \\
(0.141)\end{array}$ & $\begin{array}{c}0.135 \\
(0.154) \\
0.517^{* *} \\
(0.154)\end{array}$ \\
\hline $\begin{array}{l}\text { President X Congress } \\
\text { Position Value }\end{array}$ & $\begin{array}{l}\text { High Value High Value } \\
\text { (contraction) X (contraction) } \\
\text { High Value High Value } \\
\text { (contraction) X (expansion) } \\
\text { High Value High Value } \\
\text { (expansion) X (contraction) } \\
\text { High Value High Value } \\
\text { (expansion) X (expansion) }\end{array}$ & $\begin{array}{c}0.421 \\
(0.527) \\
0.479 \\
(0.376) \\
-0.0767 \\
(0.38) \\
0.063 \\
(0.143)\end{array}$ & $\begin{array}{c}0.295 \\
(0.259) \\
0.550 \\
(0.379) \\
-0.682^{*} \\
(0.277) \\
-0.592^{* *} \\
(0.206)\end{array}$ & $\begin{array}{l}0.618 \\
(0.496) \\
0.232 \\
(0.351) \\
0.551^{* *} \\
(0.151) \\
0.601^{* *} \\
(0.171)\end{array}$ & $\begin{array}{l}-0.651 \\
(0.442) \\
-0.033 \\
(0.285) \\
-0.941^{*} \\
(0.391) \\
-0.202 \\
(0.189)\end{array}$ \\
\hline \multicolumn{2}{|c|}{ Department-level Average Time in Senate } & $\begin{array}{l}-0.0019 \\
(0.001)\end{array}$ & $\begin{array}{c}0.001 \\
(0.001)\end{array}$ & $\begin{array}{l}-0.0002 \\
(0.0002)\end{array}$ & $\begin{array}{l}0.002^{* *} \\
(0.001)\end{array}$ \\
\hline \multicolumn{2}{|c|}{ Established Administration } & $\begin{array}{l}-0.960^{* *} \\
(0.072)\end{array}$ & $\begin{array}{l}-0.955^{* *} \\
(0.078)\end{array}$ & $\begin{array}{l}-0.748^{* *} \\
(0.091)\end{array}$ & $\begin{array}{l}-0.504^{* *} \\
(0.059)\end{array}$ \\
\hline \multicolumn{2}{|l|}{ Co-Partisan Control } & $\begin{array}{c}0.090 \\
(0.228)\end{array}$ & $\begin{array}{l}-0.295 \\
(0.217)\end{array}$ & $\begin{array}{c}0.089 \\
(0.085)\end{array}$ & $\begin{array}{l}-0.122 \\
(0.081)\end{array}$ \\
\hline \multicolumn{2}{|c|}{ Department of Defense } & $\begin{array}{c}0.160 \\
(0.121)\end{array}$ & $\begin{array}{c}0.193 \\
(0.106)\end{array}$ & $\begin{array}{l}-0.366^{* *} \\
(0.100)\end{array}$ & $\begin{array}{l}-0.756^{* *} \\
(0.110)\end{array}$ \\
\hline \multicolumn{2}{|c|}{ Administration Fixed Effects } & $\checkmark$ & $\checkmark$ & $\checkmark$ & $\checkmark$ \\
\hline \multicolumn{2}{|l|}{ Intercept } & $\begin{array}{l}-0.723^{* *} \\
(0.129)\end{array}$ & $\begin{array}{l}-1.748^{* *} \\
(0.365)\end{array}$ & $\begin{array}{l}-1.035^{* *} \\
(0.200)\end{array}$ & $\begin{array}{l}-2.554^{* *} \\
(0.038)\end{array}$ \\
\hline
\end{tabular}

Note: $\mathrm{N}=9,626$ in all models. Table entries are multinomial probit estimates of the five category Position Status.

The omitted (baseline) category is "Permanent Appointee," its coefficients have been normalized

to zero in order to identify the model and allow for comparisons across equations. Reference

category for Position Value is "Low Value." Cluster-robust standard errors appear in parentheses.

${ }^{*} \mathrm{p}<0.05,{ }^{* *} \mathrm{p}<0.01$ 
Table 5.14: Predicted Probabilities of Position Status Outcomes

\begin{tabular}{|c|c|c|c|c|c|}
\hline & & $\begin{array}{c}\text { Empty, } \\
\text { No Nominee }\end{array}$ & $\begin{array}{l}\text { Empty, } \\
\text { Nominee }\end{array}$ & $\begin{array}{c}\text { Interim, } \\
\text { No Nominee }\end{array}$ & $\begin{array}{l}\text { Interim, } \\
\text { Nominee }\end{array}$ \\
\hline \multirow{6}{*}{$\begin{array}{l}\text { President } \\
\text { Position Value }\end{array}$} & High Value (expansion) & 0.055 & 0.009 & 0.065 & 0.017 \\
\hline & & $(0.004)$ & $(0.003)$ & $(0.005)$ & $(0.002)$ \\
\hline & High Value (contraction) & 0.066 & 0.008 & 0.054 & 0.016 \\
\hline & & $(0.017)$ & $(0.003)$ & $(0.010)$ & $(0.004)$ \\
\hline & Low Value & 0.048 & 0.011 & 0.070 & 0.017 \\
\hline & & $(0.008)$ & $(0.001)$ & $(0.005)$ & $(0.004)$ \\
\hline \multirow{6}{*}{$\begin{array}{l}\text { Congress } \\
\text { Position Value }\end{array}$} & High Value (expansion) & 0.056 & 0.009 & 0.071 & 0.018 \\
\hline & & $(0.009)$ & $(0.003)$ & $(0.008)$ & $(0.002)$ \\
\hline & High Value (contraction) & 0.047 & 0.009 & 0.054 & 0.015 \\
\hline & & $(0.009)$ & $(0.003)$ & $(0.006)$ & $(0.003)$ \\
\hline & Low Value & 0.068 & 0.008 & 0.056 & 0.017 \\
\hline & & $(0.010)$ & $(0.002)$ & $(0.011)$ & $(0.004)$ \\
\hline \multirow{4}{*}{$\begin{array}{l}\text { Established } \\
\text { Administration }\end{array}$} & New Administration & 0.159 & 0.032 & 0.129 & 0.024 \\
\hline & & $(0.022)$ & $(0.003)$ & $(0.014)$ & $(0.004)$ \\
\hline & Established Administration & 0.056 & 0.009 & 0.063 & 0.017 \\
\hline & & $(0.007)$ & $(0.002)$ & $(0.005)$ & $(0.002)$ \\
\hline \multirow{4}{*}{$\begin{array}{l}\text { Co-Partisan } \\
\text { Control }\end{array}$} & Divided Control & 0.048 & 0.017 & 0.055 & 0.022 \\
\hline & & $(0.011)$ & $(0.003)$ & $(0.004)$ & $(0.003)$ \\
\hline & Co-Partisan Control & 0.056 & 0.009 & 0.063 & 0.017 \\
\hline & & $(0.007)$ & $(0.002)$ & $(0.005)$ & $(0.002)$ \\
\hline \multirow{4}{*}{ Department } & Defense & 0.074 & 0.014 & 0.038 & 0.004 \\
\hline & & $(0.009)$ & $(0.005)$ & $(0.004)$ & $(0.001)$ \\
\hline & Non-Defense & 0.053 & 0.008 & 0.068 & 0.021 \\
\hline & & $(0.007)$ & $(0.002)$ & $(0.006)$ & $(0.002)$ \\
\hline
\end{tabular}

Note: Table entries are the predicted probabilities of each position status given specified row variables. Standard errors are in parentheses. Bold and colored entries denote alignment with theoretical expectations. Explanatory variables were held constant at their mean values. 
their means. To visually complement these tables, Figure 5.13 presents the predicted probabilities of empty positions and interim appointees, with and without nominees, for each category of president's Position Value.

Figure 5.13: Adjusted Predictions of the Probability of Empty Positions and Interim Appointees, With and Without Nominees, given President's Position Value

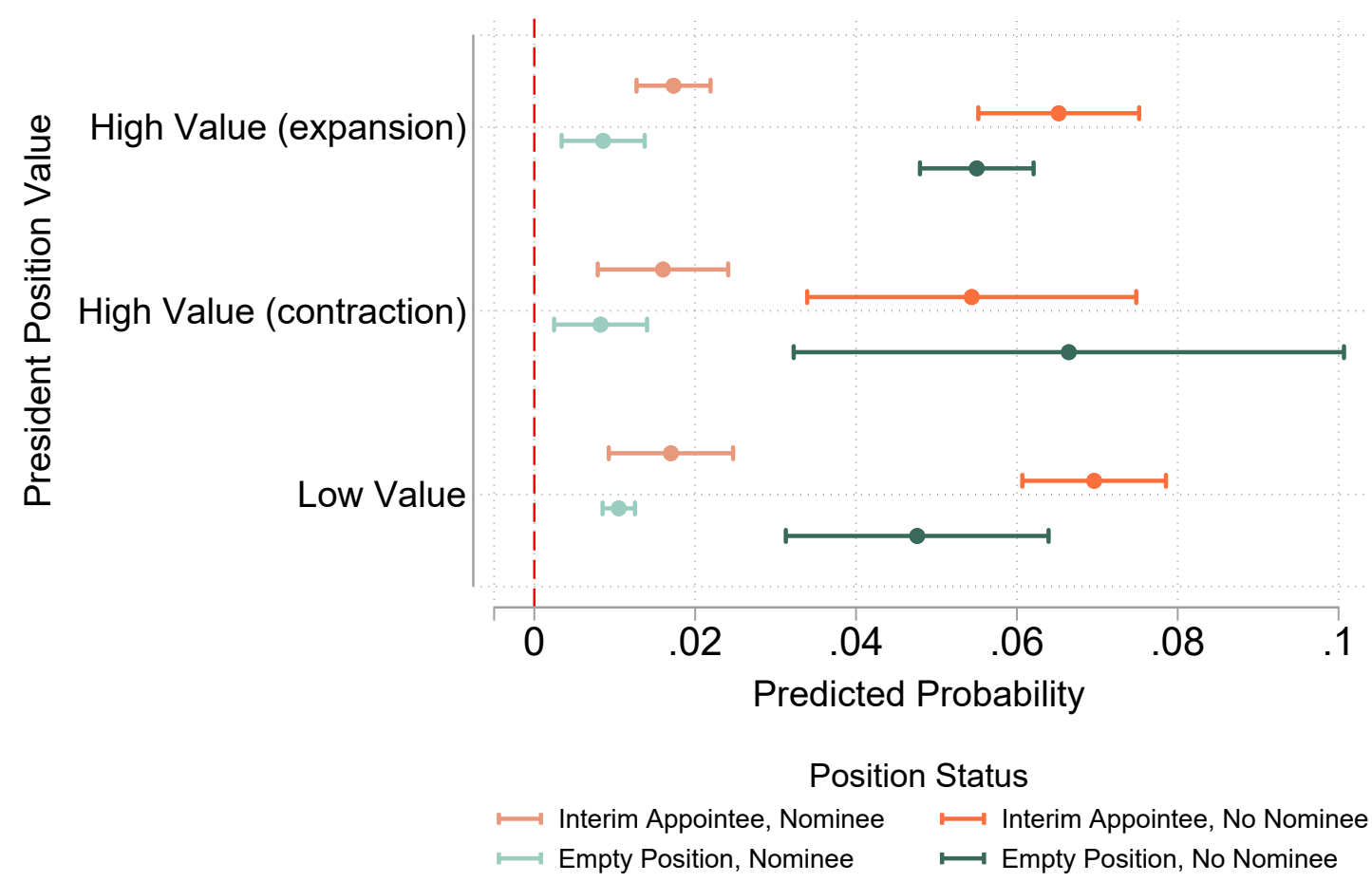

\section{H1. Empty Position Hypothesis}

From the Empty Position Hypothesis we expect that empty positions are more likely when president Position Value is "High Value (contraction)." Importantly, within my formalized framework, when the outcome of the game is a sustained empty position, a nominee was not submitted for confirmation. Thus, we would expect, empirically, that presidents are more likely to leave "High Value (contraction)" positions empty with no nominees; which is what the first column in Table 5.14 displays. Specifically, "High Value (contraction)" positions have a higher predicted 
probability (6.6\%) of being empty with no nominee than "High Value (expansion)" positions with a predicted probability of 5.5\%, and even higher than "Low Value" positions with a predicted probability of $4.8 \%$. However, as with our previous results, neither of these differences are statistically significant at even the 10 percent level ( $p=0.518$ and $p=0.173$, respectively), which is unsurprising given the overlapping confidence intervals in Figure 5.13.

Critically, with the added distinction of nominees, we can see from both Table 5.14 and Figure 5.13 that, when president Position Value is "High Value (contraction), empty positions without nominees are considerably more likely - eight times more likely - than empty positions with nominees. This fully aligns with my theoretical expectation that presidents capitalize on their first-mover advantage to choose not to submit nominees to high capacity positions when they prioritize policy contraction. That is, when presidents leave positions empty, they do so in order to advance policy priorities outside of the formal nomination-confirmation process. Furthermore, the substantively small predicted probability of an empty position with no nominee $(0.8 \%)$ sits squarely with our expectation from the No Nominee Hypothesis and previews those findings, discussed later in this section.

\section{H2. Interim Appointee Hypothesis}

The third and fourth columns in Table 5.14 report the results relating to the Interim Appointee Hypothesis. Specifically, exactly as predicted, interim appointees with no nominee are more likely in "High Value (expansion)" and "Low Value" positions, with predicted probabilities of 6.5\% and $7.0 \%$, respectively, than in "High Value (contraction)" positions with a predicted probability of 5.4\%. However, as Figure 5.13 illustrates, the differences across these categories of president Position Value are not statistically distinguishable.

Figure 5.13 also highlights that interim appointees, with and without nominees, are more likely than empty positions under the "High Value (expansion)" category of president Position Value, as predicted. Specifically, the predicted probability of interim appointees with no nomi- 
nees is $6.5 \%$ compared to $5.5 \%$ for empty positions with no nominees; and we can differentiate this difference at a 10 percent level $(p=0.095)$. Table 5.14 and Figure 5.13 also show that, as expected, "Low Value" positions are 30 percent more likely to be filled with an interim appointee with no nominee with a predicted probability of $7.0 \%$, than left empty, with a predicted probability of 5.4\%; and this difference is also statistically significant $(p=0.016)$. Furthermore, when we shift to the likelihoods of interim appointees with a nominee, we also see that they are nearly twice as likely to fill "High Value (expansion)" positions (1.7\%) than those positions are to be left empty with a nominee submitted (0.9\%). While these differences are distinguishable $(p=0.024)$, they seem substantively small.

\section{H4. No Nominee Hypothesis}

Recall that the No Nominee Hypothesis conjectures that presidents will not submit a nominee for confirmation without also appointing an interim appointee. Thus, we would expect that interim appointees with nominees are more likely than empty positions with nominees; and as Figure 5.13 presents, that is what we find. Interim appointees with nominees are significantly more likely in "High Value (expansion)" and "Low Value" positions - such that both categories have predicted probabilities of $1.7 \%$ - than empty positions with nominees in those categories of president Position Value (.9\% and 1.1\%, respectively). Again, mentioned above, these differences seem substantively small. However, if we reconsider these categories of Position Status as distinctions of a vacant position - that is, if we condition the analysis on a position not having a confirmed appointee - we will see that there are meaningful impacts of these relatively small likelihoods. Next, I present the predicted probabilities from this supplemental analysis and the MNP results producing these probabilities can be found in the appendix. 


\section{Supplemental Analysis: Position Status Among Vacancies}

The distinction between empty positions and interim appointees is fundamentally one separate from permanent appointees. While an appointment decision begins with a president's choice to fill an opening immediately with an interim appointee, or to leave it empty, and then whether or not submit a nominee for confirmation, the lack of a confirmed appointee is what initiates the process. In other words, empty positions and interim appointees - with or without nominees - have the absence of a permanent appointee as a common characteristic. And, in general, positions are considerably more likely to be filled by a permanent appointee than to be vacant. This can obscure the substantive impact of any one variable on the likelihood of each type of vacancy, as permanent appointees dominate the outcome. To highlight how president Position Value influences the likelihood of each position status, given that the position is not filled by a permanent appointee, we need to subset the analysis conditional on vacancy status. Table 5.15 and Figure 5.14 present the predicted probabilities of empty positions (with and without nominees) and interim appointees (with and without nominees), within the subset of vacancies, for each category of president Position Value. These results parallel the results derived from the full set of Position Status outcomes above; however, as a comparison of Figures 5.13 and 5.14 yields,

Table 5.15: Predicted Probabilities of Position Status Outcomes Among Vacancies

\begin{tabular}{llcccc} 
& & $\begin{array}{c}\text { Empty, } \\
\text { No Nominee }\end{array}$ & $\begin{array}{c}\text { Empty, } \\
\text { Nominee }\end{array}$ & $\begin{array}{c}\text { Interim, } \\
\text { No Nominee }\end{array}$ & $\begin{array}{c}\text { Interim, } \\
\text { Nominee }\end{array}$ \\
\hline President & High Value (expansion) & 0.372 & 0.055 & $\mathbf{0 . 4 5 2}$ & $\mathbf{0 . 1 2 1}$ \\
Position Value & $(0.0233)$ & $(0.017)$ & $(0.029)$ & $(0.014)$ \\
& High Value (contraction) & $\mathbf{0 . 4 4 9}$ & $\mathbf{0 . 0 5 6}$ & 0.378 & 0.117 \\
& & $(0.059)$ & $(0.022)$ & $(0.044)$ & $(0.036)$ \\
& Low Value & 0.328 & 0.071 & $\mathbf{0 . 4 8 7}$ & $\mathbf{0 . 1 1 4}$ \\
& & $(0.036)$ & $(0.004)$ & $(0.032)$ & $(0.022)$ \\
\hline
\end{tabular}

Note: $\mathrm{N}=1,943$. Table entries are the predicted probabilities of each position status for the subset of vacant positions. Standard errors are in parentheses. Bold and colored entries denote alignment with theoretical expectations. Explanatory variables were held constant at their mean values. 
Figure 5.14: Adjusted Predictions of the Probability that a Vacancy is Empty Position or Filled with Interim Appointee, With and Without Nominees, given President's Position Value

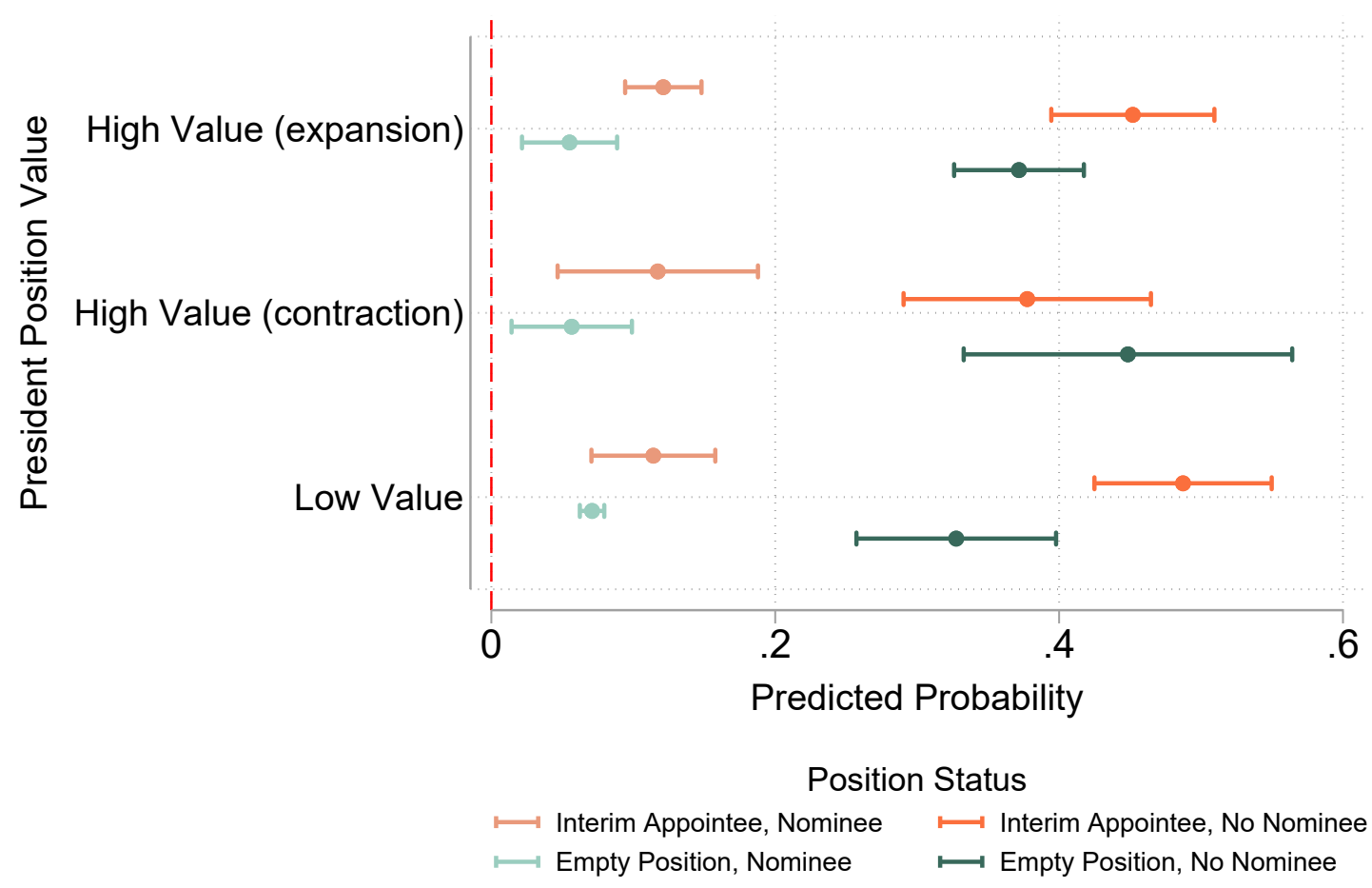

differences between the predicted probabilities for interim appointees and empty positions without nominees are now statistically distinguishable at a 5 percent level and continue to provide evidence supporting each of my hypotheses.

\subsection{Discussion}

The results presented here support the larger argument that presidents strategically manage vacancies in and appointments to PAS positions based on the capacity of the position to advance specific policy priorities, the Position Value. The first analysis examines the status of a position in the framework of a multi-choice model - one that includes the set of alternatives to fill positions 
with interim or permanent appointees or to leave them empty. It yields appreciable evidence that presidents use interim appointees to advance their expansion policy priorities, and some evidence, albeit at lower levels of significance, for the strategic use of empty positions. The second analysis takes an increasingly nuanced approach by distinguishing between both the types of vacancies and whether there was a nomination awaiting confirmation. The findings support the conjecture that presidents strategically choose to not submit nominees, yield modest evidence that presidents use empty positions to advance their contraction policy priorities, and reinforces the first model's findings on interim appointees. However, these likelihood models yield no explicit evidence for the strategic use of permanent appointees.

These data represent a significant contribution to the study of presidential appointments and vacancies therein - namely the nuanced distinction between between empty posts and interim appointees. However, there are three potential limitations. First, as mentioned previously, the discrete nature of the outcome variable - the single, yearly time-step of each record for each PAS position - does not offer a complete picture of all vacancies throughout each year of each administration. However, since positions are generally less likely to be vacant than filled with a permanent appointee, this limitation ultimately leads to more conservative estimates of any impact on position status and makes obtaining significant results more difficult and less expected. Furthermore, as explained earlier, a comprehensive analysis of the Department of Labor shows a considerable overlap (more than 93\%) of position statuses captured in a continuous dataset and those captured in this discrete one. Ultimately, this speaks to the unlikely nature of systematic missingness in the dependent variable.

Second, there is a potential limitation in the official reporting of interim appointees. There are reasons to believe that individuals serve in the position as if they were interim appointees without the official designation as an acting appointee. For instance, in June 2018, the Director of the National Park Service in the Department of the Interior was officially listed as empty. However, Dan Smith, the Deputy Director, was 'exercising the authority of the director without assuming 
the title as "Acting Director." Consequently, some set of positions identified as "empty" in my data could actually be unofficially and covertly filled by interim appointees. This aspect of the official reports could be masking strategic behavior and might contribute to the dampened results for the likelihood of empty positions. However, this tactic has only recently been employed by the Trump administration and is likely not pernicious in my data.

Lastly, there is a potential limitation in the construction of Policy Priorities. It could be that priorities vary within departments at the level of a sub-agency or bureau. This would materialize as subsets of positions with contrasting priorities from the rest of the department. Alternatively, in some cases, neutral policy priorities might actually result from having a relatively equal number of sub-agency and bureaus for which presidents prioritize contraction and expansion. This might be the case for a small number of the 517 department-years captured in this data, and the extent of which would require a matching of program level appropriations to each sub-agency and bureau. While I recognize that this variation in priorities within a department certainly exists, given the complexities of intra-departmental responsibilities on policy implementation and the labyrinth of sub-agency government appropriations, this variation is most likely not biasing the results.

In all, the analysis in this chapter yields strong support for the Interim Appointee Hypothesis and No Nominee Hypothesis, some support for the Empty Position Hypothesis and limited support for the Permanent Appointee Hypothesis. There are two potential reasons for these mixed results. First, these mixed results could be driven by changes in the institutional structure that has governed vacancies and the tenures of interim appointees. As mentioned in Chapter 2, the Vacancies Act of 1868 limits the length of time that an interim appointee could serve to 30 days; and that limit was lengthened to 120 days in 1988 by the Presidential Transitions Effectiveness Act. The most sweeping changes, however, came with the Federal Vacancies Reform Act (FVRA) of 1998, which extended an interim appointee's initial tenure to 210 days and upwards of 720 days after two rounds of submitted and returned nominees. Consequently, we might expect to find different 
patterns before and after the passage of the FVRA. In fact, we would expect that if my hypotheses are supported under one institutional regime and not the other, then the combination would potentially bias the result. Such disparate trends would help to explain the mixed results presented here and as the analysis offered in Chapter 6 will show, this is what we find.

Second, the mixed results could be driven by the concentration of vacancies - specifically, empty positions - within departments, rather than spread across departments. The likelihood model, with the position status outcome at the position level, measures the probability that any one position is either empty or filled with an interim or permanent appointee. It does not address the incidence or accumulation of these position statuses within a department. As mentioned at the outset of this chapter, the generality of my theoretical hypotheses allow for considerations of both likelihood and incidence of position status within departments. Chapter 7 takes up this question in an analysis of aggregate counts of each position status and, in doing so, finds support for my theory.

In the chapters to follow, I continue to leverage the extensive dataset described here for two additional sets of parametric tests - an extension of the MNP model and a count model - of the hypotheses derived in Chapter 4. First, in the next chapter, I begin by examining Position Status during the periods before and after the passage of the FVRA in 1998. To this end, I extend the central MNP regression analysis from this chapter in two ways. First, I add an indicator for years before and after 1998 to control for the fixed effects of the FVRA institutional regime. Critically, though, this linear addition to the model does not account for any interactive effect of the FVRA on the impact of Position Value. Consequently, I present a second analysis that models Position Status as a function of Position Value, and the other previously described predictors, separately for each subset of observations before and after 1998.

Then, in Chapter 7, I present the results from a count model that addresses the limitations of the data structure and likelihood model specification described above. To do this, I transform the Position Status variable for PAS positions in the fifteen Executive departments into aggre- 
gated counts by department-year. Accordingly, Chapter 7 first introduces and describes the Position Status count data, after which I outline my estimation strategy for the negative binomial regression analysis. Then I present the results from the count models estimated on the sets of department-year counts of each Position Status in high capacity positions. I also offer an alternative perspective from a supplementary analysis that accounts for the delay between a president's decision to appoint a permanent appointee and the realization of that choice. 


\section{CHAPTER VI}

\section{Examining Vacancies in the Context of the Federal Vacancies Reform Act}

Recall from Chapter 2 that the Federal Vacancies Reform Act (FVRA) of 1998 created a new institutional regime that stipulates who can serve as an interim appointee and for how long. Specifically, prior to the FVRA, interim appointees could serve for 120 days since 1988 and, prior to that, only 30 days. The FVRA lengthened the time restrictions so that an initial interim appointment is typically 210 days, but up to 300 days if the vacancy occurs within the first 90 days after inauguration. However, as outlined previously, an interim appointee can potentially serve much longer than just 210 days. The time restriction is suspended and the acting official can remain in office if a first nomination has been submitted to the Senate and is pending. Moreover, an interim can continue for an additional 210 days after the rejection, withdrawal, or return of that nomination. The restriction is suspended again and the acting official can remain in office if a second nomination has been submitted to the Senate and is pending. Then, if that nomination is rejected, withdrawn, or returned, an acting official can serve for another 210 days. Thus, the 210 day tenure can repeat twice: after each of two submitted nominations are rejected, withdrawn, or returned. Consequently, an interim appointee could fill the position for up to 300 days before any nomination is submitted, up to 720 days if the respective nominations are withdrawn, rejected, 
or returned, and nearly indefinitely if the Senate does not act on a submitted nomination.

The extended length that interim appointees can serve under the FVRA makes them a powerful strategy given that presidential terms are just 1,461 days. Interim appointments after the passage of the FVRA could be nearly six times longer than those before, which makes 1998 a potentially critical year for presidential appointment strategy. Ultimately, this dissertation seeks to discover what explains, and predicts, why certain positions are left empty while others are filled with interim or permanent appointees. I have proposed several formally-derived hypotheses about the role that Position Value plays in a president's calculus to fill or not fill vacant positions, and the empirical tests in Chapter 5 presented evidence that support these predictions, however only in part. The substantial difference in the prospective terms of interim appointees pre and post-FVRA could explain these mixed findings. In the next section, I test this conjecture, and my hypotheses in this context, by extending the central multinomial probit (MNP) regression analysis from Chapter 5 to specifically account for the influence of the FVRA on the conditions under which presidents engage in specific appointment strategies.

\subsection{Likelihood Models of Position Status, with Federal Vacancies Reform Act Fixed Effects}

Here, I estimate the first of two MNP models of Position Status, with cluster-robust standard errors to account for clustering within administrations, according to the specification outlined by Equation 5.1 in Chapter 5. Critically, while this analysis allows for formal statistical inference of the marginal effects of the Federal Vacancies Reform Act (FVRA) on the likelihood of each position status, it does not allow for causal inference. The primary purpose of this correlational analysis is to explore whether the insignificant effect of Position Value for the likelihood of permanent appointees might be related to a shift in institutional regimes. ${ }^{1}$ As such, in what follows, I present

\footnotetext{
${ }^{1}$ Importantly, I am not making a causal argument that the FVRA caused a change in the likelihood of permanent
} 
an analysis that falls within the scope of this dissertation as it specifically seeks to explore how presidents use vacancies and appointments. Given that the inquiry at hand is the first examination of vacancies in an inter-branch context, and the first to explicitly identify interim appointees as a part of the set of appointment strategies, there are no existing empirical expectations or previous work on the FVRA to draw from. Consequently, while I do not offer a causal claim about the altered incentives for the president to pursue one appointment over another, due to the FVRA, I do expect the analysis to show a correlated effect. This first extension additionally controls for the fixed effects of the FVRA with an indicator for the years 1998-2015 (versus 1977-1997). The second extension, detailed in the next section, estimates this model separately on the two subsets of observations before and after the FVRA. ${ }^{2}$ For convenience, I will restate the specification here: ${ }^{3}$

$$
\begin{aligned}
U_{y_{j t}}= & \alpha_{y_{j t}}+\beta_{V_{P}} V_{P y_{j t}}^{\prime}+\beta_{V_{C}} V_{C y_{j t}}^{\prime}+\beta_{V_{P x C}} V_{P y_{j t}}^{\prime} V_{C y_{j t}}^{\prime}+ \\
& \gamma_{1} E A_{t}^{\prime}+\gamma_{2} C P_{t}^{\prime}+\gamma_{3} F V R A_{t}^{\prime}+\gamma_{4} D_{j}^{\prime}+\gamma_{5} A_{t}^{\prime}+\varepsilon,
\end{aligned}
$$

such that

$$
\operatorname{Pr}\left(y_{j t}=S_{m}\right)=\operatorname{Pr}\left(u_{S_{m}}>u_{S_{k}} \forall m \neq k\right)
$$

for

$$
S_{1 m}\left\{\begin{array}{l}
0 \Rightarrow \text { Empty } \\
1 \Rightarrow \text { Interim Appointee } \\
2 \Rightarrow \text { Permanent Appointee }
\end{array}\right.
$$

where

$S_{1}$ is the status of a position $y_{j t}$ in department $j$ for year $t$ indicates whether it is empty, filled with an interim appointee, or filled with a permanent appointee;

$S_{2}$ is the status of a position $y_{j t}$ in department $j$ for year $t$ indicates whether it is empty without a nominee, empty with a nominee, filled with an interim appointee without a

appointees, which would require a research design (e.g., regression discontinuity). Future work should delve more deeply into a casual argument of how this law altered incentives.

${ }^{2}$ Naturally, this estimation strategy excludes the fixed effects for the FVRA.

${ }^{3}$ See Chapter 5, Section 2.2.1 for the detailed account of each variable. 
nominee, filled with an interim with a nominee, or filled with a permanent appointee;

$V_{P y_{j t}}$ is Position Value for the president;

$V_{C y_{j t}}$ is Position Value for Congress;

$V_{P y_{j t}} V_{C y_{j t}}$ is the interaction between the Position Value for the president and Congress, as driven by my theoretical expectations;

$E A_{t}$ and $\gamma_{1}$ is Established Administration and its effects;

$C P_{t}$ and $\gamma_{2}$ is Co-Partisan Control of the Senate and its effects;

$F V R A_{t}$ indicates the years under the FVRA (1998 to 2015); $D_{j}$ indicates the Department of Defense; $A_{t}$ is administration fixed effects; and $\varepsilon$ are the multivariate normally distributed errors.

Since the purpose of this analysis is simply to identify any impact of the FVRA on the likelihood of each Position Status, the full report of estimated coefficients and cluster-robust standard errors can be found in Table AB.1 in the Appendix. As mentioned in Chapter 5, interpreting the parameter estimates from MNP models can be a bit onerous. Instead, Table AB.2 in the Appendix reports the predicted probabilities of each position status for each category of the explanatory variables, with all other variables at their means, and reveals the precise nature and magnitude of these effects. A comparison of these tables with the respective tables in Chapter 5 show only slight changes, if any, in the magnitude of the estimates and no changes in the direction of the effects or their significance. That is, these results demonstrate the robustness of the effect of Position Value on the choice to fill a position or not. Importantly, the results indicate significant fixed effects of the FVRA on the likelihoods of interim and permanent appointees, which I will explore in detail below. First, for visual ease, Figure 6.1 displays the predicted probabilities of empty positions and interim appointees and Figure 6.2 does so for permanent appointees.

Interestingly, we can see from Figure 6.1 that interim appointees are considerably more likely in the period after the passage of the FVRA than before, while Figure 6.2 shows that perma- 
Figure 6.1: Adjusted Predictions of the Probability of an Empty Position and Interim Appointee, given FVRA Institutional Regime

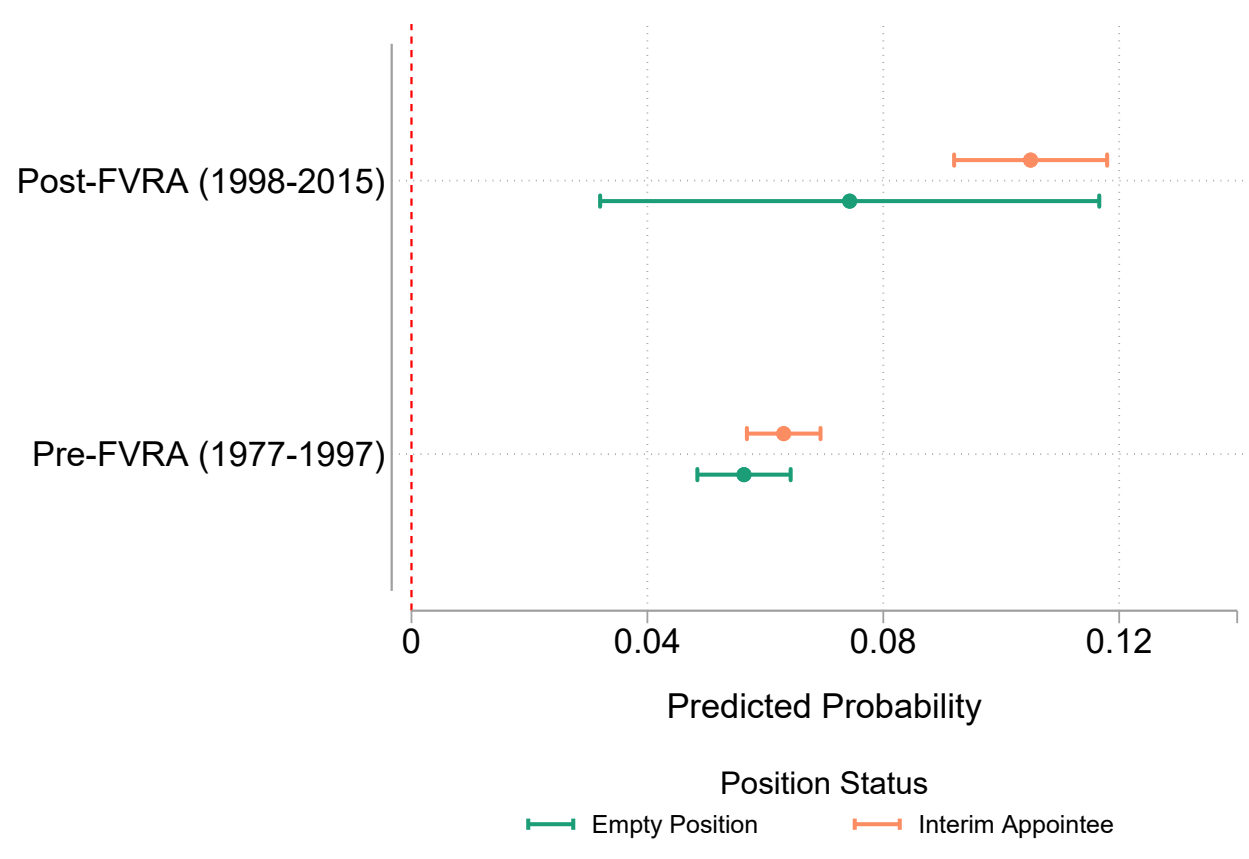

Figure 6.2: Adjusted Predictions of the Probability of a Permanent Appointee, given FVRA Institutional Regime

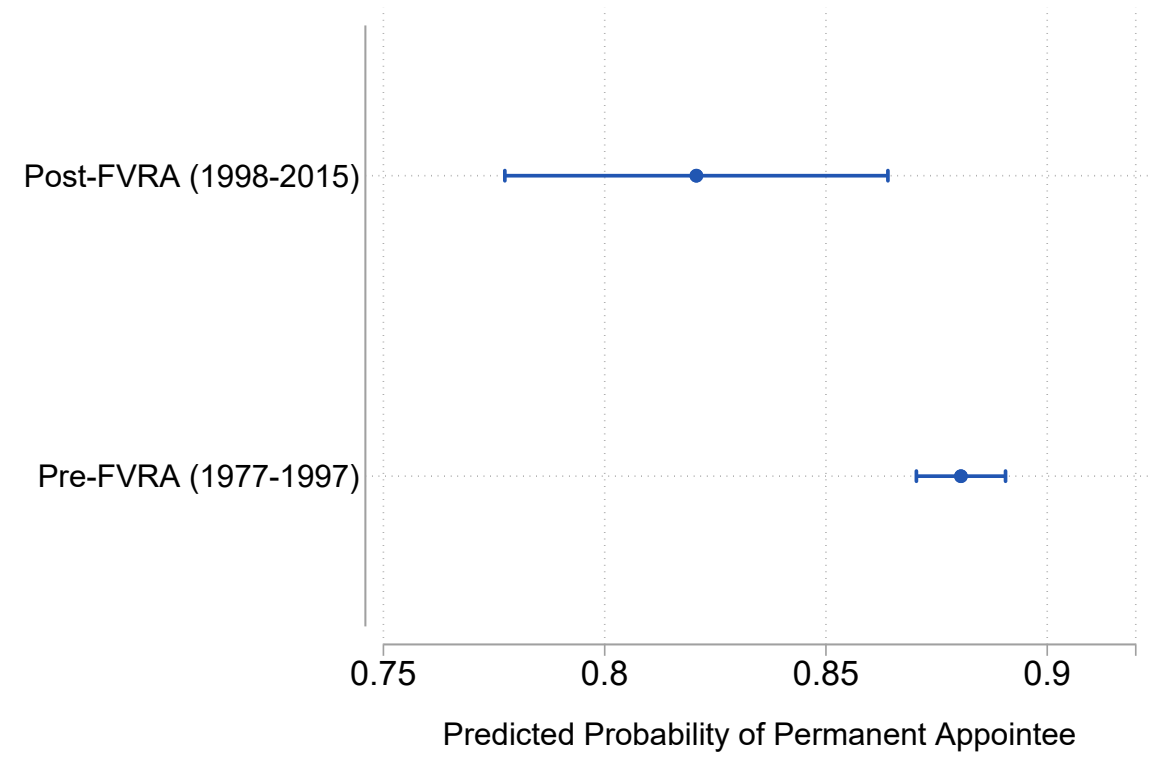


nent appointees are considerably less likely. ${ }^{4}$ While empty positions are also more likely after the FVRA, the effect is not distinguishable from the pre-FVRA period $(p=0.366)$. These findings address the conjecture that the longer tenures for interim appointees, permitted under the FVRA, make them a more powerful strategy for presidents to employ. Moreover, the fact that the predicted probabilities of empty positions are statistically indistinguishable before and after the FVRA, while the predicted probabilities of interim and permanent appointees are distinguishable suggests a potential substitution effect between the appointees. That is, after the FVRA, increasing the likelihood of an interim appointee decreases the likelihood of a permanent appointee without a discernible impact on empty positions. However, this does not indicate whether presidents simply rely on more interim and fewer permanent appointees regardless of Position Value or if they increase their strategic use of interim appointees specifically. Figures 6.3, 6.4, and 6.5 begin to examine this question and show an even starker impact of the FVRA, as they compare the effects of Position Value on the likelihoods of each Position Status estimated for the pre- and post-FVRA institutional regimes. Table 6.1 lists the predicted probabilities displayed in these figures.

Notably, Figure 6.3 reveals a discernible difference across the categories of FVRA in the predicted probabilities of empty positions when estimated for the categories of president Position Value. Here, the likelihood of empty positions is higher before the FVRA (1977-1997) than after (1998-2015) for each category of president Position Value, and these differences are statistically distinguishable at a less than 5 percent level. ${ }^{5}$ While this result seemingly reverses the estimated aggregate effect highlighted in Figure 6.1, the difference between those predicted probabilities of empty positions, as mentioned above, is not statistically different from zero. The result displayed in Figure 6.3 indicates that, while presidents are less likely to leave positions empty after the

\footnotetext{
${ }^{4}$ Both differences are statistically distinguishable at a less than 1 percent level $(p<0.000)$.

${ }^{5}$ The difference between pre-FVRA and post-FVRA for "High Value (expansion)" and "Low Value" are each significant at a less than 1 percent level ( $p=0.004$ and $p=0.006$, respectively), and for "High Value (contraction)" is significant at a 5 percent level $(p=0.014)$.
} 
Table 6.1: Predicted Probabilities of Position Status Outcomes

\begin{tabular}{|c|c|c|c|c|}
\hline \multirow{2}{*}{\multicolumn{2}{|c|}{ Estimated given pre-FVRA (1977-1997) }} & \multirow[t]{2}{*}{$\begin{array}{l}\text { Permanent } \\
\text { Appointee }\end{array}$} & \multirow[t]{2}{*}{$\begin{array}{c}\text { Interim } \\
\text { Appointee }\end{array}$} & \multirow[t]{2}{*}{$\begin{array}{l}\text { Empty } \\
\text { Position }\end{array}$} \\
\hline & & & & \\
\hline President & High Value (expansion) & 0.822 & 0.070 & 0.074 \\
\hline Position & & $(0.01)$ & $(0.01)$ & $(0.11)$ \\
\hline Value & High Value (contraction) & $\begin{array}{l}0.823 \\
(0.01)\end{array}$ & $\begin{array}{l}0.062 \\
(0.01)\end{array}$ & $\begin{array}{l}\mathbf{0 . 0 8 2} \\
(0.02)\end{array}$ \\
\hline & Low Value & $\begin{array}{l}0.833 \\
(0.01)\end{array}$ & $\begin{array}{l}\mathbf{0 . 0 7 1} \\
(0.01)\end{array}$ & $\begin{array}{l}0.065 \\
(0.01)\end{array}$ \\
\hline \multicolumn{5}{|c|}{ Estimated given post-FVRA (1998-2015) } \\
\hline $\begin{array}{l}\text { President } \\
\text { Position }\end{array}$ & High Value (expansion) & $\begin{array}{l}0.789 \\
(0.01)\end{array}$ & $\begin{array}{l}\mathbf{0 . 1 0 2} \\
(0.01)\end{array}$ & $\begin{array}{l}0.057 \\
(0.01)\end{array}$ \\
\hline Value & High Value (contraction) & $\begin{array}{l}0.791 \\
(0.02)\end{array}$ & $\begin{array}{l}0.090 \\
(0.01)\end{array}$ & $\begin{array}{l}\mathbf{0 . 0 6 6} \\
(0.02)\end{array}$ \\
\hline & Low Value & $\begin{array}{c}0.80 \\
(0.01)\end{array}$ & $\begin{array}{l}\mathbf{0 . 1 0 1} \\
(0.01)\end{array}$ & $\begin{array}{l}0.050 \\
(0.01)\end{array}$ \\
\hline
\end{tabular}

Note: Table entries are the predicted probabilities of each position status given specified row variables. Standard errors are in parentheses. Bold and colored entries denote alignment with theoretical expectations. Explanatory variables were held constant at their mean values.

FVRA, the difference appears evenly distributed. ${ }^{6}$ Next, Figures 6.4 and 6.5 present the predicted probabilities for interim and permanent appointees that are also reported in Table 6.1.

Specifically, Figure 6.4 compares the predicted probabilities of interim appointees evaluated for both category of FVRA: each of which indicates the sets of years post-FVRA and pre-FVRA, respectively. This comparison shows that the predicted probabilities of interim appiontees are higher under post-FVRA than pre-FVRA, for all categories of president Position Value, and these differences are statistically distinguishable at a less than 1 percent level $(p<0.000)$. Again, the higher likelihood of an interim appointee in an era when they can serve nearly six times longer

\footnotetext{
${ }^{6}$ In each category of president Position Value, the predicted probability of empty positions estimated for pre-FVRA is 0.02 less than those estimated for post-FVRA.
} 
Figure 6.3: Adjusted Predictions of the Probability of an Empty Position, given President Position Value and FVRA Institutional Regime

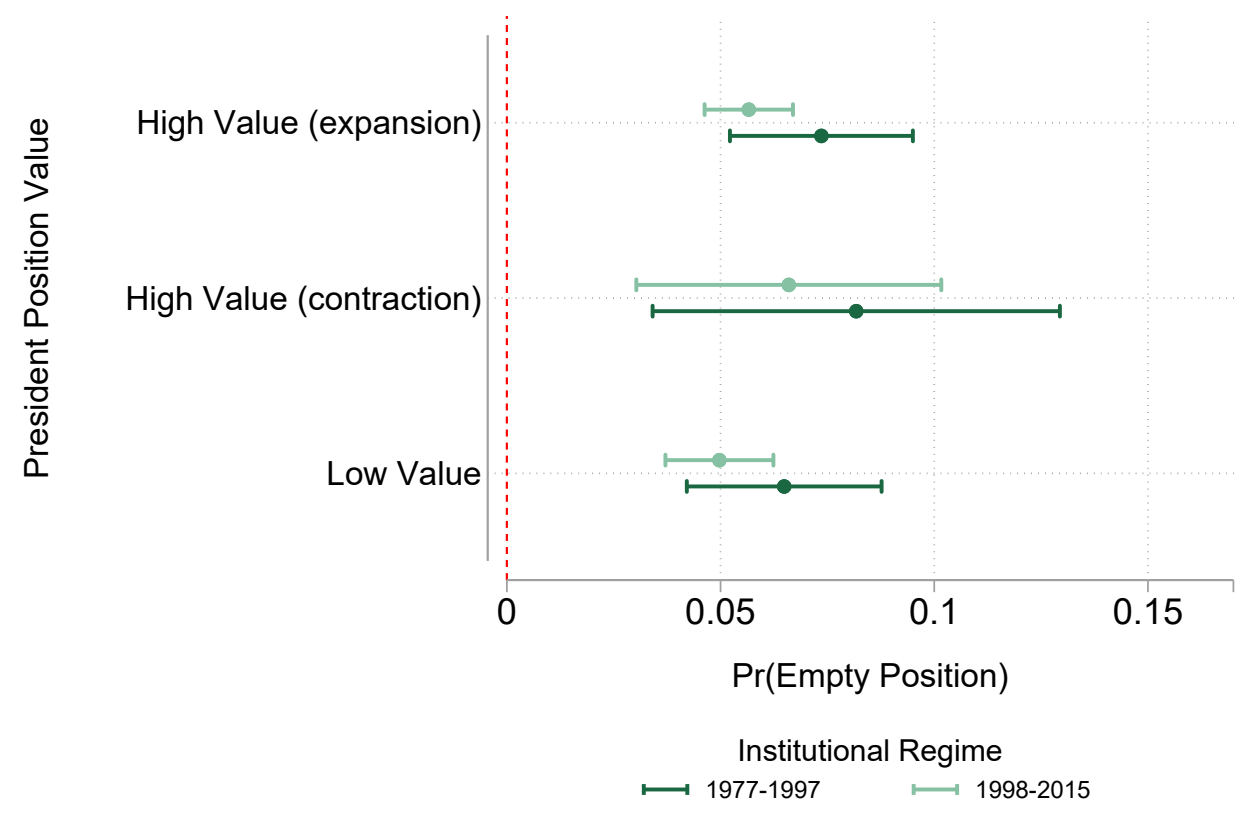

Figure 6.4: Adjusted Predictions of the Probability of an Interim Appointee, given President Position Value and FVRA Institutional Regime

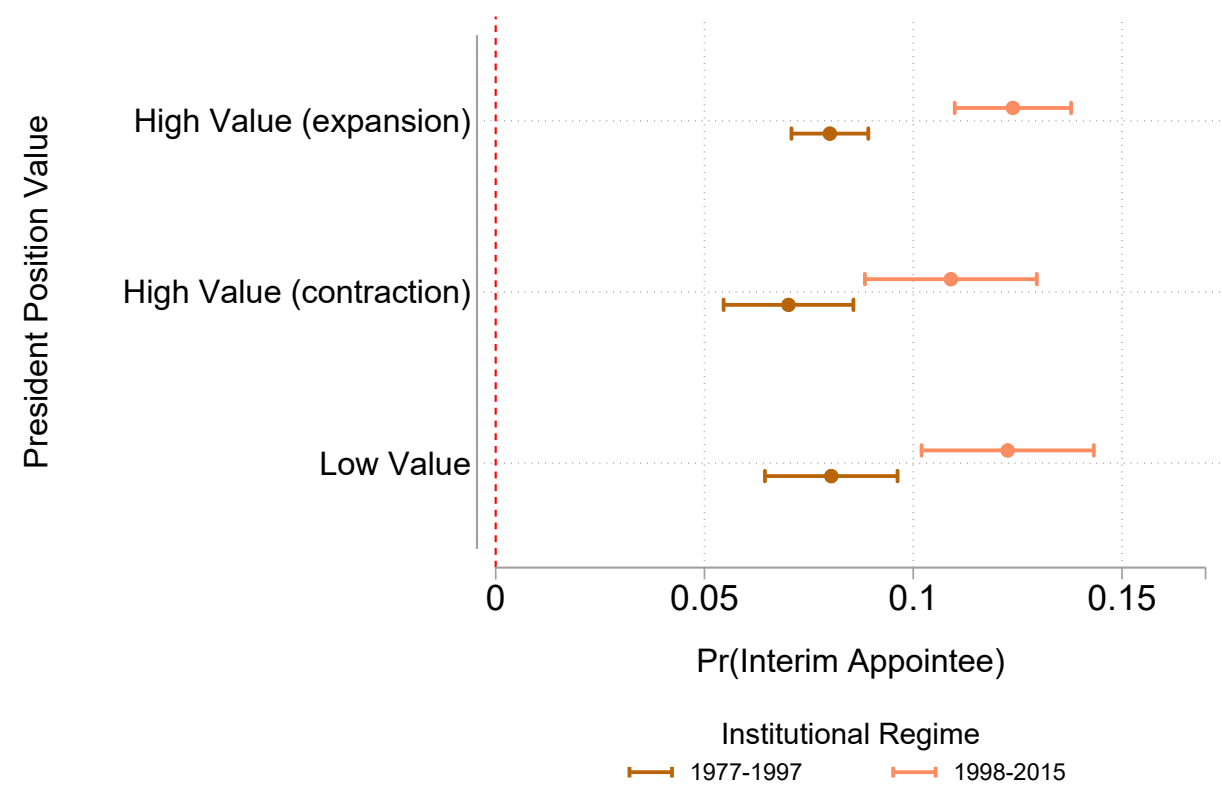


than before, supports the notion that the FVRA increased their strategic value to presidents. Furthermore, aligned with the findings from Chapter 5, "High Value (expansion)" and "Low Value" positions have higher predicted probabilities of being filled with interim appointees than "High Value (contraction)" positions under both pre and post-FVRA institutional regimes. Alternatively, Figure 6.5 illustrates how the predicted probabilities of permanent appointees are higher under pre-FVRA than under post-FVRA, and we can statistically differentiate between the two regimes at less than a 1 percent level $(p<0.000)$ for all categories of president Position Value.

Figure 6.5: Adjusted Predictions of the Probability of a Permanent Appointee, given President Position Value and FVRA Institutional Regime

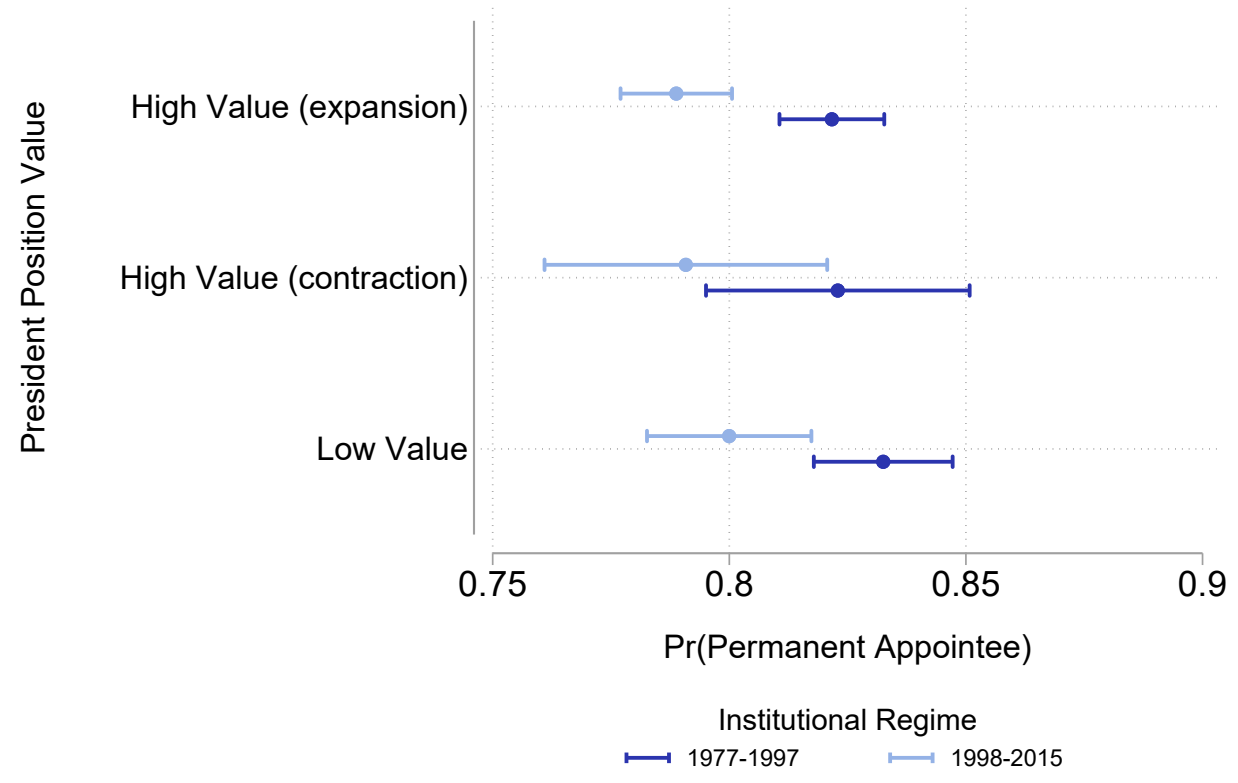

However, as mentioned above, these sets of predicted probabilities are derived from an estimated model that linearly adds the fixed effects of the FVRA. A precise estimation of how the likelihoods of each Position Status, as a function of Position Value, differ in the periods before and after the FVRA requires interacting FVRA with each of the predictors. An efficient approach to this strategy is to estimate the likelihood of Position Status separately for the observations before and after the FVRA, the results of which are presented in the next section. 


\subsection{Likelihood Models of Position Status, Before and After the Federal Vacancies Reform Act}

Here, I estimate this chapter's second set of MNP models of Position Status, according to the specification outlined by Equation 5.1 in Chapter 5 and restated in Equation 6.1 of this chapter. This second extension estimates the model separately on the set of position-year observations from the pre-FVRA regime (1977-1997) and those from the post-FVRA regime (1998-2015). As the multi-choice model simultaneously tests the three central hypotheses derived in Chapter 4 under each regime, for convenience, I also list them again here and will address them each in turn.

H1. Empty Position Hypothesis: A president is more likely to leave high value positions empty when prioritizing policy contraction.

H2. Interim Appointee Hypothesis: A president will always immediately fill low value positions with interim appointees, and is more likely to immediately fill high value positions with interims when prioritizing policy expansion.

H3. Permanent Appointee Hypothesis: Confirmed appointees are more likely in high value $P A S$ positions when the president prioritizes expansion, the Senate does not prioritize contraction, and the bargaining cost is sufficiently small (below the president's cutpoint).

The Empty Position Hypothesis predicts that presidents are more likely to leave "High Value (contraction)" positions empty; and the Interim Appointee Hypothesis predicts that presidents will fill "Low Value" and "High Value (expansion)" positions with interim appointees. In other words, similar to the expectations outlined in Chapter 5, we would expect if two positions faced the same political context and were both high value, the one under expansion presidential policy priorities would face a higher probability of being filled with an interim appointee. Alternatively, the one under contraction policy priorities would face a higher probability of being left empty. For the analysis at hand, we would expect to see these patterns to emerge within each regime, separately for the pre-FVRA and post-FVRA models.

Furthermore, the distinct features of the post-FVRA institutional regime - notably, the longer potential tenures of interim appointees - adds an extra dimension to these expectations. Each 
appointee, no matter their effectiveness, is naturally constrained by the limit of their resources. Government actions are constrained by appropriations and individuals are constrained by the limited time they are able to serve. Ultimately, each additional day presents appointees with a wider window of time to achieve the administration's policy and political objectives. If we suppose that the extended terms that interim appointees can serve makes them a more attractive option for advancing policy priorities, then we would anticipate that the FVRA will amplify our expectations. That is, we would expect higher likelihoods of interim appointees in "High Value (expansion)" and "Low Value" positions in the post-FVRA regime than in the pre-FVRA regime.

Lastly, the Permanent Appointee Hypothesis predicts that, all else equal, presidents will submit nominees for "High Value (expansion)" positions as long as these positions are also Senate "Low Value" and "High Value (expansion)" and will be confirmed. Thus, we would expect when president Position Value is "High Value (expansion)," positions will face a lower probability of being filled with a permanent appointee under Senate contraction priorities than otherwise. Below, Tables 6.2, 6.3, and 6.4 report the estimated coefficients and cluster-robust standard errors as well as the more digestible predicted probabilities for each separate estimation.

\section{H1. Empty Position Hypothesis}

If the Empty Position Hypothesis is accurate, we would expect higher predicted probabilities of empty positions for those that are "High Value (contraction)" than otherwise. As the third column in Table 6.3 reports, that is exactly what we find under the pre-FVRA regime. In fact, Figure 6.6 offers a clearer picture of the two expected relationships: between the predicted probabilities of an empty position across the categories of president Position Value and between the predicted probabilities of interim appointees and empty positions within the "High Value (contraction)" category. We can see from Figure 6.6 that "High Value (contraction)" positions have

the highest predicted probability of being empty, and it is statistically distinguishable from "High Value (expansion)" and "Low Value" positions at a 1 percent level $(p<0.000)$. Moreover, within 
Table 6.2: Likelihood Models of Presidential Appointment Strategy in Executive Departments, Pre-FVRA (1977-1997) and Post-FVRA (1998-2015)

Multinominal Probit

DV: 3 Category Position Status

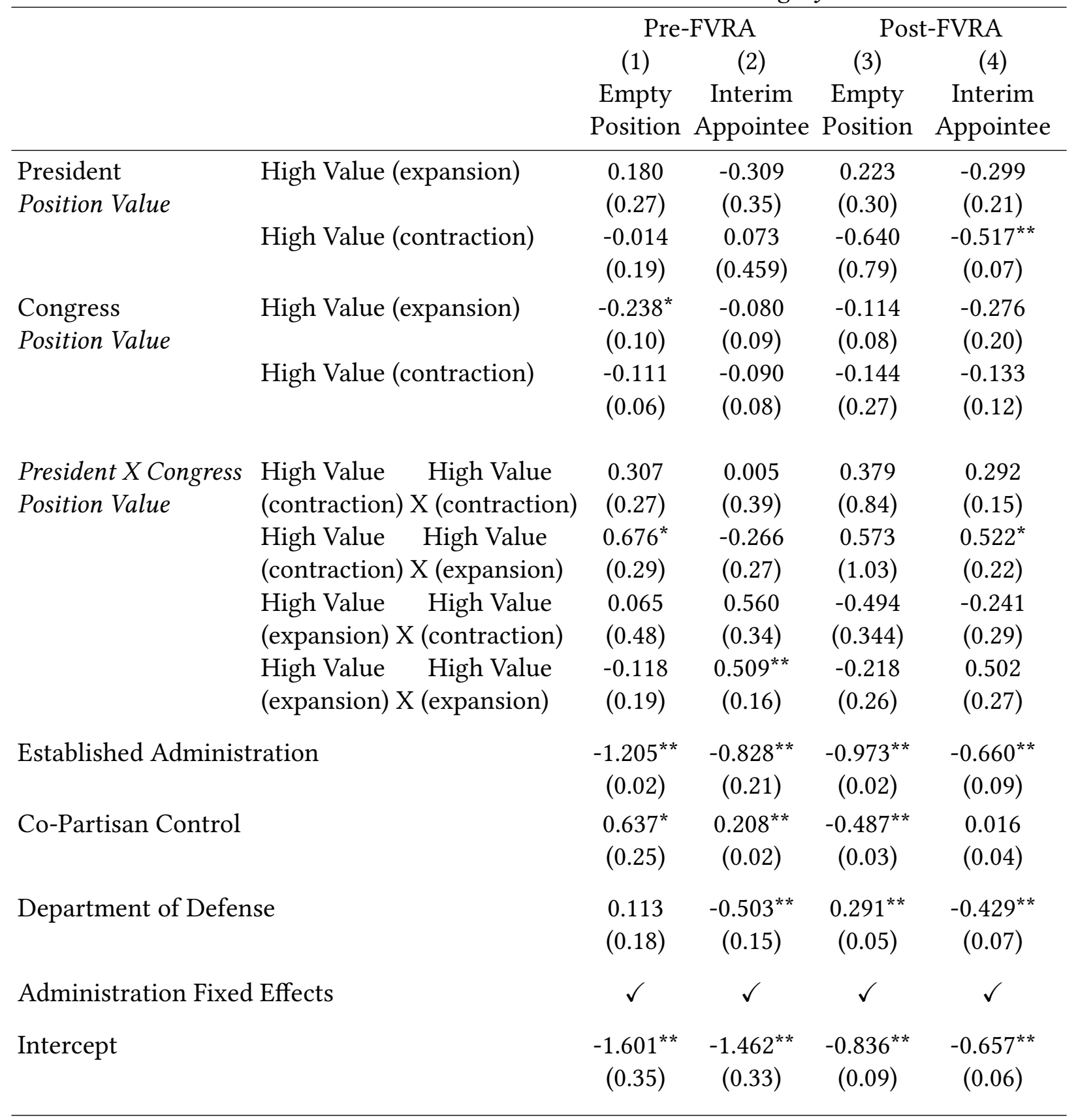

Note: $\mathrm{N}=5,174$ in models (1) and (2); $\mathrm{N}=5,116$ in models (3) and (4). Table entries are multinomial probit estimates of Position Status. The omitted (baseline) category is "Permanent Appointee," its coefficients have been normalized to zero in order to identify the model and allow for comparisons across equations. Reference category for Position Value is "Low Value." Cluster-robust standard errors appear in parentheses. ${ }^{*} \mathrm{p}<0.05,{ }^{* *} \mathrm{p}<0.01$ 
Table 6.3: Predicted Probabilities of Position Status Outcomes, Pre-FVRA (1977-1997)

\begin{tabular}{llccc}
\hline & & $\begin{array}{c}\text { Permanent } \\
\text { Appointee }\end{array}$ & $\begin{array}{c}\text { Interim } \\
\text { Appointee }\end{array}$ & $\begin{array}{c}\text { Empty } \\
\text { Position }\end{array}$ \\
\hline President & High Value (expansion) & $\mathbf{0 . 8 3 0}$ & $\mathbf{0 . 0 7 5}$ & 0.096 \\
Position & & $(0.01)$ & $(0.01)$ & $(0.02)$ \\
Value & High Value (contraction) & 0.806 & 0.054 & $\mathbf{0 . 1 3 9}$ \\
& & $(0.01)$ & $(0.01)$ & $(0.02)$ \\
& Low Value & 0.851 & $\mathbf{0 . 0 6 8}$ & 0.081 \\
& & $(0.02)$ & $(0.01)$ & $(0.01)$
\end{tabular}

Note: Table entries are the predicted probabilities of each position status given specified row variables. Standard errors are in parentheses. Bold and colored entries denote alignment with theoretical expectations. Explanatory variables were held constant at their mean values.

Table 6.4: Predicted Probabilities of Position Status Outcomes, Post-FVRA (1998-2015)

\begin{tabular}{llccc}
\hline & & $\begin{array}{c}\text { Permanent } \\
\text { Appointee }\end{array}$ & $\begin{array}{c}\text { Interim } \\
\text { Appointee }\end{array}$ & $\begin{array}{c}\text { Empty } \\
\text { Position }\end{array}$ \\
\hline $\begin{array}{l}\text { President } \\
\text { Position }\end{array}$ & High Value (expansion) & 0.852 & $\mathbf{0 . 0 9 8}$ & 0.050 \\
Value & High Value (contraction) & $(0.004)$ & $(0.01)$ & $(0.01)$ \\
& & $(0.874$ & 0.090 & 0.036 \\
& Low Value & 0.844 & $(0.01)$ & $(0.002)$ \\
& & $(0.01)$ & $(0.01)$ & $(0.001)$
\end{tabular}

Note: Table entries are the predicted probabilities of each position status given specified row variables. Standard errors are in parentheses. Bold and colored entries denote alignment with theoretical expectations. Explanatory variables were held constant at their mean values. 
positions that are "High Value (contraction)," empty positions are considerably more likely than interim appointees, and the predicted probabilities are statistically distinguishable at a 5 percent level $(p=0.011)$. While the expected patterns reverse under the post-FVRA regime, these results show that there is strong support for the Empty Position Hypothesis under the pre-FVRA regime.

Figure 6.6: Adjusted Predictions of the Probability of an Empty Position and Interim Appointee, given President Position Value, pre-FVRA (1977-1997)

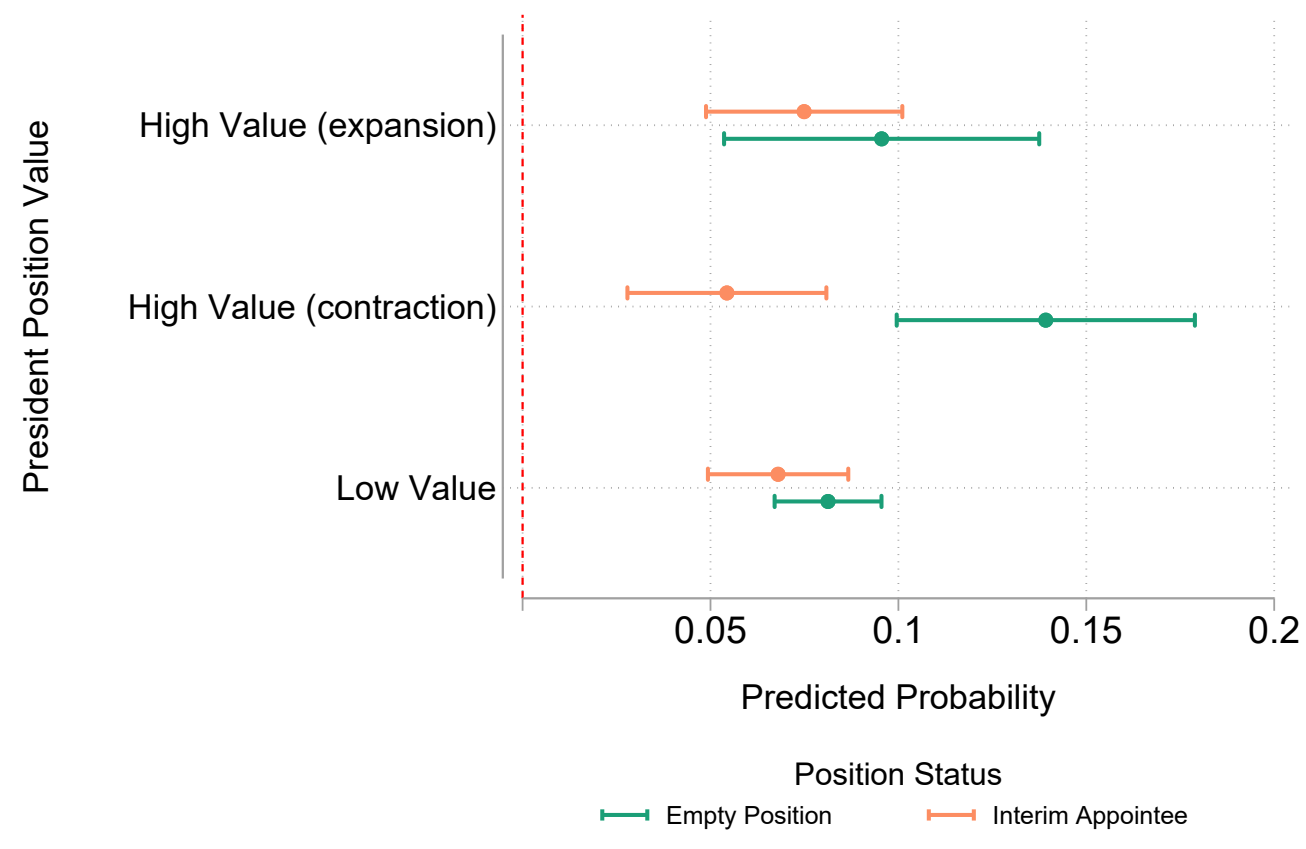

\section{H2. Interim Appointee Hypothesis}

If the Interim Appointee Hypothesis is accurate, we would expect higher predicted probabilities of interim appointees for "High Value (expansion)" and "Low Value" positions than otherwise. The second columns in Tables 6.3 and 6.4 present exactly these expected results. Moreover, Figures 6.6 and 6.7 highlight the strong evidence for the Interim Appointee Hypothesis under both the pre- and post-FVRA regimes - a result foreshadowed by the robust results from the likelihood analysis in Chapter 5. Figure 6.6 clearly illustrates that, under the pre-FVRA regime, the likelihood of interim appointees is higher for "High Value (expansion)" positions than "High Value 
(contraction)" ones, and statistically distinguishable at a 1 percent level $(p<0.000)$. While the second column in Table 6.3 reports that "Low Value" positions also have a higher likelihood than "High Value (contraction)" under the pre-FVRA regime, this difference is not statistically distinguishable $(p=0.551)$.

Additionally, the second column in Table 6.4 reports that these patterns persist under the post-FVRA regime. That is, the predicted probabilities of an interim appointee in "High Value (expansion)" and "Low Value" positions, under the post-FVRA regime, are higher than "High Value (contraction)" ones, however, they are not statistically distinguishable $(p=0.261$ and $p=0.585$, respectively). Furthermore, while the predicted probabilities, under the pre-FVRA regime, of interim appointees are less than the predicted probabilities of empty positions within "High Value (expansion)" and "Low Value" categories of president Position Value, they are not statistically distinguishable either $(p=0.536)$.

Most notably, Figure 6.7 displays a striking result. While we cannot statistically differentiate between the likelihoods of an interim appointee, under the post-FVRA regime, across the categories of president Position Value ( $p=0.261$ and $p=0.585)$, we can very clearly differentiate between them within these categories. Specifically, the predicted probabilities of an interim appointee are twice those of an empty position for "High Value (expansion)" and "Low Value" positions - which offers very strong evidence for the Interim Appointee Hypothesis. However, Figure 6.7 also shows that interim appointees are three times as likely as empty positions for "High Value (contraction)" positions, which does not align with expectations from the Empty Position Hypothesis or the Interim Appointee Hypothesis. Even so, the higher likelihoods of interim appointees under the post-FVRA regime - higher still than the likelihoods under the pre-FVRA regime - emphasize the influence, as expected, of the Federal Vacancies Reform Act on how Position Value captures the strategic value of interim appointees. 
Figure 6.7: Adjusted Predictions of the Probability of an Empty Positions and Interim Appointee, given President Position Value, post-FVRA (1998-2015)

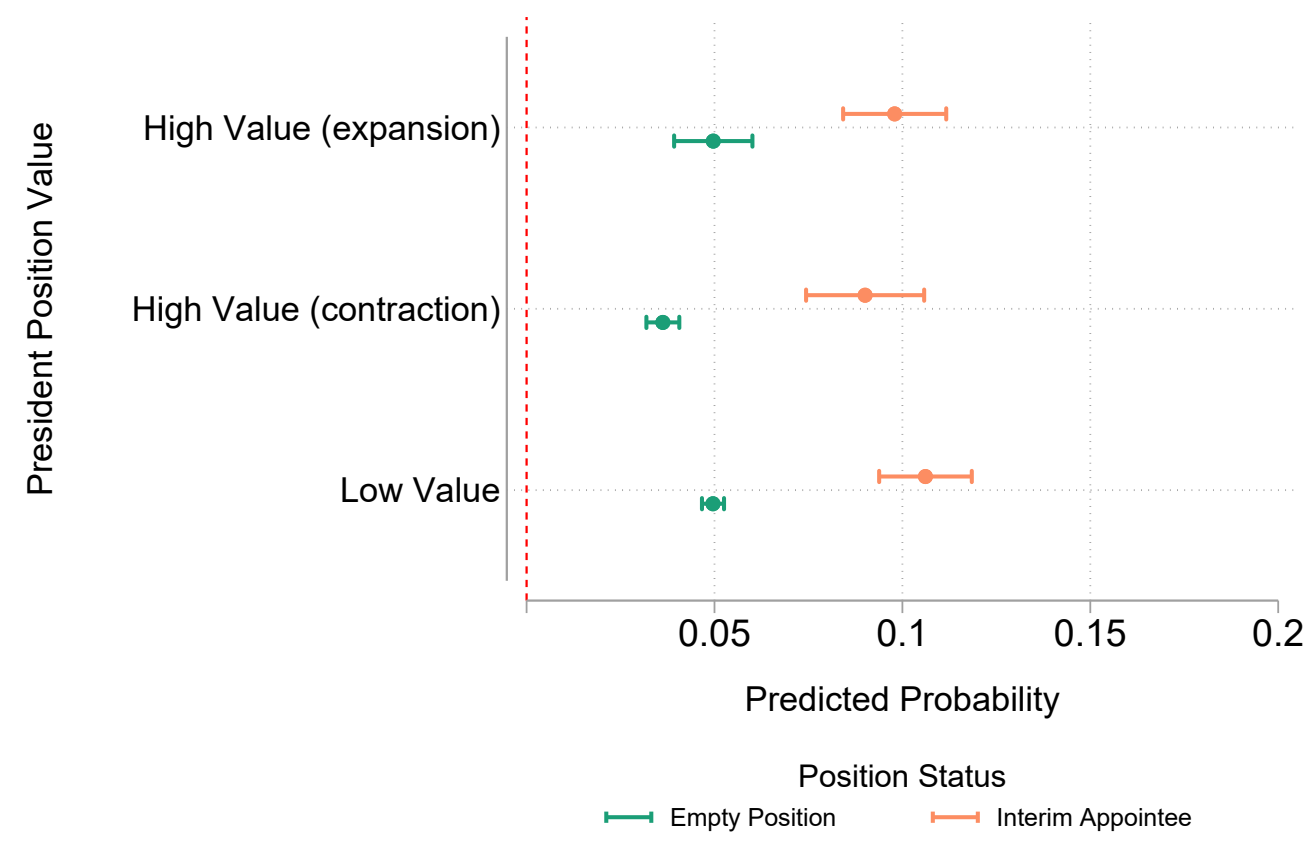

\section{H3. Permanent Appointee Hypothesis}

If the Permanent Appointee Hypothesis is accurate, we would expect higher predicted probabilities of permanent appointees for positions in the "High Value (expansion)" category of president Position Value. More specifically, we would expect permanent appointees to be more likely when presidents prioritize expansion and the Senate does not prioritize policy contraction. Furthermore, as mentioned at the outset of this chapter, a potential explanation for the insignificant results from the likelihood models in Chapter 5 could arise from divergent patterns in Position Status in the periods before and after the FVRA. As Figures 6.8, 6.9, and 6.10 present, we find evidence that meets each of these expectations, at least in part.

First, as the results in column 1 of Table 6.3 report, the likelihood of permanent appointees is higher for "High Value (expansion)" positions than "High Value (contraction)" ones under the pre-FVRA regime, as predicted. And this difference is statistically distinguishable $(p=0.009)$. In- 
Figure 6.8: Adjusted Predictions of the Probability of a Permanent Appointee, given President Position Value, Pre-FVRA (1977-1997)

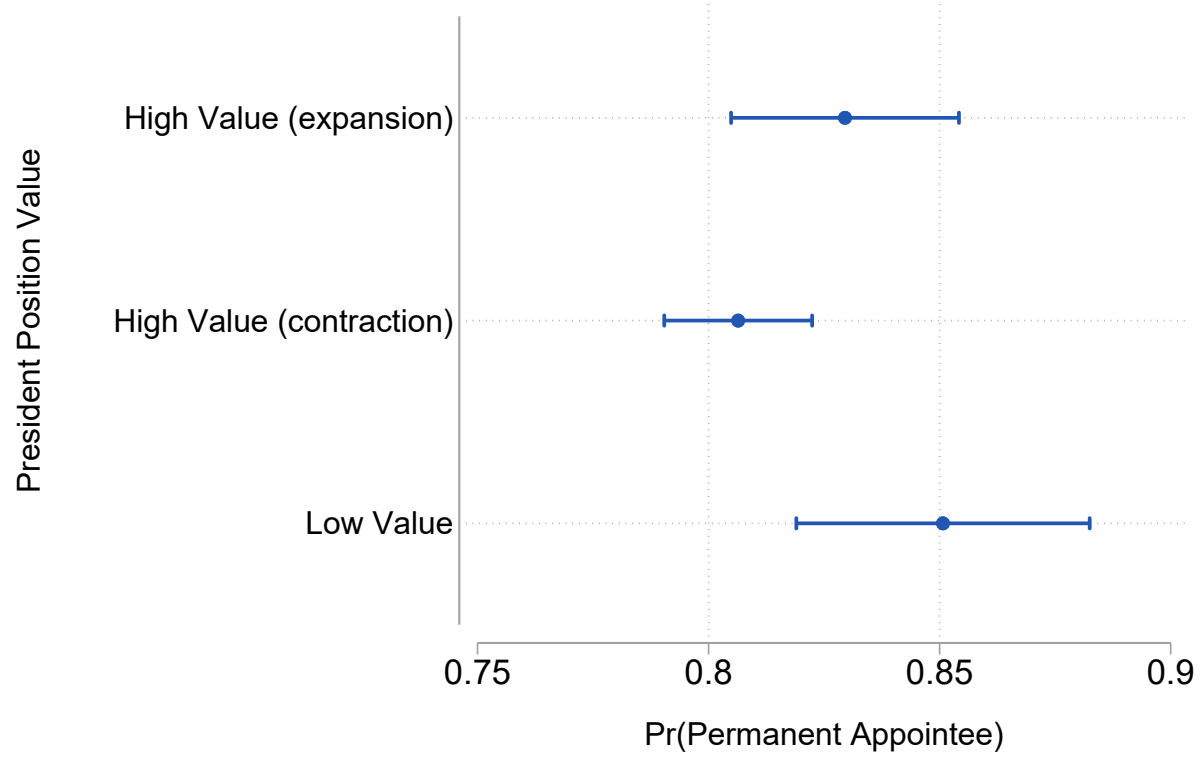

Figure 6.9: Adjusted Predictions of the Probability of a Permanent Appointee, given President Position Value, Post-FVRA (1998-2015)

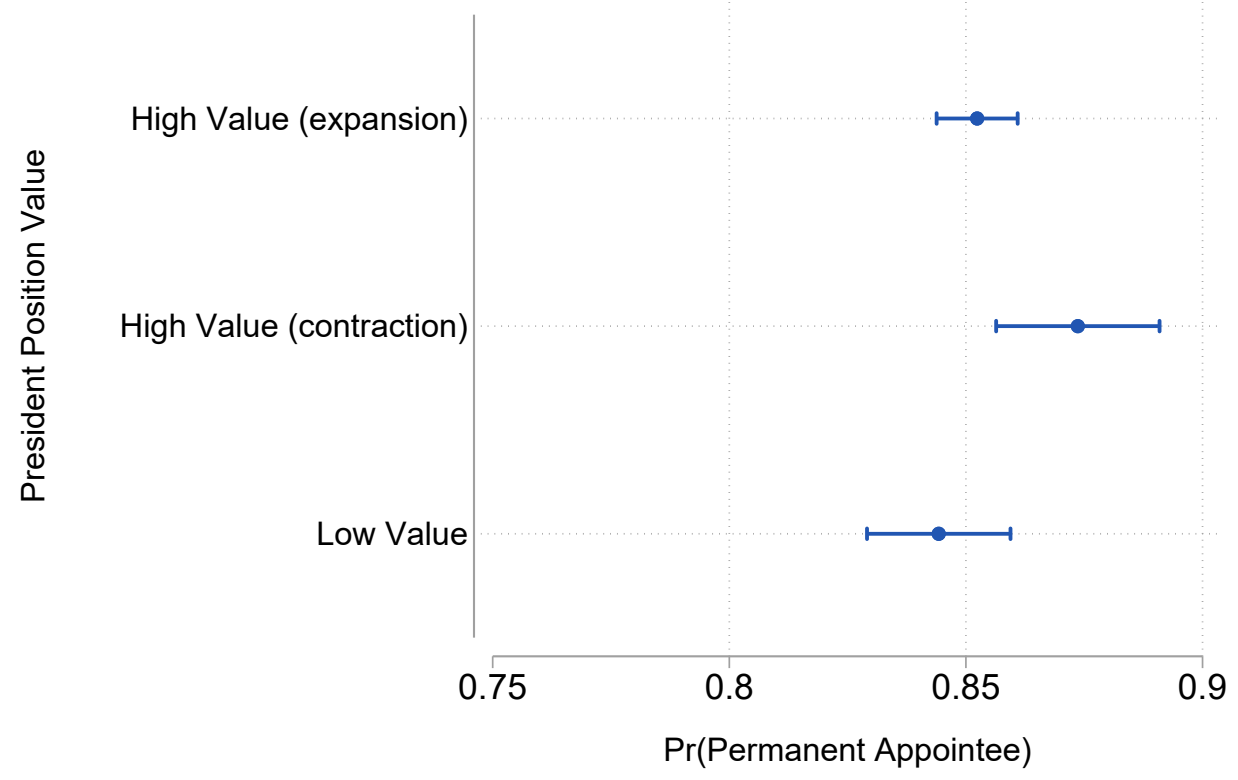


terestingly, after the FVRA was passed in 1998, this relationship reverses such that the likelihood of permanent appointees is lower for "High Value (expansion)" positions than "High Value (contraction)" ones; however, we cannot statistically differentiate between the two predicted probabilities $(p=0.095)$. Furthermore, Figures 6.8 and 6.9 clearly illustrates that, indeed, the pattern of predicted probabilities of permanent appointees inverts under the post-FVRA regime compared to the post-FVRA regime - which then contributes to the insignificant finding in Chapter 5.

Figure 6.10: Adjusted Predictions of the Probability of a Permanent Appointee, given President Position Value and Congress Position Value, Pre-FVRA (1977-1997)

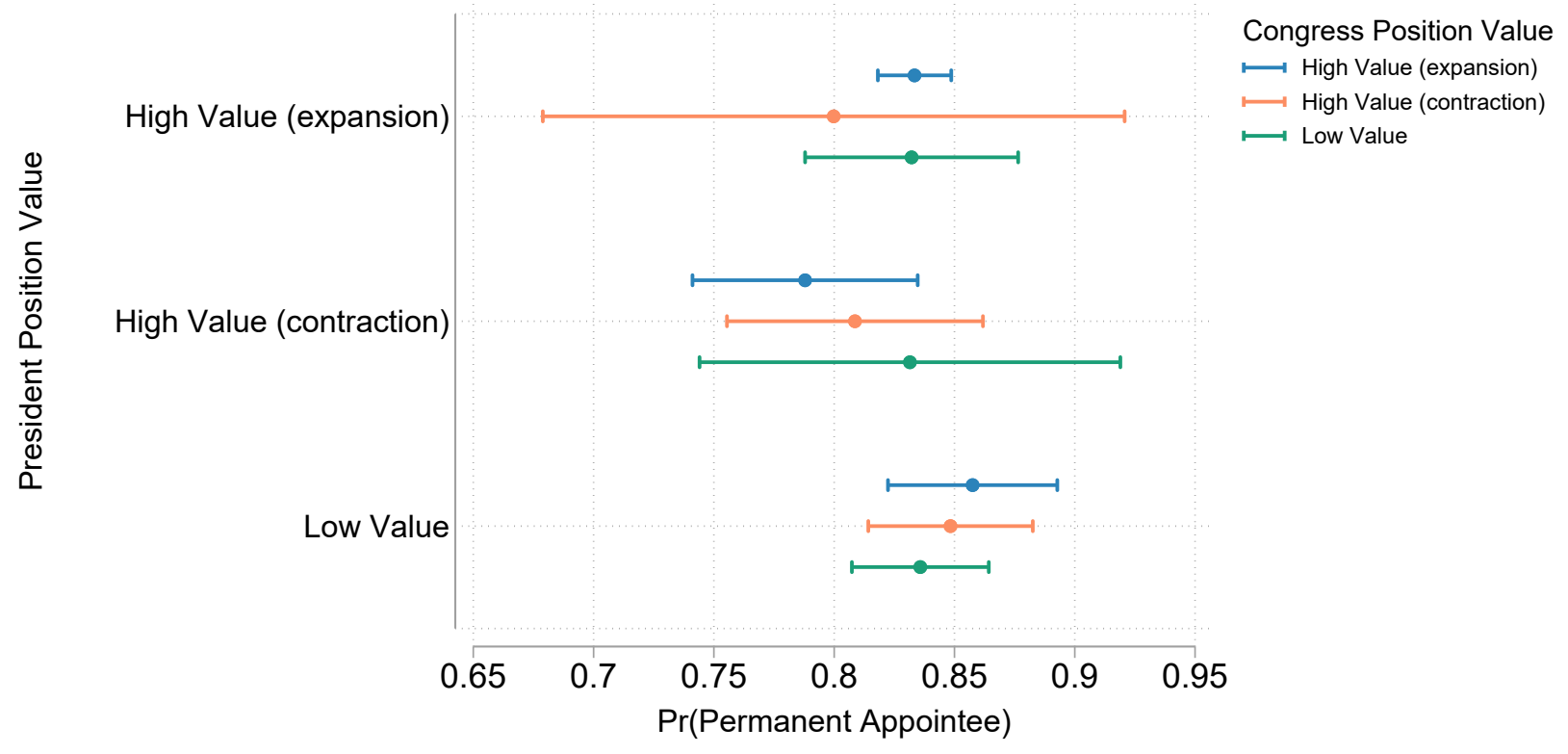

Second, Figure 6.10 presents the predicted probabilities of a permanent appointee for each category of president Position Value given the categories of Congress Position Value, under the pre-FVRA regime. This figure shows that, as expected, the likelihood of a permanent appointee is higher when Congress Position Value is not "High Value (contraction)" - when it is "High Value (expansion)" and "Low Value" - but the differences are not statistically distinguishable at even a 
10 percent level. Consequently, while this finding matches our expectations, it only faintly supports the Permanent Appointee Hypothesis.

\subsection{Discussion}

This analysis significantly contributes to a more complete explanation of what drives presidents to leave certain positions empty while seeking interim or permanent appointments for others, but there is still room for further exploration. The findings from these likelihood models - which explicitly account for the effects of the FVRA - together with those presented in Chapter 5 offer coherent and robust evidence for the Interim Appointee Hypothesis.

While we find additional, albeit only moderate, support for the Empty Position Hypothesis, the results from the likelihood models are not conclusive. One reason for this could be driven be a concentration of vacancies - specifically, empty positions - within departments, rather than a distribution across departments. Specifically, each position status might accumulate in the high capacity positions in departments for which the president has the requisite expansion or contraction policy priorities.

Ultimately, the likelihood model specification with the position-level outcome variable measures the probability that any one position is either empty or filled with an interim or permanent appointee as a function of Position Value and the other predictors. It does not address the incidence or accumulation of these separate position statuses, nor does it account for the potential set of each position status within a department. Structurally, the incidence of permanent appointees is limited by the department's total number of PAS positions; ${ }^{7}$ and, similarly, the incidence of empty positions and interim appointees is limited by the the total number of vacant PAS positions. The count model specification, outlined next in Chapter 7, estimates the expected number of empty

\footnotetext{
${ }^{7}$ In count models, the total set of observations from which the outcome variable - in this case, Position Status is observed is called the "exposure" (Cameron and Trivedi, 2013).
} 
positions, interim appointees, and permanent appointees - and models them separately - while explicitly accounting for the total potential set for each Position Status in each department. As mentioned at the outset of Chapter 5 , the generality of the theoretical hypotheses allow for considerations of both likelihood and incidence of position status. Thus, the next chapter specifies several count models to examine whether Position Value explains the incidence of Position Status. 


\section{CHAPTER VII}

\section{Examining the Incidence of Vacancies and Appointments}

The fact that PAS positions can be filled by interim appointees - exercising power without the requisite Senate confirmation - or left empty carries real implications for separation of powers. The designation that an agency position requires Senate confirmation - which Article II in the Constitution mandates for principal officers of the United States - confers legitimacy to the position's authority in directing the actions of government. That is, the checks and balances on the Executive branch's bureaucratic power begin with consenting to the individuals the president chooses to serve in those positions on a permanent ${ }^{1}$ basis. Any strategic effort to evade the Senate's advice and consent for even just one PAS position has considerable implications for separation of powers. Thus, it is equally as consequential and substantively interesting to question whether presidents strategically accumulate specific position statuses in certain agencies and not others, particularly if the pattern manifests among positions with the capacity to influence agency output and shift the direction of agency actions. Perhaps, then, the incidence of empty positions, interim appointees, and permanent appointees can also be explained by the capacity of the position to control policy output in agencies for which the president has expansion or

\footnotetext{
${ }^{1}$ The concept of a confirmed appointee being permanent, while commonplace in political discourse, journalism, and academic research on the subject (including the project at hand), is a bit of a misnomer. Studies on the tenure of political appointees within a president's four year term ranges find medians of 2.1 years (office, 1994) and 2.5 years (Dull and Roberts, 2009) and means of 2.4 years (O'Connell, 2009) and 2.7 years Chang et al. (2001), depending on the sample of appointees.
} 
contraction policy priorities. This chapter proceeds as follows. The first section introduces the aggregate measures of Position Status to be employed in the subsequent analyses. The remainder of the chapter the evaluates then three central hypotheses individually by modelling these counts of each Position Status among high capacity positions as a function of Policy Priorities.

The analysis is divided into two parts. First, Section 2 examines the impact of Policy Priorities on the incidence of high capacity positions left empty and filled interim appointees. Second, I offer an alternative perspective that accounts for the delay between a president's decision to appoint a permanent appointee and the realization of that choice. As I discuss in detail, I assess whether we see a strategic accumulation of permanent appointees after we account for the incongruity of presidential policy priorities due to the length of the formal nomination-confirmation process. Consequently, Section 3 separately examines the incidence of permanent appointees in high capacity positions while accounting for the lagged Policy Priorities. Lastly, Section 4 offers a discussion of the findings and their limitations.

\subsection{Introducing Position Status Count Data}

To begin, we need a measure that aggregates each Position Status within each departmentyear observation. Initially, this transformation seems straightforward - simply calculate the total number of empty positions, interim appointees, and permanent appointees - but it is not. Importantly, the central theoretical variable, Position Value, varies by position within each department. Hence, it cannot be aggregated for a department-level analysis. However, Position Value was purposefully constructed to make the implications of my theory as stark as possible. As such, positions are classified as "High Value" only when the position is high capacity and the president or the Senate have expansion or contraction priorities. ${ }^{2}$ Moreover, presidential and congressional Policy Priorities are department-level variables that vary by year, so they can be

\footnotetext{
${ }^{2}$ Recall that low capacity positions are classified as "Low Value" as are positions in agencies for which Policy Priorities are neutral.
} 
included in this analysis. Consequently, sub-setting the analyses to the sets of high capacity positions while including Policy Priorities mimics the high value categories of Position Value at the department-level. We can then recast the central hypotheses as expectations for a larger number of empty high capacity positions when presidents prioritize contraction and a larger number to be filled with interim and permanent appointees when presidents prioritize expansion, the latter conditioned on congressional Policy Priorities.

Table 7.1: Means and Variances of Position Status Count Data: Numbers of Empty, Interim Appointees, and Permanent Appointees in High Capacity Positions, Department-Year, 1977-2015

\begin{tabular}{|c|c|c|c|c|c|c|c|c|}
\hline \multirow{4}{*}{$\begin{array}{l}\text { President } \\
\text { Policy } \\
\text { Priorities }\end{array}$} & \multirow{2}{*}{\multicolumn{2}{|c|}{$7 /-2015$}} & \multicolumn{2}{|c|}{$\begin{array}{c}\text { Empty } \\
\text { Positions }\end{array}$} & \multicolumn{2}{|c|}{$\begin{array}{c}\text { Interim } \\
\text { Appointees }\end{array}$} & \multicolumn{2}{|c|}{$\begin{array}{l}\text { Permanent } \\
\text { Appointees }\end{array}$} \\
\hline & & & Mean & Variance & Mean & Variance & Mean & Variance \\
\hline & Expansion & $(\mathrm{N}=250)$ & 1.68 & 6.42 & 2.02 & 4.88 & 14.45 & 51.99 \\
\hline & Neutral & $(\mathrm{N}=85)$ & 1.37 & 3.93 & 1.43 & 3.30 & 14.59 & 56.55 \\
\hline & Contraction & $(\mathrm{N}=182)$ & 1.57 & 6.80 & 1.52 & 3.73 & 12.99 & 37.91 \\
\hline & Total & $(\mathrm{N}=517)$ & 1.59 & 6.13 & 1.74 & 4.26 & 13.95 & 48.03 \\
\hline
\end{tabular}

Accordingly, I construct a department-level outcome variable that collapses the position-level data into discrete counts of each status of high capacity positions per department-year. Table 7.1 presents the conditional means and variances of these count data by the categories of president Policy Priorities. ${ }^{3}$ As Table 7.1 shows, 250 of the 517 department-year observations (48 percent) were under "Expansion" president Policy Priorities compared to 85 under "Neutral" priorities (16 percent) and 182 under "Contraction" priorities (35 percent). Additionally, the average number of empty high capacity positions per department-year is 1.59 , the average number of interim appointees in high capacity positions is 1.74 per department-year, and the average number of permanent appointees in high capacity positions is 13.95 per department-year. And each of these counts have even larger variances - 6.13 for empty positions, 4.26 for interim appointees, and

\footnotetext{
${ }^{3}$ See Table AC.1 in the Appendix for the corollary summary statistics for low capacity positions.
} 
48.03 for permanent appointees - which Figures 7.1, 7.2, and 7.3 highlight as well.

Additionally, Figure 7.1 displays the distribution of the number of empty high capacity positions. It highlights that, while just over 43 percent of department-years from 1977 to 2015 have no empty high capacity positions, nearly 50 percent have between one and five. ${ }^{4}$ Alternatively, Figure 7.2 displays the distribution of the number of interim appointees in high capacity positions, which features less of a positive skew. In particular, less than 35 percent of department-years had zero interim appointees serving in high capacity positions and nearly 60 percent had between one and five. Lastly, Figure 7.3 presents the distribution of the number of permanent appointees in high capacity positions. Here, we can see that 75 percent of department-years had more than 9 permanent appointees filling high capacity positions; and Figure 7.3 also highlights that 50 percent of department-years had at least twelve permanent appointees. These distributions highlight the variation in the incidence of each position status among high capacity positions. Yet, the relationships between the conditional means and variances within these distributions are more important for the analysis to follow.

Notably, a standard Poisson model for count data assumes that the conditional variance of the distribution is equal to the expected value, its conditional mean (Long, 2014). However, Table 7.1 shows that the conditional variances $\left(\sigma_{\text {Expansion }}^{2}=4.88 ; \sigma_{\text {Neutral }}^{2}=3.30 ; \sigma_{\text {Contraction }}^{2}=\right.$ 3.73) of the count of interim appointees, given each category of president Position Value, exceeds the conditional means $\left(\mu_{\text {Expansion }}=2.02 ; \mu_{\text {Neutral }}=1.43 ; \mu_{\text {Contraction }}=1.52\right)$; and the same characteristics apply to empty positions ${ }^{5}$ and permanent appointees. ${ }^{6}$ Each conditional variance exceeds the conditional mean, which indicates over-dispersion and suggests that the data violate the Poisson count model assumptions. Thus, a negative binomial regression is a more appropriate

\footnotetext{
${ }^{4}$ Moreover, four outlying department-years experienced between 12 and 21 empty high capacity positions: Commerce and Defense in 1993 (21 and 15 empty high capacity positions, respectively) and Interior and Defense in 2001 (12 and 18, respectively).

${ }^{5} \sigma_{\text {Expansion }}^{2}=6.42 ; \sigma_{\text {Neutral }}^{2}=3.93 ; \sigma_{\text {Contraction }}^{2}=6.80$ compared to $\mu_{\text {Expansion }}=1.68 ; \mu_{\text {Neutral }}=1.37 ;$ $\mu_{\text {Contraction }}=1.57$, respectively.

${ }^{6} \sigma_{\text {Expansion }}^{2}=51.99 ; \sigma_{\text {Neutral }}^{2}=56.55 ; \sigma_{\text {Contraction }}^{2}=37.91$ compared to $\mu_{\text {Expansion }}=14.45 ; \mu_{\text {Neutral }}=$ $14.59 ; \mu_{\text {Contraction }}=12.99$, respectively
} 
Figure 7.1: Distribution of Empty High Capacity PAS Positions, 1977-2015

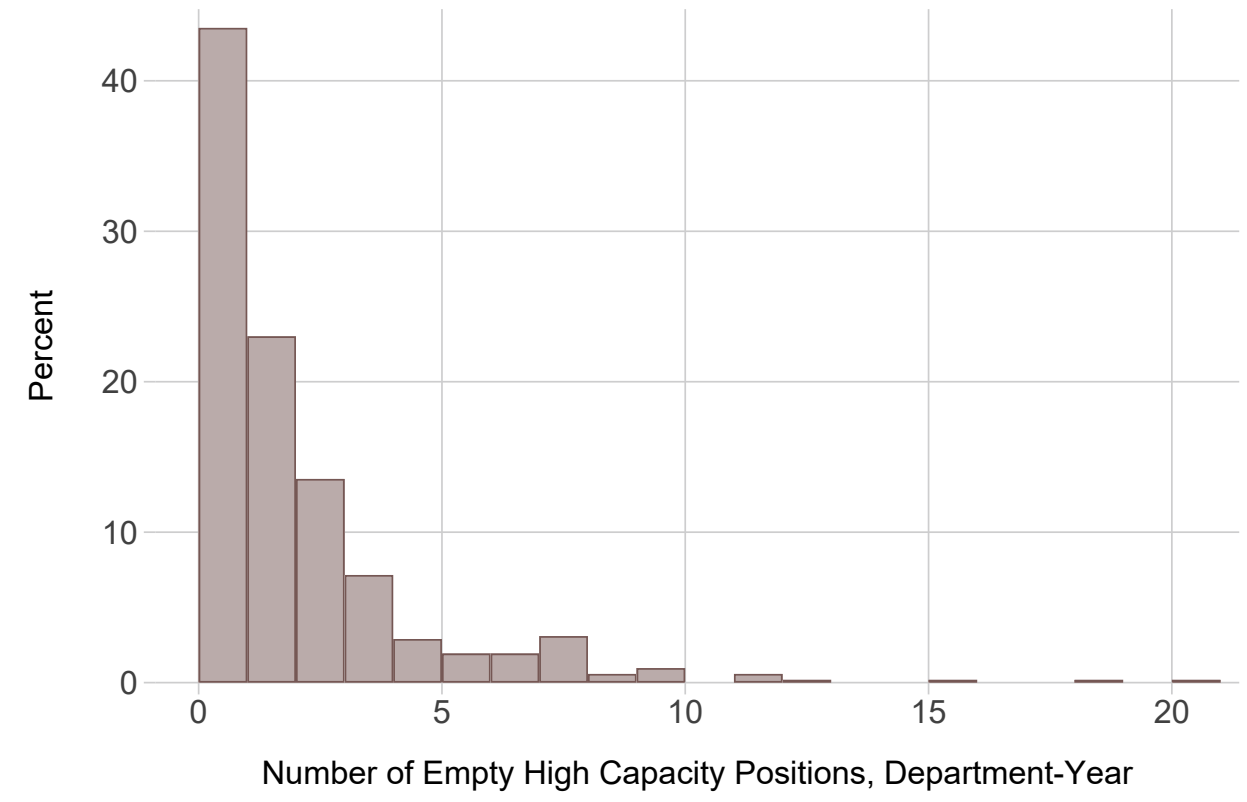

Figure 7.2: Distribution of Interim Appointees in High Capacity PAS Positions, 1977-2015

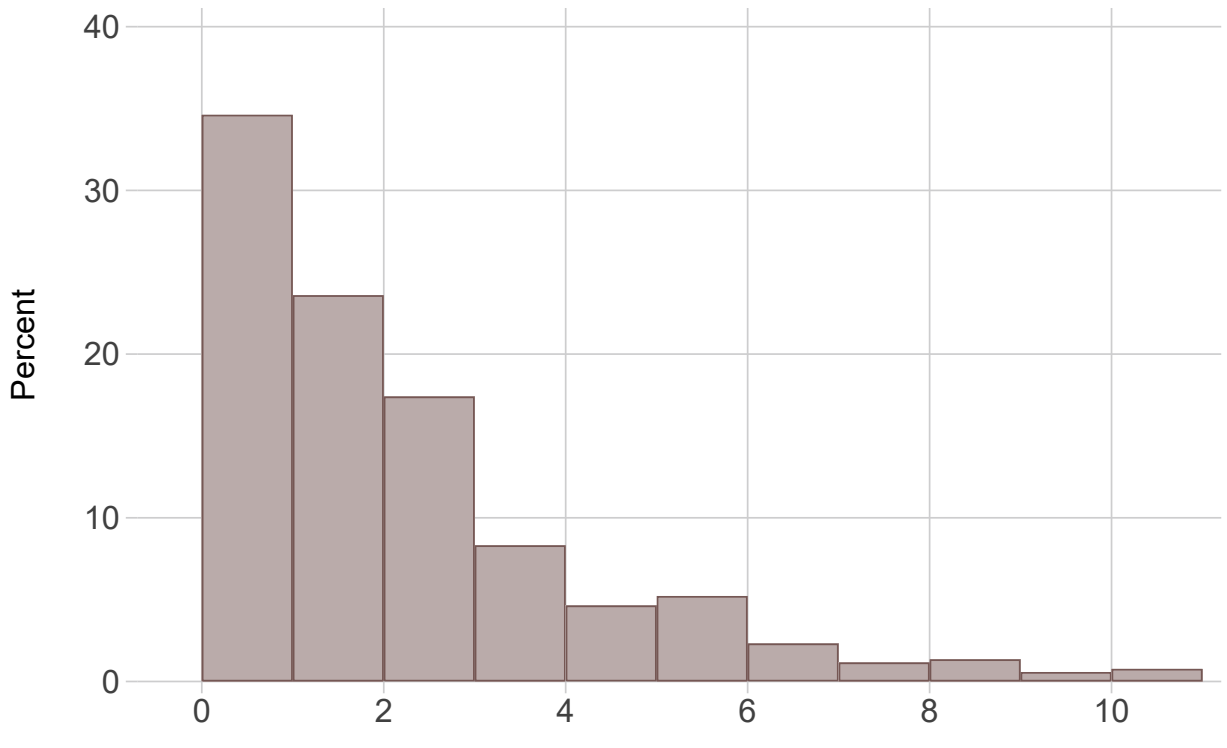

Number of Interim Appointees in High Capacity Positions, Department-Year 
Figure 7.3: Distribution of Permanent Appointees in High Capacity PAS Positions, 1977-2015

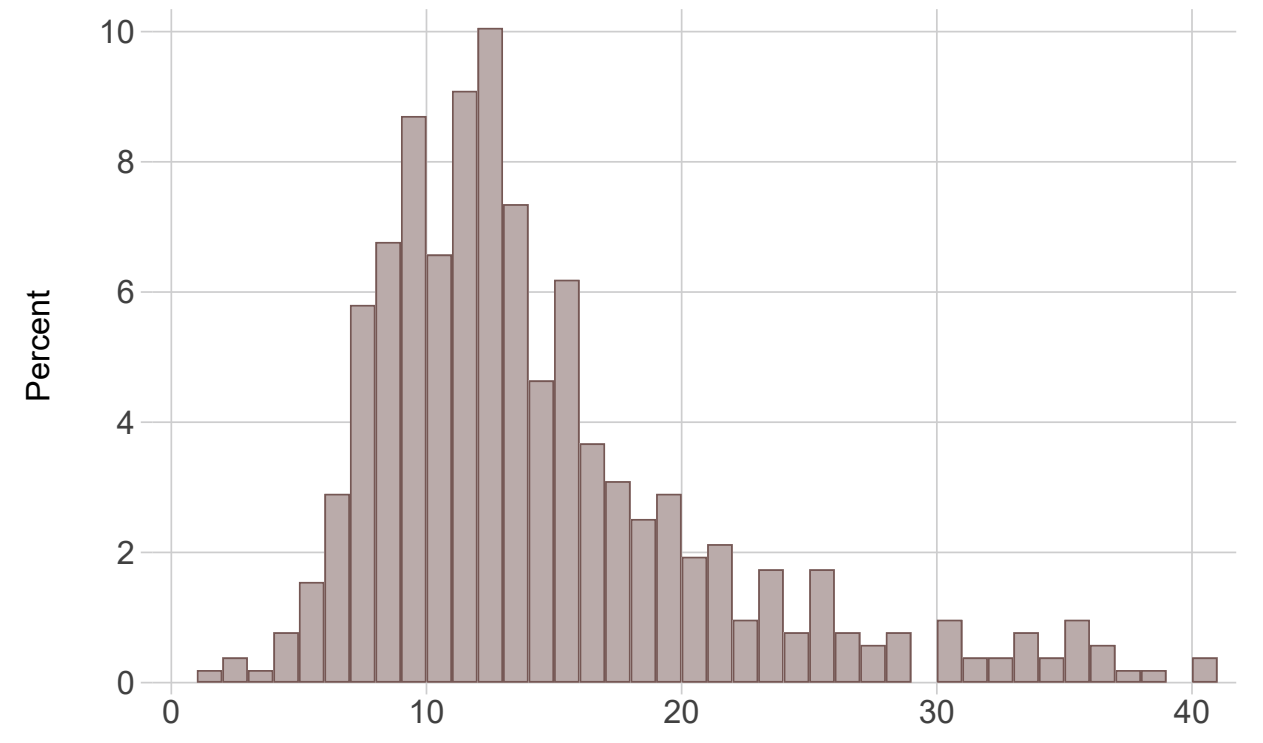

Number of Permanent Appointees in High Capacity Positions, Department-Year

estimation strategy. ${ }^{7}$ The next two sections detail the model specifications using this estimation strategy and present the results of the subsequent analysis.

\subsection{Explaining the Incidence of Position Status with Policy Priorities}

\subsubsection{Estimation Strategy: Negative Binomial Regression}

Here, I examine the impact of policy priorities on the incidence of high capacity positions left empty and filled with interim appointees using negative binomial regression, with cluster-robust standard errors to account for clustering within administrations. Specifically, I model each set of the count data described above as a function of presidential Policy Priorities and congressional Policy Priorities - as directed by my theoretical model - with controls for Established Administra-

\footnotetext{
${ }^{7}$ Additionally, even though large shares of the observations experience no empty high capacity positions or interim appointees filling time, an insignificant Vuong test indicates that modelling this data with a zero-inflated regression would not be a better fit than a negative binomial one.
} 
tion, Co-Partisan Control, and the Department of Defense, as well as administration fixed effects. ${ }^{8}$ Additionally, the incidence of empty positions and interim appointees is limited by the the total number of vacant PAS positions. ${ }^{9}$ Accordingly, this model specification includes the total potential set of vacant high capacity PAS positions for each department-year observation as the exposure variable for the count data. I estimate, using maximum likelihood estimation, negative binomial regression models of the following form:

$$
\begin{aligned}
N_{P S_{j t}}= & \alpha_{P S_{j t}}+\beta_{1} P P_{P j t}^{\prime}+\beta_{2} P P_{C j t}^{\prime}+\beta_{3} P P_{P j t}^{\prime} P P_{C j t}^{\prime}+\gamma_{1} E A_{t}^{\prime}+\gamma_{2} C P_{t}^{\prime}+ \\
& \gamma_{3} D_{j}^{\prime}+\gamma_{4} A_{t}^{\prime}+\gamma_{5} E x p_{t}+\varepsilon_{i}
\end{aligned}
$$

where

$N_{P S_{j t}}$ is a count measure of the number of high capacity positions for Position Status PS, such that $P S$ is empty and filled with interim appointees;

$P P_{P j t}$ and $\beta_{1}$ represent president Policy Priorities and its effects;

$P P_{P j t} P P_{C j t}$ is the interaction between the Position Value for the president and Congress, as driven by my theoretical expectations;

$E A_{t}$ and $\gamma_{1}$ is established administration and its effects;

$C P_{t}$ and $\gamma_{2}$ is co-partisan control of the Senate (same party as president);

$D_{j}$ indicates the Department of Defense; $A_{t}$ are administration fixed effects;

$E x p_{j t}$ is the exposure variable for the count data: the set of vacant high capacity positions (i.e., high capacity PAS positions without a permanent appointee) in department $j$ and year $t$, and $\gamma_{4}$ is $E x p_{j t}$ 's effects constrained to $1 ;^{10}$; and

$\varepsilon_{i}$ is the error term.

\footnotetext{
${ }^{8}$ See Chapter 5, Section 2.2 .1 for the detailed account of each variable.

${ }^{9}$ In count models, the total set of observations from which the outcome variable is observed is called the "exposure" (Cameron and Trivedi, 2013).

${ }^{10}$ See Cameron and Trivedi (2013).
} 
Table 7.2 reports the estimated coefficients and cluster-robust standard errors of the negative binomial regression specified above on the number of empty high capacity positions (Model 1) and the number of interim appointees in high capacity positions (Model 2). Since negative binomial regressions model the log of the outcome count variable as a function of the set of predictors, each coefficient is interpreted as the change in the log of the outcome counts (i.e., empty positions or interim appointees), given a one unit change in the predictor and with all others held constant. Additionally, the model specification includes the interaction between president Policy Priorities and Congress Policy Priorities which makes the interpretation of the coefficients a bit onerous. Instead, as reported in Table $7.3,{ }^{11}$ the predicted counts of empty and interim appointees in high capacity positions for each category of president Policy Priorities, with all other variables at their means, reveals the precise nature and magnitude of these effects.

\subsubsection{Results: Incidence of Empty Positions}

Recall that the Empty Position Hypothesis asserts that a president is more likely to leave high value positions - that is, high capacity positions in agencies for which the president's priorities are non-neutral - empty when prioritizing policy contraction. Thus, if the Empty Position Hypothesis is accurate, in this context, we would expect a higher incidence of empty high capacity positions when the president has contraction policy priorities. As Table 7.3 reports, we find exactly that. Specifically, when presidents prioritize policy contraction, the predicted number of empty high capacity positions, 1.849, is higher than the predicted number under neutral (1.519) or under expansion priorities (1.494). Furthermore, as Figure 7.4 highlights, the difference between the predicted number of empty positions under contraction priorities and under expansion priorities $(p=0.059)$ as well as that between contraction priorities and neutral ones $(p=0.066)$ are each statistically distinguishable. ${ }^{12}$

\footnotetext{
${ }^{11}$ See Table C.2 in the Appendix for the full set of predicted counts for empty positions and interim appointees, given each predictor variable.

${ }^{12}$ At a less than 7 percent level.
} 
Table 7.2: Count Models of Presidential Appointment Strategy in Executive Departments, 19772015

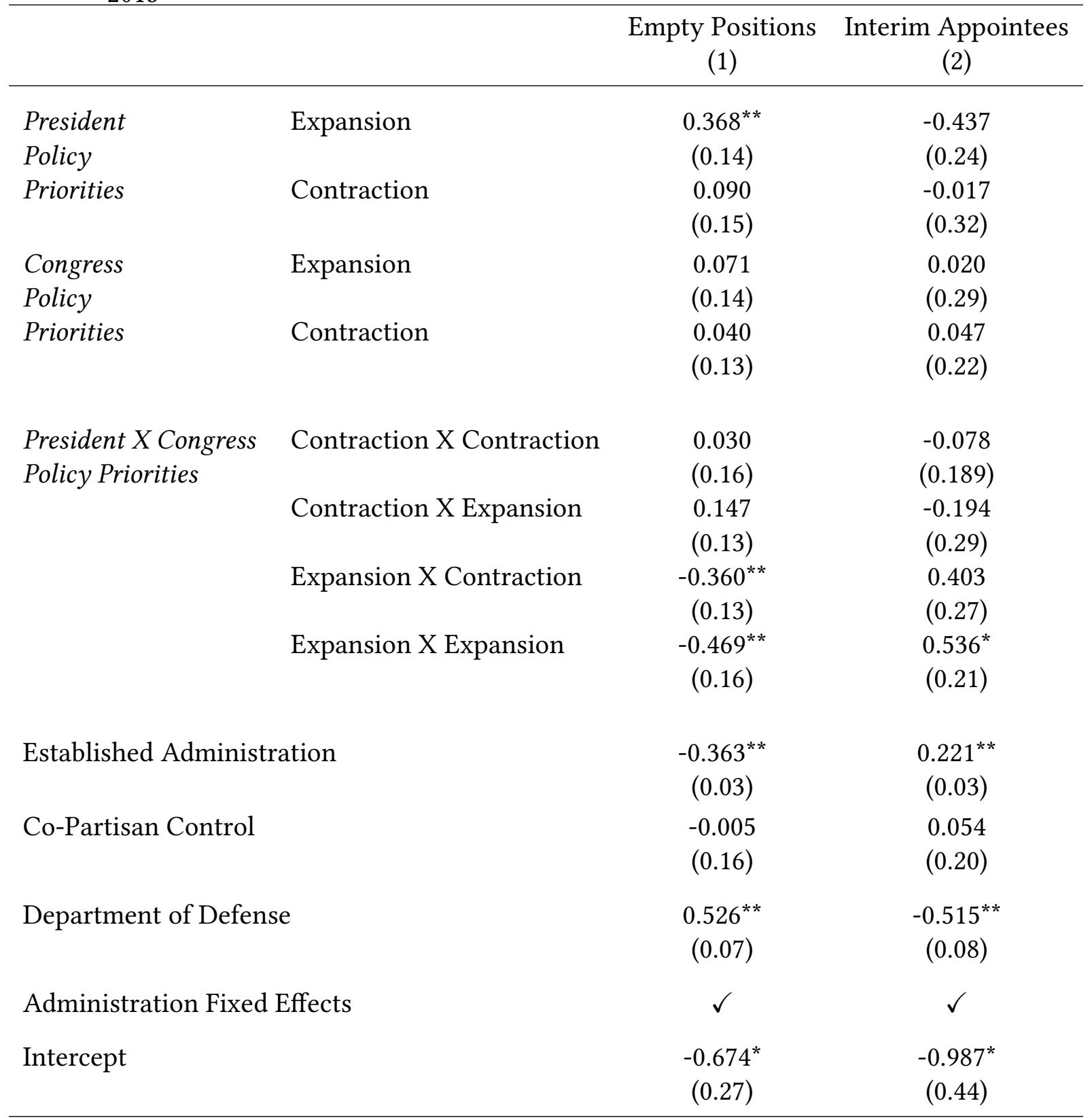

Note: $\mathrm{N}=517$ in all models. Table entries are negative binomial regression estimates of empty positions for Model 1 and interim appointees for Model 2. The outcome variables are counts of high capacity positions, per department-year, filled with interim appointees or left empty. Cluster-robust standard errors appear in parentheses. ${ }^{*} \mathrm{p}<0.05,{ }^{* *} \mathrm{p}<0.01$ 
Table 7.3: Predicted Number of Empty Positions and Interim Appointees in High Capacity Positions, 1977-2015

\begin{tabular}{llcc}
\hline & & Empty Positions & Interim Appointees \\
\hline President & Expansion & 1.494 & $\mathbf{1 . 8 3 6}$ \\
Policy & & $(0.12)$ & $(0.09)$ \\
Priorities & Neutral & 1.519 & $\mathbf{1 . 7 8 1}$ \\
& & $(0.10)$ & $(0.17)$ \\
& Contraction & $\mathbf{1 . 8 4 9}$ & 1.513 \\
& & $(0.17)$ & $(0.14)$ \\
\hline
\end{tabular}

Table entries are the predicted number of events for each position status given specified row variables. Standard errors are in parentheses. Bold and colored entries denote alignment with theoretical expectations. Predictor variables were held constant at their mean values.

Figure 7.4: Predicted Number of Empty High Capacity PAS Positions, given President Policy Priority

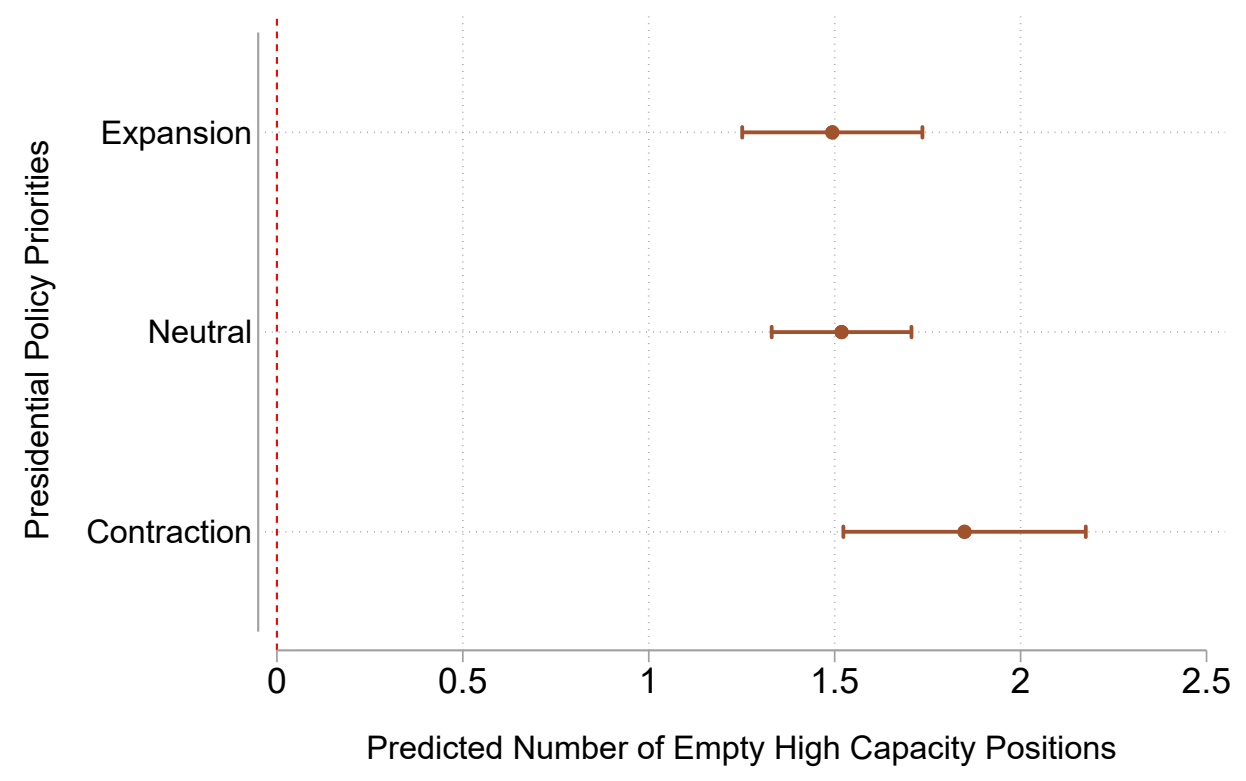

To offer some context, the average department-year has 20 PAS positions, 17 of which are high capacity positions; and, as seen above in Figure 7.1, 43.5 percent of the 517 departmentyears included in this analysis have zero empty high capacity positions. Consequently, adding 
just one empty high capacity position is not inconsequential. Overall, these results suggest that, as predicted, presidents leave more high capacity positions empty when they prioritize policy contraction.

\subsubsection{Results: Incidence of Interim Appointees}

Alternatively, recall that the Interim Appointee Hypothesis asserts that presidents with expansion policy priorities will fill high capacity positions with interim appointees. Thus, if the Interim Appointee Hypothesis is accurate, in this context, we would expect a higher incidence of interim appointees in high capacity positions when the president has expansion policy priorities. As Table 7.3 reports, we also find exactly that, although at considerably lower levels of statistical significance. Specifically, when presidents prioritize policy expansion, the predicted number of interim appointees in high capacity positions, 1.836, is higher than the predicted number under contraction priorities (1.494). However, as Figure 7.5 shows, the difference between the predicted number of interim appointees in high capacity positions under expansion priorities versus contraction priorities is not statistically distinguishable $(p=0.144)$. The magnitude of these results align with the likelihood models in Chapter 5 and offer some evidence that, as the Interim Appointee Hypothesis predicts, presidents appoint interim appointees to high capacity positions when they have expansion policy priorities. ${ }^{13}$

\footnotetext{
${ }^{13}$ The Interim Appointee Hypothesis also states that presidents will fill "Low Value" positions with interim appointees. Positions are "Low Value" when they have low position capacity, regardless of the president's priorities, or when the president Policy Priorities are "Neutral." Table 7.3 also reports that when president have neutral policy priorities, the predicted number of interim appointees, 1.781, is higher than under contraction priorities. However, Figure 7.5 shows that the difference is not statistically distinguishable $(p=0.288)$. This result is not particularly surprising as the "Low Value" category encompasses low capacity positions not captured here and, consequently, does not allow for a full test of the theoretical expectation for "Low Value" positions.
} 
Figure 7.5: Predicted Number of Interim Appointees in High Capacity PAS Positions, given President Policy Priority

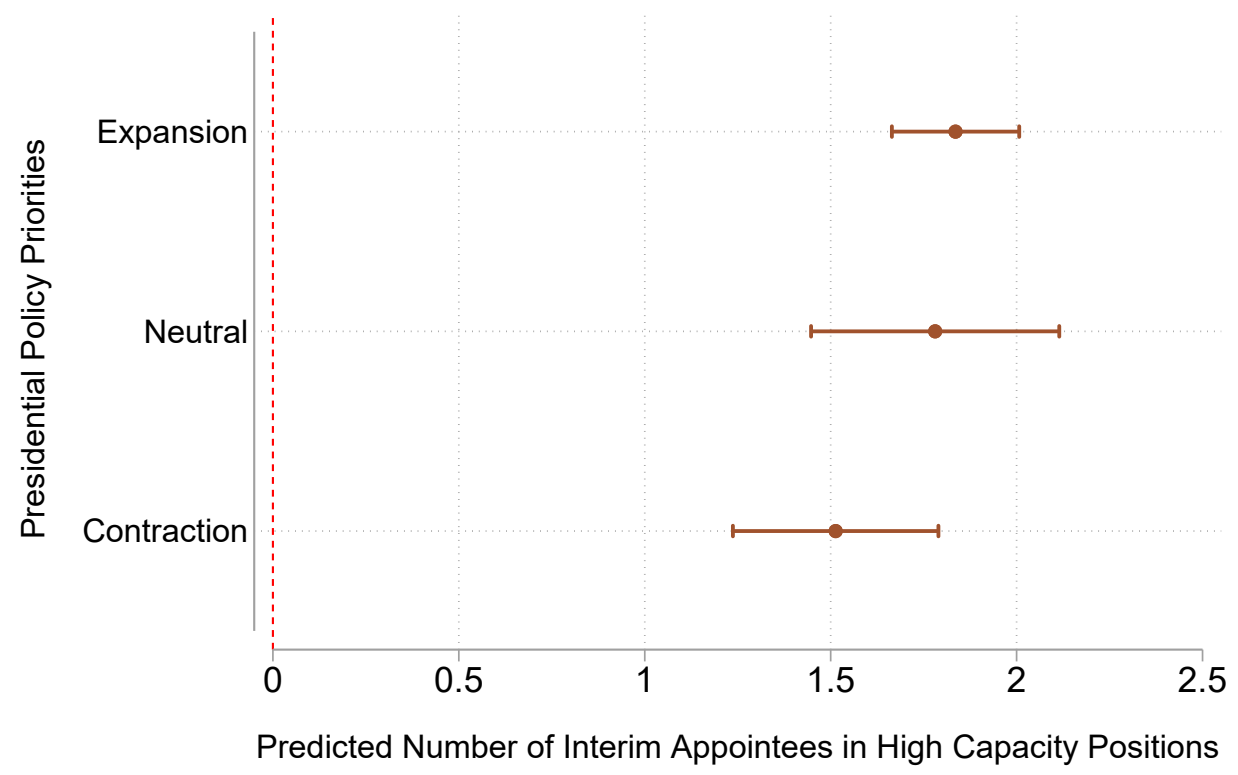

\subsection{Examining the Incidence of Permanent Appointees}

\subsubsection{Estimation Strategy: Negative Binomial Regression}

Importantly, while the results presented in Chapters 5 and 6 strongly support the first two main hypotheses, they offer only minor support for the Permanent Appointee Hypothesis. One reason for this could arise from a structural feature of the appointment process that uniquely impacts the outcome of a permanent appointee: time. Specifically, when the president chooses to fill a vacant position immediately with an interim appointee or to leave it empty, he does so unilaterally. Surely, there may be delays that impact when the interim appointee actually assumes the role; but these delays can be minimized to zero since there is no intermediary actor that plays a requisite role in the temporary appointment. Likewise, there are no delays between 
the choice to leave a vacant position empty and the outcome, since the outcome results from simply maintaining the status quo. That is, presidents' dictatorial control over the maintenance of vacancies leads to a near-instantaneous realization of their decision to leave the position empty or appoint an interim.

Alternatively, the process that yields a permanent appointee includes a formal confirmation, which introduces a non-zero time delay as the intermediary actor, the Senate, must act to make the president's choice a reality. The lag in nomination and confirmation of a permanent appointee, which is well documented, ${ }^{14}$ translates into a potential lagged impact of Policy Priorities when the placement of permanent appointees is realized. Critically, while the theoretical framework outlined in Chapter 4 does not incorporate time as a dynamic model, it does explicitly model the requisite bargaining between the Senate and the president over the proposed permanent appointee. $^{15}$

Moreover, the model formally assumes that the president's Position Value at the start of the game drives the choice to nominate (or not) at that subsequent decision node. However, in reality, the delays of the nomination-confirmation process translate to a potential incongruity between the initial president Position Value and the realized outcome of a permanent appointee. We have seen from the data description in Chapter 5 that president policy priorities vary by year and by department. Given this variation, we might easily expect that as confirmation delays grow longer, the likelihood of a shift in policy priorities also increases. Furthermore, the shift might not, and need not, only occur between nomination and confirmation. If the policy priorities

\footnotetext{
${ }^{14}$ For instance, see Nixon and Goss (2001); Binder and Maltzman (2002); Shipan and Shannon (2003); O'Connell (2014); Ostrander (2016); Hollibaugh and Rothenberg (2017) for considerable evidence and thorough examinations of delays in presidential nominations and Senate confirmation.

${ }^{15}$ The theoretical framework outlined in Chapter 4 incorporates the Permanence and Oversight parameter to account for constraints the Senate can impose through oversight on the attainment of the full value of the position, which I propose is indicated by the relative ease or toils of confirmation. Specifically, as I discussed in Section 2 of Chapter 4, a lengthier confirmation process necessarily restricts the remaining tenure of the potentially confirmed appointee - thereby restricting the value of the position that can be attained - and, if accompanied by discordant confirmation hearings, signals the likelihood of increased oversight once the confirmed appointee takes office. While the theory allows for these constraints on the achieved value of the position, it does not explicitly integrate time or delays due to prolonged confirmations.
} 
of the administration change before the permanent appointee is discharged from her position, a similar incongruity of policy priorities would occur. That is, we cannot empirically expect that the president's policy priorities at the initial decision node will remain unchanged until the outcome of a permanent appointee is observed. Thus, while timing does not enter the scope of the formal model and therefore is not explicitly captured theoretically in the Permanent Appointee Hypothesis, the delay between the decision to fill a position with a permanent appointee and the outcome of the formal nomination-confirmation process is empirically relevant.

The aggregate counts offer an additional perspective of the data, which allows me to explore alternative explanations for why the previous results were less strong. In this vein, a potentially more accurate empirical analysis would account for the incongruity described above by introducing a lagged version of president Position Value when modelling the incidence of permanent appointees. Here, I examine the impact of policy priorities on the incidence of high capacity positions filled with permanent appointees using negative binomial regression, with cluster-robust standard errors to account for clustering within administrations. As such, Equation 2 specifies the model as a function of Policy Priorities and the other predictors also included in the model specified in Equation 1. However, this specification adds a lagged version of president Policy Priorities in order to address the characteristic specific to permanent appointees: the inability for presidents to immediately fill any position with a permanent appointee. Furthermore, the incidence of permanent appointees is fundamentally limited by the department's total number of PAS positions. Accordingly, this specification also includes the total potential set of high capacity PAS positions for each department-year observation as the exposure variable for the count data. I estimate, using maximum likelihood estimation, a negative binomial regression model of the following form: 


$$
\begin{aligned}
N_{P S_{j t}}= & \alpha_{P S_{j t}}+\beta_{1} P P_{P j t}^{\prime}+\beta_{2} P P_{C j t}^{\prime}+\beta_{3} P P_{P j t}^{\prime} P P_{C j t}^{\prime}+\beta_{4} P P_{P j t-1}^{\prime}+ \\
& \gamma_{1} E A_{t}^{\prime}+\gamma_{2} C P_{t}^{\prime}+\gamma_{3} D_{j}^{\prime}+\gamma_{4} A_{t}^{\prime}+\gamma_{5} \operatorname{Exp}_{t}+\varepsilon_{i}
\end{aligned}
$$

$N_{P S_{j t}}$ is a count measure of the number of high capacity positions for Position Status PS such that $P S$ is filled with permanent appointees in department $j$ and year $t$;

$P P_{P j t}$ and $\beta_{1}$ represent president Policy Priorities and its effects;

$P P_{P j t} P P_{C j t}$ is the interaction between the Position Value for the president and Congress, as driven by my theoretical expectations;

$P P_{P j t-1}$ is the lagged president Policy Priorities for department $j$ in year $t-1$ and its effects;

$E A_{t}$ and $\gamma_{1}$ is established administration and its effects;

$C P_{t}$ and $\gamma_{2}$ is co-partisan control of the Senate (same party as president);

$D_{j}$ indicates the Department of Defense; $A_{t}$ are administration fixed effects;

$\operatorname{Exp}_{j t}$ is the exposure variable for the count data: the set of all high capacity positions in department $j$ and year $t$ for Equation 2 and $\gamma_{4}$ is its effects constrained to 1 ; and

$\varepsilon_{i}$ is the error term.

\subsubsection{Results: Incidence of Permanent Appointees}

Table 7.4 reports the estimated coefficients and cluster-robust standard errors of the negative binomial regression on the number of permanent appointees in high capacity positions. Here, the results for Model 3 are obtained by estimating the specification outlined earlier in this chapter by Equation 7.1. Alternatively, Model 4 estimates the specification outlined by Equation 7.2, which includes the lagged president Policy Priorities predictor. Importantly, the results for the count models of empty positions and interim appointees are robust to the inclusion of the lagged president Policy Priorities. Table C.4 and Figures C.1 and C.2 in the Appendix demonstrate this 
Table 7.4: Count Models of Presidential Appointment Strategy in Executive Departments, 19772015

Permanent Appointees

(3)

\begin{tabular}{|c|c|c|c|}
\hline \multirow{2}{*}{$\begin{array}{l}\text { Lagged President } \\
\text { Policy Priorities }\end{array}$} & \multicolumn{2}{|l|}{ Expansion } & 0.028 \\
\hline & \multicolumn{2}{|l|}{ Neutral } & $\begin{array}{l}-.003 \\
(0.025)\end{array}$ \\
\hline \multirow{3}{*}{$\begin{array}{l}\text { President } \\
\text { Policy } \\
\text { Priorities }\end{array}$} & \multirow[t]{2}{*}{ Expansion } & 0.053 & 0.033 \\
\hline & & $(0.049)$ & $(0.044)$ \\
\hline & Contraction & $\begin{array}{c}0.097 \\
(0.103)\end{array}$ & $\begin{array}{l}0.111 \\
(.103)\end{array}$ \\
\hline \multirow{2}{*}{$\begin{array}{l}\text { Congress } \\
\text { Policy } \\
\text { Priorities }\end{array}$} & Expansion & $\begin{array}{c}0.086 \\
(0.048)\end{array}$ & $\begin{array}{c}0.078 \\
(0.047)\end{array}$ \\
\hline & Contraction & $\begin{array}{c}0.097 \\
(0.053)\end{array}$ & $\begin{array}{l}0.097^{*} \\
(0.046)\end{array}$ \\
\hline \multirow[t]{4}{*}{$\begin{array}{l}\text { President X Congress } \\
\text { Policy Priorities }\end{array}$} & Contraction X Contraction & $\begin{array}{l}-0.108 \\
(0.107)\end{array}$ & $\begin{array}{l}-0.115 \\
(0.107)\end{array}$ \\
\hline & Contraction X Expansion & $\begin{array}{l}-0.121 \\
(0.091)\end{array}$ & $\begin{array}{l}-0.130 \\
(0.091)\end{array}$ \\
\hline & Expansion X Contraction & $\begin{array}{l}-0.032 \\
(0.051)\end{array}$ & $\begin{array}{l}-0.027 \\
(0.047)\end{array}$ \\
\hline & Expansion X Expansion & $\begin{array}{l}-0.081 \\
(0.045)\end{array}$ & $\begin{array}{l}-0.065 \\
(0.048)\end{array}$ \\
\hline \multicolumn{2}{|c|}{ Established Administration } & $\begin{array}{l}0.281^{* *} \\
(0.022)\end{array}$ & $\begin{array}{l}0.282^{* *} \\
(0.021)\end{array}$ \\
\hline \multicolumn{2}{|l|}{ Co-Partisan Control } & $\begin{array}{l}-0.005 \\
(0.044)\end{array}$ & $\begin{array}{l}-0.002 \\
(0.045)\end{array}$ \\
\hline \multicolumn{2}{|c|}{ Department of Defense } & $\begin{array}{c}0.015 \\
(0.019)\end{array}$ & $\begin{array}{c}0.015 \\
(0.016)\end{array}$ \\
\hline \multicolumn{2}{|c|}{ Administration Fixed Effects } & $\checkmark$ & $\checkmark$ \\
\hline \multicolumn{2}{|l|}{ Intercept } & $\begin{array}{l}-0.457^{* *} \\
(0.079)\end{array}$ & $\begin{array}{l}-.445^{* *} \\
(0.069)\end{array}$ \\
\hline
\end{tabular}

Note: $\mathrm{N}=514$ in all models. Table entries are negative binomial regression estimates of permanent appointees, with and without the lagged Presidential Policy Priorities variable. The outcome variables are counts of high capacity positions, per department-year, filled with permanent appointees.

Reference category for Policy Priorities is "Neutral" and "Contraction" for Lagged Policy Priorities. Cluster-robust standard errors appear in parentheses. ${ }^{*} \mathrm{p}<0.05,{ }^{* *} \mathrm{p}<0.01$ 
robustness as the results do not change significantly or substantively when we include the lagged variable, nor is the lagged variable significant. Thus, the previous year's priorities, as measured by the lagged Policy Priorities only significantly and substantively influences the count of permanent appointees, as we would expect.

Recall the Permanent Appointee Hypothesis states that presidents will fill high value positions with permanent, confirmed appointees when they prioritize expansion and the Senate does not prioritize contraction. Consequently, if the Permanent Appointee Hypothesis is accurate, in this context, we would expect a higher incidence of permanent appointees in high capacity positions when the president has expansion policy priorities. We would also expect a higher incidence when president Policy Priorities are "Expansion" and Congress Policy Priorities are not "Contraction." Furthermore, given how lagged policy priorities likely operate to influence the choice that produces a permanent appointee, we would also expect a higher incidence of permanent appointees in high capacity positions when the lagged president Policy Priorities are "Expansion." More specifically, if the lagged Policy Priorities are, in fact, the predominant predictor of the count of permanent appointees, then we would expect the coefficient estimates for the contemporaneous priorities, and for the controls, to remain relatively unchanged as the addition of the lagged variable explains the unexplained variance. Tables 7.4 and 7.5 present strong evidence to support these expectations.

First, the predicted number of permanent appointees in high capacity positions, as reported for Model 3 in Table 7.3 (first column), does not follow the expected pattern for president Policy Priorities. Similar to the estimates from the likelihood models presented in Chapter 5, these predicted counts are not higher for expansion priorities as we would expect; however, also like the likelihood results, Figure 7.6 illustrates that the results cannot be statistically differentiated across the categories of president Position Value. While these results do not align with the expectations originally set out by the Permanent Appointee Hypothesis, they do lay the groundwork for examining whether lagged Policy Priorities have a role to play. Second, Table 7.4 highlights that, 
Table 7.5: Predicted Number of Permanent Appointees in High Capacity Positions, 1977-2015

Permanent Appointees

(3)

\begin{tabular}{llcc}
\hline $\begin{array}{l}\text { Lagged } \\
\text { President }\end{array}$ & Expansion & & $\mathbf{1 4 . 2 3 9}$ \\
Policy & Neutral & & 13.802 \\
Priorities & & & $(0.276)$ \\
& Contraction & & 13.846 \\
& & & $(0.135)$ \\
President & Expansion & 13.998 & 13.984 \\
Policy & & $(0.933)$ & $(0.083)$ \\
Priorities & Neutral & 14.106 & 14.195 \\
& & $(0.185)$ & $(0.161)$ \\
& Contraction & 13.973 & 14.11 \\
& & $(0.250)$ & $(0.252)$ \\
\hline
\end{tabular}

Note: $\mathrm{N}=514$ in all models. Table entries are the predicted number of permanent appointees given specified row variables. Standard errors are in parentheses. Bold and colored entries denote alignment with theoretical expectations. Predictor variables were held constant their mean values.

as expected, the coefficient estimates are relatively stable across Models 3 and 4, such that all maintain a similar magnitude and only contraction Congress Policy Priorities change in statistical significance.

Lastly, Table 7.5 and Figure 7.7 offer compelling evidence that president Policy Priorities, albeit lagged, significantly impact the incidence of permanent appointees. Specifically, as the results from Model 4 in Table 7.5 indicate, the predicted number of permanent appointees in high capacity positions under lagged expansion policy priorities, 14.239, is higher than the predicted number under contraction policy priorities (13.846). And Figure 7.7 shows that, as expected, this difference is statistically distinguishable $(p=0.050)$. Consequently, while the contemporaneous policy priorities yield no discernible support for the Permanent Appointee Hypothesis in either the likelihood or count models, once we account for a delayed impact, we find clear support for the 
Figure 7.6: Predicted Count of Permanent Appointees in High Capacity PAS Positions, given President Policy Priority

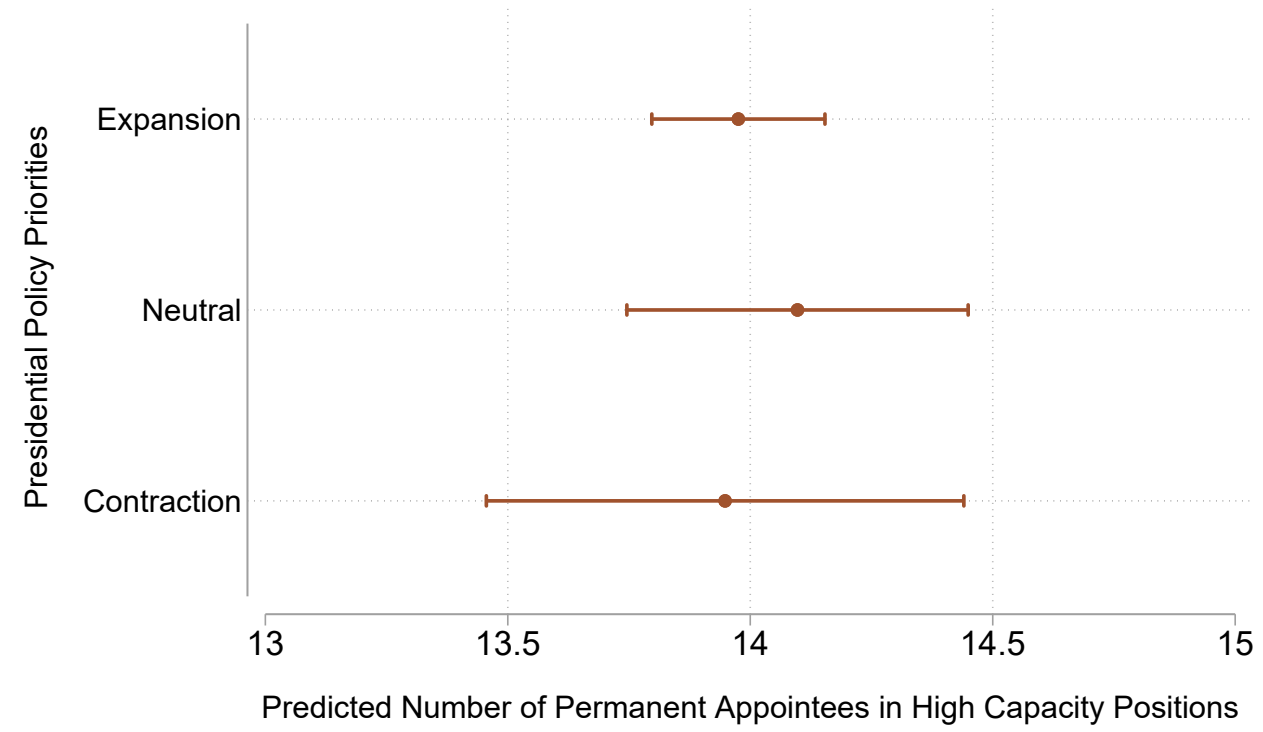

Figure 7.7: Predicted Count of Permanent Appointees in High Capacity PAS Positions, given President Policy Priority (lagged)

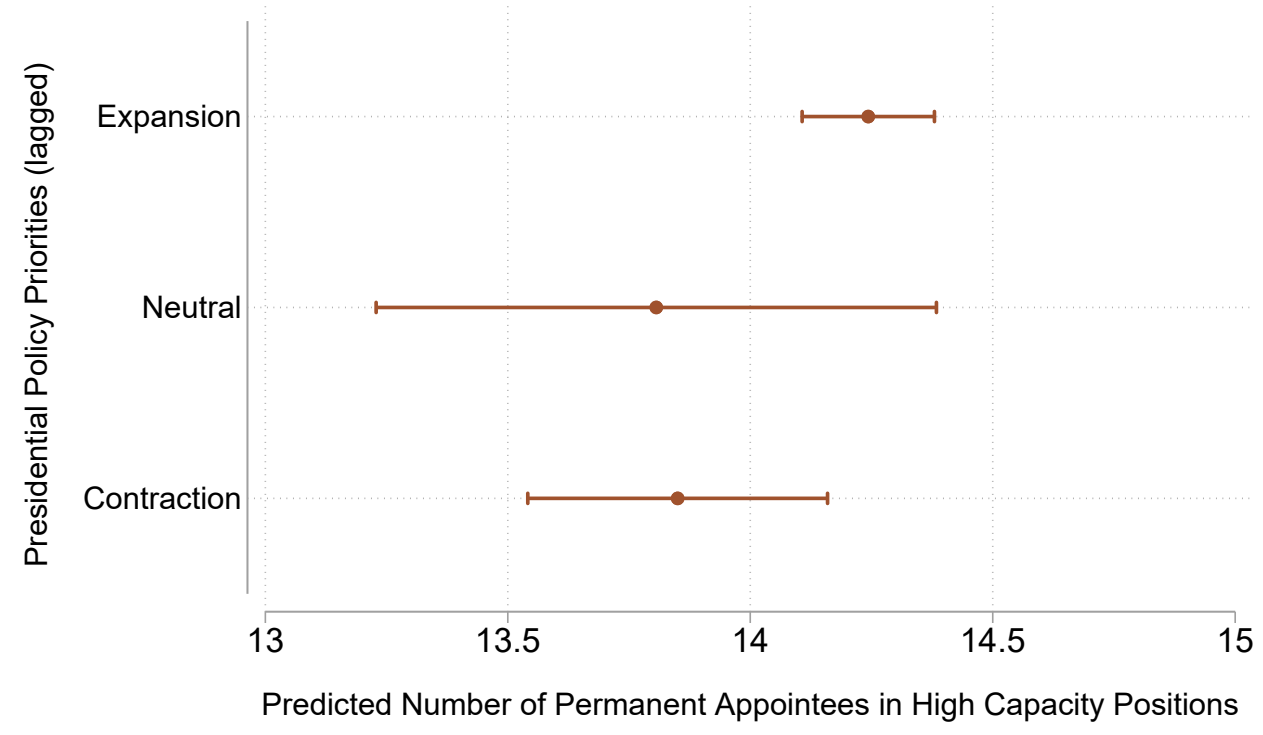


Figure 7.8: Predicted Count of Permanent Appointees in High Capacity PAS Positions, given (lagged) President and Congress Policy Priority

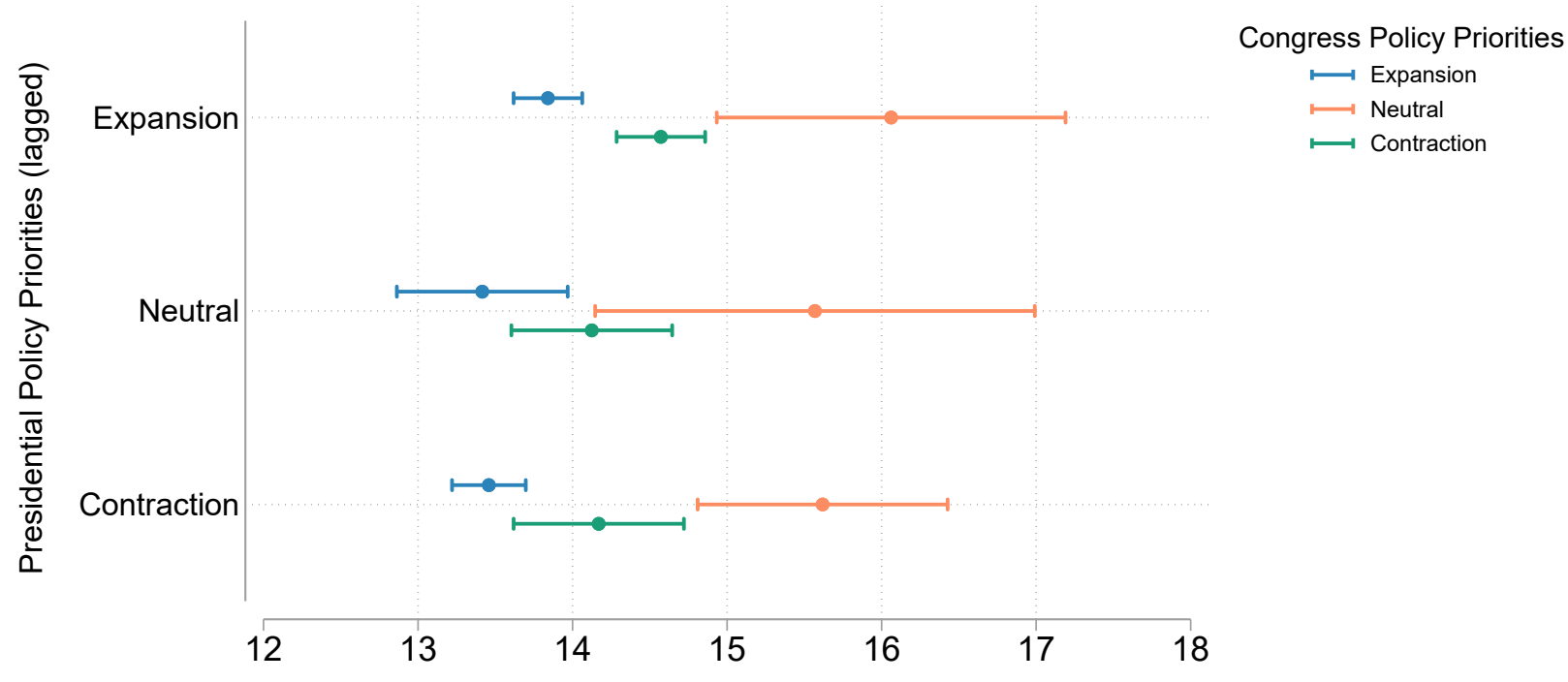

Predicted Number of Permanent Appointees in High Capacity Positions

hypothesis.

Furthermore, Figure 7.8, which displays the predicted number of permanent appointees in high capacity positions for each category of lagged president Policy Priorities given the categories of Congress Policy Priorities, matches expectations as well. Namely, Figure 7.8 shows that the highest predicted number of permanent appointees, 16.1, occurs under lagged expansion presidential policy priorities and neutral congressional policy priorities, and is statistically differentiable at a 5 percent level $(p=0.02)$. Thus, while evidence for the Permanent Appointee Hypothesis is lacking in the context of the likelihood models and the initial count model specification, accounting for the lagged impact of policy priorities yields strong evidence for the Permanent Appointee Hypothesis. 


\subsection{Discussion}

In this chapter, I examine the incidence of empty positions, interim appointees, and permanent appointees across department-years. The first section introduces the data: aggregate counts of each Position Status in high capacity positions, which ultimately mimics the construction of Position Value. Using this data, Sections 2 and 3 present separate tests of each of the three central hypotheses - the Empty Position Hypothesis, the Interim Appointee Hypothesis, and the Permanent Appointee Hypothesis - the results of which offer notable support for all three hypotheses. Specifically, the first set of tests indicate that, as expected, presidents leave more high capacity positions empty when they prioritize policy contraction, but fill more high capacity positions with interim appointees when they prioritize policy expansion.

Ultimately, the aggregate data offer an alternative perspective that allows me to look more closely at where my previous results were less strong. As such, in Section 3, I assess whether we see a strategic accumulation of permanent appointees after we account for a lagged impact of president Policy Priorities; and find appreciable evidence that this is, in fact, the case. Specifically, I find strong support for the Permanent Appointee Hypothesis despite lackluster evidence for the strategic use of permanent appointees in the multi-choice context. In other words, these findings suggest that presidents are strategically choosing to appoint a permanent appointee. The delayed realization of the president's choice to fill a position with a permanent appointee creates an incongruity in observed policy priorities, which gives future work a reason to build a more dynamic model. At its core, this dissertation seeks to explore the politics of vacancies in presidential appointments. This chapter tackles the question of when presidents choose to leave certain positions empty while filling others with interim or permanent appointees from an alternative perspective: the accumulation of vacancies and appointments. In doing so, the findings advance a more complete picture of presidents strategically using vacancies in and appointments to PAS positions based on the capacity of the position to advance specific policy priorities. 


\section{CHAPTER VIII}

\section{Conclusion}

S6 It's easier to make moves with they're acting [...] I like acting [appointees] because I can move so quickly, gives me more flexibility.

President Donald 7. Trump, CBS "Face The Nation" Interview (February 3, 2019)

At his first Cabinet meeting of 2019, six of President Trump's twenty-four Cabinet members were interim appointees. Acting Secretary of Defense Patrick Shanahan, Acting Secretary of the Interior David Bernhardt, Acting Attorney General Matthew Whitaker, Acting Administrator of the Environmental Protection Agency Andrew Wheeler, and Acting Ambassador to the United Nations Jonathan Cohen took their seats at the table without the requisite Senate confirmation. ${ }^{1}$ In fact, of the 42 individuals who have sat at the helms of the fifteen Executive departments in the first two years of the Trump administration, 22 did so as interim appointees. ${ }^{2}$ Yet our separation of powers models assume presidents are constitutionally constrained by congressional approval for these top appointments. And, with the seemingly obvious benefits of permanent, confirmed appointees, Trump's affinity for acting appointees and his perspective that they might

\footnotetext{
${ }^{1}$ The sixth interim Cabinet-level appointee, Acting White House Chief of Staff Mick Mulvaney, does not require Senate confirmation.

${ }^{2}$ As of April 12, 2019, which includes Acting Secretary of the Department of Homeland Security, Kevin McAleenan.
} 
be preferred for their flexibility might seem anomalous. Surprisingly though, as this dissertation has emphasized, it is not.

As Table 8.1 shows, from 1977 through 2019, 79 of the 266 appointees who served as the head of a department did so as an interim appointee. Restricting the set to the administrations from Carter to Obama (1977-2016), which had 167 Senate-confirmed Secretaries/Attorneys General, we can see that the remaining 57 of the 224 appointees served in interim capacities. In other words, 25 percent of department heads in the previous six administrations were interim appointees, but the Trump administration has seen that proportion climb to over half. And secretaries make up just a small portion of the department leadership positions (presidential appointments that require Senate confirmation known as PAS positions) that the president can fill unilaterally with interim appointees - positions with the authority to ultimately determine the actions of government. These observations underscore the powerful opportunities available to presidents to consolidate their political control of the bureaucracy without having to pursue Senate confirmation. Despite presidents maintaining vacancies in their appointments that require Senate confirmation, to this point we have lacked a thorough understanding of when and how presidents pursue this strategy. This dissertation has addressed these questions.

Specifically, I have argued that presidents strategically use vacancies to expand their executive power and achieve their policy priorities. In this chapter, I begin by summarizing the central argument and findings about the conditions under which presidents seek the Senate's advice and consent for certain positions while leaving others empty or filling them with interim appointees. I then discuss the contributions this analysis makes and, further, discuss the implications for our understanding of separation of powers and presidential appointments. Finally, I propose several extensions of this work that continue to investigate how and when presidents use vacancies in their appointments that require Senate confirmation. 
Table 8.1: Distribution of Confirmed and Interim Department Heads, 1977-2019

\begin{tabular}{lcc} 
Department & Confirmed & Interim \\
\hline Agriculture & 12 & 4 \\
Commerce & 16 & 4 \\
Defense & 13 & 2 \\
Education & 11 & 2 \\
Energy & 14 & 2 \\
Health and Human Services & 14 & 6 \\
Homeland Security & 6 & 3 \\
Housing and Urban Development & 12 & 6 \\
Interior & 11 & 8 \\
Justice & 14 & 9 \\
Labor & 12 & 4 \\
State & 14 & 13 \\
Transportation & 14 & 1 \\
Treasury & 14 & 7 \\
Veterans Affairs & 10 & 8 \\
\hline Total & 187 & 79
\end{tabular}

\subsection{Summary}

In Chapter 1, I argue that the president chooses to leave certain positions vacant while seeking the Senate's advice and consent for others under specific conditions structured by his policy priorities and the capacity of positions to advance them. To ground the subsequent analysis in a concrete understanding of vacancies, I offer a simple distinction that has been absent from the literature on presidential appointments. Specifically, vacancies - which, in common parlance, refers to PAS positions without Senate confirmed appointees - can be empty or filled with interim appointees, who are temporary officials exercising the powers, duties, and authority of the position without the requisite confirmation. I also summarize the full appointment process and outcomes, beginning with the president's decision to immediately fill a vacant position with an interim appointee or not. In addition, I briefly show that presidents from Carter through Obama have taken advantage of unilaterally leaving vacant positions empty and filling them with interim appointees, but that these patterns vary by year and administration. 
With this foundation in place, I preview the central argument that this dissertation develops: presidents are motivated to leave positions empty or to fill them with interim or permanent appointees when those positions have a high capacity to control agency actions and policy output, contingent on the president's and Senate's policy priorities. This argument has the potential to make an important contribution to our understanding of presidential power and the politics of presidential appointments. In particular, I offer a new, generalized model of appointments - building on the observed phenomena that have gone largely unexplained: vital policymaking positions are often filled with temporary officials without Senate confirmation or left empty entirely.

Next, Chapters 2 and 3 set the stage for the theoretical framework that I subsequently develop. In Chapter 2, to establish how this dissertation contributes to our current understanding of appointments and executive power, I review the existing research has engaged with the politics of appointments. From here, I outline the institutional regimes governing vacancies in PAS positions; where it becomes clear that interim appointments are a potentially powerful strategy for presidents to employ. Lastly, to provide a bit of historical context, I present a set of vignettes describing vacancies in PAS positions from six administrations, covering Presidents Carter to Obama.

In Chapter 3, I introduce the central element of my theory and subsequent empirical analysis: Position Value. This creates the incentives that drive the president's strategies to leave positions empty, fill them with interim appointees, or submit nominees for confirmation. Position Value also creates the incentives that drive the Senate's choice to confirm a nominee and the president's strategic choice to submit one, given the Senate's confirmation strategy. In order to examine this strategy set, which includes leaving positions empty, we need to move beyond our traditional focus on the appointee and consider how positions themselves can distinctly increase utility. That is, we need to consider their Position Value: a concept that classifies positions by their capacity to control policy output and the policy priorities for their parent agency.

In Chapter 4, I develop a theory of vacancies and appointments that incorporates the Sen- 
ate's leverage to veto a nomination and the president's power to choose not to submit one in the first place. Advancing from the existing appointments paradigm and building on a set of clear and reasonable assumptions, I analyze a new model of vacancies in presidential appointments taking into account both types of vacancies - as strategic choices driven by the capacity of those positions to achieve policy priorities. This theoretical framework identifies the conditions that lead presidents to leave certain positions empty while filling others with interim or permanent appointees. Yet, the core purpose of this model is to formalize a logic to explain the unexpected observed outcomes of interim and empty positions, and to discipline my empirical analysis. Accordingly, I use the model's empirical predictions to generate several testable hypotheses, which I examine in the subsequent three chapters.

To begin to systematically and quantitatively understand how and when vacancies in presidential appointments occur, I collected data on the status of PAS positions from Carter to Obama. In Chapter 5, I introduce this original dataset of empty positions, interim appointees, permanent appointees, and nominations from 1977 through 2015. The data includes the status of PAS positions in fifteen Executive departments, their levels of capacity to control policy outcomes, and the corresponding congressional and presidential policy priorities for each department covering a total of 10,331 position-year observations. In the second half of Chapter 5, I present the first two of four analyses that evaluate the hypotheses offered by the theory presented in Chapter 4. First, I explore several non-parametric cross-tabulations of distributions to establish the empirical consequences of a keystone of my research: the distinction between vacancies left as empty positions and those filled with interim appointees. The results offer initial evidence to support my theory. In particular, they show that when we differentiate between empty positions and interim appointees, the distributions of position status across the categories of president Position Value emerge as predicted. Critically, these findings begin to address the general underlying question of this dissertation: how do presidents use vacancies? The answer: presidents use them strategically. 
The latter half of Chapter 5 takes up two questions at the heart of this dissertation: why do presidents seek the Senate's advice and consent for certain positions and not others, and when do presidents choose to leave certain positions empty while filling others with interim or permanent appointees? By modelling the likelihood of each position status as a function of Position Value, I test my hypotheses, formally derived in Chapter 4, simultaneously. This analysis allows for a formal statistical inference of the patterns observed in the cross-tabulations and provides considerable support for the conjecture that presidents fill vacant positions with interim appointees when they prioritize policy expansion. Specifically, I find that the likelihood of an interim appointee is significantly higher when president Position Value is "High Value (expansion)" whereas the likelihood of empty positions is higher when president Position Value is "High Value (contraction)," albeit at lower levels of significance. As such, the results provide some support for the conjecture that presidents leave vacant positions empty when they prioritize policy contraction, but yields little evidence that presidents strategically fill positions with permanent appointees. The findings support the larger argument that presidents strategically manage vacancies in and appointments to PAS positions based on the capacity of the position to advance specific policy priorities, the Position Value. However, the analysis does not offer a complete examination of the president's strategic use of vacancies.

Consequently, in Chapter 6, I continue to leverage my original data in an extension of the multi-choice models presented in Chapter 5. Specifically, as detailed in Chapter 2, several institutional regimes govern who can serve as an interim appointee and for how long. The Federal Vacancies Reform Act (FVRA) of 1998, which currently governs interim appointments to Executive department PAS positions, stipulates the length of the prospective terms. Critically, the amount of time that interim appointees can serve increases considerably after the passage of the FVRA, which could explain the mixed findings presented in Chapter 5. I test this conjecture, and my hypotheses in this context, by extending the central likelihood analysis to account for the impact of the FVRA on the conditions under which presidents engage in specific appointment 
strategies. The analysis yields striking results that presidents are more likely to fill positions with interim appointees when those positions are "High Value (expansion)" positions. Additionally, I find moderate support for presidents strategic use of empty positions, and begin to see evidence for the strategic use of permanent appointees. Overall, these findings build on those from Chapter 5 as my theory continues to gather considerable support from the data, suggesting that presidents leverage vacancies to set the direction of policy outcomes.

Chapter 7 investigates when presidents choose to leave certain positions empty while filling others with interim or permanent appointees from an alternative perspective: the accumulation of vacancies and appointments. Specifically, I examine the incidence of empty positions, interim appointees, and permanent appointees across departments using aggregate counts of each position status. Consequently, I begin Chapter 7 with an introduction to these data. Next, I evaluate the three central hypotheses individually by modelling the counts of each position status among high capacity positions as a function of policy priorities. Here, I find further evidence that continues to support my theory. Specifically, presidents leave more high capacity positions empty when they prioritize policy contraction, but fill more high capacity positions with interim appointees when they prioritize policy expansion. Lastly, I assess whether we see a strategic accumulation of permanent appointees after we account for the incongruity of presidential policy priorities due to the length of the formal nomination-confirmation process; and find evidence that this is, in fact, the case. Specifically, when we include lagged president Policy Priorities, we find unmistakable evidence that presidents use permanent appointees strategically.

\subsection{Contributions}

This dissertation explores how and when presidents use vacancies to achieve their policy

goals. I show that frequent and sustained vacancies are not by chance or the mechanical byproduct of an elaborate appointment process, but rather they result from strategic choices that pres- 
idents make to advance their policy agenda. I develop and test a novel theory of appointments that corrects our conception of vacancies to differentiate between empty positions and interim appointees. Specifically, the framework generates a more accurate reversion point for confirmation bargaining when it does occur and identifies conditions under which presidents capitalize on their first-mover advantage to subvert the Senate's power to refuse confirmation. The subsequent empirical analysis explores the conjectures that policy priorities to expand or contract the reach of an agency lead rational presidents to strategically forgo appointments and nominations. Through a series of non-parametric and parametric analyses, I present considerable evidence to support my argument that vacancies are calculated choices presidents make, within their larger nomination strategies, to advance specific policy priorities.

In doing so, this dissertation makes three notable contributions to our understanding of presidential power by investigating how position characteristics and policy priorities influence the president's use of vacancies and appointments. First, this dissertation challenges the dominant paradigm in separation of powers models of presidential appointments. This paradigm proceeds from the assumption that executives are constrained by the need for legislative approval when placing principal officers in unelected office. ${ }^{3}$ This assumption itself presumes that presidents will always make appointments, through the nominations process, to head agencies. Presidents, in fact, do not. The perspective that the set of appointment choices includes only formal powers like nominations or recess appointments does not leave room to consider the informal power of unilateral presidential inaction. Hence, this dissertation highlights that, for our theories of institutions and separation of powers to be complete, they need to consider how deliberate sidestepping of formal powers impacts inter-branch bargaining and agenda setting strategies.

Second, this dissertation makes a pronounced theoretical contribution to the literature on the politics of presidential appointments. Specifically, I develop a new general theory of appointments that offers its own set of contributions. This framework provides a new and better un-

\footnotetext{
${ }^{3}$ An assumption driven entirely by the Appointments Clause of Article II in the United States Constitution.
} 
derstanding of presidential strategic behavior and the president's advantage in the nomination process. By explicitly differentiating between empty positions and those filled by interim appointees, my theory identifies the more accurate, and therefore complete, choice set available to presidents for maintaining political control of the bureaucracy. Moreover, it introduces the novel idea that these decisions are driven by the Position Value, the capacity of the positions themselves to achieving policy priorities. Since existing models of the appointments process do not incorporate the empty-interim distinction or these position-level characteristics, we previously had no sense of how they operate theoretically. The theoretical framework built here begins to fill that void.

Lastly, this dissertation makes an important empirical contribution to our larger understanding of presidential power. As discussed at length in Chapter 5, I have assembled a considerable dataset on appointments to and vacancies in PAS positions. These data highlight the patterns of empty positions and interim appointments that are absent from existing empirical studies of appointments. Ultimately, these data present a more complete picture of how presidents use their appointment power and I harness them to empirically test the implications of my theoretical model. From a series of non-parametric and parametric analyses, I find evidence to support my theory that presidents strategically use interim appointees to advance their expansion policy priorities and leave positions empty when they prioritize contraction. Moreover, these findings point to how presidents can capitalize on their unilateral power to maintain vacancies to advance their larger policy agenda. Critically, then, this dissertation contributes a better understanding of the empirical realities of the unilateral presidential power inherent in the politics of vacancies.

\subsection{Implications of Strategic Vacancies}

The broadest implication of this dissertation stems from its correction of the standard view that vacancies are simply arbitrary miscalculations within the appointment process. By treating 
vacancies as footnotes, rather than as marked features of presidential appointment strategy, existing research and policies fundamentally disregarded the role that each type of vacancy has to play. The chapters of this dissertation, together and each in their own way, illustrate that scholars and politicians have misunderstood the realities of PAS positions without Senate confirmed appointees. In particular, our previous understanding completely overlooked the fact that empty positions and interim appointees are two different outcomes and each present distinct opportunities to pursue diverging policy priorities. Furthermore, we mistakenly assumed that presidents would unfailingly pursue formal nominations and that, however stalled by institutional forces, PAS positions would always be filled by Senate confirmed appointees. This dissertation clearly documents that vacancies are not the aberration we thought they were, demonstrates that empty positions and interim appointees are separate consequences of strategic decisions, and presents the first error correction of its kind on the politics of vacancies.

Furthermore, now that we have a more precise picture of vacancies and permanent appointments, we can more accurately consider the implications that these outcomes have for bureaucratic performance and accountability. Since we had not previously differentiated between empty positions and interim appointees, our understanding has been restricted to the impact of different characteristics of permanent appointees (e.g., Lewis, 2008; Gallo and Lewis, 2011) or the organization of those appointments (e.g., Krause et al., 2006; Wood and Lewis, 2017) on performance. We now know that interim appointees and empty positions each account for approximately 10 percent of appointments, on average, which indicates that there are considerable opportunities for each to shape agency performance. Thus, while we have evidence that the absence of appointees clearly shapes agencies' ability to accomplish certain objectives (e.g., Bolton et al., 2015), we now can explore how that ability differs under the leadership of interim appointees compared to empty positions, and how each type of vacancy compares with permanent appointees.

Lastly, this dissertation draws new attention to how empty positions and interim appointees did not dissipate in the time period after the passage of the FVRA. Critically, the FVRA was 
intended to create incentives for presidents to submit nominees for Senate confirmation. The stipulations of who can legally serve as an interim appointee were designed to restrict the use of interims, while the tenure extensions were intended to ensure continuity in leadership and agency productivity (Hogue, 2008). However, they ultimately created circumstances that further encourage presidents to forgo nominations entirely. The results presented in Chapter 6 - while they do not allow for causal inference - suggest that the FVRA has not achieved its objective of curbing the use of interim appointees or explicitly encouraging presidents to submit nominees. Given that interim appointees can serve for extended lengths under the FVRA, we could easily imagine that if presidents intend to use interim appointees exclusively, they might seek actions to take full advantage of the deadlines. For instance, presidents might submit nominees who are not attractive for immediate Senate confirmation in order to pause the interim appointees' tenure limits for as long as possible; or they might maximize the interim tenure by submitting a nominee on the last day (most likely the $210^{\text {th }}$ day) of the interim appointee's legal term. By discovering the strategic potential of vacancies, and explicitly incorporating empty positions and interim appointees into presidential appointment strategy, this dissertation creates the foundation to consider how proposed stipulations in future reforms might ultimately encourage these outcomes. Consequently, this research has widespread implications for our understanding about whether reforms to the nomination process - which are necessary to safeguard the Senate's constitutional prerogative of advice and consent - will achieve their desired results.

\subsection{Future Research}

Who controls the levers of power matters greatly in the business of policy-making. Presidents manage much of this power by selecting the appointees to fill the agency leadership positions responsible for major policy implementation. Presidents also have just 1461 days to accom-

plish their policy and political goals. As legislation crawls through an increasingly intransigent 
Congress, administrative policy-making offers a pragmatic alternative that presidents have often, and decidedly, exploited (Farber and O'Connell, 2014). Yet, separation of powers insists that the individuals tasked with promulgating and enforcing administrative law are chosen with the advice and consent of the Senate. Thus, current scholarship focuses on the ways that the Senate constrains presidential preferences; ${ }^{4}$ however, this presumes that presidents will always seek advice and consent. And as we have seen here, presidents, in fact, do not.

In the course of this work, I have assembled the most comprehensive data on appointments to and vacancies in PAS positions. These data are new in political science research and can accommodate a whole host of extensions that consider the congressional-bureaucratic relations and congressional responses to executive unilateral action. For instance, inquiries into how effectively Congress can police agencies with vacancies would parlay my identifications of interim appointees into new studies of interim appointee accountability and responsiveness to congressional oversight. Alternatively, an extension, more generally, could analyze congressional incentives to oversee and investigate executive agencies that do not have Senate confirmed appointees. Furthermore, the theoretical and empirical work presented in this dissertation create a new avenue for addressing longstanding questions about congressional constraints on and responses to executive unilateral action. With the new evidence of strategic vacancies in hand, we can now take up questions about the political cost to presidents, in terms of achieving their larger legislative agenda, of circumventing the Senate's advice and consent with unilateral interim appointments.

With its novel theory and extensive data, this dissertation engages research on executive appointments and political control of the bureaucracy, contributes to the growing literatures on presidential unilateral action and legislative obstruction, and speaks to work on separation of powers more generally. Executive politics scholars claim that the Senate's refusal to confirm appointments damages the president's ability to exercise his authority and execute the law. How-

\footnotetext{
${ }^{4}$ See Lewis (2011).
} 
ever, this dissertation gives clear reasons to believe that presidents use their power to not appoint and not nominate to recapture political control of the bureaucracy without submitting for Senate confirmation. Moreover, the regularity with which appointments, arguably a president's most important instrument of political control and policy formation, are left empty suggests that national political elites are investing in incapacity. As this dissertation implies, the politics of vacancies seems to be a case of a broader trend of obstruction and avoidance that we are only now positioning ourselves to understand. 


\section{APPENDICES}




\section{APPENDIX A}

Chapter 5: Likelihood Models of Vacancies 


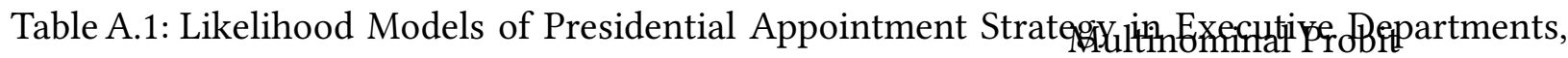
1981-2015

DV: 3 Category Position Status

\begin{tabular}{|c|c|c|c|}
\hline & & $\begin{array}{c}\text { (1) } \\
\text { Empty } \\
\text { Position }\end{array}$ & $\begin{array}{c}(2) \\
\text { Interim } \\
\text { Appointee }\end{array}$ \\
\hline $\begin{array}{l}\text { President } \\
\text { Position Value }\end{array}$ & $\begin{array}{l}\text { High Value (expansion) } \\
\text { High Value (contraction) }\end{array}$ & $\begin{array}{l}0.153 \\
(0.12) \\
-0.212 \\
(0.38)\end{array}$ & $\begin{array}{l}-0.326^{* *} \\
(0.104) \\
-0.314 \\
(0.41)\end{array}$ \\
\hline $\begin{array}{l}\text { Congress } \\
\text { Position Value }\end{array}$ & $\begin{array}{l}\text { High Value (expansion) } \\
\text { High Value (contraction) }\end{array}$ & $\begin{array}{c}-0.191^{* *} \\
(0.05) \\
-0.231 \\
(0.17)\end{array}$ & $\begin{array}{c}-0.115 \\
(0.06) \\
-0.208^{* *} \\
(0.06)\end{array}$ \\
\hline $\begin{array}{l}\text { President X Congress } \\
\text { Position Value }\end{array}$ & $\begin{array}{l}\text { High Value High Value } \\
\text { (contraction) X (contraction) } \\
\text { High Value High Value } \\
\text { (contraction) X (expansion) } \\
\text { High Value High Value } \\
\text { (expansion) X (contraction) } \\
\text { High Value High Value } \\
\text { (expansion) X (expansion) }\end{array}$ & $\begin{array}{c}0.373 \\
(0.52) \\
0.485 \\
(0.403) \\
-0.234 \\
(0.30) \\
-0.085 \\
(0.12)\end{array}$ & $\begin{array}{l}0.279 \\
(0.36) \\
0.182 \\
(0.32) \\
0.146 \\
(0.09) \\
0.430^{* *} \\
(0.15)\end{array}$ \\
\hline \multicolumn{2}{|c|}{ Established Administration } & $\begin{array}{c}-1.077^{* *} \\
(0.06)\end{array}$ & $\begin{array}{c}-0.689^{* *} \\
(0.06)\end{array}$ \\
\hline \multicolumn{2}{|l|}{ Co-Partisan Control } & $\begin{array}{l}0.027 \\
(0.27)\end{array}$ & $\begin{array}{l}0.038 \\
(0.06)\end{array}$ \\
\hline \multicolumn{2}{|c|}{ Department of Defense } & $\begin{array}{l}0.195 \\
(0.11)\end{array}$ & $\begin{array}{c}-0.480^{* *} \\
(0.10)\end{array}$ \\
\hline \multicolumn{2}{|c|}{ Administration Fixed Effects } & $\checkmark$ & $\checkmark$ \\
\hline \multicolumn{2}{|l|}{ Intercept } & $\begin{array}{c}-0.589^{* *} \\
(0.22)\end{array}$ & $\begin{array}{c}-1.041^{* *} \\
(0.17)\end{array}$ \\
\hline
\end{tabular}

Note: N=9626 in all models. Table entries are multinomial probit estimates of Position Status. The omitted (baseline) category is "Permanent Appointee," its coefficients have been normalized to zero in order to identify the model and allow for comparisons across equations. Reference category for Position Value is "Low Value." Cluster-robust standard errors appear in parentheses. ${ }^{*} \mathrm{p}<0.05,{ }^{* *} \mathrm{p}<0.01$ 


\title{
APPENDIX B
}

Chapter 6: Likelihood Models of Vacancies, Pre and

\author{
Post-FVRA
}


Table B.1: Likelihood Models of Presidential Appointment Strateglilingrecutipiperopartments, 1977-2015 DV: 3 Category Position Status

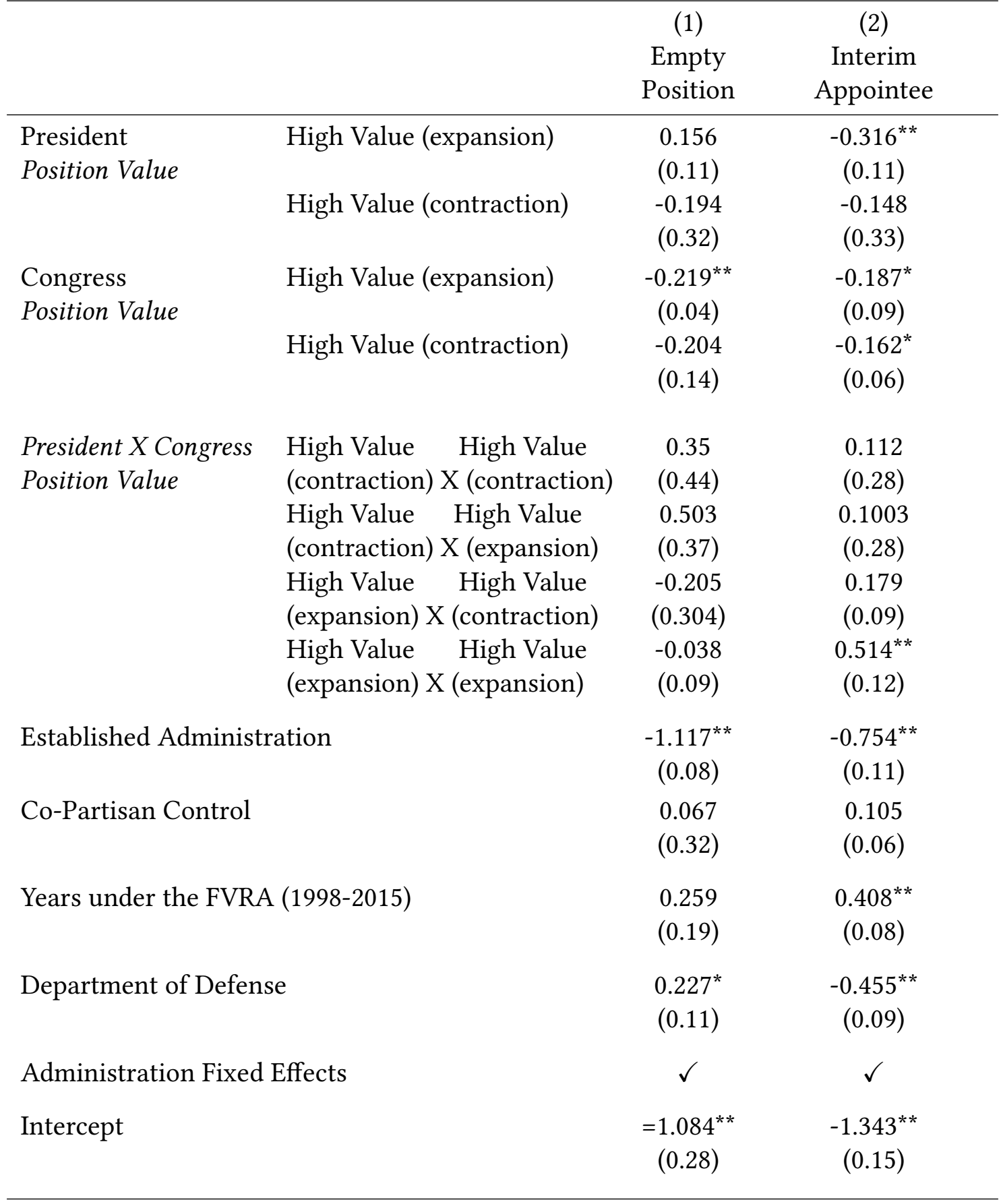

Note: $\mathrm{N}=10290$ in all models. Table entries are multinomial probit estimates of Position Status. The omitted (baseline) category is "Permanent Appointee," its coefficients have been normalized to zero in order to identify the model and allow for comparisons across equations. Reference category for Position Value is "Low Value." Cluster-robust standard errors appear in parentheses. ${ }^{*} \mathrm{p}<0.05,{ }^{* *} \mathrm{p}<0.01$ 
Table B.2: Predicted Probabilities of Position Status Outcomes

\begin{tabular}{|c|c|c|c|c|}
\hline & & $\begin{array}{l}\text { Permanent } \\
\text { Appointee }\end{array}$ & $\begin{array}{c}\text { Interim } \\
\text { Appointee }\end{array}$ & $\begin{array}{l}\text { Empty } \\
\text { Position }\end{array}$ \\
\hline \multirow{3}{*}{$\begin{array}{l}\text { President } \\
\text { Position } \\
\text { Value }\end{array}$} & High Value (expansion) & $\begin{array}{l}0.851 \\
(0.01)\end{array}$ & $\begin{array}{l}\mathbf{0 . 0 8 5} \\
(0.01)\end{array}$ & $\begin{array}{l}0.065 \\
(0.01)\end{array}$ \\
\hline & High Value (contraction) & $\begin{array}{l}0.851 \\
(0.02)\end{array}$ & $\begin{array}{l}0.075 \\
(0.01)\end{array}$ & $\begin{array}{l}\mathbf{0 . 0 7 4} \\
(0.02)\end{array}$ \\
\hline & Low Value & $\begin{array}{l}0.858 \\
(0.01)\end{array}$ & $\begin{array}{l}\mathbf{0 . 0 8 5} \\
(0.01)\end{array}$ & $\begin{array}{l}0.057 \\
(0.01)\end{array}$ \\
\hline \multirow{3}{*}{$\begin{array}{l}\text { Congress } \\
\text { Position } \\
\text { Value }\end{array}$} & High Value (expansion) & $\begin{array}{l}0.849 \\
(0.01)\end{array}$ & $\begin{array}{l}0.087 \\
(0.01)\end{array}$ & $\begin{array}{l}0.065 \\
(0.01)\end{array}$ \\
\hline & High Value (contraction) & $\begin{array}{l}0.867 \\
(0.02)\end{array}$ & $\begin{array}{l}0.075 \\
(0.01)\end{array}$ & $\begin{array}{l}0.057 \\
(0.02)\end{array}$ \\
\hline & Low Value & $\begin{array}{l}0.847 \\
(0.01)\end{array}$ & $\begin{array}{l}0.078 \\
(0.01)\end{array}$ & $\begin{array}{l}0.075 \\
(0.01)\end{array}$ \\
\hline \multirow[t]{2}{*}{$\begin{array}{l}\text { Established } \\
\text { Administration }\end{array}$} & New Administration & $\begin{array}{l}0.630 \\
(0.04)\end{array}$ & $\begin{array}{l}0.156 \\
(0.02)\end{array}$ & $\begin{array}{l}0.214 \\
(0.03)\end{array}$ \\
\hline & Established Administration & $\begin{array}{l}0.853 \\
(0.01)\end{array}$ & $\begin{array}{c}0.082 \\
(0.003)\end{array}$ & $\begin{array}{l}0.065 \\
(0.01)\end{array}$ \\
\hline \multirow[t]{2}{*}{$\begin{array}{l}\text { Co-Partisan } \\
\text { Control }\end{array}$} & Divided Control & $\begin{array}{l}0.868 \\
(0.02)\end{array}$ & $\begin{array}{c}0.072 \\
(0.003)\end{array}$ & $\begin{array}{l}0.060 \\
(0.02)\end{array}$ \\
\hline & Co-Partisan Control & $\begin{array}{l}0.853 \\
(0.01)\end{array}$ & $\begin{array}{c}0.082 \\
(0.003)\end{array}$ & $\begin{array}{l}0.065 \\
(0.01)\end{array}$ \\
\hline $\begin{array}{l}\text { Years under } \\
\text { the FVRA }\end{array}$ & Pre-FVRA (1977-1997) & $\begin{array}{l}\mathbf{0 . 8 8 1} \\
(0.01)\end{array}$ & $\begin{array}{r}\mathbf{0 . 0 6 3} \\
(0.003)\end{array}$ & $\begin{array}{l}\mathbf{0 . 0 5 6} \\
(0.004)\end{array}$ \\
\hline \multirow{3}{*}{ Department } & Post-FVRA (1998-2015) & $\begin{array}{l}\mathbf{0 . 8 2 1} \\
(0.02)\end{array}$ & $\begin{array}{l}\mathbf{0 . 1 0 5} \\
(0.01)\end{array}$ & $\begin{array}{l}\mathbf{0 . 0 7 4} \\
(0.02)\end{array}$ \\
\hline & Defense & $\begin{array}{l}0.864 \\
(0.02)\end{array}$ & $\begin{array}{c}0.044 \\
(0.004)\end{array}$ & $\begin{array}{l}0.092 \\
(0.02)\end{array}$ \\
\hline & Non-Defense & $\begin{array}{l}0.849 \\
(0.01)\end{array}$ & $\begin{array}{c}0.090 \\
(0.004)\end{array}$ & $\begin{array}{l}0.061 \\
(0.01)\end{array}$ \\
\hline
\end{tabular}

Note: Table entries are the predicted probabilities of each position status given specified row variables. Standard errors are in parentheses. Bold and colored entries denote alignment with theoretical expectations. Explanatory variables were held constant at their mean values. 
Table B.3: Predicted Probabilities of Position Status Outcomes, Pre-FVRA (1977-1997)

\begin{tabular}{|c|c|c|c|c|}
\hline & & $\begin{array}{c}\text { Permanent } \\
\text { Appointee }\end{array}$ & $\begin{array}{c}\text { Interim } \\
\text { Appointee }\end{array}$ & $\begin{array}{l}\text { Empty } \\
\text { Position }\end{array}$ \\
\hline \multirow{6}{*}{$\begin{array}{l}\text { President } \\
\text { Position } \\
\text { Value }\end{array}$} & \multirow[t]{2}{*}{ High Value (expansion) } & 0.830 & 0.075 & 0.096 \\
\hline & & $(0.01)$ & $(0.01)$ & $(0.02)$ \\
\hline & \multirow[t]{2}{*}{ High Value (contraction) } & 0.806 & 0.054 & 0.139 \\
\hline & & $(0.01)$ & $(0.01)$ & $(0.02)$ \\
\hline & \multirow[t]{2}{*}{ Low Value } & 0.851 & 0.068 & 0.081 \\
\hline & & $(0.02)$ & $(0.01)$ & $(0.01)$ \\
\hline \multirow{6}{*}{$\begin{array}{l}\text { Congress } \\
\text { Position } \\
\text { Value }\end{array}$} & \multirow[t]{2}{*}{ High Value (expansion) } & 0.837 & 0.067 & 0.096 \\
\hline & & $(0.01)$ & $(0.01)$ & $(0.02)$ \\
\hline & \multirow[t]{2}{*}{ High Value (contraction) } & 0.819 & 0.074 & 0.107 \\
\hline & & $(0.04)$ & $(0.01)$ & $(0.03)$ \\
\hline & \multirow[t]{2}{*}{ Low Value } & 0.830 & 0.060 & 0.110 \\
\hline & & $(0.01)$ & $(0.02)$ & $(0.01)$ \\
\hline \multirow{4}{*}{$\begin{array}{l}\text { Established } \\
\text { Administration }\end{array}$} & \multirow[t]{2}{*}{ New Administration } & 0.558 & 0.128 & 0.314 \\
\hline & & $(0.03)$ & $(0.02)$ & $(0.03)$ \\
\hline & \multirow[t]{2}{*}{ Established Administration } & 0.831 & 0.067 & 0.102 \\
\hline & & $(0.01)$ & $(0.01)$ & $(0.02)$ \\
\hline \multirow{4}{*}{$\begin{array}{l}\text { Co-Partisan } \\
\text { Control }\end{array}$} & \multirow[t]{2}{*}{ Divided Control } & 0.901 & 0.057 & 0.043 \\
\hline & & $(0.01)$ & $(0.002)$ & $(0.01)$ \\
\hline & \multirow[t]{2}{*}{ Co-Partisan Control } & 0.831 & 0.067 & 0.102 \\
\hline & & $(0.01)$ & $(0.01)$ & $(0.02)$ \\
\hline \multirow{4}{*}{ Department } & \multirow[t]{2}{*}{ Defense } & 0.845 & 0.033 & 0.122 \\
\hline & & $(0.04)$ & $(0.005)$ & $(0.03)$ \\
\hline & \multirow[t]{2}{*}{ Non-Defense } & 0.827 & 0.075 & 0.098 \\
\hline & & $(0.01)$ & $(0.01)$ & $(0.01)$ \\
\hline
\end{tabular}

Note: Table entries are the predicted probabilities of each position status given specified row variables. Standard errors are in parentheses. Bold and colored entries denote alignment with theoretical expectations. Explanatory variables were held constant at their mean values. 
Table B.4: Predicted Probabilities of Position Status Outcomes, Post-FVRA (1998-2015)

\begin{tabular}{|c|c|c|c|c|}
\hline & & $\begin{array}{l}\text { Permanent } \\
\text { Appointee }\end{array}$ & $\begin{array}{l}\text { Interim } \\
\text { Appointee }\end{array}$ & $\begin{array}{l}\text { Empty } \\
\text { Position }\end{array}$ \\
\hline \multirow{6}{*}{$\begin{array}{l}\text { President } \\
\text { Position } \\
\text { Value }\end{array}$} & High Value (expansion) & 0.852 & 0.098 & 0.050 \\
\hline & & $(0.004)$ & $(0.01)$ & $(0.01)$ \\
\hline & High Value (contraction) & 0.874 & 0.090 & 0.036 \\
\hline & & $(0.01)$ & $(0.01)$ & $(0.002)$ \\
\hline & Low Value & 0.844 & 0.106 & 0.050 \\
\hline & & $(0.01)$ & $(0.01)$ & $(0.001)$ \\
\hline \multirow{6}{*}{$\begin{array}{l}\text { Congress } \\
\text { Position } \\
\text { Value }\end{array}$} & High Value (expansion) & 0.845 & 0.108 & 0.047 \\
\hline & & $(0.004)$ & $(0.01)$ & $(0.001)$ \\
\hline & High Value (contraction) & 0.885 & 0.078 & 0.036 \\
\hline & & $(0.01)$ & $(0.01)$ & $(0.01)$ \\
\hline & Low Value & 0.855 & 0.093 & 0.052 \\
\hline & & $(0.02)$ & $(0.02)$ & $(0.02)$ \\
\hline \multirow{4}{*}{$\begin{array}{l}\text { Established } \\
\text { Administration }\end{array}$} & New Administration & 0.681 & 0.177 & 0.142 \\
\hline & & $(0.01)$ & $(0.02)$ & $(0.01)$ \\
\hline & Established Administration & 0.857 & 0.098 & 0.045 \\
\hline & & $(0.001)$ & $(0.002)$ & $(0.002)$ \\
\hline \multirow{4}{*}{$\begin{array}{l}\text { Co-Partisan } \\
\text { Control }\end{array}$} & Divided Control & 0.820 & 0.087 & 0.093 \\
\hline & & $(0.003)$ & $(0.01)$ & $(0.01)$ \\
\hline & Co-Partisan Control & 0.857 & 0.098 & 0.045 \\
\hline & & $(0.001)$ & $(0.002)$ & $(0.002)$ \\
\hline \multirow{4}{*}{ Department } & Defense & 0.056 & 0.056 & 0.072 \\
\hline & & $(0.01)$ & $(0.01)$ & $(0.01)$ \\
\hline & Non-Defense & 0.107 & 0.107 & 0.041 \\
\hline & & $(0.002)$ & $(0.002)$ & $(0.003)$ \\
\hline
\end{tabular}

Note: Table entries are the predicted probabilities of each position status given specified row variables. Standard errors are in parentheses. Bold and colored entries denote alignment with theoretical expectations. Explanatory variables were held constant at their mean values. 
Figure B.1: Predicted Count of Interim Appointees in High Capacity PAS Positions, given President Policy Priority (lagged)

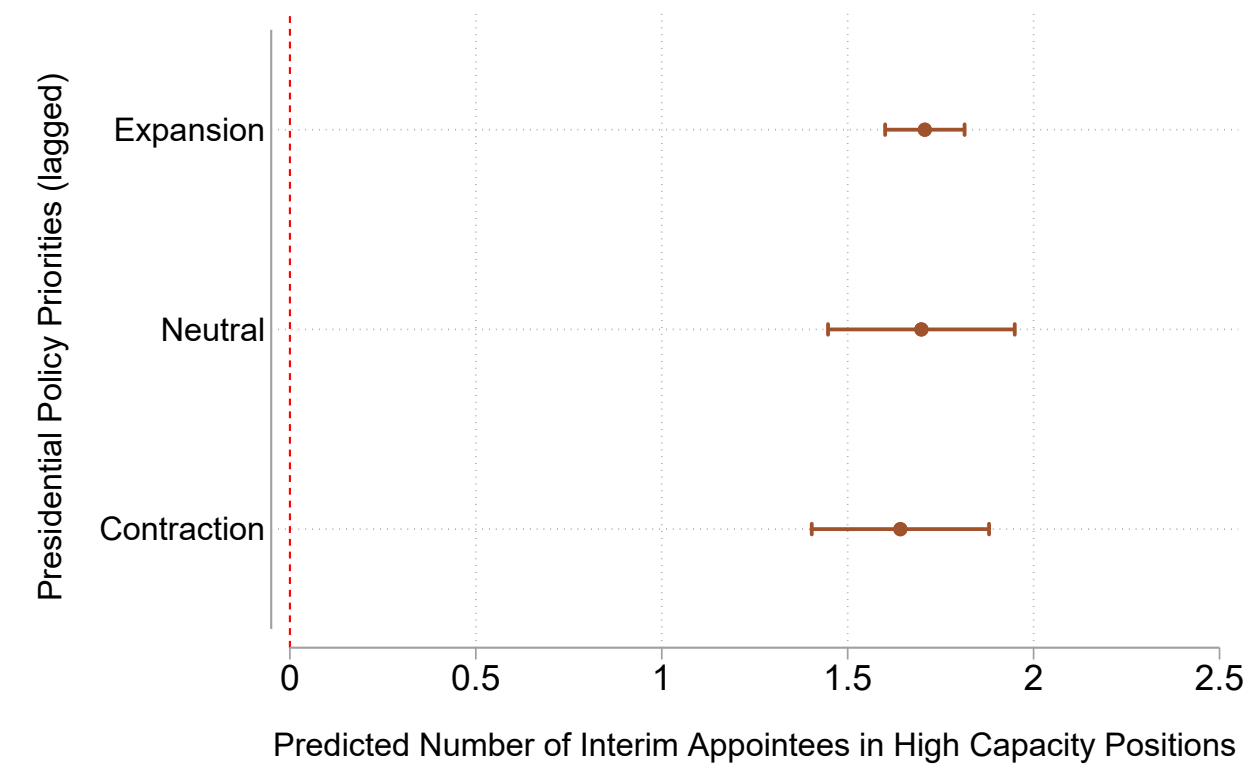

Figure B.2: Predicted Count of Empty High Capacity PAS Positions, given President Policy Priority (lagged)

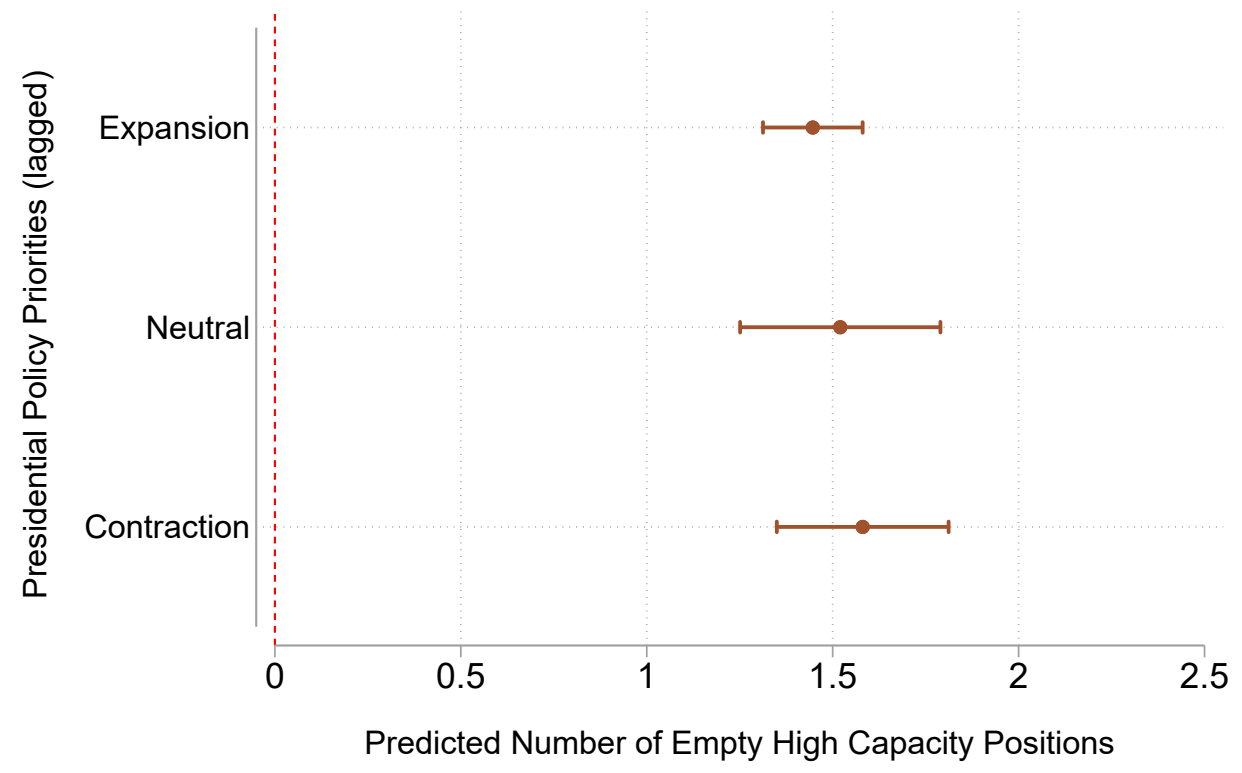


Table B.5: Means and Variances of Position Status Count Data: Numbers of Empty, Interim Appointees, and Permanent Appointees in Low Capacity Positions, Department-Year, 1977-2015

\begin{tabular}{|c|c|c|c|c|c|c|c|c|}
\hline \multirow{4}{*}{$\begin{array}{l} \\
\text { President } \\
\text { Policy } \\
\text { Priorities }\end{array}$} & \multirow{2}{*}{\multicolumn{2}{|c|}{$1-2015$}} & \multicolumn{2}{|c|}{$\begin{array}{l}\text { Empty } \\
\text { Positions }\end{array}$} & \multicolumn{2}{|c|}{$\begin{array}{c}\text { Interim } \\
\text { Appointees }\end{array}$} & \multicolumn{2}{|c|}{$\begin{array}{l}\text { Permanent } \\
\text { Appointees }\end{array}$} \\
\hline & & & Mean & Variance & Mean & Variance & Mean & Variance \\
\hline & Expansion & $(\mathrm{N}=250)$ & 0.26 & 0.28 & 0.42 & 0.53 & 2.23 & 2.38 \\
\hline & Neutral & $(\mathrm{N}=85)$ & 0.29 & 0.37 & 0.20 & 0.21 & 2.06 & 1.77 \\
\hline & Contraction & $(\mathrm{N}=182)$ & 0.25 & 0.32 & 0.26 & 0.28 & 1.98 & 2.31 \\
\hline & Total & $(\mathrm{N}=517)$ & 0.26 & 0.31 & 0.33 & 0.39 & 2.11 & 2.26 \\
\hline
\end{tabular}

Figure B.3: Predicted Count of Permanent Appointees in High Capacity PAS Positions, given President and Congress Policy Priority

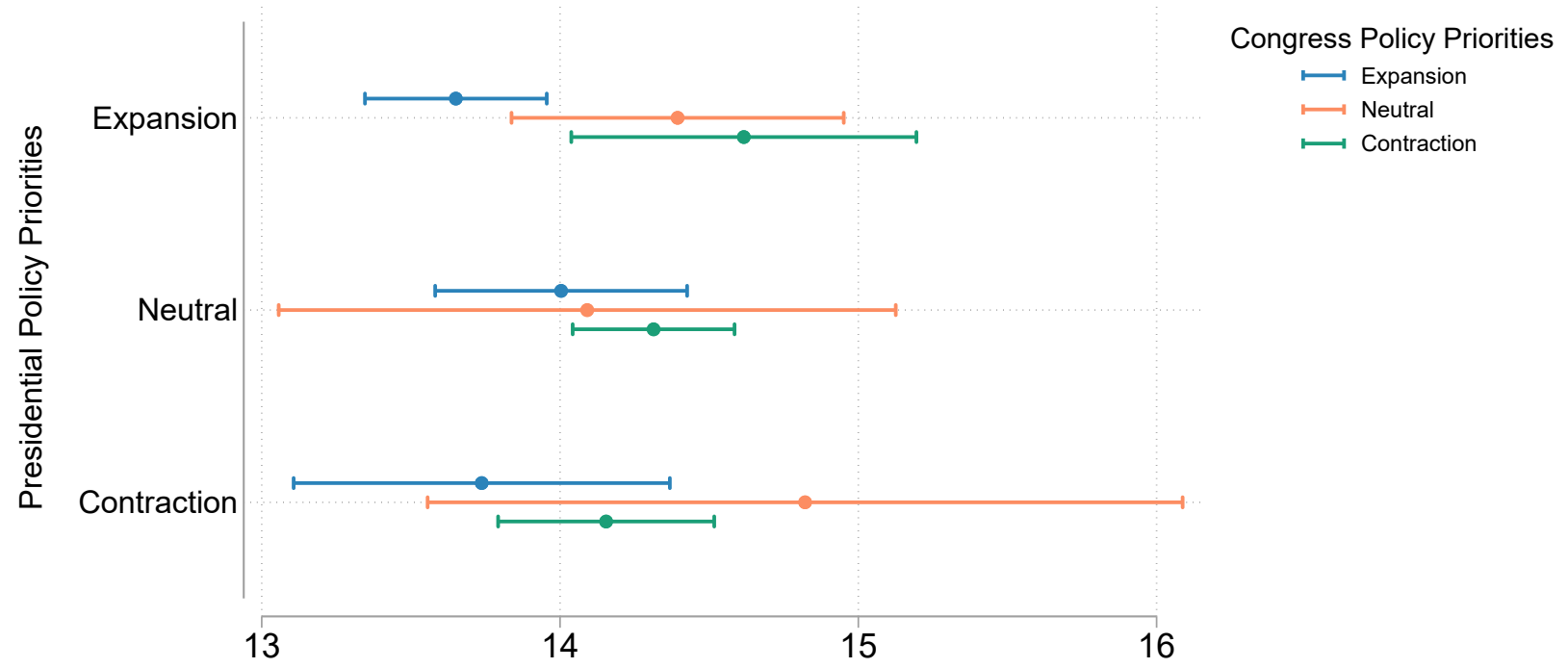

Predicted Number of Permanent Appointees in High Capacity Positions 
Table B.6: Predicted Number of Empty Positions and Interim Appointees in High Capacity Positions, 1977-2015

\begin{tabular}{|c|c|c|c|}
\hline & & Empty Positions & Interim Appointees \\
\hline \multirow{6}{*}{$\begin{array}{l}\text { President } \\
\text { Policy } \\
\text { Priorities }\end{array}$} & \multirow[t]{2}{*}{ Expansion } & 1.392 & 1.795 \\
\hline & & $(0.060)$ & $(0.085)$ \\
\hline & \multirow[t]{2}{*}{ Neutral } & 1.438 & 1.767 \\
\hline & & $(0.073)$ & $(0.168)$ \\
\hline & \multirow[t]{2}{*}{ Contraction } & 1.756 & 1.473 \\
\hline & & $(0.146)$ & $(0.145)$ \\
\hline \multirow{6}{*}{$\begin{array}{l}\text { Congress } \\
\text { Policy } \\
\text { Priorities }\end{array}$} & \multirow[t]{2}{*}{ Expansion } & 1.513 & 1.692 \\
\hline & & $(0.058)$ & $(0.071)$ \\
\hline & \multirow[t]{2}{*}{ Neutral } & 1.683 & 1.403 \\
\hline & & $(0.125)$ & $(0.192)$ \\
\hline & \multirow[t]{2}{*}{ Contraction } & 1.484 & 1.707 \\
\hline & & $(0.168)$ & $(0.139)$ \\
\hline \multirow{4}{*}{$\begin{array}{l}\text { Established } \\
\text { Administration }\end{array}$} & \multirow[t]{2}{*}{ New Administration } & 1.887 & 1.439 \\
\hline & & $(0.062)$ & $(0.048)$ \\
\hline & \multirow[t]{2}{*}{ Established Administration } & 1.310 & 1.800 \\
\hline & & $(.013)$ & $(.033)$ \\
\hline \multirow{4}{*}{$\begin{array}{l}\text { Co-Partisan } \\
\text { Control }\end{array}$} & \multirow[t]{2}{*}{ Divide Control } & 1.524 & 1.613 \\
\hline & & $(0.143)$ & $(0.194)$ \\
\hline & \multirow[t]{2}{*}{ Co-Partisan Control } & 1.516 & 1.707 \\
\hline & & $(0.104)$ & $(0.145)$ \\
\hline \multirow{4}{*}{ Department } & \multirow[t]{2}{*}{ Defense } & 2.485 & 1.039 \\
\hline & & $(0.182)$ & $(0.075)$ \\
\hline & \multirow[t]{2}{*}{ Non-Defense } & 1.460 & 1.735 \\
\hline & & $(0.021)$ & $(0.039)$ \\
\hline
\end{tabular}

Note: $\mathrm{N}=514$ in all models. Table entries are the predicted number of events for each position status given specified row variables. Standard errors are in parentheses. Bold and colored entries denote alignment with theoretical expectations. Predictor variables were held constant at their mean values. 
Table B.7: Predicted Number of Permanent Appointees in High Capacity Positions, 1977-2015

Permanent Appointees

(3)

\begin{tabular}{|c|c|c|c|}
\hline \multirow{5}{*}{$\begin{array}{l}\text { Lagged } \\
\text { President } \\
\text { Policy } \\
\text { Priorities }\end{array}$} & \multicolumn{2}{|l|}{ Expansion } & $\begin{array}{c}14.239 \\
(0.1)\end{array}$ \\
\hline & \multicolumn{2}{|l|}{ Neutral } & 13.802 \\
\hline & & & $(0.276)$ \\
\hline & \multirow{2}{*}{\multicolumn{2}{|c|}{ Contraction }} & 13.846 \\
\hline & & & $(0.135)$ \\
\hline \multirow{6}{*}{$\begin{array}{l}\text { President } \\
\text { Policy } \\
\text { Priorities }\end{array}$} & \multirow[t]{2}{*}{ Expansion } & 13.998 & 13.984 \\
\hline & & $(0.933)$ & $(0.083)$ \\
\hline & \multirow[t]{2}{*}{ Neutral } & 14.106 & 14.195 \\
\hline & & $(0.185)$ & $(0.161)$ \\
\hline & \multirow[t]{2}{*}{ Contraction } & 13.973 & 14.11 \\
\hline & & $(0.250)$ & $(0.252)$ \\
\hline \multirow{6}{*}{$\begin{array}{l}\text { Congress } \\
\text { Policy } \\
\text { Priorities }\end{array}$} & \multirow[t]{2}{*}{ Expansion } & 13.861 & 13.907 \\
\hline & & $(0.065)$ & $(0.070)$ \\
\hline & \multirow[t]{2}{*}{ Neutral } & 13.795 & 13.876 \\
\hline & & $(0.338)$ & $(0.396)$ \\
\hline & \multirow[t]{2}{*}{ Contraction } & 14.429 & 14.476 \\
\hline & & $(0.225)$ & $(0.216)$ \\
\hline \multirow{4}{*}{$\begin{array}{l}\text { Established } \\
\text { Administration }\end{array}$} & \multirow[t]{2}{*}{ New Administration } & 11.090 & 11.136 \\
\hline & & $(0.201)$ & $(0.196)$ \\
\hline & \multirow[t]{2}{*}{ Established Administration } & 14.695 & 14.768 \\
\hline & & $(0.050)$ & $(0.050)$ \\
\hline \multirow{4}{*}{$\begin{array}{l}\text { Co-Partisan } \\
\text { Control }\end{array}$} & \multirow[t]{2}{*}{ Divide Control } & 14.025 & 14.054 \\
\hline & & $(0.367)$ & $(0.368)$ \\
\hline & \multirow[t]{2}{*}{ Co-Partisan Control } & 13.953 & 14.023 \\
\hline & & $(0.251)$ & $(0.259)$ \\
\hline \multirow{4}{*}{ Department } & \multirow[t]{2}{*}{ Defense } & 14.155 & 14.216 \\
\hline & & $(0.233)$ & $(0.191)$ \\
\hline & \multirow[t]{2}{*}{ Non-Defense } & 13.951 & 14.003 \\
\hline & & $(0.426)$ & $(0.035)$ \\
\hline
\end{tabular}

Note: $\mathrm{N}=514$ in all models. Table entries are the predicted number of events for each position status given specified row variables. Standard errors are in parentheses. Bold and colored entries denote alignment with theoretical expectations. Predictor variables were held constant at their mean values. 
Table B.8: Count Models of Presidential Appointment Strategy in Executive Departments, 19772015

\begin{tabular}{|c|c|c|c|}
\hline & & $\begin{array}{l}\text { Empty Positions } \\
\text { (1) }\end{array}$ & $\begin{array}{c}\text { Interim Appointees } \\
(2)\end{array}$ \\
\hline \multirow{4}{*}{$\begin{array}{l}\text { Lagged President } \\
\text { Policy Priorities }\end{array}$} & Expansion & -0.089 & 0.039 \\
\hline & & $(0.117)$ & $(0.105)$ \\
\hline & Neutral & -0.039 & 0.034 \\
\hline & & $(0.105)$ & $(0.093)$ \\
\hline \multirow{4}{*}{$\begin{array}{l}\text { President } \\
\text { Policy } \\
\text { Priorities }\end{array}$} & Expansion & $0.398^{* *}$ & -0.398 \\
\hline & & $(0.131)$ & $(0.228)$ \\
\hline & Contraction & 0.141 & -0.111 \\
\hline & & $(0.146)$ & $(0.286)$ \\
\hline \multirow{4}{*}{$\begin{array}{l}\text { Congress } \\
\text { Policy } \\
\text { Priorities }\end{array}$} & Expansion & 0.055 & 0.063 \\
\hline & & $(0.157)$ & $(0.322)$ \\
\hline & Contraction & 0.0228 & 0.059 \\
\hline & & $(0.144)$ & $(0.226)$ \\
\hline \multirow{8}{*}{$\begin{array}{l}\text { President X Congress } \\
\text { Policy Priorities }\end{array}$} & Contraction X Contraction & -0.018 & 0.018 \\
\hline & & $(0.203)$ & $(0.137)$ \\
\hline & Contraction X Expansion & 0.091 & -0.132 \\
\hline & & $(0.128)$ & $(0.283)$ \\
\hline & Expansion X Contraction & $-0.343^{* *}$ & 0.353 \\
\hline & & $(0.132)$ & $(0.289)$ \\
\hline & Expansion X Expansion & $-0.462^{* *}$ & 0.456 \\
\hline & & $(0.176)$ & $(0.238)$ \\
\hline \multirow{2}{*}{\multicolumn{2}{|c|}{ Established Administration }} & $-0.363^{* *}$ & $0.23^{* *}$ \\
\hline & & $(0.035)$ & $(0.034)$ \\
\hline \multirow{2}{*}{\multicolumn{2}{|c|}{ Co-Partisan Control }} & -0.011 & 0.057 \\
\hline & & $(0.159)$ & $(0.202)$ \\
\hline \multirow{2}{*}{\multicolumn{2}{|c|}{ Department of Defense }} & $0.527^{* *}$ & $-0.512^{* *}$ \\
\hline & & $(0.067)$ & $(0.083)$ \\
\hline \multicolumn{2}{|c|}{ Administration Fixed Effects } & $\checkmark$ & $\checkmark$ \\
\hline \multirow{2}{*}{\multicolumn{2}{|c|}{ Intercept }} & $-0.801^{* *}$ & $-0.946^{*}$ \\
\hline & & $(0.235)$ & $(0.411)$ \\
\hline
\end{tabular}

Note: $\mathrm{N}=$ in all models. Table entries are negative binomial regression estimates of interim appointees and empty positions with and without the lagged Presidential Policy Priorities variable. The outcome variables are counts of high capacity positions, per department-year, filled with permanent appointees. Reference category for Policy Priorities is "Neutral." Bold and colored entries denote alignment with theoretical expectations. Cluster-robust standard errors appear in parentheses. ${ }^{*} \mathrm{p}<0.05,{ }^{* *} \mathrm{p}<0.01$ 


\section{APPENDIX C}

\section{Chapter 7: Count Models of Vacancies}

Table C.1: Means and Variances of Position Status Count Data: Numbers of Empty, Interim Appointees, and Permanent Appointees in Low Capacity Positions, Department-Year, 1977-2015

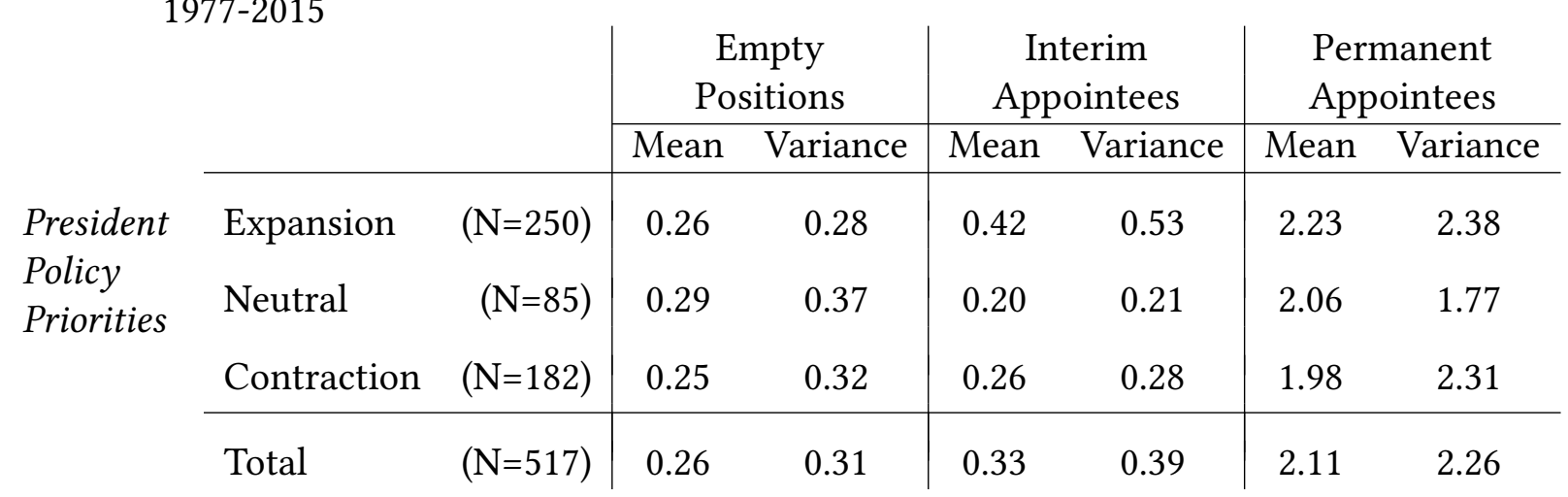


Table C.2: Predicted Number of Empty Positions and Interim Appointees in High Capacity Positions, $1977-2015$

\begin{tabular}{llcc}
\hline & & Empty Positions & Interim Appointees \\
\hline $\begin{array}{l}\text { President } \\
\text { Policy }\end{array}$ & Expansion & 1.392 & 1.795 \\
Priorities & Neutral & $(0.060)$ & $(0.085)$ \\
& & 1.438 & 1.767 \\
& Contraction & $(0.073)$ & $(0.168)$ \\
Congress & Expansion & 1.756 & 1.473 \\
$\begin{array}{l}\text { Policy } \\
\text { Priorities }\end{array}$ & Neutral & $(0.146)$ & $(0.145)$ \\
& & 1.513 & 1.692 \\
& Contraction & $(0.058)$ & $(0.071)$ \\
& & 1.683 & 1.403 \\
Established & New Administration & $(0.125)$ & $(0.192)$ \\
Administration & & 1.484 & 1.707 \\
& & $(0.168)$ & $(0.139)$ \\
& Established Administration & 1.887 & 1.439 \\
Co-Partisan & Divide Control & $(0.062)$ & $(0.048)$ \\
Control & & $(.310$ & 1.800 \\
& & 1.524 & $(.033)$ \\
& Co-Partisan Control & $(0.143)$ & 1.613 \\
& & 1.516 & $(0.194)$ \\
& & $(0.104)$ & 1.707 \\
Department & Defense & 2.485 & $(0.145)$ \\
& & $(0.182)$ & 1.039 \\
& Non-Defense & 1.460 & $(0.075)$ \\
& & $(0.021)$ & 1.735 \\
& & $0.039)$ \\
\hline
\end{tabular}

Note: $\mathrm{N}=514$ in all models. Table entries are the predicted number of events for each position status given specified row variables. Standard errors are in parentheses. Bold and colored entries denote alignment with theoretical expectations. Predictor variables were held constant at their mean values. 
Figure C.1: Predicted Count of Interim Appointees in High Capacity PAS Positions, given President Policy Priority (lagged)

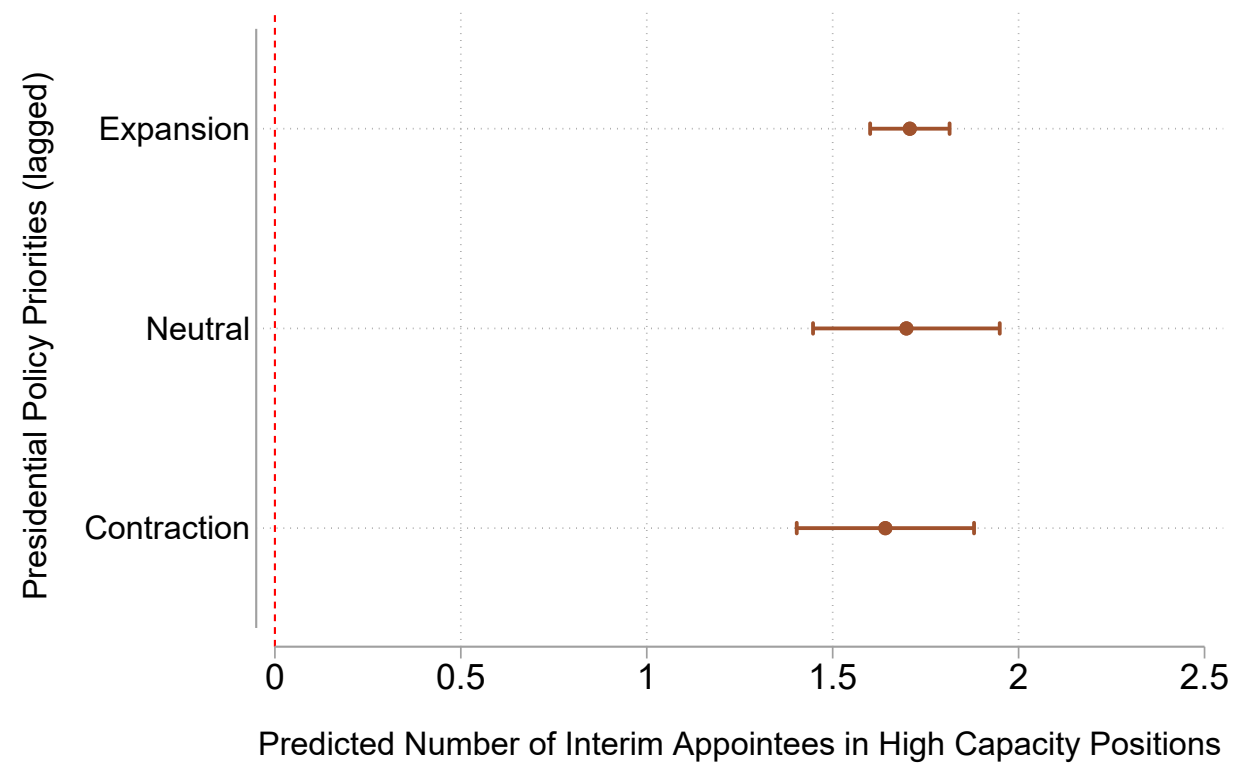

Figure C.2: Predicted Count of Empty High Capacity PAS Positions, given President Policy Priority (lagged)

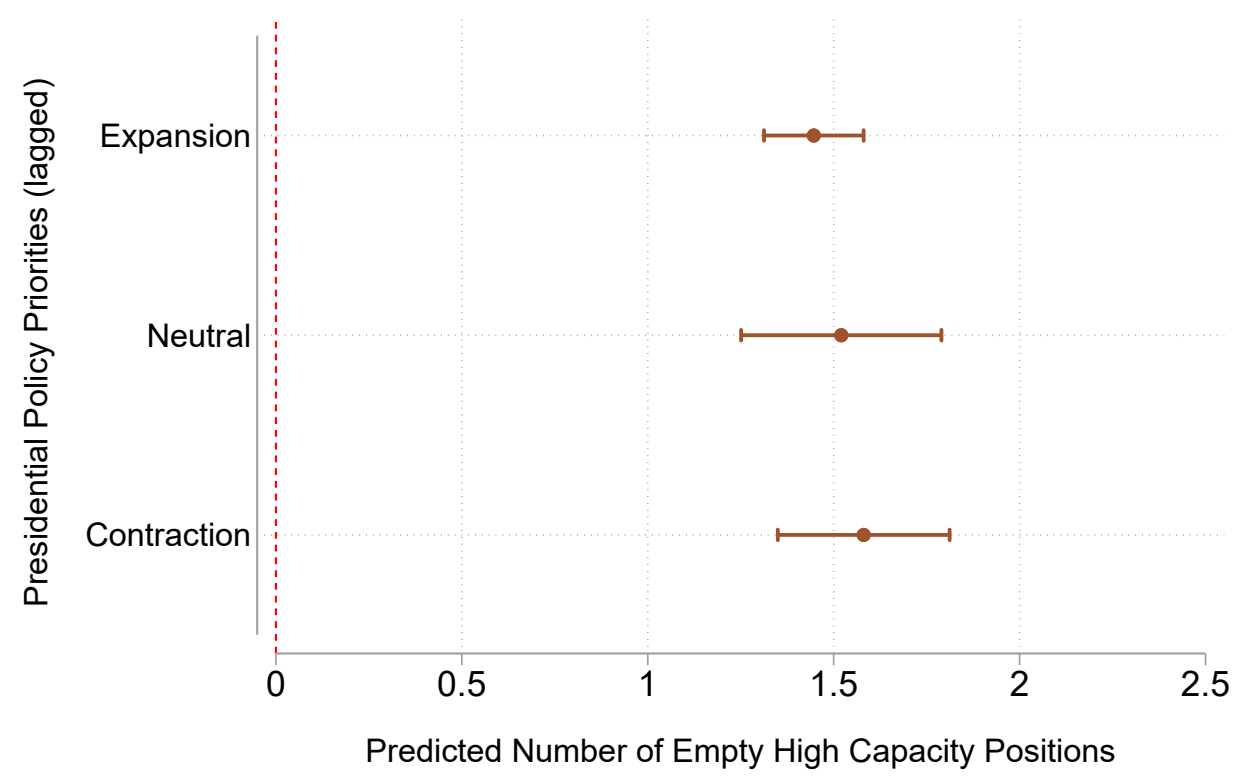


Table C.3: Predicted Number of Permanent Appointees in High Capacity Positions, 1977-2015

Permanent Appointees

(3)

\begin{tabular}{|c|c|c|c|}
\hline \multirow{5}{*}{$\begin{array}{l}\text { Lagged } \\
\text { President } \\
\text { Policy } \\
\text { Priorities }\end{array}$} & \multicolumn{2}{|l|}{ Expansion } & $\begin{array}{c}14.239 \\
(0.1)\end{array}$ \\
\hline & \multicolumn{2}{|l|}{ Neutral } & 13.802 \\
\hline & & & $(0.276)$ \\
\hline & \multirow{2}{*}{\multicolumn{2}{|c|}{ Contraction }} & 13.846 \\
\hline & & & $(0.135)$ \\
\hline \multirow{6}{*}{$\begin{array}{l}\text { President } \\
\text { Policy } \\
\text { Priorities }\end{array}$} & \multirow[t]{2}{*}{ Expansion } & 13.998 & 13.984 \\
\hline & & $(0.933)$ & $(0.083)$ \\
\hline & \multirow[t]{2}{*}{ Neutral } & 14.106 & 14.195 \\
\hline & & $(0.185)$ & $(0.161)$ \\
\hline & \multirow[t]{2}{*}{ Contraction } & 13.973 & 14.11 \\
\hline & & $(0.250)$ & $(0.252)$ \\
\hline \multirow{6}{*}{$\begin{array}{l}\text { Congress } \\
\text { Policy } \\
\text { Priorities }\end{array}$} & \multirow[t]{2}{*}{ Expansion } & 13.861 & 13.907 \\
\hline & & $(0.065)$ & $(0.070)$ \\
\hline & \multirow[t]{2}{*}{ Neutral } & 13.795 & 13.876 \\
\hline & & $(0.338)$ & $(0.396)$ \\
\hline & \multirow[t]{2}{*}{ Contraction } & 14.429 & 14.476 \\
\hline & & $(0.225)$ & $(0.216)$ \\
\hline \multirow{4}{*}{$\begin{array}{l}\text { Established } \\
\text { Administration }\end{array}$} & \multirow[t]{2}{*}{ New Administration } & 11.090 & 11.136 \\
\hline & & $(0.201)$ & $(0.196)$ \\
\hline & \multirow[t]{2}{*}{ Established Administration } & 14.695 & 14.768 \\
\hline & & $(0.050)$ & $(0.050)$ \\
\hline \multirow{4}{*}{$\begin{array}{l}\text { Co-Partisan } \\
\text { Control }\end{array}$} & \multirow[t]{2}{*}{ Divide Control } & 14.025 & 14.054 \\
\hline & & $(0.367)$ & $(0.368)$ \\
\hline & \multirow[t]{2}{*}{ Co-Partisan Control } & 13.953 & 14.023 \\
\hline & & $(0.251)$ & $(0.259)$ \\
\hline \multirow{4}{*}{ Department } & \multirow[t]{2}{*}{ Defense } & 14.155 & 14.216 \\
\hline & & $(0.233)$ & $(0.191)$ \\
\hline & \multirow[t]{2}{*}{ Non-Defense } & 13.951 & 14.003 \\
\hline & & $(0.426)$ & $(0.035)$ \\
\hline
\end{tabular}

Note: $\mathrm{N}=514$ in all models. Table entries are the predicted number of events for each position status given specified row variables. Standard errors are in parentheses. Bold and colored entries denote alignment with theoretical expectations. Predictor variables were held constant at their mean values. 
Table C.4: Count Models of Presidential Appointment Strategy in Executive Departments, 19772015

\begin{tabular}{|c|c|c|c|}
\hline & & $\begin{array}{c}\text { Empty Positions } \\
\text { (1) }\end{array}$ & $\begin{array}{c}\text { Interim Appointees } \\
(2)\end{array}$ \\
\hline \multirow[t]{2}{*}{$\begin{array}{l}\text { Lagged President } \\
\text { Policy Priorities }\end{array}$} & Expansion & $\begin{array}{l}-0.089 \\
(0.117)\end{array}$ & $\begin{array}{c}0.039 \\
(0.105)\end{array}$ \\
\hline & Neutral & $\begin{array}{l}-0.039 \\
(0.105)\end{array}$ & $\begin{array}{c}0.034 \\
(0.093)\end{array}$ \\
\hline \multirow{2}{*}{$\begin{array}{l}\text { President } \\
\text { Policy } \\
\text { Priorities }\end{array}$} & Expansion & $\begin{array}{l}0.398^{* *} \\
(0.131)\end{array}$ & $\begin{array}{l}-0.398 \\
(0.228)\end{array}$ \\
\hline & Contraction & $\begin{array}{c}0.141 \\
(0.146)\end{array}$ & $\begin{array}{l}-0.111 \\
(0.286)\end{array}$ \\
\hline \multirow{2}{*}{$\begin{array}{l}\text { Congress } \\
\text { Policy } \\
\text { Priorities }\end{array}$} & Expansion & $\begin{array}{c}0.055 \\
(0.157)\end{array}$ & $\begin{array}{c}0.063 \\
(0.322)\end{array}$ \\
\hline & Contraction & $\begin{array}{l}0.0228 \\
(0.144)\end{array}$ & $\begin{array}{c}0.059 \\
(0.226)\end{array}$ \\
\hline \multirow[t]{4}{*}{$\begin{array}{l}\text { President X Congress } \\
\text { Policy Priorities }\end{array}$} & Contraction X Contraction & $\begin{array}{l}-0.018 \\
(0.203)\end{array}$ & $\begin{array}{c}0.018 \\
(0.137)\end{array}$ \\
\hline & Contraction X Expansion & $\begin{array}{c}0.091 \\
(0.128)\end{array}$ & $\begin{array}{l}-0.132 \\
(0.283)\end{array}$ \\
\hline & Expansion X Contraction & $\begin{array}{l}-0.343^{* *} \\
(0.132)\end{array}$ & $\begin{array}{c}0.353 \\
(0.289)\end{array}$ \\
\hline & Expansion X Expansion & $\begin{array}{l}-0.462^{* *} \\
(0.176)\end{array}$ & $\begin{array}{c}0.456 \\
(0.238)\end{array}$ \\
\hline \multicolumn{2}{|c|}{ Established Administration } & $\begin{array}{l}-0.363^{* *} \\
(0.035)\end{array}$ & $\begin{array}{l}0.23^{* *} \\
(0.034)\end{array}$ \\
\hline \multicolumn{2}{|l|}{ Co-Partisan Control } & $\begin{array}{l}-0.011 \\
(0.159)\end{array}$ & $\begin{array}{c}0.057 \\
(0.202)\end{array}$ \\
\hline \multicolumn{2}{|c|}{ Department of Defense } & $\begin{array}{l}0.527^{* *} \\
(0.067)\end{array}$ & $\begin{array}{c}-0.512^{* *} \\
(0.083)\end{array}$ \\
\hline \multicolumn{2}{|c|}{ Administration Fixed Effects } & $\checkmark$ & $\checkmark$ \\
\hline \multicolumn{2}{|l|}{ Intercept } & $\begin{array}{l}-0.801^{* *} \\
(0.235)\end{array}$ & $\begin{array}{l}-0.946^{*} \\
(0.411)\end{array}$ \\
\hline
\end{tabular}

Note: $\mathrm{N}=$ in all models. Table entries are negative binomial regression estimates of interim appointees and empty positions with and without the lagged Presidential Policy Priorities variable. The outcome variables are counts of high capacity positions, per department-year, filled with permanent appointees. Reference category for Policy Priorities is "Neutral." Bold and colored entries denote alignment with theoretical expectations. Cluster-robust standard errors appear in parentheses. ${ }^{*} \mathrm{p}<0.05,{ }^{* *} \mathrm{p}<0.01$ 
Figure C.3: Predicted Count of Permanent Appointees in High Capacity PAS Positions, given President and Congress Policy Priority

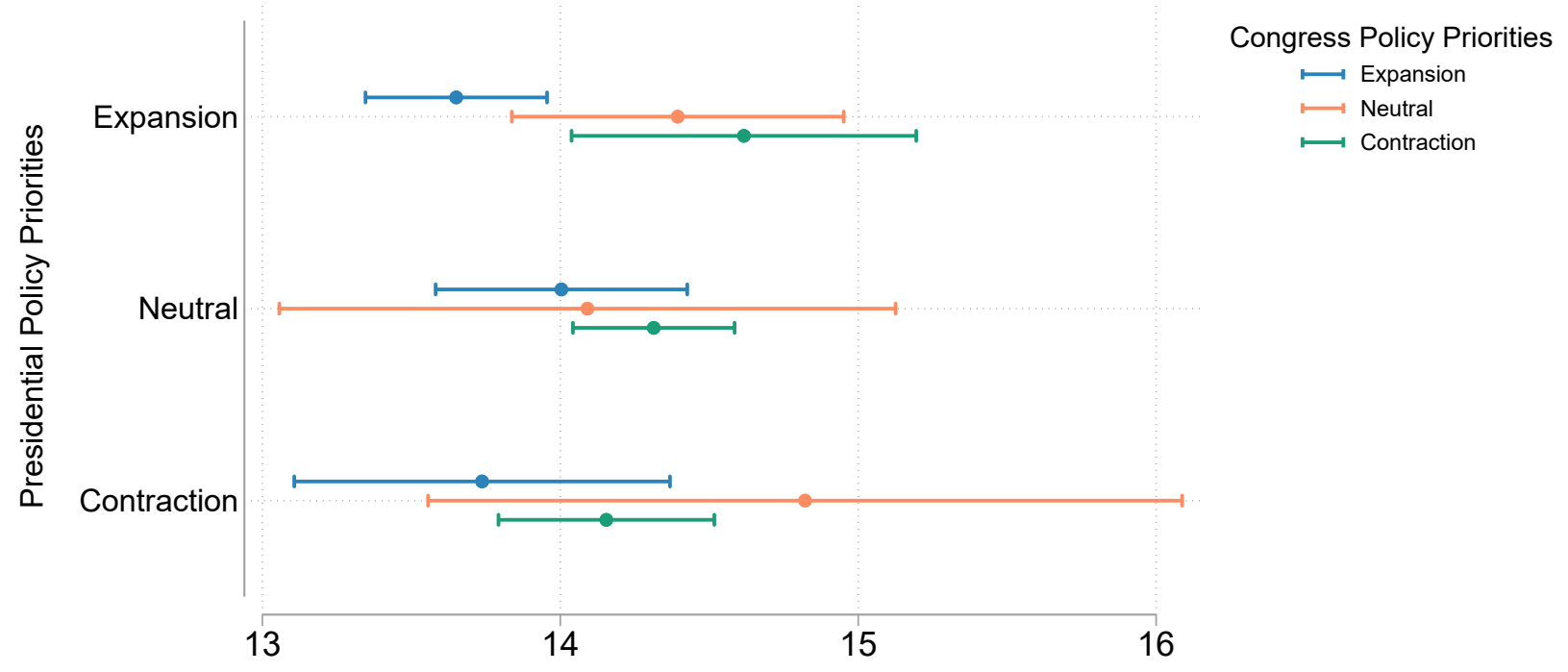

Predicted Number of Permanent Appointees in High Capacity Positions 


\section{BIBLIOGRAPHY}




\section{BIBLIOGRAPHY}

Aberbach, Joel D (2001). Keeping a watchful eye: The politics of congressional oversight. Brookings Institution Press.

Aberbach, Joel D. and Bert A. Rockman (2000). Senior executives in a changing political environment. In The Future of Merit: Twenty Years After the Civil Service Reform Act, pp. 81-99. Johns Hopkins University Press.

Bailey, Michael and Kelly H Chang (2001). Comparing presidents, senators, and justices: interinstitutional preference estimation. Journal of Law, Economics, and Organization 17(2), 477-506.

Bawn, Kathleen (1995). Political control versus expertise: Congressional choices about administrative procedures. American Political Science Review 89(1), 62-73.

Beckmann, Matthew N (2010). Pushing the agenda: Presidential leadership in US lawmaking, 19532004. Cambridge University Press.

Bendor, Jonathan and Adam Meirowitz (2004). Spatial models of delegation. American Political Science Review 98(2), 293-310.

Bertelli, Anthony and Sven E Feldmann (2006). Strategic appointments. Journal of Public Administration Research and Theory 17(1), 19-38.

Binder, Sarah A and Forrest Maltzman (2002). Senatorial delay in confirming federal judges, 1947-1998. American Journal of Political Science, 190-199.

Black, Ryan C, Anthony J Madonna, Ryan J Owens, and Michael S Lynch (2007). Adding recess appointments to the president's "tool chest" of unilateral powers. Political Research Quarterly 60(4), 645-654.

Bok, Derek (2003). Government personnel policy in comparative perspective. For the people: Can we fix public service, 255-272.

Bolton, Alexander, Rachel Augustine Potter, and Sharece Thrower (2015). Organizational capacity, regulatory review, and the limits of political control. The fournal of Law, Economics, and Organization 32(2), 242-271. 
Bond, Jon R , Richard Fleisher, and Glen S Krutz (2009). Malign neglect: Evidence that delay has become the primary method of defeating presidential appointments. In Congress \& the Presidency, Volume 36, pp. 226-243. Taylor \& Francis.

Bonica, Adam , Jowei Chen, and Tim Johnson (2015). Senate gate-keeping, presidential staffing of 'inferior offices,' and the ideological composition of appointments to the public bureaucracy. Quarterly Journal of Political Science 10(1), 5-40.

Brady, David W and Craig Volden (2018). Revolving Gridlock: Politics and Policy from fimmy Carter to George W. Bush. Routledge.

Brannon, Valerie C. (2017). The vacancies act: A legal overview. Congressional Research Service.

Brown, Emma (2016). Senate committee votes to confirm john king, obama's nominee for education secretary. The Washington Post (March 9).

Buell, Ryan W. (2016). A transformation is under way at u.s. veterans affairs. we got an inside look. Harvard Business Review (December 22). https : //hbr.org/2016/12/ a-transformation-is-underway-at-u-s-veterans-affairs-we-got-an-insid Accessed 05-23-2018.

Calvert, Randall L, Mathew D McCubbins, and Barry R Weingast (1989). A theory of political control and agency discretion. American journal of political science, 588-611.

Cameron, A Colin and Pravin K Trivedi (2013). Regression analysis of count data, Volume 53. Cambridge university press.

Cameron, Charles M (2000). Veto bargaining: Presidents and the politics of negative power. Cambridge University Press.

Cameron, Charles M and Jeffrey A Segal (1998). The politics of scandals: The case of supreme court nominations, 1877-1994. In annual meeting of the Midwest Political Science Association, April, Volume 23.

Canes-Wrone, Brandice (2001). The president's legislative influence from public appeals. American Journal of Political Science, 313-329.

Carpenter, Daniel (2010). Reputation and power: organizational image and pharmaceutical regulation at the FDA. Princeton University Press.

Carpenter, Daniel and George A Krause (2014). Transactional authority and bureaucratic politics. fournal of Public Administration Research and Theory 25(1), 5-25.

Carpenter, Daniel P (2001). The forging of bureaucratic autonomy: Reputations, networks, and policy innovation in executive agencies, 1862-1928. Princeton University Press. 
Chang, Kelly , David E Lewis, and Nolan McCarty (2001). The tenure of political appointees. In Annual Meeting of the Midwest Political Science Association, Chicago, April, pp. 19-22.

Chang, Kelly H (2001). The president versus the senate: Appointments in the american system of separated powers and the federal reserve. Journal of Law, Economics, and Organization 17(2), 319-355.

Chiou, Fang-Yi and Lawrence S Rothenberg (2014). Executive appointments: Duration, ideology, and hierarchy. Journal of Theoretical Politics 26(3), 496-517.

Chiou, Fang-Yi and Lawrence S Rothenberg (2017). The Enigma of Presidential Power: Parties, Policies and Strategic Uses of Unilateral Action. Cambridge University Press.

Clinton, Joshua D , Anthony Bertelli, Christian R Grose, David E Lewis, and David C Nixon (2012). Separated powers in the united states: The ideology of agencies, presidents, and congress. American fournal of Political Science 56(2), 341-354.

Corley, Pamela C (2006). Avoiding advice and consent: Recess appointments and presidential power. Presidential Studies Quarterly 36(4), 670-680.

Cottrell, David, Charles R Shipan, and Richard J Anderson (2019). The power to appoint: Presidential nominations and change on the supreme court. The fournal of Politics 81(3), 000-000.

Dull, Matthew and Patrick S Roberts (2009). Continuity, competence, and the succession of senate-confirmed agency appointees, 1989-2009. Presidential Studies Quarterly 39(3), 432-453.

Dull, Matthew , Patrick S Roberts, Michael S Keeney, and Sang Ok Choi (2012). Appointee confirmation and tenure: The succession of us federal agency appointees, 1989-2009. Public Administration Review 72(6), 902-913.

Durant, Robert F and William G Resh (2010a). Presidential agendas, administrative strategies, and the bureaucracy. In The Handbook of the American Presidency. Oxford: Oxford University Press.

Durant, Robert F and William G Resh (2010b). "presidentializing” the bureaucracy. In The Oxford handbook of American bureaucracy.

Durant, Robert F and Adam L Warber (2001). Networking in the shadow of hierarchy: Public policy, the administrative presidency, and the neoadministrative state. Presidential Studies Quarterly 31(2), 221-244.

Earley, Pete (1984). Lawmakers assail reagan's nlrb. The Washington Post October 18.

Edwards III, George C (2001). Why not the best? the loyalty-competence trade-off in presidential appointments. The Brookings Review 19(2), 12. 
Edwards III, George C and Andrew Barrett (2000). Presidential agenda setting in congress. In Polarized politics: Congress and the president in a partisan era, pp. 109-33. CQ Press Washington, DC.

Epstein, David and Sharyn O'Halloran (1999). Delegating powers: A transaction cost politics approach to policy making under separate powers. Cambridge University Press.

Epstein, David and Sharyn O'halloran (1994). Administrative procedures, information, and agency discretion. American fournal of Political Science 38(3), 697-722.

Epstein, David and Sharyn O'Halloran (2000). Majority-minority districts and the new politics of congressional elections. In Continuity and change in House elections, pp. 87-109. Stanford, CA: Stanford University Press.

Farber, Daniel A and Anne Joseph O'Connell (2014). The lost world of administrative law. Texas Law Review 92, 1137-1189.

Ferejohn, John and Charles Shipan (1990). Congressional influence on bureaucracy. $\mathcal{~ L ~ E c o n ~ \& ~}$ Org. 6, 1.

Gailmard, Sean (2002). Expertise, subversion, and bureaucratic discretion. Fournal of Law, Economics, and Organization 18(2), 536-555.

Gailmard, Sean and John W Patty (2007). Slackers and zealots: Civil service, policy discretion, and bureaucratic expertise. American Journal of Political Science 51(4), 873-889.

Gallo, Nick and David E Lewis (2011). The consequences of presidential patronage for federal agency performance. Journal of Public Administration Research and Theory 22(2), 219-243.

Gelman, Jeremy, Gilad Wilkenfeld, and E Scott Adler (2015). The opportunistic president: how us presidents determine their legislative programs. Legislative Studies Quarterly 40(3), 363-390.

Greene, William H and David A Hensher (2010). Modeling ordered choices: A primer. Cambridge University Press.

Hammond, Thomas H and Jeffrey S Hill (1993). Deference or preference? explaining senate confirmation of presidential nominees to administrative agencies. fournal of Theoretical Politics 5(1), 23-59.

Havemann, Judith (1989). Federal vacancies becoming drag on policymaking. The Washington Post March 18, A10.

Heclo, Hugh (1977). A government of strangers: Executive politics in Washington. Brookings Institution Press.

Hogue, Henry B (2008). Temporarily filling presidentially appointed, senate-confirmed positions. Senate of the United States: Committees, Rules, and Procedures, 229. 
Hogue, Henry B. (2017). Temporarily filling presidentially appointed, senate-confirmed positions. Technical report, Congressional Research Service.

Hollibaugh, Gary E (2015). Vacancies, vetting, and votes: A unified dynamic model of the appointments process. Fournal of Theoretical Politics 27(2), 206-236.

Hollibaugh, Gary E , Gabriel Horton, and David E Lewis (2014). Presidents and patronage. American Journal of Political Science 58(4), 1024-1042.

Hollibaugh, Gary E and Lawrence S Rothenberg (2017). The when and why of nominations: Determinants of presidential appointments. American Politics Research 45(2), 280-303.

Howe, Amy (2017). Francisco confirmed as solicitor general. SCOTUSblog September 19.

Howell, William G (2003). Power without persuasion: The politics of direct presidential action. Princeton University Press.

Howell, William G and David E Lewis (2002). Agencies by presidential design. The fournal of Politics 64(4), 1095-1114.

Huber, John D and Nolan McCarty (2004). Bureaucratic capacity, delegation, and political reform. American Political Science Review 98(3), 481-494.

Huber, John D and Nolan McCarty (2006). Bureaucratic capacity and legislative performance. In The Macropolitics of Congress, pp. 50. Princeton University Press.

Huber, John D and Charles R Shipan (2002). Deliberate discretion?: The institutional foundations of bureaucratic autonomy. Cambridge University Press.

Jo, Jinhee and Lawrence S Rothenberg (2012). Rational incompetence. Fournal of Theoretical Politics 24(1), 3-18.

Jones, Bryan D and Frank R Baumgartner (2005). The politics of attention: How government prioritizes problems. University of Chicago Press.

Kam, Cindy and Robert J Franzese (2009). Modeling and interpreting interactive hypotheses in regression analysis. University of Michigan Press.

Kaufman, Herbert (1981). Fear of bureaucracy: A raging pandemic. Public Administration Review, $1-9$.

Kesling, Ben and Colleen McCain Nelson (2014). Vacancies at va's top add to agency's problems: Unfilled posts lead to a management vacuum. The Wall Street fournal (June 11).

Knott, Stephen (2018). George h.w. bush: Foreign affairs. Miller Center of Public Affairs, University of Virginia. https : //millercenter.org/president/bush. Accessed on 15-052018. 
Konyndyk, Jeremy (2017). Clinton and helms nearly ruined state. tillerson wants to finish the job. Politico Magazine (May 4).

Krause, George A , David E Lewis, and James W Douglas (2006). Political appointments, civil service systems, and bureaucratic competence: Organizational balancing and executive branch revenue forecasts in the american states. American fournal of Political Science 50(3), 770-787.

Krause, George A and Anne Joseph O'Connell (2016). Experiential learning and presidential management of the us federal bureaucracy: Logic and evidence from agency leadership appointments. American Journal of Political Science 60(4), 914-931.

Krotoszynski Jr, Ronald J (2014). Transcending formalism and functionalism in separation-ofpowers analysis: reframing the appointments power after noel canning. Duke Lf 64, 1513.

Lee, Frances E (2009). Beyond ideology: Politics, principles, and partisanship in the US Senate. University of Chicago Press.

Leonnig, Carol D. (2008). Widespread complaints about a rudderless government. The Washington Post November 6.

Lewis, David E (2005). Staffing alone: Unilateral action and the politicization of the executive office of the president, 1988-2004. Presidential Studies Quarterly 35(3), 496-514.

Lewis, David E (2008). The politics of presidential appointments: Political control and bureaucratic performance. Princeton University Press.

Lewis, David E (2009). Revisiting the administrative presidency: Policy, patronage, and agency competence. Presidential Studies Quarterly 39(1), 60-73.

Lewis, David E (2011). Presidential appointments and personnel. Annual Review of Political Science 14, 47-66.

Lewis, David E and Jennifer L Selin (2012). Sourcebook of united states executive agencies. Administrative Conference of the United States, Office of the Chairman.

Long, J. Scott (2014). Regression models for nominal and ordinal outcomes. In H. Best and C. Wolf (Eds.), The SAGE Handbook of Regression Analysis and Causal Inference. Sage Publications.

Lowande, Kenneth (2018a). Delegation or unilateral action? The fournal of Law, Economics, and Organization 34(1), 54-78.

Lowande, Kenneth (2018b). Who polices the administrative state? American Political Science Review 112(4), 874-890.

Lowande, Kenneth S (2014). The contemporary presidency after the orders: Presidential memoranda and unilateral action. Presidential Studies Quarterly 44(4), 724-741. 
Lupia, Arthur and Mathew D McCubbins (1994a). Designing bureaucratic accountability. Law and contemporary problems 57(1), 91-126.

Lupia, Arthur and Mathew D McCubbins (1994b). Learning from oversight: Fire alarms and police patrols reconstructed. Fournal of Law, Economics, \& Organization, 96-125.

Madonna, Anthony and Ian Ostrander (2017). No vacancy: holdover capacity and the continued staffing of major commissions. Fournal of Public Policy 37(4), 341-361.

Madonna, Anthony J , James E Monogan III, and Richard L Vining Jr (2016). Confirmation wars, legislative time, and collateral damage: The impact of supreme court nominations on presidential success in the us senate. Political Research Quarterly 69(4), 746-759.

Maraniss, David (1996). Clinton acts to protect utah land. The Washington Post (September 19).

Martin, Bernard H. (2008). Office of management and budget. In M. A. Abramson, J. D. Breul, J. M. Kamensky, and G. M. Wagner (Eds.), Getting It Done: A Guide for Government Executives. Rowman Littlefield.

McCarty, Nolan (2004). The appointments dilemma. American fournal of Political Science 48(3), 413-428.

McCarty, Nolan , Keith T Poole, and Howard Rosenthal (2016). Polarized America: The dance of ideology and unequal riches. MIT Press.

McCarty, Nolan and Rose Razaghian (1999). Advice and consent: Senate responses to executive branch nominations 1885-1996. American Journal of Political Science, 1122-1143.

McCarty, Nolan M and Keith T Poole (1995). Veto power and legislation: An empirical analysis of executive and legislative bargaining from 1961 to 1986. FL Econ. \& Org. 11, 282.

McCubbins, Mathew D , Roger G Noll, and Barry R Weingast (1987). Administrative procedures as instruments of political control. Journal of Law, Economics, \& Organization 3(2), 243-277.

McCubbins, Matthew D , Roger G Noll, and Barry R Weingast (1989). Structure and process, politics and policy: Administrative arrangements and the political control of agencies. Virginia Law Review, 431-482.

McCubbins, Mathew D and Thomas Schwartz (1984). Congressional oversight overlooked: Police patrols versus fire alarms. American fournal of Political Science, 165-179.

McGrath, Robert J (2013). Congressional oversight hearings and policy control. Legislative Studies Quarterly 38(3), 349-376.

Miller, Gary J (2005). The political evolution of principal-agent models. Annual Review of Political Science 8, 203-225. 
Moe, Terry M (1985). Control and feedback in economic regulation: The case of the nlrb. American Political Science Review 79(4), 1094-1116.

Moe, Terry M (1989). The politics of bureaucratic structure. In Can the government govern?, pp. 267-271. Brookings Institution.

Moe, Terry M (1993). Presidents, institutions, and theory. In G. C. Edwards III, J. H. Kessel, and B. A. Rockman (Eds.), Researching the presidency: Vital questions, new approaches, pp. 337-85. Pittsburgh: University of Pittsburgh Press.

Moe, Terry M and William G Howell (1999). The presidential power of unilateral action. The Journal of Law, Economics, and Organization 15(1), 132-179.

Moore, Emily H (2018). Polarization, excepted appointments, and the administrative presidency. Presidential Studies Quarterly 48(1), 72-92.

Moraski, Bryon J and Charles R Shipan (1999). The politics of supreme court nominations: A theory of institutional constraints and choices. American fournal of Political Science, 10691095.

Nathan, Richard P (1983). The administrative presidency. John Wiley \& Sons.

Naylor, Brian (2009). Posts remain empty as white house vetting slows. National Public Radio March 6.

Nixon, David C (2001). Appointment delay for vacancies on the federal communications commission. Public Administration Review 61(4), 483-492.

Nixon, David C (2004). Separation of powers and appointee ideology. Fournal of Law, Economics, and Organization 20(2), 438-457.

Nixon, David C and David L Goss (2001). Confirmation delay for vacancies on the circuit courts of appeals. American Politics Research 29(3), 246-274.

O'Connell, Anne Joseph (2009). Vacant offices: Delays in staffing top agency positions. Southern California Law Review 82, 913-1001.

O’Connell, Anne Joseph (2014). Shortening agency and judicial vacancies through filibuster reform-an examination of confirmation rates and delays from 1981 to 2014. Duke Law fournal 64, 1645-1715.

O'Connell, Anne Joseph (2015). Shortening agency and judicial vacancies through filibuster reform-an examination of confirmation rates and delays from 1981 to 2014. Duke Law fournal 64, 1645.

office, Government Accountability (1994). Political appointees: turnover rates in executive schedule positions requiring Senate confirmation, Volume GAO/GGD-94-115FS. 
Ostrander, Ian (2016). The logic of collective inaction: Senatorial delay in executive nominations. American Journal of Political Science 60(4), 1063-1076.

Ouyang, Yu and Richard W Waterman (2015). How legislative (in) activity, ideological divergence, and divided government impact executive unilateralism: A test of three theories. In Congress \& the Presidency, Volume 42, pp. 317-341. Taylor \& Francis.

Pasachoff, Eloise (2016). The president's budget as a source of agency policy control. Yale Law fournal 125(8), 1.

Peterson, Mark A. (1990). Legislating Together: The White HOuse and Capitol Hill from Eisenhower to Reagan. Harvard University Press.

Pfiffner, James P (2001). Presidential appointments: Recruiting executive branch leaders. Innocent until nominated: The breakdown of the presidential appointments process, 50-80.

Reeves, Andrew and Jon C Rogowski (2018). The public cost of unilateral action. American fournal of Political Science 62(2), 424-440.

Resh, William G (2015). Rethinking the Administrative Presidency: Trust, Intellectual Capital, and Appointee-Careerist Relations in the George W. Bush Administration. JHU Press.

Romer, Thomas and Howard Rosenthal (1978). Political resource allocation, controlled agendas, and the status quo. Public choice 33(4), 27-43.

Rosenberg, Morton (1998). The new vacancies act: Congress acts to protect the senate's confirmation prerogative. Congressional Research Service, Library of Congress.

Rottinghaus, Brandon and Jason Maier (2007). The power of decree: Presidential use of executive proclamations, 1977-2005. Political Research Quarterly 60(2), 338-343.

Samuels, Brett (2019). Trump: 'no hurry' to name permanent replacements for acting cabinet members. The Hill (January 06).

Samuelsohn, Darren (2016). Obama's vanishing administration: Why are so many crucial jobs empty? a politico investigation.

Segal, Jeffrey (1987). Senate confirmation of supreme court justices: Partisan and institutional politics. The fournal of Politics 49(4), 998-1015.

Shenon, Philip (2007). Interim heads increasingly run federal agencies. New York Times October 15.

Shipan, Charles R (2004). Regulatory regimes, agency actions, and the conditional nature of congressional influence. American Political Science Review 98(3), 467-480. 
Shipan, Charles R, Brooke Thomas Allen, and Andrew Bargen (2014). Choosing when to choose: Explaining the duration of presidential supreme court nomination decisions. In Congress \& the Presidency, Volume 41, pp. 1-24. Taylor \& Francis.

Shipan, Charles R and Megan L Shannon (2003). Delaying justice (s): A duration analysis of supreme court confirmations. American fournal of Political Science 47(4), 654-668.

Shogan, Colleen (2004). Presidential campaigns and the congressional agenda: Reagan, clinton, and beyond.

Sievert, Joel and Ian Ostrander (2017). Constraining presidential ambition: Controversy and the decline of signing statements. Presidential Studies Quarterly 47(4), 752-776.

Silver, Edward and Joan McAvoy (1987). The national labor relations act at the crossroads. Fordham Law Review 56, 181.

Skrzycki, Cindy (2007). The consumer safety agency, stalled by room at the top. The Washington Post February 20.

Snyder, Susan K and Barry R Weingast (2000). The american system of shared powers: the president, congress, and the nlrb. Journal of Law, Economics, and Organization 16(2), 269-305.

Tausanovitch, Chris and Christopher Warshaw (2013). Measuring constituent policy preferences in congress, state legislatures, and cities. The fournal of Politics 75(2), 330-342.

Volden, Craig (2002). A formal model of the politics of delegation in a separation of powers system. American fournal of Political Science, 111-133.

Volden, Craig and Alan E Wiseman (2014). Legislative Effectiveness in the United States Congress: The Lawmakers. Cambridge University Press.

Weingast, Barry R (1984). The congressional-bureaucratic system: a principal agent perspective (with applications to the sec). Public Choice 44(1), 147-191.

Weingast, Barry R and Mark J Moran (1983). Bureaucratic discretion or congressional control? regulatory policymaking by the federal trade commission. Fournal of Political Economy 91(5), 765-800.

Whitford, Andrew B (2005). The pursuit of political control by multiple principals. Fournal of Politics 67(1), 28-49.

Wood, Abby K and David E Lewis (2017). Agency performance challenges and agency politicization. Journal of Public Administration Research and Theory 27(4), 581-595.

Wood, B Dan and Richard W Waterman (1991). The dynamics of political control of the bureaucracy. American Political Science Review 85(3), 801-828.

Wood, B Dan and Richard W Waterman (1994). Bureaucratic dynamics: The role of bureaucracy in a democracy. Westview Press. 